\title{
Vapochromism in Coordination Complexes: Chemical Sensors for Volatile Organic Compounds
}

\begin{tabular}{|r|l|}
\hline Journal: & Chemical Reviews \\
\hline Manuscript ID: & cr-2012-00396p.R1 \\
\hline Manuscript Type: & Review \\
\hline Date Submitted by the Author: & n/a \\
\hline Complete List of Authors: & Wenger, Oliver; University of Basel, Department of Chemistry \\
\hline
\end{tabular}

SCHOLARONE $^{\text {Ix }}$

Manuscripts 


\section{Vapochromism in Organometallic and Coordination}

\section{Complexes: Chemical Sensors for Volatile Organic}

\section{Compounds}

Oliver S. Wenger*

Universität Basel, Departement für Chemie, Spitalstrasse 51, CH-4056 Basel, Switzerland.

oliver.wenger@unibas.ch

Contents

1. Introduction

1.1 Scope of the review

1.2 Metal-metal interactions in $\mathrm{d}^{8}$ and $\mathrm{d}^{10}$ compounds

1.3 Unifying themes for research on vapochromic substances

2. Platinum compounds

2.1 Materials with charge-neutral Pt(II) complexes

2.1.1 $\left[\operatorname{Pt}(\alpha\right.$-diimine $\left.)(\mathrm{CN})_{2}\right]$ complexes and their derivatives

2.1.2 $\left[\operatorname{Pt}(\alpha\right.$-diimine $\left.)(\text { acetylide })_{2}\right]$ complexes

2.1.3 [Pt(isocyanide $\left.)_{2}(\mathrm{CN})_{2}\right]$ complexes

2.2 Platinum(II) / palladium(II) double salts

2.3 Cationic Pt(II) complexes with tridentate $\mathrm{N}^{\wedge} \mathrm{N}^{\wedge} \mathrm{N}$ ligands 


\subsubsection{Terpyridine complexes}

2.3.2 Complexes with 2,6-bis( $N$-alkylbenzimidazol-2'-yl)pyridine

2.3.3 Complexes with 2,6-bis-(1H-imidazol-2-yl)pyridine

2.4 Cyclometalated Pt(II) complexes

2.4.1 Complexes with 2,6-diphenylpyridine $\left(\mathrm{N}^{\wedge} \mathrm{C}^{\wedge} \mathrm{N}\right)$ ligands

2.4.2 Complexes with 6-phenyl-2,2'-bipyridine $\left(\mathrm{C}^{\wedge} \mathrm{N}^{\wedge} \mathrm{N}\right)$ ligands

2.4.3 Complexes with 2,6-di(2’-naphthyl)pyridine $\left(\mathrm{C}^{\wedge} \mathrm{N}^{\wedge} \mathrm{C}\right)$ ligands

2.4.4 Complexes with 7,8-benzoquinolinato and 2-phenylpyridine $\left(\mathrm{C}^{\wedge} \mathrm{N}\right)$ ligands

\subsubsection{Pincer complexes}

2.4.6 NHC complexes

2.5 Pt(II) complexes with S-, P-, and As-ligand atoms

2.6 MMX chains made from $\left[\mathrm{Pt}_{2}(\text { pop })_{4} \mathrm{I}\right]^{4-}$ units

3. Gold(I) compounds

3.1 Dicyanoaurates

3.2 Di- and trinuclear $\mathrm{Au}(\mathrm{I})$ complexes

3.3 Gold-thallium complexes

3.4 Gold-silver complexes

3.5 Other $\mathrm{Au}(\mathrm{I})$ complexes

4. Compounds with metals other than platinum or gold

4.1 Vapochromism as a result of analyte-induced changes in the first coordination sphere of the metal
4.1.1 A vanadium complex
4.1.2 Cobalt complexes
4.1.3 Nickel complexes 


\subsubsection{Copper complexes}

4.1.5 Tin compounds

\subsubsection{Metalloporphyrins}

4.2 Vapochromism as a result of indirect analyte-metal interactions

4.2.1 Vapochromism as a consequence of a change in spin state

4.2.2 Hydrogen-bonded proton transfer assemblies

4.2.3 Metallophilic, $\pi-\pi$, and donor-acceptor interactions

4.2.4 Vapochromism in coordination polymers and metal-organic frameworks

4.2.5 Vapochromism in cyanometallates

5. Summary of detectable VOCs

6. Concluding remarks

1. Introduction

1.1 Scope of the review

The development of chemical sensors is a subject that continues to fascinate chemists in academic research. Aside from the purely academic interest there is of course the important issue of finding suitable sensors for harmful chemical substances that might be present in the environment or at our workplaces. Consequently, the detection of volatile organic compounds (VOCs) by simple means requiring only a low-cost technology is an attractive research target. In this context vapochromism is a promising phenomenon. A vapochromic substance changes color upon exposure to certain vapors, ${ }^{1}$ and therefore the detection of analytes can often occur even by naked eye. In addition, there is the phenomenon of luminescence vapochromism, often called 
vapoluminescence, which refers to changes in photoluminescence properties in the course of vapor exposure. The class of compounds in which these two closely related phenomena occur most frequently is undoubtedly the area of coordination complexes. This review therefore focusses on transition metal compounds that change color and/or their emission properties when exposed to VOCs. Where appropriate, information regarding the detection of other analytes (e. g., oxygen, humidity in air, acids or bases) will be included as well. Along the same lines, the related phenomena of mechanochromism or thermochromism will be discussed briefly where appropriate and were thematically fitting.

The article is written from the perspective of a coordination chemist with an emphasis on understanding the origin of the vapochromic / vapoluminescent responses of the individual sensor materials. In this sense the current review is less geared towards applications than much of what has been published under the broadly defined label "electronic noses". ${ }^{2-6}$ Nevertheless the present review includes analytical details for the sensors for which such information is available, but many original studies do not report quantitative analytical results and focused themselves on understanding the vapochromism / vapoluminescence phenomenon on a molecular level rather aiming to develop actual sensing devices. A separate section with an comprehensive table summarizes the available analytical information in a compact manner.

Many of the coordination compounds discussed in the current article have been part of other reviews. For example, there exist several recent reviews on chemosensing with platinum(II) and gold(I) complexes. ${ }^{7-17}$ Most recently, a "feature article" on the specific subject of recent advances in the field of vapoluminescence in metal complexes appeared, ${ }^{18}$ but the scope of the current review is significantly broader, and it contains substantially more detailed information. The optical spectroscopic and photophysical properties of some of the metal complexes relevant 
for the current article have been reviewed separately, ${ }^{19-22}$ and reviews on the related phenomena of thermochromism and mechanochromism also exist. ${ }^{23-27}$

The two largest families of vapochromic / vapoluminescent substances are platinum(II) and gold(I) containing compounds which are treated in two separate dedicated sections of this review. Sensors devoid of these two elements are discussed in a subsequent section which is divided into subsections according to the transition metals they contain. Until now purely organic vapochromic / vapoluminescent substances are relatively rare and are not considered here. $\mathrm{Pt}(\mathrm{II})$ and $\mathrm{Au}(\mathrm{I})$ containing vapochromic substances are treated in separate sections not only because by mere number they represent the two most important classes of vapochromic substances, but also because a more or less common mode of operation can be identified for many of these particular substances (sections 1.3 and 6). Briefly, in many of the $\mathrm{Pt}(\mathrm{II})$ and $\mathrm{Au}(\mathrm{I})$ compounds the vapochromic response is the result of changes in intermolecular interactions (e. g., weak metalmetal interactions, $\pi$-stacking, hydrogen-bonding, C-H- $\pi$ interactions) as a result of analyte uptake into the crystal lattice, while for many (but not all) of the substances presented in section 4 direct ligation of an analyte to a metal center is observed.

\subsection{Metal-metal interactions in $\mathrm{d}^{8}$ and $\mathrm{d}^{10}$ compounds}

Because of the special importance of $\mathrm{Pt}(\mathrm{II})$ and $\mathrm{Au}(\mathrm{I})$ compounds in the field of vapochromism it is useful to recapitulate a few elementary aspects regarding weakly interacting metals with $\mathrm{d}^{8}$ and $\mathrm{d}^{10}$ electron configurations. There exist numerous didactical articles on non-covalent Pt(II)Pt(II) and aurophilic interactions, ${ }^{7,22,28-31}$ hence only the most fundamental aspects needed to 
comprehend the photophysical behavior of some of the vapochromic substances discussed in sections 2 and 3 will be briefly discussed here.

Square planar $\mathrm{d}^{8}$ and linear $\mathrm{d}^{10}$ complexes tend to approach each other in such a way that their $5 d_{z 2}$ and $6 p_{z}$ orbitals can interact with each other. ${ }^{32}$ Figure 1 shows the relevant part of the molecular orbital diagram for $\mathrm{d}^{8}-\mathrm{d}^{8}$ dimers. The interaction of $5 \mathrm{~d}_{\mathrm{z} 2}$ and $6 \mathrm{p}_{\mathrm{z}}$ orbitals leads the formation of bonding and anti-bonding dimer orbitals, commonly designated as $d \sigma / d \sigma^{*}\left(5 d_{z 2}\right)$ and $p \sigma / p \sigma^{*}\left(6 p_{z}\right) .^{31}$ In the electronic ground state of $d^{8}-d^{8}$ and $d^{10}-d^{10}$ dimers the $d \sigma$ and $d \sigma^{*}$ orbitals are filled whereas the $\mathrm{p} \sigma$ and $p \sigma^{*}$ orbitals are empty. In both cases there is the possibility of $d \sigma^{*} \rightarrow \mathrm{p} \sigma$ transitions leading to excited-states in which the metal-metal distance is shorter than in the ground state due to an increase in bond order. However, in many of the cases from sections 2 and 3 for which intermetallic interactions are relevant the LUMO is a ligand-based orbital, typically with $\pi$ or $\pi^{*}$ character; $\pi-\pi$ interactions between ligands may themselves lead to “dimer $\pi$ orbitals". The HOMO-LUMO transition in these cases is a so-called metal/metal-toligand charge transfer (MMLCT) which distinguishes itself from ordinary metal-to-ligand charge transfer (MLCT) transitions in that the HOMO is a "dimer orbital" (or "oligomer" / "polymer" orbital) resulting from intermetallic interactions. Depending on the strength of the metal-metal interaction the dimer HOMO shifts in energy, and for many sensors this forms the basis for vapochromism or vapoluminescence. However, there are numerous other mechanisms that may lead to vapor-induced color and emission changes, and the full breadth of possibilities will become obvious from the following sections. 

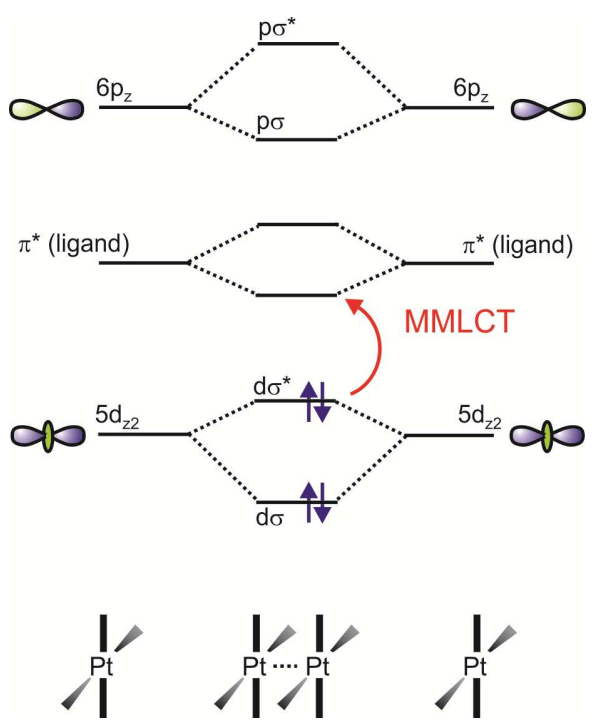

Figure 1. Simplified MO diagram illustrating metal-metal interactions between square planar $\mathrm{Pt}(\mathrm{II})$ complexes. MMLCT $=$ metal/metal-to-ligand charge transfer. More elaborate diagrams can be found in the literature. ${ }^{33,34}$

\subsection{Unifying themes in research on vapochromic substances}

The vapochromism of many of the $\mathrm{Pt}(\mathrm{II})$ and $\mathrm{Au}(\mathrm{I})$ containing substances discussed in sections 2 and 3 is more or less closely related to metallophilic interactions and/or $\pi$-stacking. A common theme for many (but not all) of the vapochromic substances presented in section 4 is the occurrence of changes in the first coordination sphere, including both alterations in coordination number and coordination geometry. This is particularly true for several of the vanadium, cobalt, nickel, copper, and metalloporphyrin-based vapochromic substances. One may therefore differentiate between two fundamentally different manners by which vapochromic substances respond to VOCs: Type I of vapochromic substances exhibits more or less subtle structural changes in crystal packing leading to alterations in intermolecular interactions such as for 
example metal-metal interactions, $\pi$-stacking, hydrogen-bonding, and $\mathrm{C}-\mathrm{H}-\pi$ interactions. In type II vapochromic substances direct ligation of an analyte to a solid-state material occurs. Type I is of key importance in sections 2 and 3, type II is prominent in section 4 (subsection 4.1) but several substances from section 4 are type I vapochromic systems (subsection 4.2).

A unifying theme for many vapochromic substances is an exceptionally high complexity of the solid-state structures. Aside from the intermolecular interactions mentioned above, the presence of voids plays an important role in many cases. In this context, the size and shape of counterions can have an important influence. In several cases the vapochromic property is strongly dependent on the polymorph or solvate which is formed; while one polymorph or solvate may exhibit spectacular vapochromism, a closely related polymorph or solvate may be completely insensitive to VOCs. The most important insights to vapochromism therefore come from solid-state investigations including X-ray crystallography, powder X-ray diffraction, thermogravimetry, and solid state absorption (or reflectance), and luminescence. Solution studies are usually considerably less insightful. However, as will be seen from this review, even the simplest structure-property relationships in many vapochromic materials have remained extremely elusive. Consequently, it is very difficult to "engineer" vapochromic materials. It is even difficult to optimize the VOC response behavior of known vapochromic substances because even the slightest changes can lead to complete disappearance of the vapochromic property. In short, many challenges are associated with research on vapochromism. 
2. Platinum(II) compounds

2.1 Materials with charge-neutral Pt(II) complexes

2.1.1 $\left[\mathrm{Pt}(\alpha\right.$-diimine $\left.)(\mathrm{CN})_{2}\right]$ complexes and their derivatives

One of the earliest reports of vapochromism in a platinum(II) coordination compound dates from 1974. ${ }^{35}$ Gillard and coworkers found that $\left[\mathrm{Pt}(\mathrm{bpy})(\mathrm{CN})_{2}\right]$ (bpy $=2,2$ '-biypridine) (1) (Scheme 1) changes color from red to yellow when solid samples are exposed to $\mathrm{HF}, \mathrm{H}_{2} \mathrm{O}$ or $\mathrm{H}_{2} \mathrm{~S}$ vapors. Similarly, $\left[\mathrm{Pt}(\mathrm{phen})(\mathrm{CN})_{2}\right]($ phen $=1,10$-phenanthroline) $(\mathbf{2})$ was observed to turn from yellow to red upon exposure to anhydrous organic solvent vapors. At that time the existence of a red and yellow form of $\left[\mathrm{Pt}(\mathrm{bpy}) \mathrm{Cl}_{2}\right](3)$ was already known from the early work by Morgan and Burstall. $^{36}$ In the Gillard paper the vapor-induced color changes were discussed in terms of protonation of the $\mathrm{CN}$ ligands, and it was speculated that covalent addition of $\mathrm{H}_{2} \mathrm{O}$ to one of the pyridine rings of bpy might also play a role.

Scheme 1. $\left[\mathrm{Pt}(\alpha\right.$-diimine $\left.)(\mathrm{CN})_{2}\right]$ complexes, part I.
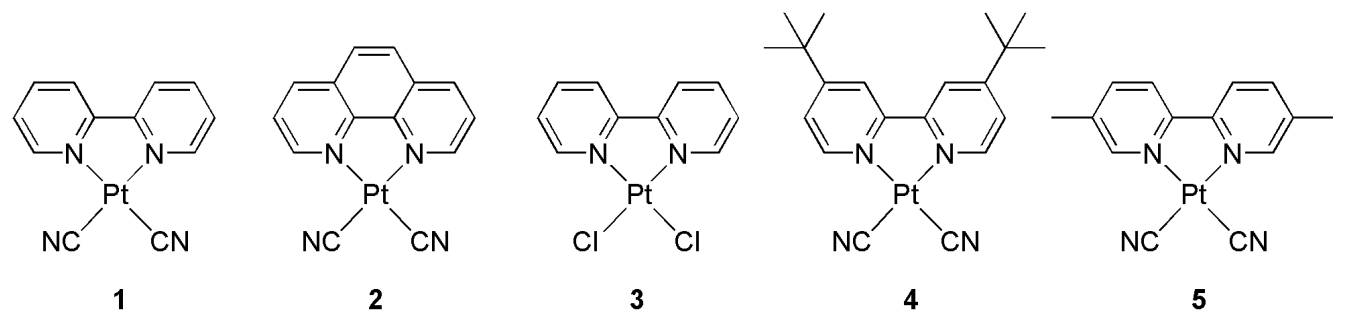
absorptions are in the UV. The compound $\left[\mathrm{Pt}\left(5,5^{\prime}-\mathrm{Me}_{2} \mathrm{bpy}\right)(\mathrm{CN})_{2}\right]\left(5,5^{\prime}-\mathrm{Me}_{2} \mathrm{bpy}=5,5^{\prime}-\right.$ dimethyl-2,2'-bipyridine) (5) was investigated in the same study and was found to change color from light yellow to deep orange on hydration. ${ }^{37}$ Thus, by investigating a series of $\left[\mathrm{Pt}(\mathrm{bpy})(\mathrm{CN})_{2}\right]$ complexes with bpy ligands bearing substituents of variable steric bulk, Shih and Herber arrived at the conclusion that control over the metal-metal distance of neighboring complexes is desirable for obtaining materials which change color upon hydration. This important concept holds true for many vapochromic materials that are discovered only nowadays.

Nearly another 10 years later the Kato group began to publish an entire series of papers on vapochromic $\left[\operatorname{Pt}(\alpha\right.$-diimine $\left.)(\mathrm{CN})_{2}\right]$ compounds. ${ }^{13,}{ }^{38-42}$ Initial studies focused on the $\left[\operatorname{Pt}(\right.$ bpy $\left.)(\mathrm{CN})_{2}\right]$ material (1) investigated already by Gillard and coworkers. ${ }^{38}$ Based on X-ray crystallographic investigations it was possible to elucidate the origin of the water-vapor induced color change. The anhydrous red form of $\left[\mathrm{Pt}(\mathrm{bpy})(\mathrm{CN})_{2}\right]$ was found to contain infinite stacks of complexes with regular intermolecular Pt(II)-Pt(II) distances of $3.34 \AA$, while in the yellow $\left[\mathrm{Pt}(\mathrm{bpy})(\mathrm{CN})_{2}\right] \cdot \mathrm{H}_{2} \mathrm{O}\left(\mathbf{1} \cdot \mathrm{H}_{2} \mathrm{O}\right)$ material the sorbed water molecule causes a deformation of the stacking structure and an interruption of the infinite $\mathrm{Pt}(\mathrm{II})-\mathrm{Pt}(\mathrm{II})$ chain. In the yellow form there are inclined stacks with alternating short $(3.3289(3) \AA)$ and long (4.6814(3) $\AA) \operatorname{Pt}(\mathrm{II})-\mathrm{Pt}(\mathrm{II})$ distances, and the crystal water connects individual stacks via hydrogen-bonding to the cyanide ligands. Thus it became clear that vapochromism of $\left[\mathrm{Pt}(\mathrm{bpy})(\mathrm{CN})_{2}\right]$ was due to changes in the $\mathrm{Pt}(\mathrm{II})-\mathrm{Pt}(\mathrm{II})$ interaction brought about by a structural change upon water sorption. This conclusion was particularly obvious in light of prior vapochromism studies with platinum double salts by Mann and coworkers (see below), and the fundamental work on the electronic structures of $\mathrm{d}^{8}-\mathrm{d}^{8}$ dimers, ${ }^{43,44}$ stacked platinum(II) diimine complexes, ${ }^{45-48}$ and tetracyanoplatinates. ${ }^{22}$ 
Kato and coworkers noted that the photoluminescence band maximum of $\left[\mathrm{Pt}(\mathrm{bpy})(\mathrm{CN})_{2}\right](\mathbf{1})$ shifts from $602 \mathrm{~nm}$ to $566 \mathrm{~nm}$ upon exposure to humid air while maintaining similar emission intensity. ${ }^{38}$ Thus, unlike the yellow form of $\left[\mathrm{Pt}(\mathrm{bpy}) \mathrm{Cl}_{2}\right]$ which is a much weaker emitter than its red polymorph, ${ }^{49}$ the yellow form of $\left[\mathrm{Pt}(\mathrm{bpy})(\mathrm{CN})_{2}\right]$ is strongly emissive. Presumably this is because $\left[\mathrm{Pt}(\mathrm{bpy})(\mathrm{CN})_{2}\right] \cdot \mathrm{H}_{2} \mathrm{O}\left(\mathbf{1} \cdot \mathrm{H}_{2} \mathrm{O}\right)$ contains dimers with short $\mathrm{Pt}(\mathrm{II})-\mathrm{Pt}(\mathrm{II})$ distances which are able to exhibit ${ }^{3} \mathrm{MMLCT}$ emission while yellow $\left[\mathrm{Pt}(\mathrm{bpy}) \mathrm{Cl}_{2}\right](3)$ has no short contacts between Pt(II) centers. ${ }^{46}$

Scheme 2. $\left[\mathrm{Pt}(\alpha\right.$-diimine $\left.)(\mathrm{CN})_{2}\right]$ complexes, part II.
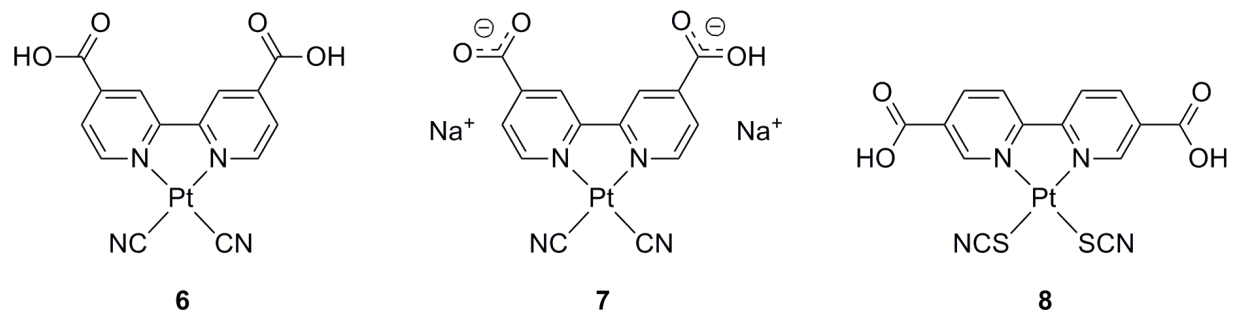

The complex $\left[\mathrm{Pt}\left(4,4^{\prime}-\mathrm{H}_{2} \mathrm{dcbpy}\right)(\mathrm{CN})_{2}\right]\left(4,4^{\prime}-\mathrm{H}_{2} \mathrm{dcbpy}=4,4^{\prime}\right.$ '-dicarboxyl-2,2'-bipyridine) (6) (Scheme 2) represents a milestone discovery in the area of vapochromic platinum compounds. ${ }^{13}$, ${ }^{39}$ The color of this material is dependent on the $\mathrm{pH}$ at which it is recrystallized and can adopt a range of colors from white to yellow, red, blue and purple. The different colors are a manifestation of different polymorphs with variable $\mathrm{Pt}(\mathrm{II})-\mathrm{Pt}(\mathrm{II})$ interactions and are unusually diverse for linear-chain platinum(II) compounds. The red form was found to have short Pt(II)$\mathrm{Pt}(\mathrm{II})$ contacts of about $3.3 \AA$ and a network structure with relatively large cavities in which water molecules can be included. The cavities form as a result of molecular alignments dictated by $\mathrm{Pt}(\mathrm{II})-\mathrm{Pt}(\mathrm{II})$ interactions and hydrogen bonds between carboxylic acid and cyano groups. Upon exposure of any of the polymorphs to volatile organic compounds, reversible color 
changes can be induced. Because the differently colored forms of $\left[\mathrm{Pt}\left(4,4^{\prime}-\mathrm{H}_{2} \mathrm{dcbpy}\right)(\mathrm{CN})_{2}\right]$ are all emissive, vapor exposure further induces changes in the luminescence properties (Figure 2).

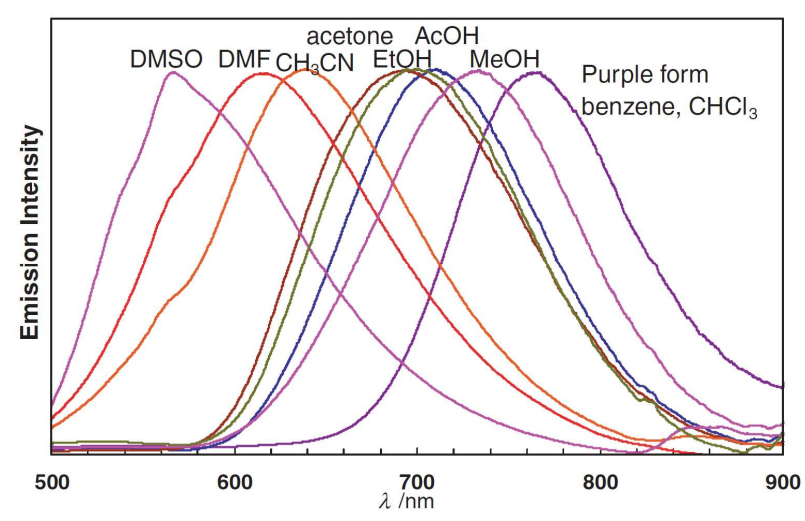

Figure 2. Photoluminescence of $\left[\mathrm{Pt}\left(4,4^{\prime}-\mathrm{H}_{2} \mathrm{dcbpy}\right)(\mathrm{CN})_{2}\right](\mathbf{6})$ after exposure to different VOCs. ${ }^{13}$ Reproduced with permission from the Chemical Society of Japan.

In this system, there is a reasonably good correlation between the emission band maximum and the dielectric constant of the vapors to which the material is exposed; solvents such as DMSO and DMF cause significantly more blue-shifted emission than substances like benzene or chloroform. The emission originates from a ${ }^{3} \mathrm{MMLCT}$ state which shifts to lower energy with increasing metal-metal interaction; direct evidence for the correlation between the luminescence band maximum and the Pt(II)-Pt(II) distance comes from the observation of thermochromism in the red form of $\left[\mathrm{Pt}(\mathrm{dcbpy})(\mathrm{CN})_{2}\right]$ and from the observed shortening of the metal-metal distance from $3.28 \AA$ at ambient temperature to $3.22 \AA$ at $100 \mathrm{~K}^{39}$

When $\left[\mathrm{Pt}\left(4,4^{\prime}-\mathrm{H}_{2} \mathrm{dcbpy}\right)(\mathrm{CN})_{2}\right](\mathbf{6})$ is exposed to sodium methoxide in $\mathrm{CH}_{3} \mathrm{OH}$ solution the carboxylic acid groups of the bpy ligand are deprotonated and a material with the stoichiometry $\mathrm{Na}_{2}\left[\mathrm{Pt}\left(4,4^{\prime}\right.\right.$-dcbpy $\left.)(\mathrm{CN})_{2}\right] \cdot 2 \mathrm{H}_{2} \mathrm{O}\left(7 \cdot 2 \mathrm{H}_{2} \mathrm{O}\right)$ is obtained. ${ }^{40}$ The coordination unit in this compound 
is formally anionic, but since it contains the deprotonated form of the complex discussed in the preceding paragraph it appears meaningful to discuss this vapochromic material in the current section.

$\mathrm{Na}_{2}\left[\mathrm{Pt}\left(4,4\right.\right.$ '-dcbpy) $\left.(\mathrm{CN})_{2}\right] \cdot 2 \mathrm{H}_{2} \mathrm{O}\left(\mathbf{7} \cdot 2 \mathrm{H}_{2} \mathrm{O}\right)$ was obtained as a red and amorphous substance which changes color to yellow in humid air or when exposed to hydrophilic organic vapors such as those from methanol, acetone or DMF. Powder X-ray experiments reveal that the color change is accompanied by a structural transformation from an amorphous to a crystalline state, but inclusion of organic vapors into the solid did not occur. According to single crystal X-ray studies the yellow form of $\mathbf{7} \cdot 2 \mathrm{H}_{2} \mathrm{O}$ has long $(>4.9 \AA)$ intermolecular Pt(II)-Pt(II) distances while the red amorphous polymorph probably has short metal-metal contacts, hence the difference in color. The most interesting aspect of this material is certainly the fact that it exhibits structural changes upon exposure to hydrophilic VOCs without actually adsorbing anything. Unfortunately these structural transformations seem to be irreversible, limiting the application potential of the respective material severely. Both forms of $7 \cdot 2 \mathrm{H}_{2} \mathrm{O}$ are luminescent when irradiated with UV light, and thus vapor exposure can be monitored both in absorption and emission (Figure 3).
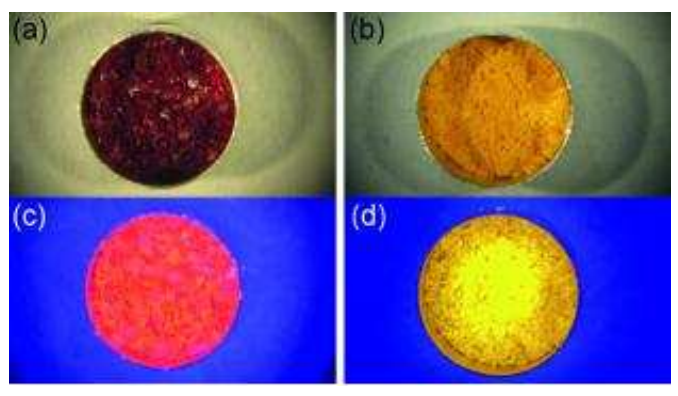

Figure 3. Photographs of $7 \cdot \mathrm{H}_{2} \mathrm{O}$ before (a) and after (b) exposure to $\mathrm{MeOH}$ vapor. Panels (c) and (d) show the emission of the same compound before and after $\mathrm{MeOH}$ exposure. (A. Kobayashi, T. Yonemura, M. Kato: Vapor-Induced Amorphous-Crystalline Transformation of a 
Luminescent Platinum(II)-Diimine Complex. Eur. J. Inorg. Chem., 2010, 2465-2470. Copyright Wiley-VCH Verlag GmbH \& Co. KGaA. Reproduced with permission.)

When the cyano ligands of $\left[\mathrm{Pt}\left(4,4^{\prime}-\mathrm{H}_{2} \mathrm{dcbpy}\right)(\mathrm{CN})_{2}\right]$ are replaced by $\mathrm{SCN}^{-}$an unusual vapochromic material results. ${ }^{50}$ By synthesizing the $\left[\mathrm{Pt}\left(4,4^{\prime}-\mathrm{H}_{2} \mathrm{dcbpy}\right)(\mathrm{SCN})_{2}\right]$ complex $(\mathbf{8})$ at 0 ${ }^{\circ} \mathrm{C}$ it was possible to obtain the S-bound linkage isomer of this material, which, by analogy to the thiocyanato complex $\left[\mathrm{Pt}(\mathrm{bpy})(\mathrm{SCN})_{2}\right]$ is presumably the kinetically (but not thermodynamically) favored product. The $\left[\mathrm{Pt}\left(4,4^{\prime}-\mathrm{H}_{2} \mathrm{dcbpy}\right)(\mathrm{SCN})_{2}\right]$ complex is an orange non-luminescent material which crystallizes as a monohydrate $\left(\mathbf{8} \cdot \mathrm{H}_{2} \mathrm{O}\right)$. Exposure to DMF vapor induces a change in color to red, and the material becomes emissive $\left(\lambda_{\max }=660 \mathrm{~nm}, \tau=16 \mathrm{~ns}\right)$, presumably from a ${ }^{3}$ MMLCT excited state indicative of $\mathrm{Pt}(\mathrm{II})-\mathrm{Pt}(\mathrm{II})$ interactions. The $\mathrm{CN}$ stretching frequency redshifts from $2128 \mathrm{~cm}^{-1}$ to $2115 \mathrm{~cm}^{-1}$ in the course of DMF uptake, and the three ${ }^{1} \mathrm{H}$ NMR resonances from the bpy backbone undergo high-field shifts. These two observations are consistent with a linkage isomerization reaction from S-bound thiocyanate to N-bound isothiocyanate. According to thermogravimetric studies the DMF adduct contains 3 molecules of DMF per formula unit (8·3DF). By crystallization from DMF solution it was possible to obtain single-crystals of the formulation $\mathbf{8} \cdot 4 \mathrm{DMF}$ in which the $\mathrm{SCN}^{-}$ligand is clearly nitrogen bound, but there are no short intermetallic contacts in this specific material. Some of the DMF molecules form hydrogen-bonds to the carboxyl groups and indeed, the CO stretching frequency of DMF in 8.3DMF is lowered by $22 \mathrm{~cm}^{-1}$ compared to liquid DMF, suggesting that in the material with only 3 molecules of DMF, hydrogen-bonding between DMF and carboxyl groups of the $\mathrm{H}_{2} \mathrm{dcbpy}$ ligand occurs as well. Thus, hydrogen-bonding seems to play an important role in the vaporinduced linkage isomerization. This interpretation is supported by the finding that solvents with a 
Gutmann donor number above 26 induce the isomerization reaction for both $\mathrm{SCN}^{-}$ligands of a given complex (DMSO, DMF, dimethylacetamide), whereas solvents with donor numbers between 10 and 26 (methanol, ethanol, acetone, acetonitrile) induce S-to-N isomerization of only one of the two ligands. ${ }^{50}$ Presumably, the explanation for this behavior is that the initial S-bound form is stabilized by hydrogen-bonding between the terminal (more electronegative) N-atoms of the thiocyanato-ligands and the carboxyl-groups of neighboring complexes; upon sorption of a good hydrogen-bond donor these existing hydrogen-bonds are disrupted, making the thiocyanato-ligation thermodynamically unstable. Even though the crystal structure of 8.4DMF fails to provide direct evidence for intermetallic interactions it is easy to see why such interactions are more likely to occur in $\mathbf{8} \cdot 3 \mathrm{DMF}$ than in $\mathbf{8} \cdot \mathrm{H}_{2} \mathrm{O}$ : S-coordinated thiocyanate has a bent structure which can be directed up or down from the coordination plane, whereas Ncoordinated isothiocyanate is expected to lead to essentially planar complexes, hence close $\mathrm{Pt}(\mathrm{II})-\mathrm{Pt}(\mathrm{II})$ contacts become more readily possible.

Building on their own prior work Kato and Kobayashi recently reported on a series of coordination polymers containing $\left[\mathrm{Pt}(\mathrm{bpy})(\mathrm{CN})_{2}\right]$ units. Specifically, their work focused on $\left[\mathrm{Pt}\left(5,5^{\prime} \text {-dcbpy }\right)(\mathrm{CN})_{2}\right]^{2-} \quad$ complexes $\quad\left(5,5^{\prime}-\mathrm{H}_{2} \mathrm{dcbpy}=5,5^{\prime}\right.$-dicarboxyl-2,2'-bipyridine $) \quad\left(\mathbf{9}^{2-}\right)$ bridged by $\mathrm{Mg}^{2+}, \mathrm{Ca}^{2+}, \mathrm{Sr}^{2+}, \mathrm{Ba}^{2+}$ or $\mathrm{Zn}^{2+}$ cations (Scheme 3). ${ }^{41,}{ }^{42}$ Respective systems with formally anionic platinum complexes are discussed in this chapter because of their chemical and functional kinship to the materials discussed above.

Scheme 3. $\left[\mathrm{Pt}(\alpha\right.$-diimine $\left.)(\mathrm{CN})_{2}\right]$ complexes, part III. 


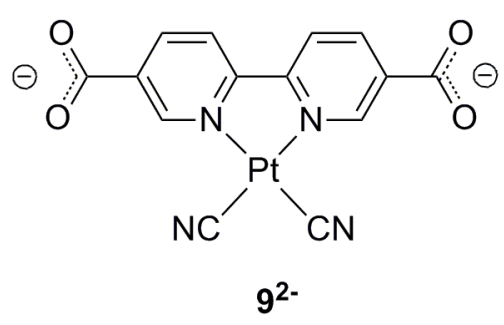

In the zinc compound the $\left[\mathrm{Pt}\left(5,5^{\prime} \text {-dcbpy }\right)(\mathrm{CN})_{2}\right]^{2-}$ units act as bridges between individual $\mathrm{Zn}^{2+}$ ions to form an infinite chain. ${ }^{41}$ The platinum complexes themselves are stacked perpendicularly to these chains with an intermetallic distance of 3.309(1) $\AA$ which is responsible for the orange color as well as the ${ }^{3}$ MMLCT emission (at $614 \mathrm{~nm}$ ) exhibited by the $\mathrm{Zn}\left[\mathrm{Pt}\left(5,5^{\prime}\right.\right.$ debpy) $\left.(\mathrm{CN})_{2}\right] \cdot 4 \mathrm{H}_{2} \mathrm{O}$ material at room temperature. Three of the four water molecules from this formula unit are coordinated to $\mathrm{Zn}$ (II) (along with two carboxylate oxygens), while the fourth water molecule is only hydrogen-bonded to a cyano group. When heating to $100^{\circ} \mathrm{C}$ all four water molecules can be driven off, thereby inducing a color change from orange to red and finally purple. The anhydrous purple form is vapochromic; when exposed to humid air at room temperature it readily re-converts to the initial orange tetrahydrate form. Thus, water adsorption/desorption occurs predominantly at the $\mathrm{Zn}(\mathrm{II})$ site, but this influences the stacking of the chromophoric and emitting platinum complexes (Figure 4). 


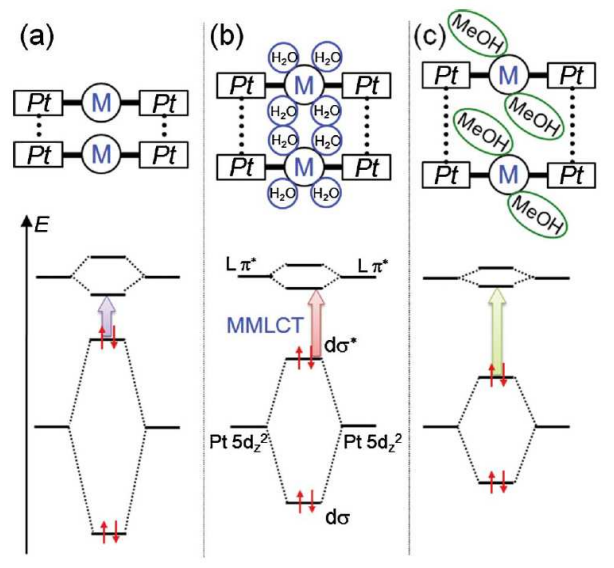

Figure 4. Illustration how solvent uptake at the $\mathrm{Zn}(\mathrm{II})$ sites in the $\mathrm{M}\left[\mathrm{Pt}\left(5,5^{\prime}-\mathrm{dcbpy}\right)(\mathrm{CN})_{2}\right]$ coordination polymers affects the $\mathrm{Pt}(\mathrm{II})-\mathrm{Pt}(\mathrm{II})$ distance (upper part) and the energy level structure (MO diagrams in lower part). Reprinted with permission from ref. ${ }^{42}$. Copyright 2011 The Royal Society of Chemistry.

When replacing $\mathrm{Zn}$ (II) by other dications it becomes possible to alter the intermolecular Pt(II)$\mathrm{Pt}(\mathrm{II})$ distances in the $\mathrm{M}\left[\mathrm{Pt}\left(5,5^{\prime}\right.\right.$-dcbpy $\left.)(\mathrm{CN})_{2}\right] \cdot n \mathrm{H}_{2} \mathrm{O}$ coordination polymers, ${ }^{42}$ in a way this is similar to cation exchange in tetracyanoplatinates although the accessible Pt(II)-Pt(II) distance range is more narrow for the newly explored coordination polymers. ${ }^{22}$ Compounds with $\mathrm{M}^{2+}=$ $\mathrm{Mg}^{2+}, \mathrm{Ca}^{2+}, \mathrm{Sr}^{2+}$, and $\mathrm{Ba}^{2+}$ are thought to be isomorphous with $\mathrm{Zn}\left[\mathrm{Pt}\left(5,5^{\prime}-\mathrm{dcbpy}\right)(\mathrm{CN})_{2}\right] \cdot 4 \mathrm{H}_{2} \mathrm{O}$, and hence it appears plausible that the alkaline earth metals act as water adsorbing sites similar to the $\mathrm{Zn}(\mathrm{II})$ ion in the parent compound, but this is not known for sure. By analogy to the zinc compound discussed above, heating to $100^{\circ} \mathrm{C}$ drives off all four water molecules in all compounds, and the resulting anhydrous forms readily re-adsorb water vapor at ambient temperature. In the case of the compounds with $\mathrm{Mg}^{2+}$ and $\mathrm{Ca}^{2+}$ this is accompanied by significant chromic shifts both in absorption and emission, hence these two materials may be considered vapochromic substances. Contrary to the zinc compound, the alkaline earth metal based 
coordination polymers can all adsorb methanol vapor, and this alters their luminescence with respect to the anhydrous forms. It is thought that the methanol molecules simply occupy the adsorption sites filled with water in the $\mathrm{M}\left[\mathrm{Pt}\left(5,5^{\prime}-\mathrm{dcbpy}\right)(\mathrm{CN})_{2}\right] \cdot n \mathrm{H}_{2} \mathrm{O}$ forms.

\subsection{2 $\left[\operatorname{Pt}(\alpha\right.$-diimine $\left.)(\text { acetylide })_{2}\right]$ complexes}

The search for phosphorescent metal complexes which can be used as triplet harvesters in organic light emitting diodes (OLEDs) has lead, inter alia, to platinum(II) complexes with acetylide ligands. ${ }^{16,51-55}$ When combining acetylide ligands with $\alpha$-diimines or cyclometalating chelating agents very strong ligand fields can be exerted on coordinated Pt(II) centers, ${ }^{56,57}$ and this is beneficial for the luminescence properties due to suppression of multiphonon relaxation from metal-localized (d-d) excited states. ${ }^{58}$ In the course of research on such complexes a few vapochromic materials have been discovered.

Scheme 4. $\left[\operatorname{Pt}(\alpha\right.$-diimine $\left.)(\text { acetylide })_{2}\right]$ complexes, part I.
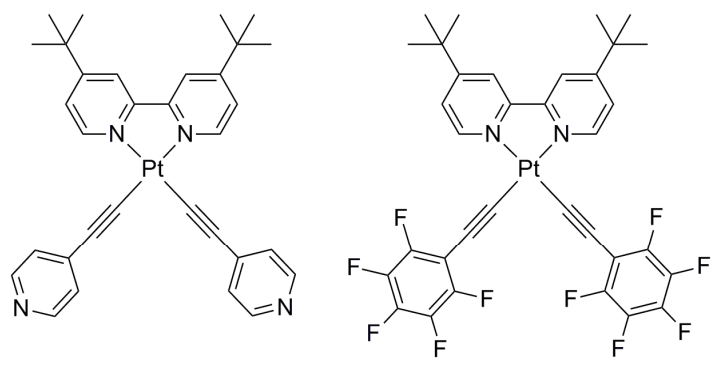

11

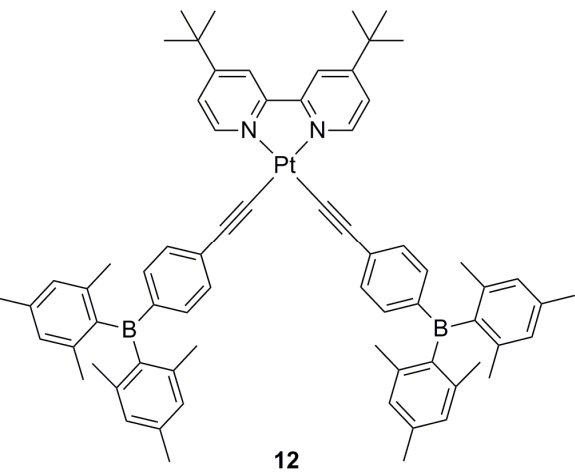


Che, Wong, and coworkers report on a series of $\left[\mathrm{Pt}^{t}\left(\mathrm{Bu}_{2} \mathrm{bpy}\right)(\text { arylacetylide })_{2}\right]$ complexes two of which are vapoluminescent (Scheme 4). ${ }^{59}$ Thin films of the complex in which the arylacetylide is 4-ethynylpyridine exhibit greatly enhanced green luminescence upon sorption of $\mathrm{CH}_{2} \mathrm{Cl}_{2}$ or $\mathrm{CHCl}_{3}$ vapor; the detection limits are around 25 and $450 \mathrm{ppm}$, respectively, while polar VOCs such as methanol produce no response. In crystals of $\left[\mathrm{Pt}^{t}\left({ }^{t} \mathrm{Bu}_{2} \mathrm{bpy}\right)(4-\right.$ ethynylpyridine $\left.)_{2}\right] \cdot \mathrm{CH}_{2} \mathrm{Cl}_{2}\left(\mathbf{1 0} \cdot \mathrm{CH}_{2} \mathrm{Cl}_{2}\right)$ there are interactions between the relatively acidic protons of $\mathrm{CH}_{2} \mathrm{Cl}_{2}$ and the 4-ethynylpyridine $\mathrm{C} \equiv \mathrm{C}$ bonds. ${ }^{59}$ As a consequence, an infinite chain of $\mathrm{CH}_{2} \mathrm{Cl}_{2}$ molecules forms within a hydrophobic channel between the platinum complexes; $\mathrm{C}$ $\mathrm{H}-\mathrm{N}$ interactions between the ${ }^{t} \mathrm{Bu}_{2}$ bpy ligands and the pyridyl $\mathrm{N}$ atoms complement the network of noncovalent interactions. Presumably, the high selectivity for $\mathrm{CH}_{2} \mathrm{Cl}_{2}$ in the vapoluminescent response of neat $\left[\mathrm{Pt}^{t}\left(\mathrm{Bu}_{2} \mathrm{bpy}\right)(4 \text {-ethynylpyridine })_{2}\right](\mathbf{1 0})$ is at least partly due to the hydrogen bonding interactions which have been observed in crystals of the $\mathrm{CH}_{2} \mathrm{Cl}_{2}$ adduct. Acetonitrile has less acidic protons hence hydrogen bonding to the 4-ethynylpyridine $\mathrm{C} \equiv \mathrm{C}$ bonds is weaker and no vapoluminescence is observed; alcoholic vapors presumably cannot intrude into the hydrophobic environment produced by the tert.-butyl substituents. The emission spectrum of the crystalline $\mathrm{CH}_{2} \mathrm{Cl}_{2}$ adduct is similar to that obtained when dissolving the complex $\mathbf{1 0}$ in $\mathrm{CH}_{2} \mathrm{Cl}_{2}$ and has been interpreted in terms of ${ }^{3} \mathrm{MLCT}$ emission from discrete molecules; there are no short $\mathrm{Pt}(\mathrm{II})-\mathrm{Pt}(\mathrm{II})$ contacts in the crystalline form.

When the arylacetylide is ethynylpentafluorophenyl another vapoluminescent material is obtained. ${ }^{59}$ When crystallized from benzene solution $\left[\mathrm{Pt}\left({ }^{\mathrm{t}} \mathrm{Bu}_{2} \mathrm{bpy}\right)(\text { ethynylpentafluorophenyl })_{2}\right]$ (11) forms orange crystals which exhibit an intense structureless emission with $\lambda_{\max }=595 \mathrm{~nm}$. Upon exposure to $\mathrm{CH}_{2} \mathrm{Cl}_{2}$ vapor, the orange emission gradually changes to green $\left(\lambda_{\max }=500\right.$ $\mathrm{nm})$. While the orange photoluminescence is thought to be excimeric emission originating from 
electronically interacting complexes the green luminescence was attributed to ${ }^{3}$ MLCT emission from isolated complexes. The dichloromethane adduct of this material could not be crystallized but it was possible to investigate $\mathbf{1 1} \cdot \mathrm{CH}_{3} \mathrm{CN}$ by X-ray crystallography. The shortest $\mathrm{Pt}(\mathrm{II})-\mathrm{Pt}(\mathrm{II})$ contact in the acetonitrile adduct is at $9.957 \AA$, while in the solvent-free compound the shortest metal-metal distance is $5.172 \AA$. In the latter, the distances between neighboring luminophore layers are between $3.3 \AA$ and $3.6 \AA$ which is indicative of $\pi$-stacking between pentafluorophenylrings and ${ }^{t} \mathrm{Bu}_{2}$ bpy. The excimeric orange emission of solvent-free $\mathbf{1 1}$ may have its origin in these weak intermolecular interactions.

Wang and coworkers recently reported on a structurally related platinum(II) material exhibiting vapochromism that relies on an entirely different concept which has nothing to do with metal-metal distances or $\pi$-stacking. ${ }^{60}$ Instead, the vapochromism of complex 12 appears to be due to changes in the excited-state structure resulting from direct interactions between the complex and adsorbed molecules. Complex 12 contains two triarylboron groups, similar to those investigated in the context of fluoride sensors or electron-deficient materials. ${ }^{61-63}$ Neat 12 shows yellow ${ }^{3}$ MLCT emission $\left(\lambda_{\max }=559 \mathrm{~nm}\right)$ following UV irradiation (Figure 5). Exposure to $n$ hexane, toluene or methanol vapors quenches the luminescence, while exposure to benzene or cyclohexane induces a change in emission color from yellow to red $\left(\lambda_{\max }=580-620 \mathrm{~nm}\right)$. By contrast, when the same complex is exposed to vapors of $\mathrm{CH}_{2} \mathrm{Cl}_{2}, \mathrm{CHCl}_{3}, \mathrm{CH}_{3} \mathrm{CN}$, acetone, THF, or ethanol, the emission color shifts from yellow to green $\left(\lambda_{\max }=490-500 \mathrm{~nm}\right)$. Thus, complex 12 exhibits unusual behavior in that different groups of solvent vapors induce emission color shifts to either shorter or longer wavelengths. 


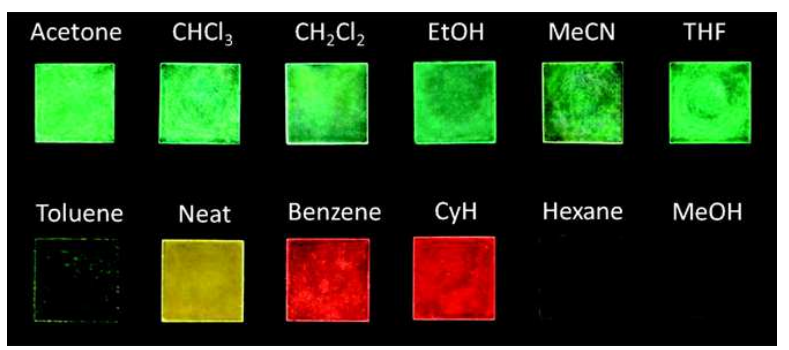

Figure 5. Photoluminescence of complex 12 after exposure to different VOCs. Reprinted with permission from ref. ${ }^{60}$. Copyright 2011 American Chemical Society.

This phenomenon has been explained in terms of solvent-induced switching in the nature of the emissive excited-states: While the yellow luminescence of neat $\mathbf{1 2}$ and the red emission after exposure to benzene or cyclohexane are assumed to originate from a ${ }^{3}$ MLCT state, the green emission following adsorption of more polar vapors is attributed to ligand-centered emission $\left({ }^{3} \mathrm{LC}\right)$. This interpretation makes sense in view of the fact that many $\mathrm{Pt}(\mathrm{II})$ complexes exhibit negative solvatochromism, because of their large ground-state dipole moments which are opposite to the direction of the MLCT. ${ }^{64,65}$ In complex 12, solvents of a certain threshold polarity shift the ${ }^{3} \mathrm{MLCT}$ state energetically above the ${ }^{3} \mathrm{LC}$ level which is then largely insensitive to further polarity changes (left part of Figure 6); this explains why solvents ranging in polarity from $\mathrm{CH}_{2} \mathrm{Cl}_{2}$ to $\mathrm{CH}_{3} \mathrm{CN}$ all lead to essentially the same green emission. ${ }^{60}$ Conversely, nonpolar solvents decrease the energy of the ${ }^{3}$ MLCT state, resulting either in red luminescence (benzene, cyclohexane) or, in the extreme case ( $n$-hexane), to emission quenching.

Single-crystal X-ray diffraction of $\mathbf{1 2} \cdot 4 \mathrm{CH}_{2} \mathrm{Cl}_{2}$ reveals that the shortest intermolecular Pt(II)$\operatorname{Pt}(\mathrm{II})$ separation is above $12 \AA$ and the shortest distance between aromatic planes is $\sim 5.7 \AA .^{60}$ Powder X-ray studies show that $\mathrm{CH}_{2} \mathrm{Cl}_{2}$, benzene, and hexane adducts are structurally very similar to neat 12. This finding is corroborated by solid state NMR studies monitoring the ${ }^{1} \mathrm{H}$, 
${ }^{13} \mathrm{C}$, and ${ }^{195} \mathrm{Pt}$ nuclei. ${ }^{11} \mathrm{~B}$ NMR spectroscopy shows that the boron center is unaltered by adsorption of $\mathrm{CH}_{2} \mathrm{Cl}_{2}$ or benzene. On the basis of these observations Wang and coworkers postulated that interactions between the bpy ligands and the adsorbed molecules are responsible for the energetic changes in the emissive ${ }^{3}$ MLCT state. ${ }^{60}$

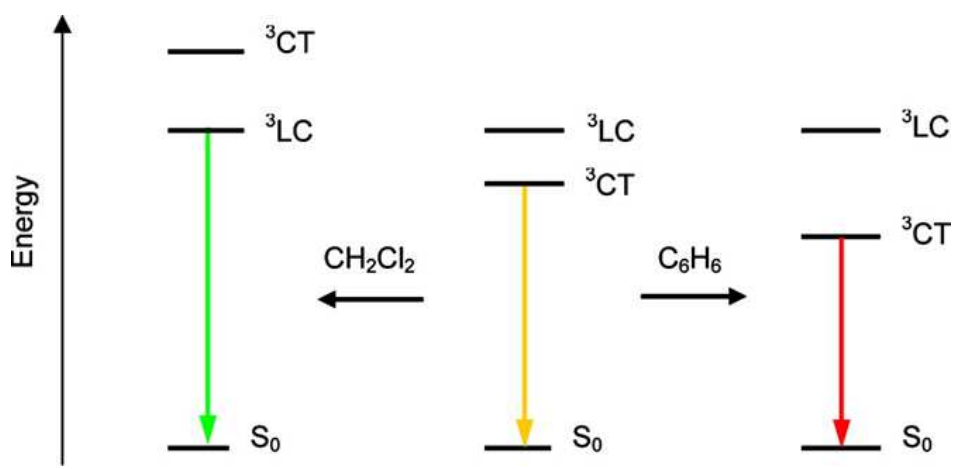

Figure 6. Changes of the excited-state structure in complex 12 as a function of VOC exposure. Reprinted with permission from ref. ${ }^{60}$. Copyright 2011 American Chemical Society.

Chen and coworkers report on a vapoluminescent platinum(II) bis(acetylide) complex (13) with a bpy ligand substituted at its 5- and 5'-positions with trimethylsilyl-protected ethynyl groups, ${ }^{66}$ its acetylide ligands are two 5-ethynyl-2,2'-bipyridine molecules (Scheme 5). The luminescence of $\mathbf{1 3}$ is strongly sensitive to a variety of VOCs. When exposed to acetone, structured luminescence with a band maximum at $562 \mathrm{~nm}$ is observed while exposure to THF leads to unstructured emission with $\lambda_{\max }$ at $747 \mathrm{~nm}$. For other solvent vapors, emission band maxima between these two extremes are detected. Structural investigations of different solvent adducts of 13 reveal that there is a correlation between the shortest $\mathrm{Pt}(\mathrm{II})-\mathrm{Pt}(\mathrm{II})$ distance $\left(\mathrm{d}_{\mathrm{Pt}-\mathrm{Pt}}\right)$ with the solvent-induced shift of the emission band maximum: While for the acetone and $n$ hexane adducts $\mathrm{d}_{\mathrm{Pt}-\mathrm{Pt}}=4.8406(15) \AA$ and 4.3091(9) $\AA$, respectively, chloroform and THF adducts 
exhibit short Pt(II)-Pt(II) contacts of 3.2363(15) $\AA$ and 3.2195(5) $\AA$. Thus, it appears plausible that the emissive state changes from ${ }^{3} \mathrm{MLCT}$ to ${ }^{3} \mathrm{MMLCT}$ for VOCs such as acetone, $\mathrm{CH}_{2} \mathrm{Cl}_{2}$, and $n$-hexane. In the $\mathrm{CH}_{2} \mathrm{Cl}_{2}$ adduct, intermolecular $\pi$ - $\pi$ stacking as well as $\mathrm{C}-\mathrm{H} / \pi(\mathrm{C} \equiv \mathrm{C})$ interactions may play a role as well. ${ }^{66}$

Scheme 5. $\left[\operatorname{Pt}(\alpha\right.$-diimine $\left.)(\text { acetylide })_{2}\right]$ complexes, part II.
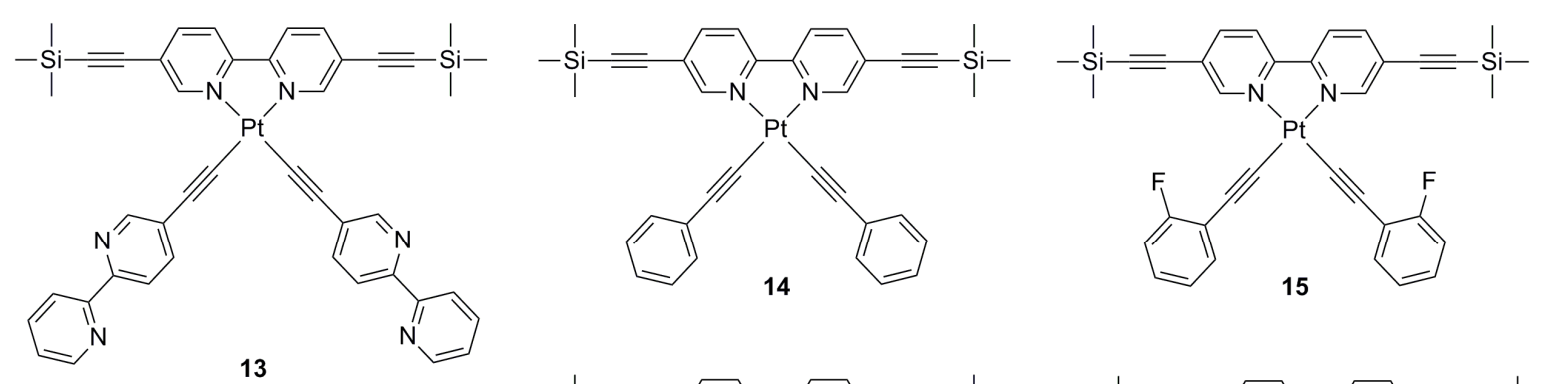

13
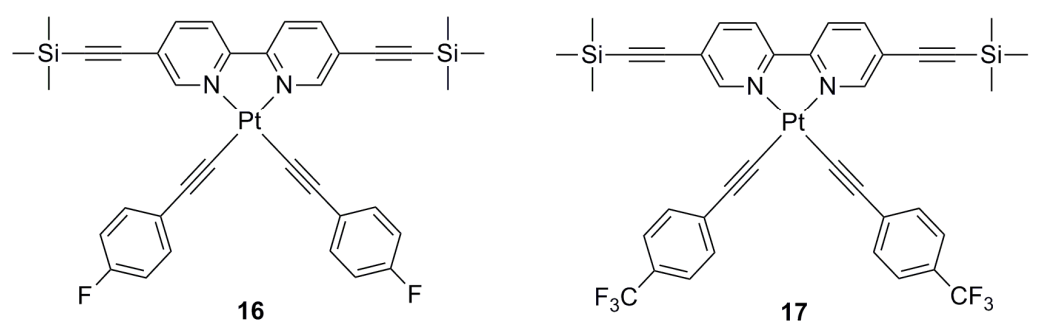

Chen and coworkers further reported on a Pt(II) complex with 5,5'-bis(trimethylsilylethynyl)2,2'-bipyridine and phenylacetylene ligands (14) exhibiting selective vapoluminescence response to volatile halohydrocarbons with only one carbon atom and molecular masses below 150 g/mol. ${ }^{67}$ The crystal structure of neat $\mathbf{1 4}$ as well as those of solvent adducts with 1,2dichloroethane and toluene exhibit no Pt(II)-Pt(II) distances shorter than $4.7 \AA$. By contrast, in the structure of the $\mathrm{CHCl}_{3}$ adduct there is a short intermetallic distance of 3.302(1) $\AA$ between pairs of complexes. The structural changes following $\mathrm{CHCl}_{3}$ uptake are accompanied by a change from orange $\left(\lambda_{\max }=561 \mathrm{~nm}\right.$ and $\left.603 \mathrm{~nm}\right)$ to red emission $\left(\lambda_{\max }=761 \mathrm{~nm}\right)$, which has 
been explained by a changeover from ${ }^{3}$ MLCT emission with some admixed ${ }^{3}$ LLCT character $(\tau$ $=2.12 \mu \mathrm{s})$ to ${ }^{3} \mathrm{MMLCT}$ emission. Computational studies support this interpretation and hint to an admixture of ${ }^{3}$ LLCT character even to the ${ }^{3}$ MMLCT luminescence. Neat 14 was exposed to a variety of different solvent vapors including those from diethyl ether, ethyl acetate, methyl acetate, acetone, methanol, ethanol, acetonitrile, pyridine, dibromomethane, bromoform, carbon tetrachloride, 1,2-dichloroethane, 1,2-dibromoethane, 1,1,2-trichloroethane, and toluene. However, a vapoluminescence response was only obtained with $\mathrm{CH}_{2} \mathrm{Cl}_{2}, \mathrm{CHCl}_{3}$, and $\mathrm{CH}_{3} \mathrm{I}$. The vapochromic response to $\mathrm{CH}_{2} \mathrm{Cl}_{2}$ is illustrated by Figure 7 .

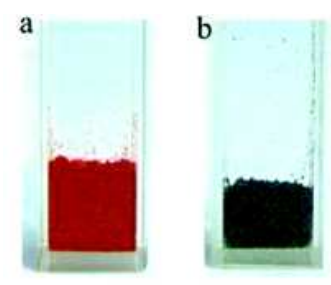

Figure 7. Photograph of crystalline samples of 14 (a) and $14 \cdot \mathrm{CH}_{2} \mathrm{Cl}_{2}$ (b). Reprinted with permission from ref. ${ }^{66}$. Copyright 2009 American Chemical Society.

Complexes 15 and 16 differ from 14 only by the fluoro-substituents at the phenylacetylene ligands yet exhibit substantially different vapoluminescence behavior. ${ }^{68}$ Complex 15 is specifically selective to $\mathrm{CHCl}_{3}$ vapors, while complex 16 responds to both $\mathrm{CHCl}_{3}$ and $\mathrm{CH}_{2} \mathrm{Cl}_{2}$. Unlike 14, neither 15 nor 16 are sensitive to $\mathrm{CH}_{3} \mathrm{I}$, but the effect of chloroform and/or dichloromethane exposure is the same in all three complexes, namely the change from orange ${ }^{3} \mathrm{MLCT} /{ }^{3} \mathrm{LLCT}$ to red ${ }^{3} \mathrm{MMLCT} /{ }^{3} \mathrm{LLCT}$ emission mentioned above for $\mathbf{1 4}$. The structure of the adduct between $\mathbf{1 5}$ and 1,2-dichloroethane, as well as the structures of $\mathbf{1 6} \cdot 0.5 \mathrm{CH}_{2} \mathrm{Cl}_{2}$, 
16. $\mathrm{CH}_{2} \mathrm{ClCH}_{2} \mathrm{Cl}$, and 16. $\mathrm{CH}_{2} \mathrm{BrCH}_{2} \mathrm{Br}$ were determined by single crystal $\mathrm{X}$-ray diffraction (Figure 8). Individual complexes are either stacked in staggered or anti-parallel fashion in these structures. The staggered mode permits formation of $\mathrm{Pt}(\mathrm{II})-\mathrm{Pt}(\mathrm{II})$ contacts shorter than $3.4 \AA$, whereas in the anti-parallel mode individual complexes are forced to slide away from each other so as to enforce intermetallic distances longer than $3.5 \AA$. Both stacking modes appear in the structure of $\mathbf{1 6} \cdot 0.5 \mathrm{CH}_{2} \mathrm{Cl}_{2}$ as there are pairs of complexes with short (3.315(9) $\AA$ ) and long (4.853(10) $\AA$ ) metal-metal distances (Figure 8). The structures of $\mathbf{1 5} \cdot \mathrm{CH}_{2} \mathrm{ClCH}_{2} \mathrm{Cl}$ and 15. $\mathrm{CH}_{2} \mathrm{ClCH}_{2} \mathrm{Cl}$ exhibit relatively short intermetallic contacts $(3.514(16) \AA$ and $3.513(5) \AA)$ as well, but there is no significant vapoluminescence response of $\mathbf{1 5}$ or $\mathbf{1 6}$ to 1,2-dichloroethane. A notable feature of several of the abovementioned crystal structures is the presence of C$\mathrm{H} / \pi(\mathrm{C} \equiv \mathrm{C})$ interactions between the halocarbon adsorbents and the fluorophenylacetylides. The reversible structural changes following the conversion of $16 \cdot \mathrm{CH}_{2} \mathrm{BrCH}_{2} \mathrm{Br}$ to $16 \cdot \mathrm{CH}_{2} \mathrm{Cl}_{2}$ were studied by monitoring X-ray diffraction (XRD) patterns after different times following exposure to $\mathrm{CH}_{2} \mathrm{Cl}_{2}$ or 1,2-dibromoethane vapors. Given the reversibility of the structural transformations the observation of fully reversible vapoluminescence responses by $\mathbf{1 5}$ and $\mathbf{1 6}$ is not particularly surprising. Several solvent adducts of $\mathbf{1 5}$ and $\mathbf{1 6}$ were found to exhibit mechanochromic luminescence. ${ }^{23,68}$

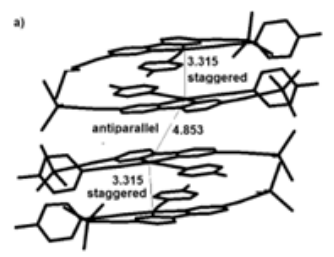


Figure 8. Molecular packing in single crystals of $\mathbf{1 6} \cdot 0.5 \mathrm{CH}_{2} \mathrm{Cl}_{2}$. (J. Ni, X. Zhang, Y.-H. Wu, L.Y. Zhang, Z.-N. Chen. Chem. Eur. J., 2011, 17, 1171-1183. Copyright Wiley-VCH Verlag GmbH \& Co. KGaA. Reproduced with permission.)

A closely related Pt(II) complex has two 4-trifluoromethylphenylacetylide ligands (17) and is selectively sensitive to vapors from cyclic ethers such as THF, dioxane, or tetrahydropyrane (THP) (Figure 9). ${ }^{69}$ As in the case of $\mathbf{1 3}-\mathbf{1 6}$, the vapoluminescence response of $\mathbf{1 7}$ is triggered by changes in intermetallic distances causing a red-shift in luminescence due to the changeover from ${ }^{3} \mathrm{MLCT} /{ }^{3} \mathrm{LLCT}$ to ${ }^{3} \mathrm{MMLCT}$ emission. In $\mathbf{1 7}$. THF there is a short (3.255(8) $\AA$ ) $\mathrm{Pt}(\mathrm{II})-\mathrm{Pt}(\mathrm{II})$ distance between staggered complexes, and the overall crystal structure appears to be stabilized by host-guest interactions through hydrogen-bonding between $\mathrm{C}-\mathrm{H}$ groups of the complex and the oxygen atom of THF, as well as between $\mathrm{C}-\mathrm{H}$ groups of THF and the trifluoromethyl group of the phenylacetylide ligands. It is possible that this is the origin of the selective vapoluminescence response to certain O-heterocyclic compounds (Figure 9). XRD studies reveal that the structural conversion between $17 \cdot \mathrm{CH}_{2} \mathrm{ClCH}_{2} \mathrm{Cl}$ and $\mathbf{1 7} \cdot \mathrm{THF}$ is fully reversible. Exposure to vapors of methanol, ethanol, acetone, furan, diethyl ether, ethyl acetate, hexane, toluene, pyridine, and various halohydrocarbons produces no significant vapoluminescence changes. The initial motivation for introducing the electron-withdrawing trifluoromethyl group at the phenylacetylide ligands was to increase the HOMO-LUMO energy gap, and the expected emission blue-shift could indeed be observed ( $\lambda_{\max }$ of 17 in $\mathrm{CH}_{2} \mathrm{Cl}_{2}$ solution: $568 \mathrm{~nm}$; $\lambda_{\max }$ of 14 in $\mathrm{CH}_{2} \mathrm{Cl}_{2}: 616 \mathrm{~nm}$ ). However, the selective vapoluminescence response of $\mathbf{1 7}$ is most likely an accidental result. 
Similar to $\mathbf{1 5}$ and 16, neat $\mathbf{1 7}$ and some of its solvent adducts exhibit mechanochromic properties and luminescence thermochromism. ${ }^{23,69}$

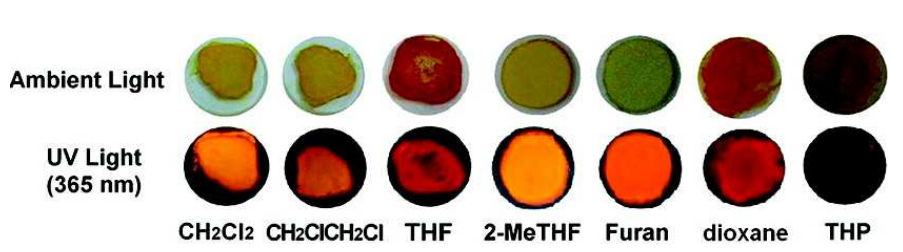

Figure 9. Vapochromic and vapoluminescent response of complex 17 to selected VOCs. Reprinted with permission from ref. ${ }^{69}$. Copyright 2012 American Chemical Society.

\subsection{3 $\left[\mathrm{Pt}(\text { isocyanide })_{2}(\mathrm{CN})_{2}\right]$ complexes}

When heating double salt compounds of the stoichiometry $\left[\mathrm{Pt}(\mathrm{CNR})_{4}\right]\left[\mathrm{Pt}(\mathrm{CN})_{4}\right]$ (see next chapter) to their melting point in absence of solvent, ligand rearrangement occurs and isomeric charge-neutral $\left[\mathrm{Pt}(\mathrm{CNR})_{2}(\mathrm{CN})_{2}\right]$ complexes are formed. ${ }^{70}$ Starting from the respective double salt, Mann and coworkers prepared $\left[\mathrm{Pt}\left(\mathrm{CN}-\mathrm{C}_{6} \mathrm{H}_{4}-\mathrm{C}_{2} \mathrm{H}_{5}\right)_{2}(\mathrm{CN})_{2}\right](\mathbf{1 8})$ at $201{ }^{\circ} \mathrm{C}$ (Scheme 6).

Scheme 6. Vapochromic $\left[\mathrm{Pt}(\text { isocyanide })_{2}(\mathrm{CN})_{2}\right]$ complexes.

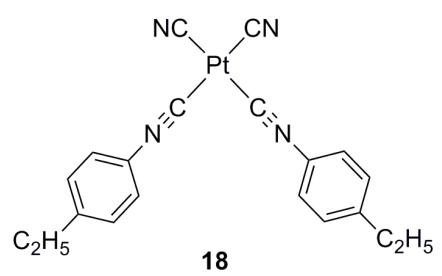

18

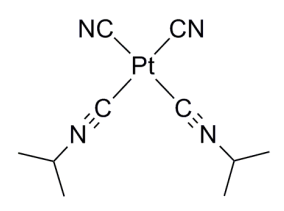

19

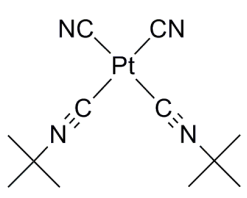

20

Subsequent re-crystallization of the raw product gives either an orange or a purple form of the same product: Slow crystallization from $\mathrm{CH}_{2} \mathrm{Cl}_{2}$ yields the orange form, while the purple isomer 
is obtained via rapid addition of hexanes to the $\mathrm{CH}_{2} \mathrm{Cl}_{2}$ solution. Of specific interest here is the orange form because it exhibits vapoluminescence, whereas the purple isomer does not appear to respond to VOCs. Orange $\mathbf{1 8}$ is the cis-isomer of $\mathbf{1 8}$ (cis-18) and exhibits luminescence from a $\mathrm{d} \sigma^{*} \rightarrow \mathrm{p} \sigma$ excited state similar to tetracyanoplatinates. When exposed to vapors of toluene, benzene, chlorobenzene, $p$-xylene, mesitylene, or ethanol in an $\mathrm{N}_{2}$ stream at $296 \mathrm{~K}$, the maximum of the broad emission band of cis-18 shifts from $611 \mathrm{~nm}$ to shorter wavelengths by up to $46 \mathrm{~nm}$ (Figure 10). In the case of toluene a VOC mole fraction of 0.0337 in the $\mathrm{N}_{2}$ stream is necessary to induce this blue-shift while in the case of mesitylene only a mole fraction of 0.0028 is required to induce the same effect. Analysis of the luminescence data suggests that toluene sorption occurs in two steps, involving adducts with the stoichiometry cis-18 $0.25 \mathrm{C}_{6} \mathrm{H}_{5} \mathrm{CH}_{3}$ and cis-18 $0.5 \mathrm{C}_{6} \mathrm{H}_{5} \mathrm{CH}_{3}$. Gravimetric studies, however, indicate that cis-18 rapidly sorbs 0.5 equivalents of toluene while prolonged exposure produces an adduct with 0.9 equivalents of toluene. Subsequent partial removal of toluene by continued purging with $\mathrm{N}_{2}$ occurs readily, but the last 0.25 equivalents are held with tenacity and neat cis-18 can only be recovered with simultaneous heating.

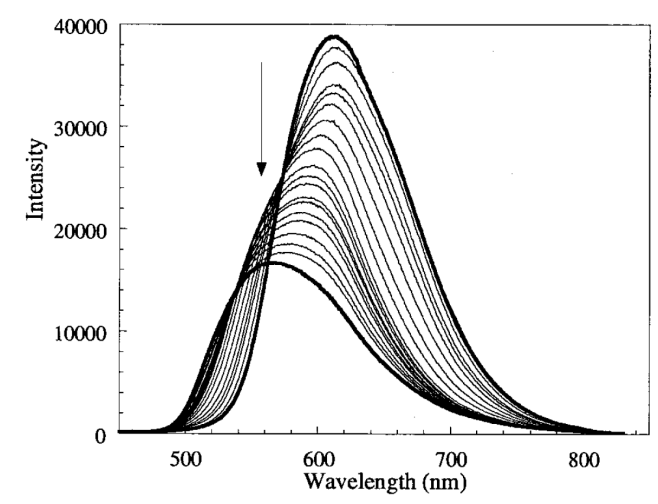

Figure 10. Emission spectral changes of cis-18 in the course of toluene vapor uptake. Reprinted with permission from ref. ${ }^{70}$. Copyright 2002 American Chemical Society. 
The structures of $c i s-\mathbf{1 8} \cdot 0.5 \mathrm{C}_{6} \mathrm{H}_{5} \mathrm{CH}_{3}$ and cis-18 $\times$ (hexanes) were determined by X-ray analysis. ${ }^{70}$ The packing arrangements in both structures are nearly identical, there are infinite stacks of cis- $\left[\mathrm{Pt}\left(\mathrm{CN}-\mathrm{C}_{6} \mathrm{H}_{4}-\mathrm{C}_{2} \mathrm{H}_{5}\right)_{2}(\mathrm{CN})_{2}\right]$ molecules with chains of $\mathrm{Pt}(\mathrm{II})$ atoms along the c-axis. The in-chain $\mathrm{Pt}(\mathrm{II})-\mathrm{Pt}(\mathrm{II})$ separation in the toluene adduct is alternating between $3.281 \AA$ and $3.300 \AA$, but the chain is slightly zigzagged with Pt-Pt-Pt angles of $175.5^{\circ}$. The cis18. $0.5 \mathrm{C}_{6} \mathrm{H}_{5} \mathrm{CH}_{3}$ adduct incorporates 4 toluene molecules per unit cell, thereby the volume of the latter increases by $160 \AA^{3}$ or $43 \%$ of the estimated volume of 4 toluene molecules $\left(372 \AA^{3}\right)$. Uptake of toluene vapor increases the packing efficiency by $10 \%$, which is significantly greater to what is commonly observed for the vapochromic $\mathrm{Pt}(\mathrm{II})$ double salts discussed in the next section (6\%). Toluene sorption increases the length of the unit cell along the c-axis by $0.35 \AA$, resulting in an increase of the $\mathrm{Pt}(\mathrm{II})-\mathrm{Pt}(\mathrm{II})$ distance by about $0.09 \AA$. However, among the VOCs investigated, no obvious correlation between the magnitude of the vapochromic luminescence band shift and any one VOC molecular parameter was found, and it was cautiously suggested that the molecular shape of the VOC guest plays an important role.

When the $\left[\mathrm{Pt}(\mathrm{CNR})_{4}\right]\left[\mathrm{Pt}(\mathrm{CN})_{4}\right]$ double salt with $\mathrm{R}=\mathrm{C}_{6} \mathrm{H}_{4}-\mathrm{C}_{2} \mathrm{H}_{5}$ is heated to reflux in chloroform, the purple trans-isomer of compound $\mathbf{1 8}$ is obtained. ${ }^{71}$ Expectedly, trans-18 differs from cis-18 not only in color (purple vs. orange) but by an ensemble of physical properties, e. g., different cyanide stretching frequencies, different chemical shifts for the ${ }^{195} \mathrm{Pt}$ NMR signals, and molecular packing in single crystals. The Pt(II)-Pt(II) separation (3.1253(8) $\AA$ ) in trans-18 is one of the shortest in the entire class of $\mathrm{Pt}(\mathrm{II})$ double salts. Furthermore, there are intermolecular $\pi-\pi$ interactions between isocyanide ligands of different stacks leading to a relatively close-packed structure in two of the three dimensions. As noted by Mann and coworkers, it is possible that the 
compact two-dimensional packing motif is responsible for the absence of vapochromism or vapoluminescence of trans-18. ${ }^{71}$

This cis-isomer of $\left[\mathrm{Pt}\left(\mathrm{CN}_{-}{ }^{i} \mathrm{C}_{3} \mathrm{H}_{7}\right)_{2}(\mathrm{CN})_{2}\right]($ cis-19) was synthesized from the respective double salt like cis-18. ${ }^{72}$ Individual Pt(II) complexes in cis-19 are slip-stacked in staggered fashion along the c-axis with an intermetallic distance of $3.256 \AA$, the color of the material is yellow. When exposed to benzene vapors, the structure changes to an eclipsed orientation of Pt(II) complexes with an intermetallic separation that has increased to $3.485 \AA$, and the color of this compound (cis-19.0.5 $\left.\mathrm{C}_{6} \mathrm{H}_{6}\right)$ is blue. The structural change including a $20 \%$ expansion in unit cell volume is further accompanied by a change in luminescence properties (Figure 11). Modeling of the spectral changes observed in the course of exposure to benzene leads to the conclusion that benzene uptake is a consecutive two-step reaction $(\mathrm{A} \rightarrow \mathrm{B} \rightarrow \mathrm{C})$ with an intermediate $\mathrm{B}$ of unknown structure. Interestingly, cis-19 does not respond to vapors of substituted derivates of benzene such as toluene, $p$-xylene, $m$-xylene, $o$-xylene, mesitylene, chloroform, and hexafluorobenzene. Presumably the selectivity of cis-19 for benzene has its origin in the absence of a stable solvate phase for adducts such as cis-19. $n\left(\mathrm{C}_{6} \mathrm{H}_{5} \mathrm{CH}_{3}\right)$. Unfortunately, the reversibility of the benzene uptake is poor due to crystalline degradation. The slow kinetics for benzene sorption additionally limits the usefulness of $c i s-\mathbf{1 9}$ as a benzene sensor for practical purposes.

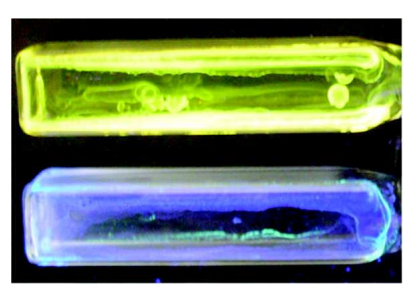


Figure 11. Photoluminescence of cuvettes filled with crystalline films of cis-19 before (top) and after (bottom) exposure to benzene vapor. Reprinted with permission from ref. ${ }^{72}$. Copyright 2009 American Chemical Society.

Using the compound $\left[\mathrm{Pt}\left(\mathrm{CN}-{ }^{t} \mathrm{Bu}\right)_{2}(\mathrm{CN})_{2}\right]$ (20) it has been possible to fabricate vaporresponsive microwires. ${ }^{73}$ For this purpose, 20 was dissolved in methanol and deposited onto insulating $\mathrm{SiO}_{2}$ substrates bearing two pre-installed small gold electrodes on the surface. The microwires were typically longer than $10 \mu \mathrm{m}$ and hence they were able to cross over two neighboring electrodes. When slowly evaporating solvent over a time period of 6 days the diameter of the microwires was typically on the order of $1.2 \mu \mathrm{m}$. The electrical conductivity of an operating electrode-microwire-electrode device at a bias of 5 Volts was determined to be 6.86 $\mu \mathrm{A}$. The conductivity is perturbed upon VOC exposure, but only toluene, acetonitrile, and methanol produce a significant response. Vapors of THF, acetone, ethyl acetate, diethyl ether, petroleum ether, hexane, nitromethane, ammonia, chlorobenzene, cyclohexane, dichloromethane, chloroform, and hydrazine lead to a comparatively small change in conductivity. It has been suggested that changes in the $\mathrm{Pt}(\mathrm{II})-\mathrm{Pt}(\mathrm{II})$ interactions are responsible for the vapor-induced variations in conductivity. ${ }^{73} \mathrm{X}$-ray diffraction indicates that upon acetonitrile uptake the Pt(II)Pt(II) distance remains almost unchanged (3.354(1) $\AA$ vs. 3.3525(2) $\AA$ ), but the coordination bond angles around the $\mathrm{Pt}(\mathrm{II})$ center are altered. ${ }^{74}$ Consequently, $\mathrm{CH}_{3} \mathrm{CN}$ exposure is associated with a relatively small change in luminescence properties and the $5 \mathrm{~d} \sigma^{*} \leftarrow 6 \mathrm{p} \sigma$ emission simply decreases in intensity but does not change color ( $\lambda_{\max }$ stays at $\left.534 \mathrm{~nm}\right)$. 


\subsection{Platinum(II) / palladium(II) double salts}

When stirring an acetonitrile solution of $\mathrm{Pt}\left(\mathrm{CH}_{3} \mathrm{CN}\right)_{2} \mathrm{Cl}_{2}$ and $\left[(n-\mathrm{Bu})_{4} \mathrm{~N}\right]_{2}\left[\mathrm{M}(\mathrm{CN})_{4}\right](\mathrm{M}=\mathrm{Pt}$, $\mathrm{Pd}$ ) in presence of isopropylisocyanide one obtains two compounds which are reminiscent of the Magnus Green Salt (MGS, $\left.\left[\mathrm{Pt}\left(\mathrm{NH}_{3}\right)_{4}\right]\left[\mathrm{PtCl}_{4}\right]\right)$, namely $\left[\mathrm{Pt}\left(\mathrm{CN}_{-}{ }^{i} \mathrm{C}_{3} \mathrm{H}_{7}\right)_{4}\right]\left[\mathrm{Pt}(\mathrm{CN})_{4}\right]$ (21) and $\left[\mathrm{Pt}\left(\mathrm{CN}_{-}{ }^{i} \mathrm{C}_{3} \mathrm{H}_{7}\right)_{4}\right]\left[\mathrm{Pd}(\mathrm{CN})_{4}\right](\mathbf{2 2})($ Scheme 7$) .{ }^{75}$

Scheme 7. Vapochromic $\mathrm{d}^{8}-\mathrm{d}^{8}$ double salts, part I.

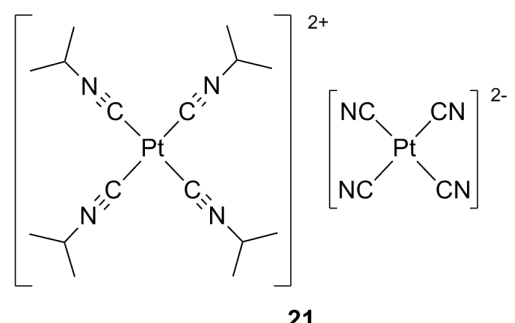

21

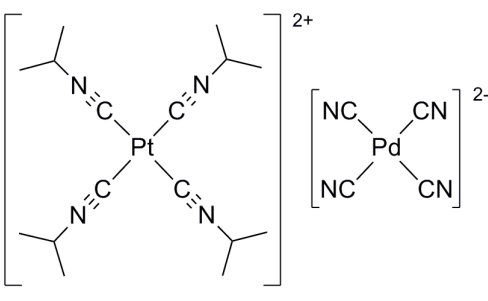

22

Bulk samples of $\mathbf{2 1}$ are red with a green metallic reflectance whereas $\mathbf{2 2}$ is yellow. From aqueous solution $\mathbf{2 1}$ crystallizes as a hexahydrate adduct with alternating cation-anion stacking similar to MGS (Figure 12), and the water molecules connect individual stacks through hydrogen-bonding to the cyanide ligands of the anion. Gravimetric investigations demonstrated that dry 21 readily uptakes either 12 molecules of $\mathrm{H}_{2} \mathrm{O}, 8$ molecules of methanol, 6 molecules of chloroform, or 4 molecules of trifluoroethanol when exposed to the corresponding vapors. 


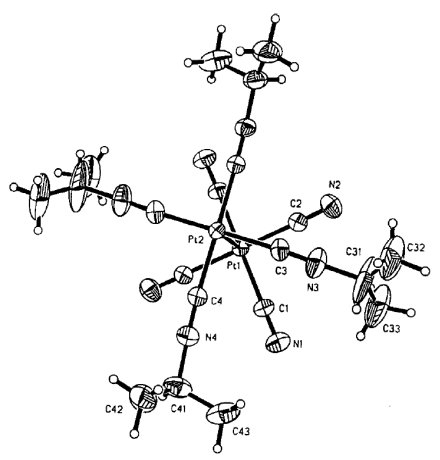

Figure 12. A cation-anion pair in compound 21. Reprinted with permission from ref. ${ }^{75}$. Copyright 1998 American Chemical Society.

Interestingly, none of these sorption processes influences the $\mathrm{Pt}(\mathrm{II})-\mathrm{Pt}(\mathrm{II})$ distance much, the unit cell parameter in the stacking direction (c-axis) varies in the narrow range from 6.303(2) $\AA$ to $6.337(2) \AA$. As a consequence, the absorption maximum of the lowest-energetic absorption varies only from $573 \mathrm{~nm}$ to $603 \mathrm{~nm}$ and vapochromism is not particularly spectacular. However, the vapor-sorption induced changes in the distance between individual $\mathrm{Pt}(\mathrm{II})-\mathrm{Pt}(\mathrm{II})$ stacks in the $a b$ plane are all the more noteworthy; the respective distance varies between $10.416 \AA$ (1) (in dry 21) to $18.271(4) \AA$ (in $\mathbf{2 1} \cdot 12 \mathrm{H}_{2} \mathrm{O}$ ). Large unit cell volume expansions reflecting the size of the guest vapor are observed: For $\mathrm{H}_{2} \mathrm{O}$ the cell volume expands by $54 \%$, for methanol $60 \%$, for trifluoroethanol $73 \%$, and for chloroform $94 \%$ relative to the volume of dry $\mathbf{2 1}$. Thus, it is clearly the size of the guest, and not the size of any preexisting pores in the host material which determines the magnitude of the lattice expansion. Principally these changes in the plane perpendicular to the $\mathrm{Pt}(\mathrm{II})-\mathrm{Pt}(\mathrm{II})$ stacking direction are thought to be responsible for the weak vapochromism of $\mathbf{2 1}$, but how exactly this occurs is not known. ${ }^{75}$

Scheme 8. Vapochromic $\mathrm{d}^{8}-\mathrm{d}^{8}$ double salts, part II. 

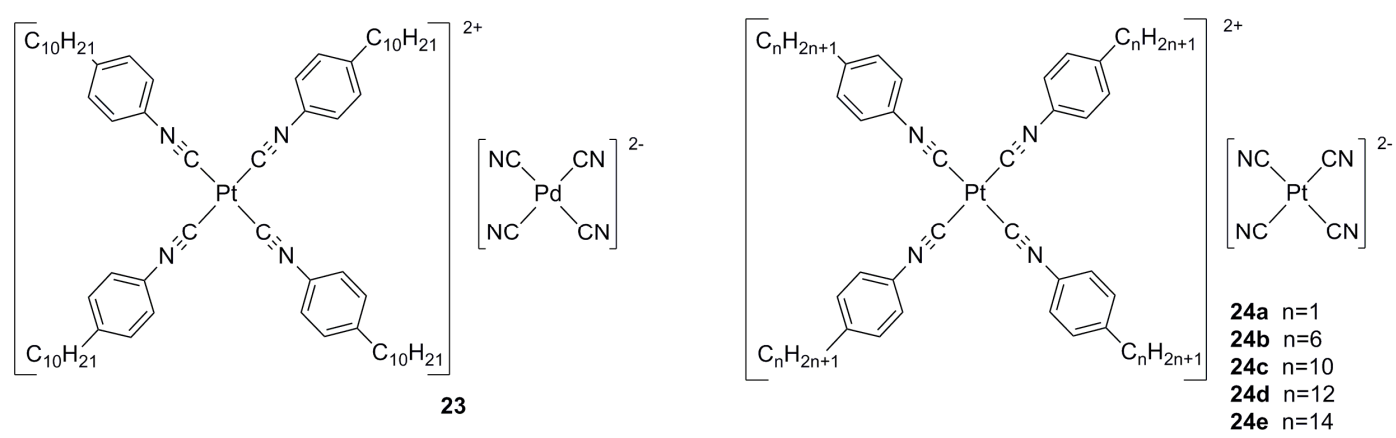

A variety of different isonitrile ligands can be used for obtaining vapochromic double salts similar to 21 or 22, an early example is $\left[\mathrm{Pt}\left(\mathrm{CN}-\mathrm{C}_{6} \mathrm{H}_{4}-\mathrm{C}_{10} \mathrm{H}_{21}\right)\right]\left[\mathrm{Pd}(\mathrm{CN})_{4}\right]$ (23) (Scheme 8). ${ }^{76}$ Analogous compounds with isonitriles containing $n \mathrm{C}_{6}, \mathrm{C}_{12}$, and $\mathrm{C}_{14}$ chains were investigated as well, but the $\mathrm{C}_{10}$ compound has the highest responsivity to solvent vapors. Thin films of $\mathbf{2 3}$ change color from pink to blue with a response time $\left(\mathrm{t}_{1 / 2}\right)$ of $\sim 350 \mathrm{~ms}$ when exposed to $\mathrm{CHCl}_{3}$ saturated air at room temperature. The associated shift of the visible absorption band from 548 $\mathrm{nm}$ to $578 \mathrm{~nm}$ is reversible thanks to a minimal disruption of crystallinity upon vapor sorption. It has been suggested that this is possible due to the rather large size mismatch between $\operatorname{Pt}($ II) dications and $\mathrm{Pd}(\mathrm{II})$ dianions, producing a relatively large free volume through which $\mathrm{CHCl}_{3}$ can easily move in and out of the material. IR spectroscopy suggests that the $\mathrm{CHCl}_{3}$ guest interacts predominantly with the $\left[\mathrm{Pd}(\mathrm{CN})_{4}\right]^{2-}$ anion because the $\mathrm{CN}$ vibration in pure 23 exhibits a single band at $2125 \mathrm{~cm}^{-1}$ while in the $\mathrm{CHCl}_{3}$ adduct a splitting into two bands (at 2127 and $2132 \mathrm{~cm}^{-1}$ ) is observed; the $\mathrm{CN}$ stretching frequency of the isonitrile ligands of the cation are invariant to $\mathrm{CHCl}_{3}$ uptake.

Bailey and Hupp reported on chemoresponsive diffraction gratings which make use of the vapochromic $\left(\left[\mathrm{Pt}\left(\mathrm{CN}-\mathrm{C}_{6} \mathrm{H}_{4}-\mathrm{C}_{10} \mathrm{H}_{21}\right)_{4}\right]\left[\mathrm{Pd}(\mathrm{CN})_{4}\right]\right.$ material (23). ${ }^{77} \mathrm{~A}$ film of compound 23 was cast onto a patterned poly(dimethylsiloxane) stamp having $5 \times 5 \mu^{2}$ wells arranged periodically, and 
the stamp was subsequently brought into contact with a transparent microscope slide. The lattice periodicity of $10 \mu \mathrm{m}$ is nicely observable by AFM and permits the diffraction of visible light. The uptake of chloroform vapor by the vapochromic layer results in an increase of the refractive index of the diffraction grating because voids (or initially present water molecules) in the vapochromic material are replaced by an organic substance. The increase in refractive index difference between grating and surrounding medium in turn causes an increase in diffraction efficiency. This effect is particularly strong when using light of a wavelength at which the diffraction lattice absorbs: Using $632.8 \mathrm{~nm}$ as an irradiation wavelength the loss-corrected diffraction efficiency is $\sim 3000$ times larger than when irradiating at a wavelength where the lattice does not absorb. Because the magnitude and the direction of the vapor-induced absorption band shifts in compound $\mathbf{2 3}$ depends on the VOC, the resonance effect observed in diffraction efficiency at a given irradiation wavelength is dependent on analyte, i. e., the effect shows certain solvent selectivity. Based on uptake isotherms a detection limit of a few $\mathrm{mg} / \mathrm{m}^{3}$ was estimated for $\mathrm{CHCl}_{3}$ vapor.

Analogous double salts with tetracyanoplatinate(II) instead of tetracyanopalladate(II) anions exhibit vapochromism as well. On the cations, arylisocyanide ligands $\left(p-\mathrm{CN}-\mathrm{C}_{6} \mathrm{H}_{4}-\mathrm{C}_{n} \mathrm{H}_{2 n+1}\right)$ with $n=1,6,10,12,14$ were explored, and it was found that compounds with $n=1,6(\mathbf{2 4 a}, \mathbf{2 4 b})$ respond better to polar VOCs whereas compounds with $n>6$ are more sensitive to nonpolar VOCs $(\mathbf{2 4 c}, \mathbf{2 4 d}, \mathbf{2 4 e})$ with compound $\mathbf{2 4 c}(n=10)$ being the most responsive. ${ }^{78}$ Despite the change from a $4 \mathrm{~d}$ to a $5 \mathrm{~d}$ metal in the dianion, there is still a significant size mismatch between counterions which is important for the reversible vapochromism of this family of compounds (Figure 13). 


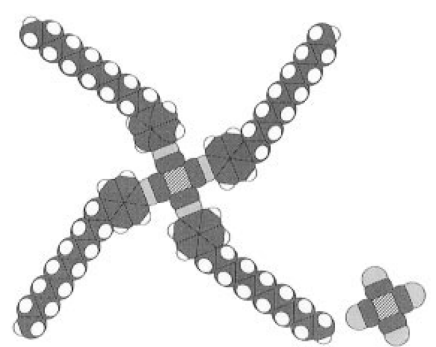

Figure 13. Space-filling model of double salt 24d. Reprinted with permission from ref. ${ }^{78}$. Copyright 1998 American Chemical Society.

These Pt(II)-Pt(II) double salts are mostly insoluble solids with a blue color, caused by a $d \sigma^{*} \rightarrow p \sigma$ transition arising from $5 d_{z 2}-5 d_{z 2}$ and $6 p_{z}-6 p_{z}$ orbital overlaps between neighboring $\mathrm{Pt}$ (II) atoms in linear stacks of alternating cations and anions (Figure 2). In neat 24c the maximum of the respective absorption is at $746 \mathrm{~nm}$, and upon exposure of a thin film of $\mathbf{2 4 c}$ to $\mathrm{CHCl}_{3} \lambda_{\max }$ shifts to $837 \mathrm{~nm}$. Methanol, ethanol, 2-propanol, diethyl ether, acetonitrile, hexanes, acetone, benzene, and dichloromethane produce vapochromic shifts as well, but to a smaller extent than chloroform $(11-65 \mathrm{~nm})$. The luminescence of $\mathbf{2 4 c}$ is affected by vapor sorption, too, but the emission band maximum of neat $\mathbf{2 4 c}$ is already outside the visible spectral range (944 $\mathrm{nm}$ ) and further moves into the NIR upon vapor sorption (e. g., to $1018 \mathrm{~nm}$ for $\mathrm{CHCl}_{3}$ ). The timescale of the vapochromic response is $\sim 500 \mathrm{~ms}\left(\mathrm{t}_{1 / 2}\right)$. IR spectroscopy monitoring the $\mathrm{CN}$ stretching vibrations of the cyanide and arylisonitrile ligands indicates that solvents capable of forming hydrogen bonds mostly interact with the $\left[\mathrm{Pt}(\mathrm{CN})_{4}\right]^{2-}$ anion, whereas apolar VOCs (e. g., benzene) cause very small shifts in $v(\mathrm{CN})$ but produce a significant change in the NIR portion of the optical absorption spectrum. From these observations it was concluded that the vapochromic response of this family of compounds is governed by a complicated interplay of hydrogenbonding, lypophilic, and dipole-dipole interactions. 
In-depth IR studies of $\mathbf{2 4 c}$ revealed a correlation between the cyanide stretching frequency and the hydrogen-bonding ability of the adsorbed VOC, ${ }^{79}$ as expressed by Abraham's $\alpha$ parameter. ${ }^{80}$ The vapor-induced $v(\mathrm{CN})$ shifts are between 1 and $17 \mathrm{~cm}^{-1}$. The only solvent which does not at all fit into the correlation between $v(\mathrm{CN})$ and $\alpha$ is water, due to its inability to pass the $h$ ydrophobic barriers imposed by the long alkyl chains of the dications.

Scheme 9. Vapochromic $\mathrm{d}^{8}-\mathrm{d}^{8}$ double salts, part III.

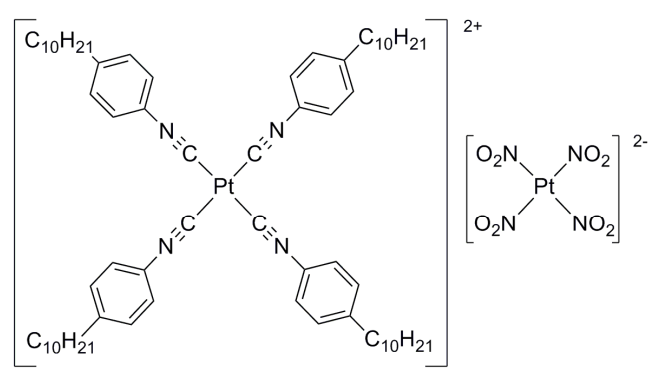

25

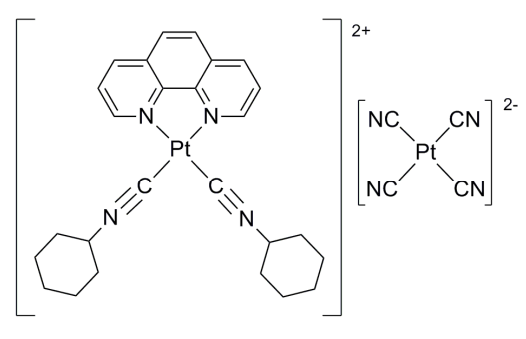

26

Based on the double salt family of vapochromic compounds several molecular devices were constructed. The first to be mentioned here is that of a vapochromic light-emitting diode (LED). ${ }^{81}$ For this purpose, a 700-nm layer of tris-(4-(2-thienyl)phenylamine) was deposited on an ITO coated glass and oligomerized anodically to produce a hole transport layer. This was followed by casting a 200-nm film of compound 25 (Scheme 9) on top. Finally, vapor deposition was used to deposit a 700-nm film of aluminum on top of everything. Application of an external voltage then resulted in electron flow from aluminum through the two molecular layers to ITO, inducing electroluminescence with a photon/electron efficiency of about $0.01 \%$. The electroluminescence was clearly due to compound $\mathbf{2 5}$ and exhibited a similar response to acetone vapor as the photoluminescence spectrum of $\mathbf{2 5}$, namely a shift of $\lambda_{\max }$ from 540 to $575 \mathrm{~nm}$. The 
motivation for using $\mathbf{2 5}$ with its tetranitroplatinate(II) anion instead of the analogous tetracyanoplatinate(II) salt (24c) was mainly the experience that $\mathbf{2 5}$ forms better films.

A device containing the same components but with somewhat different film thicknesses was used as a vapochromic photodiode. ${ }^{82}$ Rectification of the current favoring electron flow from aluminum through the two molecular layers was observed, the rectification ratio at 5 Volts was 100. Under application of 2 Volts of reverse bias it is possible to induce a photocurrent using the visible light output of a $450 \mathrm{~W}$ Xenon lamp. When blowing acetone vapor into the device, the photocurrent increased more than 10 times within 2 minutes. It was noted that this photodiode acts like vapochromic absorption sensor without the need for a separate detector.

Scheme 10. Vapochromic $\mathrm{d}^{8}-\mathrm{d}^{8}$ double salts, part IV.
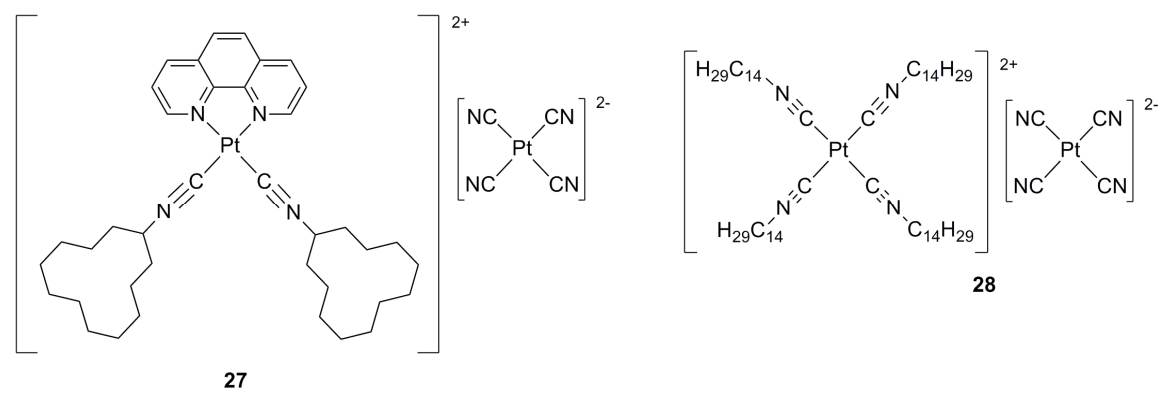

28

In addition to the vapochromic LED and the vapochromic photodiode Mann and coworkers reported on electronic nose devices based on vapoluminescent $\mathrm{Pt}(\mathrm{II})-\mathrm{Pt}(\mathrm{II})$ double salts. ${ }^{83,84}$ The principle of electronic noses is to use an array of chemical substances which respond differently when exposed to different vapors such that one obtains a response pattern from which one is able to discriminate between various odors. ${ }^{2,}{ }^{85}$ Using a combination of compounds $\mathbf{2 7 ,} \mathbf{2 8}$ and 26 (Scheme 10), deposited in submilligram quantities onto inert support disks made from platinum or carbon fibers, it was possible to construct a device which is able to differentiate chloroform, 
water, methanol, and dichloromethane from a broad variety of other solvent vapors. Interestingly, the device is able to differentiate between two the isomeric forms of propanol, but $n$-hexane and cyclohexane are not well resolved from each other. ${ }^{83}$ The discrimination ability of this device relies on the fact that compounds $\mathbf{2 7}$ and $\mathbf{2 6}$ give differently pronounced gradual vapor-induced luminescence shifts, whereas compound $\mathbf{2 8}$ acts essentially as a binary sensor with only two distinct responses. Principal component analysis of the overall luminescence spectra after vapor exposure then permits distinction between different vapors.

Scheme 11. Vapochromic $d^{8}-d^{8}$ double salts, part V.

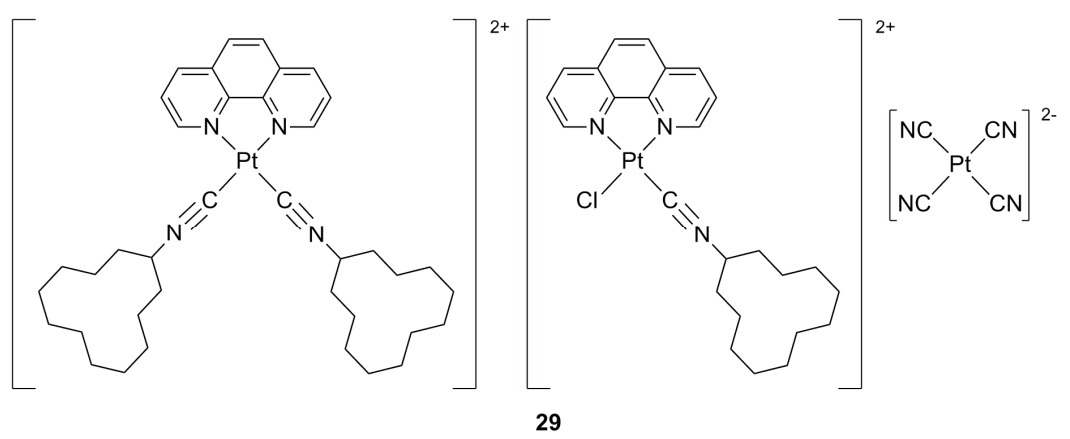

In subsequent electronic nose studies, compound $\mathbf{2 8}$ was replaced by the more temperatureresistant compound 29, a mixed cation platinum(II) double salt which can be formulated as $[\text { dication }]_{2}[\text { monocation }]_{2}\left[\operatorname{Pt}(\mathrm{CN})_{4}\right]_{3}($ Scheme 11$) .^{84}$ This was necessary because heating and cooling cycles of the array elements while purging with $\mathrm{N}_{2}$ gas between solvent vapor exposures turned out to be the most effective way to increase the reversibility and reproducibility of the device response. In addition, elevated operating temperatures (typically $50^{\circ} \mathrm{C}$ ) did at least partially eliminate the problem of undesired devices responses to air humidity. Using principal component analysis of vapor-induced luminescence changes the electronic nose constructed from 
compounds 27, 26 and 29 was able to differentiate between 10 different solvents. The detection limit for acetone was at $12 \%$ saturation $\left(75 \mathrm{~g} / \mathrm{m}^{3}\right)$, for methanol an even lower detection limit of $3 \%\left(6 \mathrm{~g} / \mathrm{m}^{3}\right)$ was determined. ${ }^{84}$

Scheme 12. Vapochromic $\mathrm{d}^{8}-\mathrm{d}^{8}$ double salts, part VI.

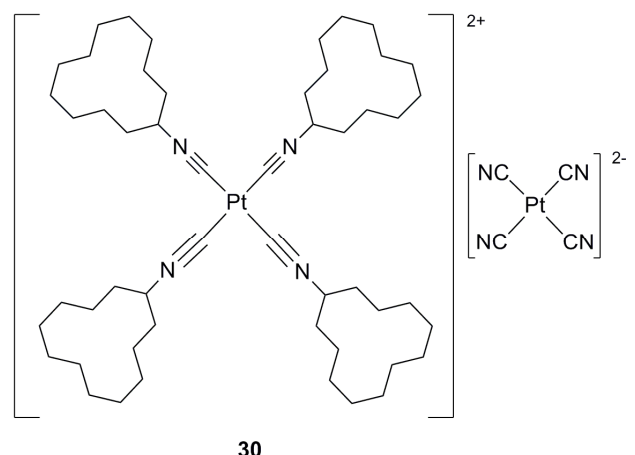

30

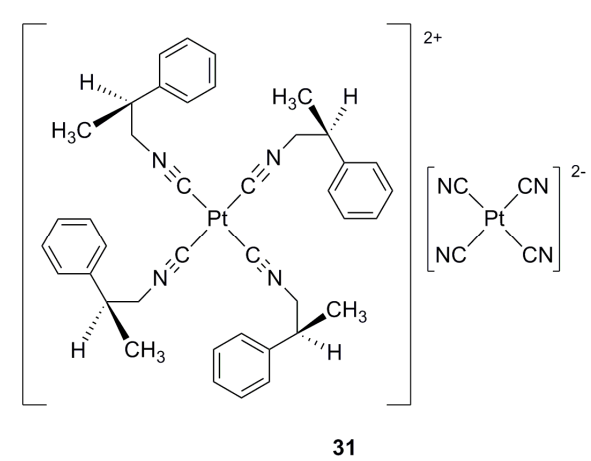

31

Unusually direct insight into the phenomenon of vapochromism in $\mathrm{Pt}(\mathrm{II})-\mathrm{Pt}(\mathrm{II})$ double salts was obtained from investigation of compound $\mathbf{3 0}$ using a quartz crystal microbalance on which mass changes and spectral changes as a function of water uptake from air humidity could be detected simultaneously (Scheme 12). ${ }^{86}$ The employed experimental setup revealed a type of behavior which was not previously known for this class of compounds, namely a strongly nonlinear response behavior to varying concentrations of water vapor. At low water vapor concentrations compound $\mathbf{3 0}$ sorbs 0.5 water molecules per formula unit, followed by a sudden uptake of 2.5 water molecules per formula unit when the water vapor concentration increases to $\sim 25 \%$ relative humidity. This phenomenon is accompanied by a stepwise change of the reflectance spectrum of compound $\mathbf{3 0}$ on the quartz crystal microbalance, i. e., optical spectroscopic and sorptive properties of thin films of $\mathbf{3 0}$ changed in a correlated fashion. $\mathrm{CH}_{2} \mathrm{Cl}_{2}$ and $\mathrm{CHCl}_{3}$ vapors produce reflectance changes as well, but as their concentrations are increased 
the step-like response behavior is much less pronounced than for water vapor. Benzene, toluene, and $p$-xylene induce a gradual vapochromic response. It thus appears that vapors capable of hydrogen-bonding produce fundamentally different optical species in $\mathbf{3 0}$ than non-hydrogenbonding VOCs.

Starting from enantiomerically pure isocyanide ligands, Drew, Mann and coworkers recently synthesized and explored a double salt which is capable of enantiomerically selective vapoluminescence sensing. ${ }^{87}$ Compound $\mathbf{3 1}$ with chiral $\beta$-methylphenethylisocyanide ligands on the cation can be obtained in pure $R$ - and $S$-forms, and the two enantiomers are able to differentiate between vapors of $R$-2-butanol and $S$-2-butanol. The enantiomeric selectivity cannot be pinned down to one specific effect but was rather considered as resulting from a combination of three possible effects: (i) differential selective hydrogen-bonding between the chiral 2-butanol guest and the cyanide ligands, (ii) selective solvation at the chiral host sites, and (iii) selective permeation of the chiral guest into the interstitial voids of the chiral host. Compound $\mathbf{3 1}$ suffers from water sensitivity and stability issues which need to be resolved before efficient vapochromic devices with enantiomeric selectivity can be envisaged; however, the proof of concept has clearly been provided.

\subsection{Cationic $\operatorname{Pt}(\mathrm{II})$ complexes with tridentate $\mathrm{N}^{\wedge} \mathrm{N}^{\wedge} \mathrm{N}$ ligands}

\subsubsection{Terpyridine complexes}

Electrostatic repulsion is a significant obstacle to obtaining stacks of cationic $\mathrm{Pt}(\mathrm{II})$ complexes with short metallophilic contacts. In view of this problem, many researchers have turned their 
attention to $2,2^{\prime}: 6^{\prime}, 2$ ' '-terpyridine ligands because they have strong $\sigma$-donating and $\pi$-accepting character, because these properties are beneficial for $\mathrm{Pt}(\mathrm{II})-\mathrm{Pt}(\mathrm{II})$ stacking.

Scheme 13. Pt(II) terpyridine complexes, part I.
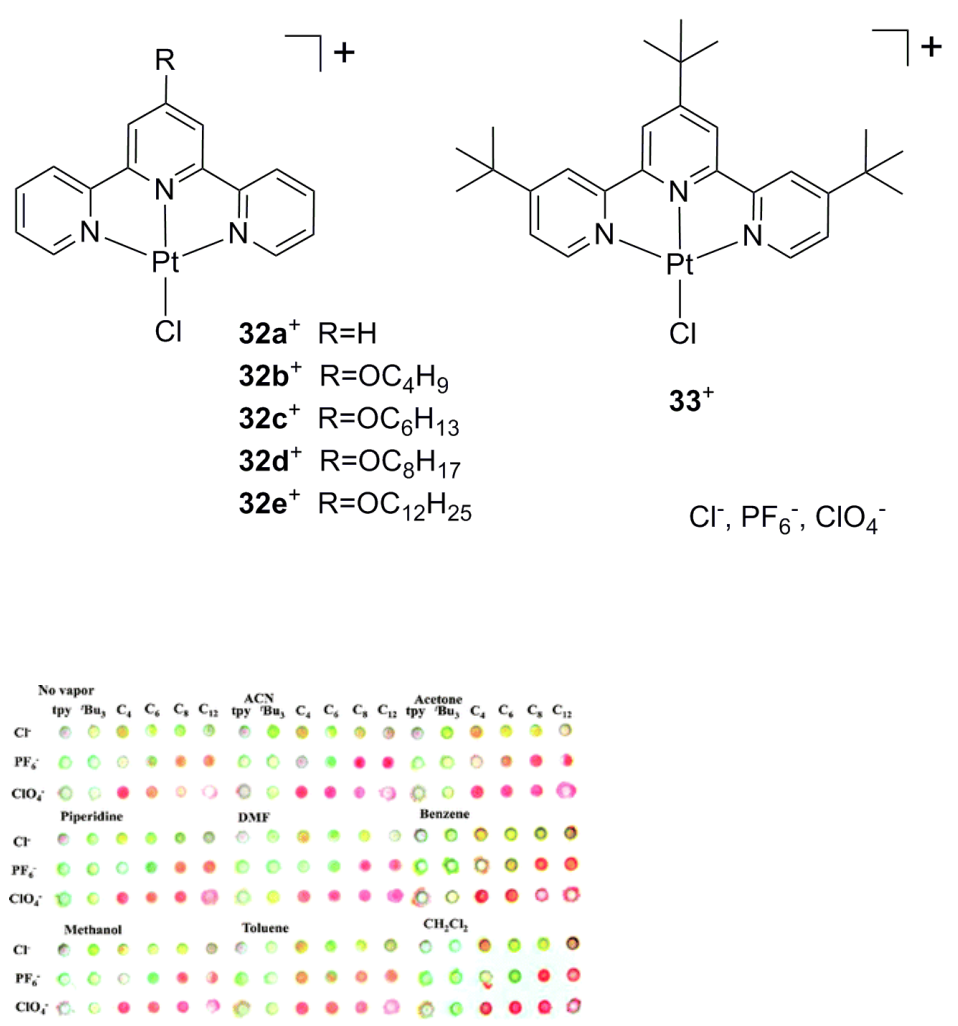

Figure 14. Vapochromic response of microarrays with complexes $\mathbf{3 2 a - e ^ { + }}-\mathbf{3 3}^{+}$. Reprinted with permission from ref. ${ }^{88}$. Copyright 2008 The Royal Society of Chemistry.

Among the structurally most simple Pt(II) terpyridine complexes that have been investigated in the context of vapochromism and vapoluminescence are the cations $\mathbf{3 2 a - e ^ { + }}-\mathbf{3 3}^{+}$which were each isolated as a chloride, hexafluorophosphate, and perchlorate salt, resulting in a total of 18 compounds (Scheme 13). ${ }^{88} 4 \mathrm{nmol}$ portions of these substances were put into $6 \times 3$ microarrays from which the vapor-induced color and luminescence changes could be detected using a flatbed 
scanner (Figure 14). Alkoxy-substitutents on terpyridine were used because they have previously been demonstrated to favor $\pi$-stacking, ${ }^{89}$ whereas the tert.-butyl groups are likely to lead to longer metal-metal contacts. Variation of the counterion affects packing of the $\mathrm{Pt}(\mathrm{II})$ terpyridine cations in the crystals. $^{48}$ Making these simple chemical variations on the chloro(terpyridine)platinum(II) backbone, it was hoped that exposure to different VOCs would produce distinct colorimetric / luminometric patterns and that the microarrays would be able to qualitatively mimic the olfactory system. ${ }^{88}$ Indeed, the individual $\mathrm{Pt}(\mathrm{II})$ salts respond distinctively to different analytes, but research on microarrays with these salts did not go far beyond providing the proof of concept. Anyhow, it was demonstrated that VOCs with lone pairs such as acetonitrile, piperidine and DMF produce the greatest vapochromic and vapoluminescent changes in the salts of complexes $\mathbf{3 2 a}-\mathbf{e}^{+}-\mathbf{3 3}^{+}$.

Scheme 14. Pt(II) terpyridine complexes, part II.
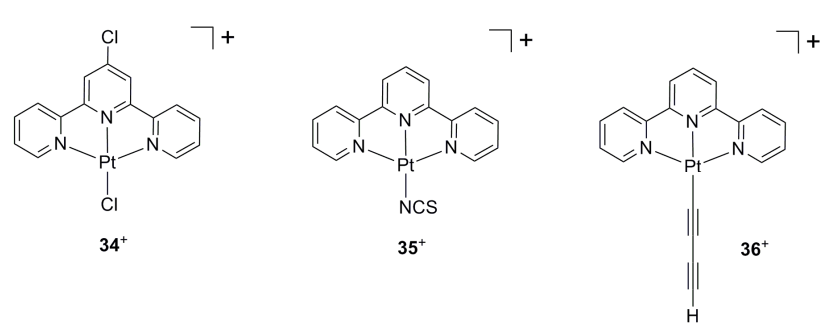

Despite its chemical simplicity the chloride salt of the (4-chloroterpyridine)platinum(II) complex $\mathbf{3 4}^{+}$is a highly selective vapoluminescent sensing material (Scheme 14).$^{90}$ It responds only to methanol vapor whereas all other tested VOCs, including halogenated solvents $\left(\mathrm{CH}_{2} \mathrm{Cl}_{2}\right.$, $\mathrm{CHCl}_{3}, \mathrm{CCl}_{4}$ ), aromatic substances (benzene, toluene, $p$-xylene, pyridine), amines (triethylamine, diethylamine, diisopropyl amine), other alcohols (ethanol, isopropanol, $n$-butanol, $t$-butanol), 
THF, diethyl ether, acetone, ethyl acetate and alkanes elicit no response. Methanol uptake is accompanied by a color change from red to yellow, and the emission band maximum undergoes a blue-shift from $665 \mathrm{~nm}$ to $615 \mathrm{~nm}$. Even though no crystallographic data is available it is reasonable to assume that the red form contains short $\mathrm{Pt}(\mathrm{II})-\mathrm{Pt}(\mathrm{II})$ contacts which make a ${ }^{3}$ MMLCT state the energetically lowest and emissive excited state, whereas the yellow color of the methanol-exposed material signals the absence of significant metallophilic interactions. Consequently, the vapoluminescence response most likely relies on the disruption metal-metal contacts and changeover from ${ }^{3}$ MMLCT to ${ }^{3}$ MLCT emission. In addition to the unusual selectivity, the high reversibility of the vapoluminescence response is an attractive feature of $34 \mathrm{Cl}$.

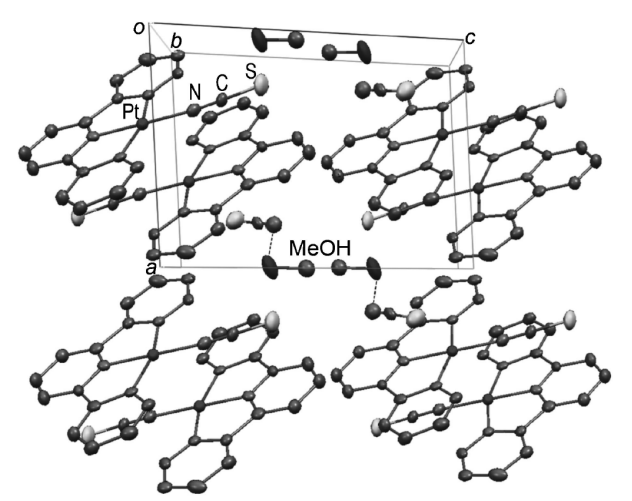

Figure 15. Packing diagram for $35 \mathrm{SCN} \cdot \mathrm{MeOH}$. Reprinted with permission from ref. ${ }^{91}$. Copyright 2009 The Chemical Society of Japan.

After the chloro(terpyridine)platinum(II) complexes the chemically next simple $\operatorname{Pt}(\mathrm{II})$ terpyridine exhibiting vapochromism is the thiocyanato complex $\mathbf{3 5}^{+}$. When exposing the rhodanide salt of this complex (35SCN) to methanol vapor, an unusual stepwise vapochromism 
response is detected. ${ }^{91}$ Initially, the $35 \mathrm{SCN}$ compound is red but upon methanol exposure there is first a color change to dark red before the material turns yellow. The structure of the yellow compound was determined by X-ray diffraction on single crystals grown from methanol solution and was found to consist of dimers of cations with an intermetallic distance of 3.4567(3) $\AA$ (Figure 15). Between individual dimers there are no metal-metal contacts shorter than $6 \AA$. Methanol solvate molecules are hydrogen-bonded to the $\mathrm{N}$ atoms of the $\mathrm{NCS}^{-}$anions, forming one-dimensional channels along the crystallographic b-axis. In air, the yellow crystals rapidly change to red due to facile methanol loss. On the basis of combined diffuse reflectance and powder X-ray diffraction studies, a two-step structural transformation from the initial red methanol-free form to an intermediate dark red form containing some methanol to finally a yellow fully adsorbed form was postulated. The color changes were explained by an increase of $\pi-\pi$ stacking and/or $\operatorname{Pt}(\mathrm{II})-\mathrm{Pt}(\mathrm{II})$ interactions when the first methanol molecules enter the structure of neat $35 \mathrm{SCN}$, followed by a decrease of the respective interactions in the course of further methanol uptake. In other words, methanol sorption is accompanied by shrinking and elongation processes resembling a breathing motion of the crystalline lattice. ${ }^{91}$

The hexafluoroantimonate salt of $\mathbf{3 5}^{+}$was found to exhibit vapochromic behavior which is selective and reversible for vapors of acetonitrile, DMF, and pyridine. ${ }^{92}$ Using ${ }^{15} \mathrm{~N}$ NMR spectroscopy it was demonstrated that in solution $95 \%$ of the complexes have nitrogen-bound NCS ligands while only 5\% are sulfur-bound, and this was explained by the electronwithdrawing nature of the terpyridine ligand making the Pt(II) center relatively hard. The crystal structure of the acetonitrile solvate $35 \mathrm{SbF}_{6} \cdot \mathrm{CH}_{3} \mathrm{CN}$ contains dimers of cations with $\mathrm{Pt}(\mathrm{II})-\mathrm{Pt}(\mathrm{II})$ distances of 3.293(1) $\AA$, the shortest intermetallic distance between individual dimers is 4.246(1) $\AA$. The crystal structure of $35 \mathrm{SbF}_{6}$ without $\mathrm{CH}_{3} \mathrm{CN}$ is not known, but it is assumed that the $\operatorname{Pt}(\mathrm{II})$ - 
$\mathrm{Pt}(\mathrm{II})$ interactions within dimers are retained when acetonitrile is removed and that intact cation dimers can slide into new positions such that an infinite linear chain structure with extensive $\mathrm{Pt}(\mathrm{II})-\mathrm{Pt}(\mathrm{II})$ interactions is adopted. This structural transformation would explain the maroon color and the observation of ${ }^{3} \mathrm{MMLCT}$ emission of neat $35 \mathrm{SbF}_{6}$. Upon exposure to acetonitrile, DMF or pyridine the maroon color rapidly changes to yellow, and thermogravimetric studies demonstrated that 1 equivalent of $\mathrm{CH}_{3} \mathrm{CN}$ or 0.5 equivalents of DMF or pyridine are adsorbed. The solvates can be converted back to the neat material upon gentle heating.

(a)

(b)

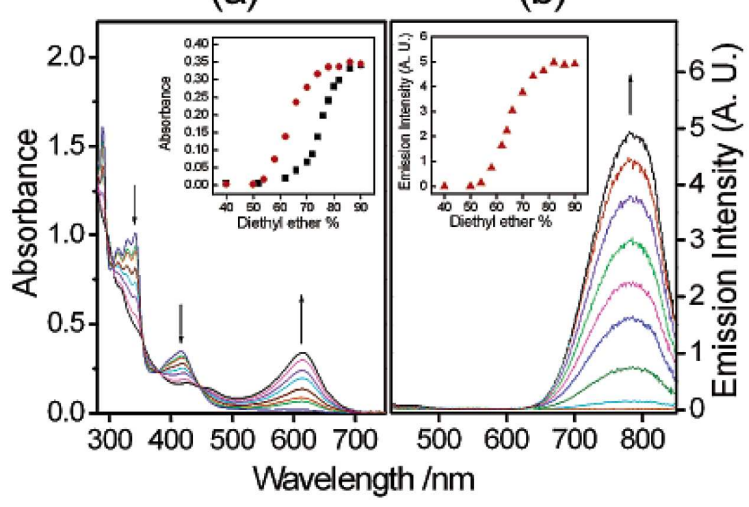

Figure 16. (a) Absorption and (b) emission changes as a function of diethyl ether addition to acetonitrile solutions of compound 36. Reprinted with permission from ref. ${ }^{64}$. Copyright 2002 American Chemical Society.

A Pt(II) terpyridine diynyl complex was found to exhibit strong solvatochromism but no vapochromism and will therefore be treated only very briefly here. ${ }^{64}[\mathrm{Pt}(\operatorname{tpy})(\mathrm{C} \equiv \mathrm{C}-\mathrm{C} \equiv \mathrm{CH})] \mathrm{OTf}$ (36) crystallizes in a dark green form with platinum atoms arranged in a linear chain with intermetallic contacts of $3.388 \AA$, and a red form exhibiting a dimeric structure with zigzag

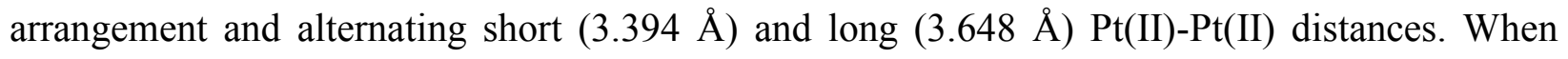


dissolved at $\sim 10^{-4} \mathrm{M}$ concentration in $\mathrm{CH}_{3} \mathrm{CN}$ the color of the resulting solution is yellow but upon addition of increasing amounts of diethyl ether the color changes first to green and finally to blue (Figure 16). This phenomenon has been explained by solvent-induced aggregation of individual Pt complexes to dimer, trimer, or even oligomer structures. Moreover, ether addition induces a dramatic enhancement of the luminescence emitted by these solutions; the emission has been assigned to a ${ }^{3}$ MMLCT state.

Scheme 15. Pt(II) terpyridine complexes, part III.
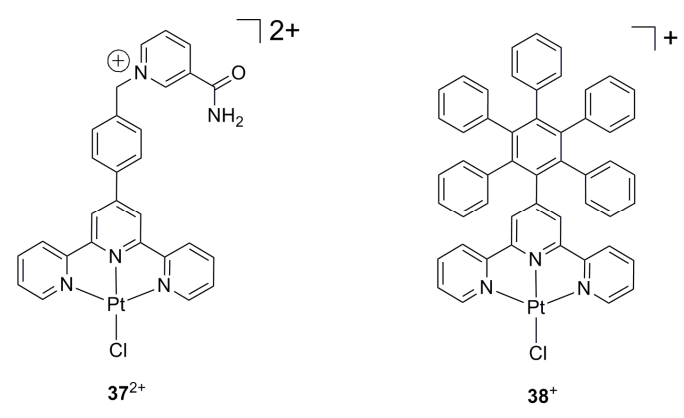

A study of a $\mathrm{Pt}(\mathrm{II})$ terpyridine-nicotinamide complex $\left(37^{2+}\right)($ Scheme 15$)$ provided unusually direct insight into the phenomenon of vapochromism because it was possible to structurally characterize both the neat form of $37\left(\mathrm{PF}_{6}\right)_{2}$ as well as its $\mathrm{CH}_{3} \mathrm{OH}$ adduct using the same single crystal before and after methanol vapor exposure. ${ }^{93}$ This is remarkable because such singlecrystal transformations involving the loss or gain of solvent molecules while at the same time retaining the integrity of the crystal lattice are rare. Both the red solvent-free form and the orange methanol adduct contain dimers of cations which are doubly hydrogen-bonded through their nicotinamide groups. ${ }^{93}$ There are three important differences in cation packing between the two forms: (i) the Pt-Pt-Pt arrangement is significantly more linear in the red form (Pt-Pt-Pt angle of 
$\left.171.9^{\circ}\right)$ than in the orange form $\left(126.7^{\circ}\right)$ (Figure 17); (ii) the separation between the planes of individual tpy ligands alternates between $3.453 \AA$ and $3.660 \AA$ in the red form (distance between $\mathrm{N}$-atoms of central pyridine ring), but increases to alternating distances of $3.692 \AA$ and $3.763 \AA$ in the orange form; (iii) the $\mathrm{Pt}(\mathrm{II})-\mathrm{Pt}(\mathrm{II})$ distances increase from $3.301 \AA / 3.336 \AA$ in the red form to $3.622 \AA / 3.964 \AA$ in the orange form. These structural changes clearly help to promote $\pi-\pi$ stacking and $\mathrm{Pt}(\mathrm{II})-\mathrm{Pt}(\mathrm{II})$ interactions between neighboring complexes in the solvent-free red form, while such interactions are essentially absent in the orange methanol adduct. Accordingly, the emission of red $37\left(\mathrm{PF}_{6}\right)_{2}$ is assigned to a ${ }^{3} \mathrm{MMLCT}$ state $\left(\lambda_{\max }=660 \mathrm{~nm}\right)$ while the luminescence of $37\left(\mathrm{PF}_{6}\right)_{2} \cdot \mathrm{CH}_{3} \mathrm{OH}\left(\lambda_{\max }=630 \mathrm{~nm}\right)$ is attributed to ${ }^{3} \mathrm{MLCT}$ emission of isolated chromophores. Thus, compound $37\left(\mathrm{PF}_{6}\right)_{2}$ is not only vapochromic but also vapoluminescent. It exhibits a selective and reversible vapochromic response when exposed to methanol, acetonitrile, or pyridine. ${ }^{93}$
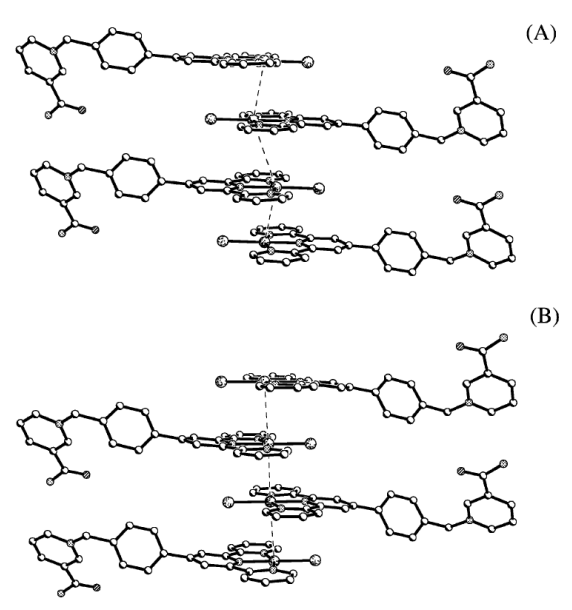

Figure 17. Stacking of complexes in (a) $37\left(\mathrm{PF}_{6}\right)_{2} \cdot \mathrm{CH}_{3} \mathrm{OH}$ (orange form) and (b) $37\left(\mathrm{PF}_{6}\right)_{2}$ (red form). Reprinted with permission from ref. ${ }^{93}$. Copyright 2004 American Chemical Society. 
A platinum(II) complex with a pentaphenyl-benzene moiety linked to a terpyridine chelating agent $(\mathbf{3 8 C l})$ has been reported to exhibit unusually large vapor-induced luminescence band shifts from the red to the green spectral range upon exposure to VOCs (Figure 18). ${ }^{94}$ This vapoluminescence response is relatively selective and occurs only for $\mathrm{CH}_{2} \mathrm{Cl}_{2}$, ethanol, $\mathrm{CH}_{3} \mathrm{CN}$, and ethyl acetate although the response time is by far the shortest for $\mathrm{CH}_{2} \mathrm{Cl}_{2}$. The initial red form of $\mathbf{3 8 C l}$ is a methanol adduct and contains $\mathrm{Pt}(\mathrm{II})$ cations which are stacked in a spiral fashion with each complex rotated by ca. $120^{\circ}$ along the stacking direction. There are four independent nearest-neighbor Pt(II)-Pt(II) distances in this helix, two of which $(3.30 \AA$ and 3.34 Å) are indicative of metallophilic interactions. Therefore it has been concluded that the red emission $\left(\lambda_{\max }=654 \mathrm{~nm}\right)$ of this form originates from a ${ }^{3}$ MMLCT state. Crystals of the green form of $\mathbf{3 8 C l}$ were grown from dichloromethane solution and contain one molecule of $\mathrm{CH}_{2} \mathrm{Cl}_{2}$ (instead of $\mathrm{CH}_{3} \mathrm{OH}$ ) per formula unit. This entails a dramatic change in cation packing and leads to a zigzag arrangement of neighboring Pt(II) complexes which are now found to be in head-totail orientation with $\mathrm{Pt}(\mathrm{II})-\mathrm{Pt}(\mathrm{II})$ distances $(3.9092(9) \AA$ and $4.5483(11) \AA$ ). Both of these distances are both significantly beyond what can be considered a metallophilic contact. Consequently, the green emission $\left(\lambda_{\max }=514 \mathrm{~nm}\right)$ of this form was attributed to ${ }^{3}$ MLCT luminescence from isolated $\mathrm{Pt}(\mathrm{II})$ terpyridine chromphores. Clearly the disruption of $\mathrm{Pt}(\mathrm{II})-\mathrm{Pt}(\mathrm{II})$ interactions is responsible for the strong vapochromic and vapoluminescence response of compound $\mathbf{3 8 C l}$. 


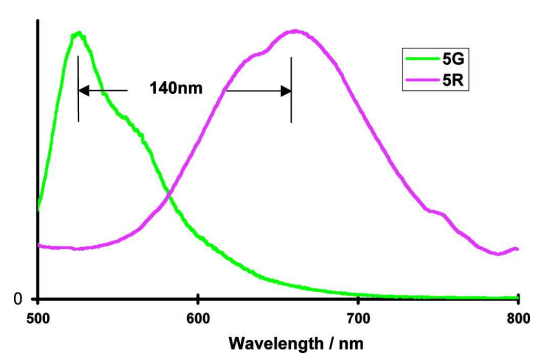

Figure 18. Photoluminescence of the green $(5 \mathrm{G})$ and red $(5 \mathrm{R})$ form of $38 \mathrm{Cl}$. Reprinted with permission from ref. ${ }^{94}$. Copyright 2008 American Chemical Society.

An interesting aspect is the absence of thermochromism of the red form of $38 \mathrm{Cl} .^{94}$ This is noteworthy because linear-chain compounds with stacked Pt(II) complexes exhibiting ${ }^{3}$ MMLCT luminescence often show a pronounced red-shift of the emission with decreasing temperature due to contraction of the crystal lattice and a shortening of $\mathrm{Pt}(\mathrm{II})-\mathrm{Pt}(\mathrm{II})$ distances, resulting in a smaller HOMO/LUMO energy gap. ${ }^{13,46}$ The absence of thermochromism in red $\mathbf{3 8 C l}$ is presumably due to the bulky nature of the pentaphenyl-benzene unit and its propeller-shaped nature which impedes tighter stacking of individual Pt(II) complexes at lower temperatures.

\subsubsection{Complexes with 2,6-bis( $N$-alkylbenzimidazol-2'-yl $)$ pyridine}

Scheme 16. Vapochromic 2,6-bis( $N$-alkylbenzimidazol-2'-yl)pyridine complexes.

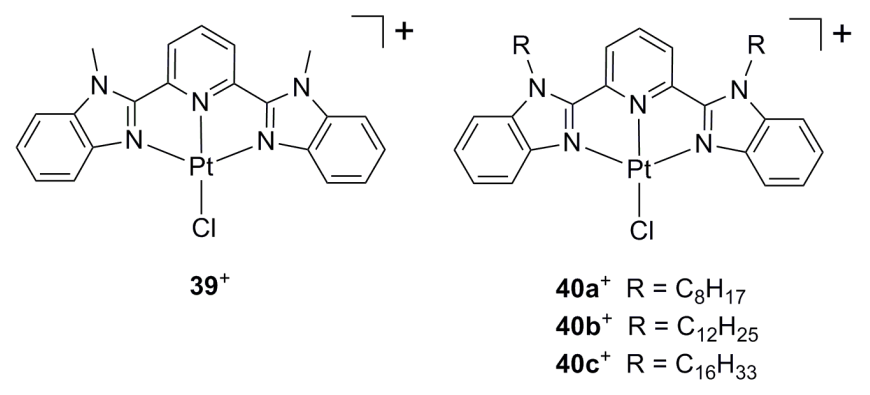


Complex $3^{+}$(Scheme 16) forms vapochromic salts with chloride and hexafluorophosphate anions. $^{95}$ 39 $\mathrm{Cl}$ changes color from yellow-orange to red when exposed to methanol, ethanol, chloroform, or acetonitrile (Figure 19). A color change from yellow to violet is detected upon exposure of $39 \mathrm{PF}_{6}$ to acetonitrile, but many other solvents (including water, methanol, ethanol, 2-propanol, diethyl ether, $\mathrm{CH}_{2} \mathrm{Cl}_{2}, \mathrm{CHCl}_{3}, \mathrm{CCl}_{4}$, acetone, hexanes, and benzene) produce no response. Gravimetric studies indicate that $39 \mathrm{Cl}$ sorbs up to two molecules of $\mathrm{CH}_{3} \mathrm{OH}$ per formula unit whereas $39 \mathrm{PF}_{6}$ can only sorb one equivalent of $\mathrm{CH}_{3} \mathrm{CN}$. Unlike for some of the $\mathrm{Pt}(\mathrm{II})$ terpyridine materials from the prior section in which VOC uptake results in the disruption of metallophilic contacts, the yellow-to-red color change observed for $39 \mathrm{Cl}$ and $39 \mathrm{PF}_{6}$ rather suggests that $\mathrm{Pt}(\mathrm{II})-\mathrm{Pt}(\mathrm{II})$ interactions strengthen in the course of methanol and acetonitrile sorption. Indeed, 2,6-bis( $N$-alkylbenzimidazol-2'-yl)pyridine complexes of $\mathrm{Pt}(\mathrm{II})$ are known to have a strong tendency to aggregate in solution. ${ }^{47,96}$

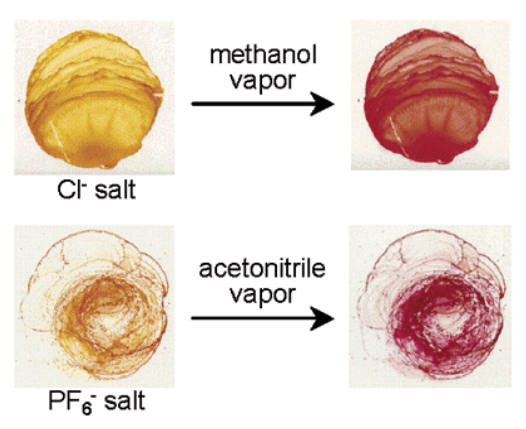

Figure 19. Vapochromic response of $39 \mathrm{Cl}$ and $39 \mathrm{PF}_{6}$. Reprinted with permission from ref. ${ }^{95}$. Copyright 2004 American Chemical Society. 
In the crystal structure of $39 \mathrm{PF}_{6} \cdot \mathrm{DMF} \mathrm{Pt}(\mathrm{II})$ complexes are oriented in zigzag head-to-tail arrangement with long intermolecular contacts (4.336(2) $\AA$ and 4.565(2) $\AA$ ) but comparatively short distances between the ligand planes $(3.35 \AA$ and $3.39 \AA) .{ }^{97}$ Chloride anions and DMF solvent molecules fill the voids between the columns of cations. Exposure of single crystals of $39 \mathrm{PF}_{6} \cdot \mathrm{DMF}$ to acetonitrile vapor induced a color change from orange to violet as noted above for powder samples of solvent-free $39 \mathrm{PF}_{6}$, but subsequent X-ray diffraction yielded only powder rings. Thus, the precise structure of the acetonitrile adduct remains unknown, but an interesting hypothesis has been put forward: The slippage of $\mathrm{Pt}(\mathrm{II})$ complexes by $1.35 \AA$ along vectors lying parallel to the plane of each complex to give cation dimers with $\mathrm{Pt}(\mathrm{II})-\mathrm{Pt}(\mathrm{II})$ distances of $\sim 3.39 \AA$ is conceivable since this represents the simplest imaginable deformation upon $\mathrm{CH}_{3} \mathrm{CN}$ uptake. This structural rearrangement would be in line the yellow-to-violet color change and the high reversibility of the vapochromism.

An unrelated but noteworthy observation is that orange powder samples of $39 \mathrm{PF}_{6}$ quickly sorb 1 equivalent of $\mathrm{DMF}$ and turn violet, but the $39 \mathrm{PF}_{6} \cdot \mathrm{DMF}$ single crystals grown from mixed $\mathrm{CH}_{3} \mathrm{CN} / \mathrm{DMF}$ solution are orange and unresponsive to DMF vapor. These observations suggest that there is both an orange and a violet polymorph of the DMF adduct.

When complex $\mathbf{3 9} \mathrm{Cl}$ is incorporated into a zirconium phosphate $(\mathrm{ZrP})$ framework, a different type of vapochromic behavior is observed. ${ }^{98}$ First of all, different colors than in neat $39 \mathrm{Cl}$ are obtained with certain VOCs. Secondly, despite the lower concentration of the platinum(II) complexes in $\mathrm{ZrP}$ compared to neat $39 \mathrm{Cl}$, the color response is equally strong or even stronger in the inorganic framework. The Pt:ZrP ratio was typically between 1:5 and 1:30, yet the vapochromic response upon exposure to water, $\mathrm{MeOH}, \mathrm{CH}_{3} \mathrm{CN}, \mathrm{CH}_{2} \mathrm{Cl}_{2}$, THF, benzene, and $n$ hexane occurs within minutes. Interestingly, the vapochromic response patterns of the $\mathrm{ZrP}$ - 
incorporated complex are different than those of neat $39 \mathrm{Cl}$ or $39 \mathrm{PF}_{6}$. Fast and reversible $\left({ }^{3}\right.$ MMLCT) vapoluminescence responses were detected.

An entire series of 2,6-bis( $N$-alkylbenzimidazol-2'-yl)pyridine complexes of $\mathrm{Pt}(\mathrm{II})$ with various alkyl-substituents $(\mathrm{R})$ and counterions was found to exhibit vapochromic behavior similar to that of $39 \mathrm{Cl}$ and $39 \mathrm{PF}_{6}{ }^{99}$ This includes the chloride salts of complexes with $\mathrm{R}=\mathrm{C}_{8} \mathrm{H}_{17}$ (40a), $\mathrm{C}_{12} \mathrm{H}_{25}$ (40b), $\mathrm{C}_{16} \mathrm{H}_{33} \quad(\mathbf{4 0 c})$, as well as the hexafluorophosphate, perchlorate, tetrafluoroborate, triflate, and acetate salts of the complex with $\mathrm{R}=\mathrm{C}_{16} \mathrm{H}_{33}$ (40c). Both the alkyl chain length and the size of the anion affect the vapochromic response because these factors influence the molecular stacking pattern. However, no clear systematic trends could be recognized. When constructing an array from all these vapochromic substances it becomes possible to distinguish between different VOCs, i. e., to some extent the array can function as an electronic nose. The solvents to which these arrays were exposed are acetone, acetonitrile, methanol, ethanol, dichloromethane, chloroform, ethyl acetate and benzene. The majority of the vapochromic responses involve a transition from lighter to darker color (typically from yelloworange to red or violet), similar to what has been observed for $39 \mathrm{Cl}$ and $39 \mathrm{PF}_{6}$, suggesting that $\mathrm{Pt}(\mathrm{II})-\mathrm{Pt}(\mathrm{II})$ interactions are strengthened upon VOC uptake. Two notable exceptions are the chloride and triflate salts of 40c which change from deep orange to yellow. In these two salts solvent uptake seems to reduce $\mathrm{Pt}(\mathrm{II})-\mathrm{Pt}(\mathrm{II})$ and/or $\pi-\pi$ interactions.

2.3.3 Complexes with 2,6-bis-(1H-imidazol-2-yl)pyridine

Scheme 17. A vapochromic Pt(II) 2,6-bis-(1H-imidazol-2-yl)pyridine complex. 


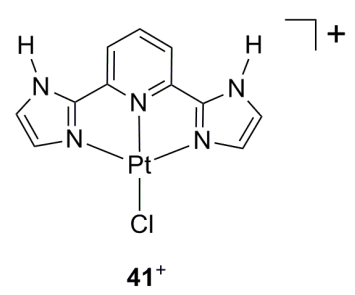

Complex $\mathbf{4 1}^{+}$was synthesized along with a few other related complexes with a view to obtaining a quasi-2D framework made of planar Pt(II) complexes. ${ }^{100}$ The idea was to exploit $\mathrm{Pt}(\mathrm{II})-\mathrm{Pt}(\mathrm{II})$ interactions and $\pi-\pi$ stacking to induce ordering of individual complexes along one direction while at the same time making use of hydrogen-bonding interactions to induce ordering along a second direction. In the course of these studies it was discovered that $41 \mathrm{Cl}$ is a vapoluminescent substance. Solvent-free $41 \mathrm{Cl}$ exhibits emission with $\lambda_{\max }$ at $525 \mathrm{~nm}$, the occurrence of vibrational fine structure with $\sim 1500 \mathrm{~cm}^{-1}$ intervals between individual progression members suggests that the emission contains significant intraligand $\pi-\pi^{*}$ character. When brought in contact with vapors from $\mathrm{CH}_{2} \mathrm{Cl}_{2}, \mathrm{CH}_{3} \mathrm{CN}, \mathrm{CH}_{3} \mathrm{OH}$ or acetone, the emission red-shifts to $\lambda_{\max }=630 \mathrm{~nm}$ and becomes broad and unstructured. The red emission has been tentatively attributed to the presence of close $\mathrm{Pt}(\mathrm{II})-\mathrm{Pt}(\mathrm{II})$ contacts or $\pi-\pi$ interactions between ligands. Support for this hypothesis comes from the X-ray crystal structure of $41 \mathrm{Cl} \cdot \mathrm{DMSO} \cdot 2 \mathrm{H}_{2} \mathrm{O}$ which exhibits intermolecular $\pi-\pi$ distances of $3.370 \AA$ and $3.395 \AA$, but in this specific solvate structure the shortest $\mathrm{Pt}(\mathrm{II})-\mathrm{Pt}(\mathrm{II})$ distance is $4.33 \AA$.

An electron mobility value of $0.4 \mathrm{~cm}^{2} \mathrm{~V}^{-1} \mathrm{~s}^{-1}$ has been determined for solvent-free $41 \mathrm{Cl}$ which is a low value compared to that measured for a related 2,6-bis( $1 H$-pyrazol-3-yl)pyridine complex of $\operatorname{Pt}(\mathrm{II})\left(20 \mathrm{~cm}^{2} \mathrm{~V}^{-1} \mathrm{~s}^{-1}\right) \cdot{ }^{100}$ Cofacial $\pi-\pi$ and $\mathrm{Pt}(\mathrm{II})-\mathrm{Pt}(\mathrm{II})$ interactions are thought to be responsible for the high electron mobility in the pyrazolyl-complex. It has been noted that if such 
interactions could be induced by vapor (e. g., in $\mathbf{4 1 C l}$ or related other materials), transistor-based sensors and other multi-functionalized optoelectronic devices could be created based on Pt(II) complexes.

\subsection{Cyclometalated Pt(II) complexes}

2.4.1 Complexes with 2,6-diphenylpyridine $\left(\mathrm{N}^{\wedge} \mathrm{C}^{\wedge} \mathrm{N}\right)$ ligands

Scheme 18. Vapochromic cyclometalated Pt(II) complexes, part I.

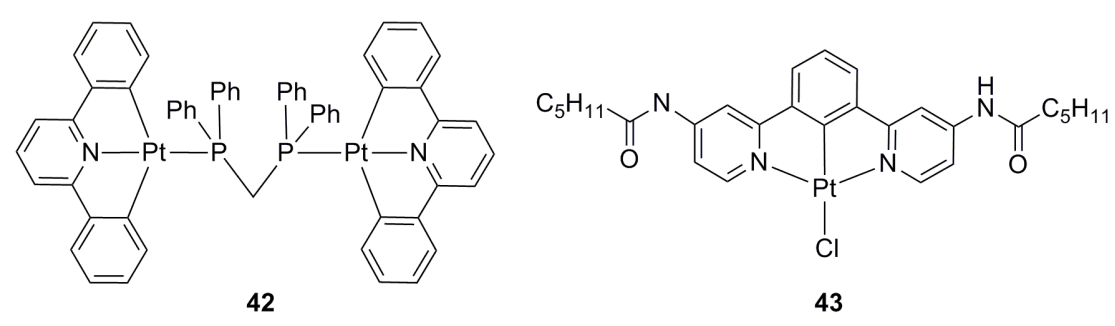

The bis(diphenylphosphino)methane (dppm) bridged dinuclear Pt(II) complex 42 (Scheme 18) is a vapochromic substance functioning on the basis of intramolecular $\pi-\pi$ stacking rather than inter- or intramolecular Pt(II)-Pt(II) interactions. ${ }^{101}$ Both a solvent-free yellow form and an orange chloroform adduct of this charge-neutral complex were characterized crystallographically, and it was found that the yellow form exhibits weak $\pi-\pi$ interactions between one of the $\operatorname{Pt}\left(\mathrm{N}^{\wedge} \mathrm{C}^{\wedge} \mathrm{N}\right)$ planes and a phenyl ring of the dppm ligand with interplanar

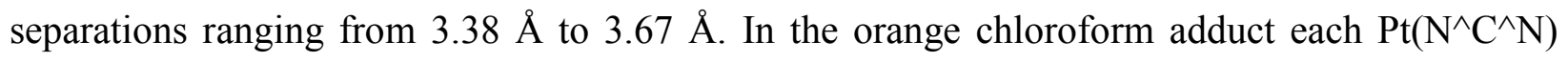
plane makes a $\pi-\pi$ interaction with a phenyl ring from different $\mathrm{P}$-atoms of the dppm ligand, and the interplanar distances are in the range of $3.12 \AA$ to $3.29 \AA$ (Figure 20), i. e., noticeably shorter than in the yellow form. A variety of different VOCs $\left(\mathrm{CH}_{2} \mathrm{Cl}_{2}, \mathrm{CH}_{3} \mathrm{OH}\right.$, acetone, benzene, 
pentane) induce a change in color from yellow to orange, and given the structural information from above it appears plausible to conclude that each of these solvents induces a strengthening of intramolecular $\pi-\pi$ interactions when sorbed by the yellow form of $\mathbf{4 2}$.

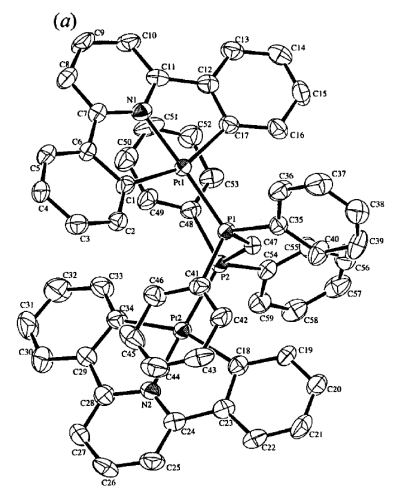

Figure 20. Crystal structure of 42. Reprinted with permission from ref. ${ }^{101}$. Copyright 2001 American Chemical Society.

The amide-decorated $[\operatorname{Pt}(2,6$-diphenylpyridine)Cl] complex 43 exhibits an interesting combination of mechanochromism and vapochromism. ${ }^{102}$ When crystallizing from DMF, one obtains green emitting 43.DMF. This material exhibits sharp diffraction peaks in powder X-ray analysis. When $43 \cdot \mathrm{DMF}$ is ground in a ceramic mortar one obtains an orange luminescent powder which does not give clear X-ray diffraction. Subsequent exposure of this amorphous substance to methanol vapors leads to $43 \cdot \mathrm{CH}_{3} \mathrm{OH}$, a yellow emitter which exhibits sharp X-ray diffraction peaks again. This two-step conversion from crystalline $\mathbf{4 3} \cdot \mathrm{DMF}$ to amorphous $\mathbf{4 3}$ and finally crystalline $43 \cdot \mathrm{CH}_{3} \mathrm{OH}$ is a highly unusual phenomenon. X-ray diffraction studies on single crystals reveal long Pt(II)-Pt(II) contacts of $4.854 \AA$ between nearest neighbors in the DMF adduct, whereas in $\mathbf{4 3} \cdot \mathrm{CH}_{3} \mathrm{OH}$ the shortest intermetallic separation is only $3.385 \AA$. The observation of metal-metal distance shrinking may explain the change from green to red 
luminescence accompanying the two-step transformation from $43 \cdot \mathrm{DMF}$ to $43 \cdot \mathrm{CH}_{3} \mathrm{OH}$. The hydrogen-bonding ability of the dangling amide groups is suspected to play an important role for the mechano- and vapochromism of $\mathbf{4 3}$ because the hexanoylamide groups form hydrogen-bonds to the DMF and methanol guest molecules in crystals of $43 \cdot \mathrm{DMF}$ and $43 \cdot \mathrm{CH}_{3} \mathrm{OH}$. Heating crystals of 43.DMF to $150{ }^{\circ} \mathrm{C}$ induces release of the DMF molecule and produces the same luminescence change as grinding, suggesting that the amorphous orange-luminescent powder is a solvent-free form of $\mathbf{4 3}$. Along with complex $\mathbf{4 3}$ two closely related $\mathrm{Pt}(\mathrm{II})$ complexes with shorter alkanoylamide groups were investigated, but these substances did not show any mechano- or vapoluminescence properties, demonstrating once again how subtle the search for materials with such properties has to be. ${ }^{102}$

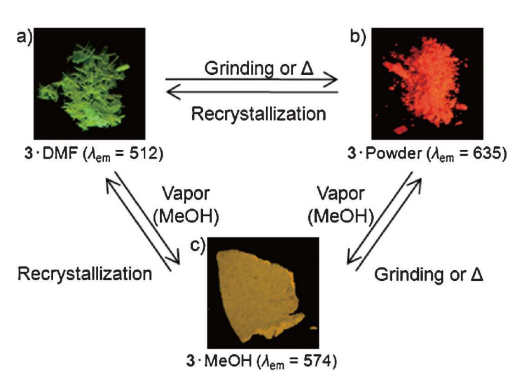

Figure 21. Mechano- and vapoluminescent properties of 43. Copyright 2012 The Chemical Society of Japan.

2.4.2 Complexes with 6-phenyl-2,2'-bipyridine $\left(\mathrm{C}^{\wedge} \mathrm{N}^{\wedge} \mathrm{N}\right)$ ligands

Scheme 19. Vapochromic Pt(II) complexes with $\mathrm{C}^{\wedge} \mathrm{N}^{\wedge} \mathrm{N}$ ligands. 

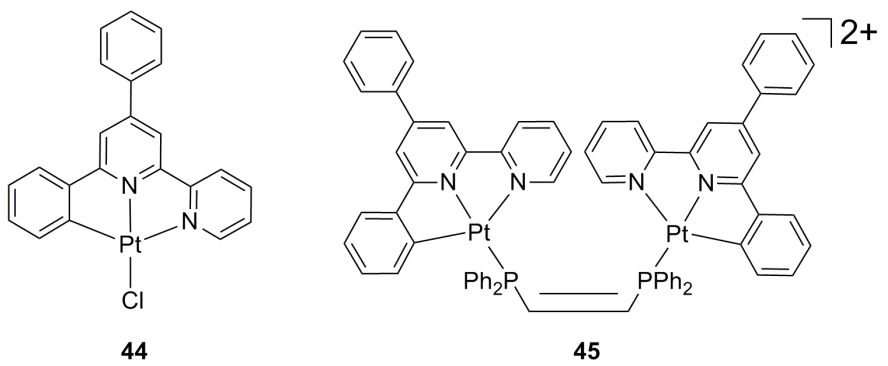

The luminescent complex 44 (Scheme 19) was reacted with amino-decorated silica gel in order to immobilize a luminescent probe on the surface of a supporting matrix. ${ }^{103}$ It was envisioned that host-guest interactions between the surface-bound complexes and VOC analytes would affect metal-metal and/or ligand-ligand interactions to the extent that a vapochromic or vapoluminescent response would result. Indeed this turned out to be possible when using MCM41 and MCM-48 silica gel supports which were first reacted with (3-aminopropyl)triethoxysilane and then loaded with $2.8 \mathrm{wt} \%$ of platinum in the form of complex 44 . The resulting material displays red emission at $662 \mathrm{~nm}\left(\lambda_{\max }\right)$ at room temperature. When placing the Pt-decorated silica gel samples into an air-tight tank containing a saturated atmosphere of pentane, benzene, chloroform, or dichloromethane for $\sim 10$ minutes, the emission shifted to substantially shorter wavelength $\left(\lambda_{\max }=548 \mathrm{~nm}\right)$. Drying in air for 3 days then restores the initial red luminescence. Presumably the red emission is due to ${ }^{3} \mathrm{MMLCT}$ states resulting from tightly interacting Pt(II) complexes whereas the yellow luminescence comes from ${ }^{3}$ MLCT excited states of isolated complexes. The disruption of metal-metal and/or $\pi-\pi$ interactions following the uptake of nonpolar solvents may potentially be explained by the high sorption capacity of silica for such substances.

Complex $\mathbf{4 5}^{2+}$ contains two $\operatorname{Pt}\left(\mathrm{C}^{\wedge} \mathrm{N}^{\wedge} \mathrm{N}\right)$ units which are linked by a rigid cis-1,2bis(diphenylphosphino)ethylene ligand. This dinuclear complex responds to vapors of 
heteroatom-containing VOCs such as acetonitrile, ethanol, diethyl ether, THF, ethyl acetate, $\mathrm{CH}_{2} \mathrm{Cl}_{2}, \mathrm{CHCl}_{3}$ by a change in color from yellow to deep red. ${ }^{104}$ Since no structural information is available for compound $\mathbf{4 5}\left(\mathrm{ClO}_{4}\right)_{2}$ an explanation for its vapochromism cannot be provided. It is clear, however, that intramolecular stacking leading to closer $\mathrm{Pt}(\mathrm{II})-\mathrm{Pt}(\mathrm{II})$ contacts after solvent exposure (as observed for the dppm-bridged dinuclear Pt(II) complex 42) is impossible for complex $\mathbf{4 5}^{2+}$ due to the rigidity of the cis-1,2-bis(diphenylphosphino)ethylene bridging ligand.

\subsubsection{Complexes with 2,6-di( $2^{\prime}$-naphthyl)pyridine $\left(\mathrm{C}^{\wedge} \mathrm{N}^{\wedge} \mathrm{C}\right)$ ligands}

Scheme 20. A vapochromic dinuclear complex with $\mathrm{C}^{\wedge} \mathrm{N}^{\wedge} \mathrm{C}$ ligands.

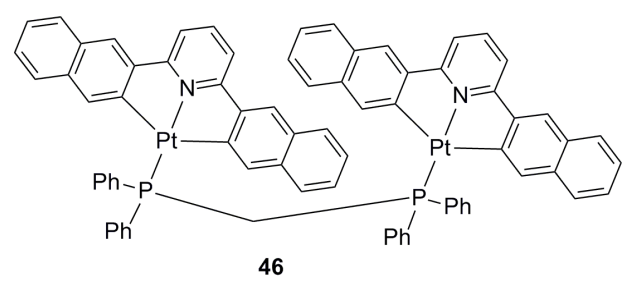

Building on the prior observation of weak vapochromism in the dinuclear dppm-bridged $\operatorname{Pt}\left(\mathrm{N}^{\wedge} \mathrm{C}^{\wedge} \mathrm{N}\right)$ complex 42 a series of dinuclear $\operatorname{Pt}^{(}\left(\mathrm{C}^{\wedge} \mathrm{N}^{\wedge} \mathrm{C}\right)$ complexes was investigated with a view to obtaining new vapochromic or vapoluminescent materials. ${ }^{105}$ It was anticipated that the large $\pi$-system of 2,6-di(2'-naphthyl)pyridine would be beneficial for $\pi-\pi$ and $\mathrm{C}-\mathrm{H}-\pi$ interactions between this ligand and VOCs, and that the disruption of such weak non-covalent interactions would potentially entail a significant vapochromic response. In one out of four investigated complexes of this type (46) (Scheme 20) this turned out to be the case. ${ }^{104}$ The solvent-free form 
of complex 46 is a weak emitter, but exposure to a variety of different VOCs produces an enhancement of its orange-yellow luminescence $\left(\lambda_{\max }=602 \mathrm{~nm}\right)$ (Figure 22).

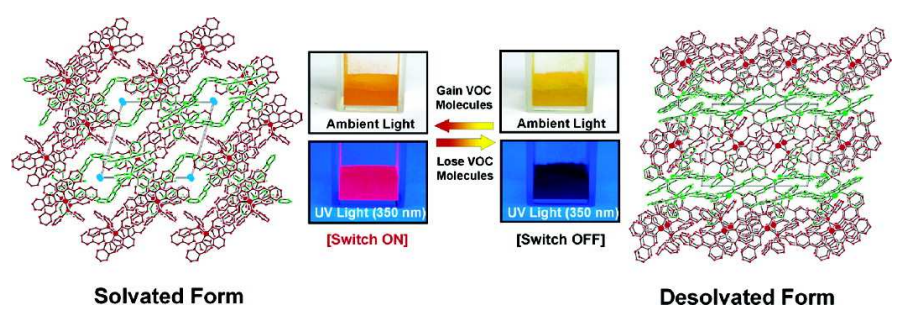

Figure 22. Changes in crystal structure, color, and photoluminescence upon vapor uptake / release by compound 46. Reprinted with permission from ref. ${ }^{105}$. Copyright 2006 American Chemical Society.

Halogenated vapors $\left(\mathrm{CH}_{2} \mathrm{Cl}_{2}, \mathrm{CH}_{2} \mathrm{Br}_{2}, \mathrm{CHCl}_{3}\right.$, 1,2-dichloroethane, 1,2-dibromoethane, $\mathrm{CH}_{3} \mathrm{I}$ but not $\mathrm{CCl}_{4}$ ) lead to particularly strong luminescence enhancements, but small polar VOCs such as acetone, diethyl ether, THF, ethyl acetate also produce a significant response. X-ray diffraction studies on $\mathbf{4 6} \cdot 6 \mathrm{CHCl}_{3} \cdot \mathrm{C}_{5} \mathrm{H}_{12}$ reveal that both the syn- and anti-conformations of 46 are present in the combined chloroform/pentane adduct. The most notable feature of this crystal structure is the presence of continuous solvent channels with an aperture size of ca. $6.5 \AA \times 4.3$ $\AA$ along the c-axis (Figure 22). Such large channels are absent in the crystal structures of three analogous dinuclear complexes bearing aromatic substituents at the 4-position of the central pyridine ring of the $\mathrm{C}^{\wedge} \mathrm{N}^{\wedge} \mathrm{C}$ ligand, and this may understand why vapoluminescence is observed exclusively for complex 46. ${ }^{104}$ X-ray diffraction of the desolvated form shows that the crystallographic a-axis decreases substantially upon solvent removal, resulting in a reduction of the unit cell volume from $7374 \AA^{3}$ to $6188 \AA^{3}$. The intramolecular Pt(II)-Pt(II) distance increases from $3.29(3) \AA$ to $3.40(3) \AA$ in the syn form, whereas in the anti-conformer there is an increase 


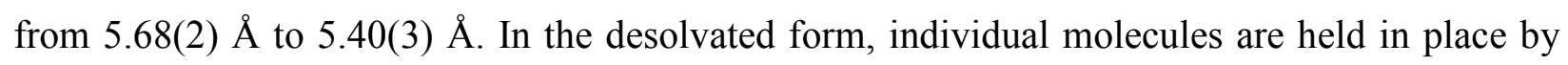
intermolecular $\pi-\pi$ interactions (the relevant interplanar separations range from $3.20 \AA$ to 3.47 $\AA$ ) and by C-H- $\pi$ interactions. Aggregation of the syn- and anti-forms in solvent-free $\mathbf{4 6}$ is tighter than in $46 \cdot 6 \mathrm{CHCl}_{3} \cdot \mathrm{C}_{5} \mathrm{H}_{12}$, and it has been proposed that this is the origin of the luminescence quenching in dry 46. In other words, the molecular conformations (syn or anti) do not appear to play a decisive role for the vapoluminescence. Temperature-dependent luminescence studies indicate that there can be emission from a ${ }^{3} \pi \pi^{*}$ state of isolated complexes and excimeric ${ }^{3} \pi \pi^{*}$ luminescence at longer wavelengths resulting from aggregated complexes; the formation of tight aggregates in the solvent-free form of $\mathbf{4 6}$ can red-shift the excimeric ${ }^{3} \pi \pi^{*}$ states to the extent that radiative relaxation is no longer competitive with multiphonon relaxation. Sorption of VOCs can then restore the luminescence by disruption of aggregation. The observation that acetonitrile, methanol, and ethanol produce no vapoluminescence response was explained by insufficient hydrophobicity of these solvents, whereas the insensitivity of $\mathbf{4 6}$ to benzene, toluene and $n$ hexane was explained by the size of these VOCs.

\subsubsection{Complexes with 7,8-benzoquinolinato and 2-phenylpyridine $\left(\mathrm{C}^{\wedge} \mathrm{N}\right)$ ligands}

Scheme 21. Two anionic vapochromic Pt(II) complexes.

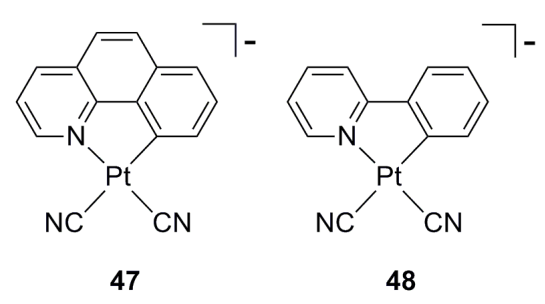


Complexes $47^{-}$and $4^{-}$(Scheme 21) are two rare examples of anionic $\mathrm{Pt}(\mathrm{II})$ complexes exhibiting vapochromism. Their optical spectroscopic properties are strongly dependent on the cation: The tetrabutylammonium salts are yellow, whereas the respective potassium salts are obtained as red and purple solids which are to be formulated as monohydrates $\left(\mathbf{K 4 7} \cdot \mathrm{H}_{2} \mathrm{O}\right.$ and $\left.\mathrm{K} 48 \cdot \mathrm{H}_{2} \mathrm{O}\right) .{ }^{106}$ When heating to $110{ }^{\circ} \mathrm{C}$ the crystal water can be removed, and this procedure induces a change in color from red or purple to yellow (Figure 23).

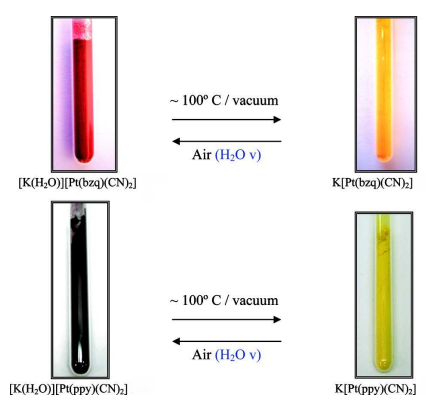

Figure 23. Color changes in $\mathrm{K} 47 \cdot \mathrm{H}_{2} \mathrm{O}$ and $\mathrm{K} 48 \cdot \mathrm{H}_{2} \mathrm{O}$ upon water release and uptake. Reprinted with permission from ref. ${ }^{106}$. Copyright 2008 American Chemical Society.

In air, the red and purple forms rapidly regenerate due to spontaneous water uptake. This behavior is opposite to that observed for red $\left[\mathrm{Pt}(\mathrm{bpy})(\mathrm{CN})_{2}\right]$ which sorbs water to form yellow $\left[\mathrm{Pt}(\mathrm{bpy})(\mathrm{CN})_{2}\right] \cdot \mathrm{H}_{2} \mathrm{O} .^{38}$ Apparently, in $\mathbf{K 4 7} \cdot \mathrm{H}_{2} \mathrm{O}$ and $\mathrm{K} 48 \cdot \mathrm{H}_{2} \mathrm{O}$ short $\mathrm{Pt}(\mathrm{II})-\mathrm{Pt}(\mathrm{II})$ contacts lead to MMLCT absorptions which are responsible for the red and purple colors of these forms while in the anhydrous yellow forms intermetallic contacts are largely disrupted. ${ }^{106}$ Thin films of $\mathbf{K 4 7} \cdot \mathrm{H}_{2} \mathrm{O}$ are responsive to a variety of anhydrous VOCs with response time increasing in the order of methanol $(\sim 5 \mathrm{~s})$, ethanol $(\sim 10 \mathrm{~s})$, acetonitrile $(\sim 30 \mathrm{~s})$, acetone ( $2 \mathrm{~min})$, and THF ( 45 $\min$ ). $\mathrm{K} 48 \cdot \mathrm{H}_{2} \mathrm{O}$ does not respond to any of these anhydrous solvent vapors, perhaps because the 
crystal water molecule is more strongly bound to the lattice than in the case of $\mathbf{K} \mathbf{4 7} \cdot \mathrm{H}_{2} \mathrm{O}$. This interpretation is in line with thermogravimetric analyses.

\subsubsection{Pincer complexes}

The complexes presented in this chapter are exceptional vapochromic $\mathrm{Pt}(\mathrm{II})$ compounds in that they exhibit vapochromism as a result of direct ligation of the analyte to the metal center. Thus, unlike the vast majority of the other compounds from section 2 , the pincer complexes in this chapter are type II vapochromic substances according to the definition used in section 1.3.

Scheme 22. Vapochromic pincer complexes, part I.

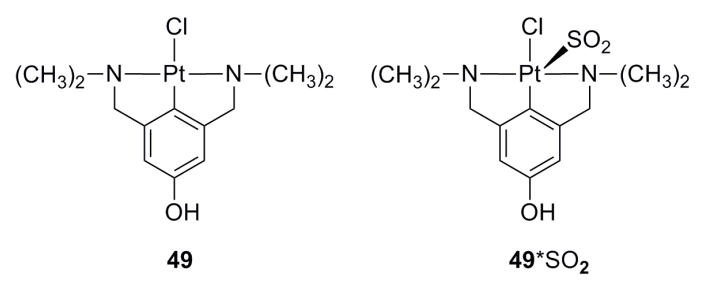

Several square-planar $\mathrm{Pt}(\mathrm{II})$ complexes with monoanionic $\mathrm{N}^{\wedge} \mathrm{C}^{\wedge} \mathrm{N}$ pincer ligands were found to be highly selective sensors for gaseous $\mathrm{SO}_{2}$. Complex 49 (Scheme 22) self-assembles in the solid state to form a network with intramolecular hydrogen-bonds between the chloro-ligand of one complex and the hydroxyl-group of its neighbor (Figure 24). ${ }^{107}$ Exposure of 49 to sulfur dioxide for $\sim 1$ minute affords the $\mathrm{SO}_{2}$ adduct $49 \cdot \mathrm{SO}_{2}$ in which a sulfur dioxide molecule is ligating to the $\mathrm{Pt}(\mathrm{II})$ center. Remarkably, the crystallinity of compound 49 is retained in the course of this process. Associated with the uptake of $\mathrm{SO}_{2}$ is a change in coordination geometry from squareplanar to pyramidal, and this affects the packing index and the density of the material. 

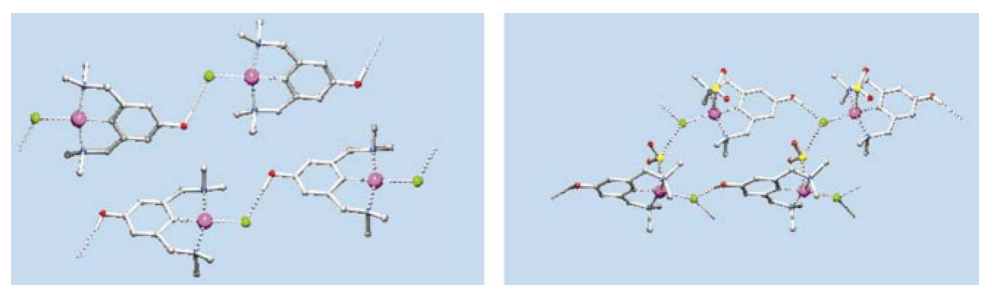

Figure 24. Extracts from the crystal structure of 49 before (left) and after $\mathrm{SO}_{2}$ uptake (right). Reprinted by permission from Macmillan Publishers Ltd: Nature 2000, 406, 970, copyright 2000 .

The unit cell volume increases by more than $15 \%$ upon $\mathrm{SO}_{2}$ sorption, whereas the density decreases from $2.1606(6) \mathrm{g} / \mathrm{cm}^{3}$ to $2.1473(6) \mathrm{g} / \mathrm{cm}^{3}$. The pyramidal complex retains the hydrogen bonds between chloro-ligands and hydroxyl-groups of adjacent ligands (the O-Cl distance remains virtually unchanged: $3.126(8) \AA$ before and 3.127(8) $\AA$ after $\mathrm{SO}_{2}$ uptake). In addition there are non-covalent interactions between $\mathrm{SO}_{2}$ and chloro-ligands of adjacent complexes perpendicularly to the hydrogen-bonding network. 49 is colorless while $49 \cdot \mathrm{SO}_{2}$ is deep orange hence the transformation can easily be detected by naked eye. The recovery of 49 from $49 \cdot \mathrm{SO}_{2}$ in an atmosphere of air was studied by time-dependent powder X-ray diffraction and infrared spectroscopy (monitoring the $\mathrm{SO}_{2}$ stretching vibrations at $1072 \mathrm{~cm}^{-1}$ and $1236 \mathrm{~cm}^{-1}$ ), and it was concluded that $\mathrm{SO}_{2}$ release follows a zero-order rate law with the absolute rate being strongly dependent on the surface area of the sample. It was assumed that the rate-determining step in $\mathrm{SO}_{2}$ release is the diffusion-controlled transfer of $\mathrm{SO}_{2}$ molecules from one complex to the other from the inner part of the crystalline material to its surface.

Scheme 23. Vapochromic pincer complexes, part II. 

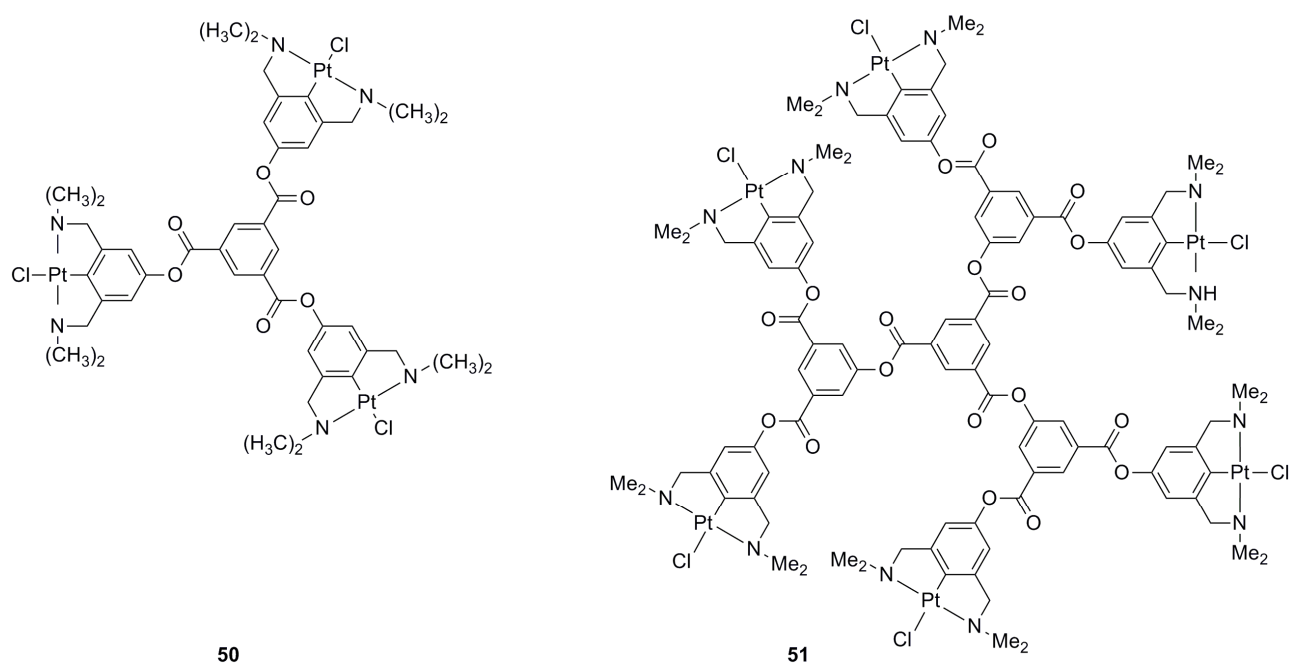

Immobilization of the pincer complex 49 on a surface is of interest for obtaining a functional $\mathrm{SO}_{2}$ sensor device. Instead of layering these complexes into a polymer in which they may be less accessible to $\mathrm{SO}_{2}$ from the atmosphere, functional dendrimers $(\mathbf{5 0}, \mathbf{5 1})$ (Scheme 23) with welldefined connectivities were synthesized and explored. ${ }^{108}$ According to molecular models, the macromolecular constructs have disk-like structures with diameters of $2.4 \mathrm{~nm}$ and $3.4 \mathrm{~nm}$, respectively, and they are found to maintain the high sensitivity for $\mathrm{SO}_{2}$ observed for the monometallic complex 49. When coating a cellulose surface with dendritic $\mathbf{5 0}$ at a density of 20 $\mathrm{nm} / \mathrm{mm}^{2}$ the detection of $\mathrm{SO}_{2}$ at a concentration of $8.5 \pm 0.5 \mu \mathrm{g} / \mathrm{cm}^{3}$ is possible. Even at $190 \mathrm{~K}$, the response (a change from colorless to orange) occurs within $2 \mathrm{~ms}$. Exposure to $\mathrm{SO}_{2}$-free air regenerates the initial colorless state within a few minutes. A promising resistance against atmospheric impurities such as water and acids has also been noted.

Scheme 24. Vapochromic pincer complexes, part III. 


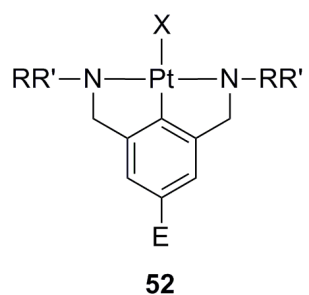

Fundamental studies in which the electronic structure and the steric bulk of mononuclear pincer complexes are varied systematically have been conducted. ${ }^{109}$ On the generic structure 52 (Scheme 24) the monodentate ligand $\mathrm{X}$ was varied from $\mathrm{Cl}$ to $\mathrm{Br}$, I, and $p$-tolyl in order to modulate the electron density at the metal center. The substituents $\mathrm{R}$ and $\mathrm{R}$ ' at the nitrogen donor atoms were varied between methyl and ethyl in order to explore the influence of steric constraints on $\mathrm{SO}_{2}$ binding. Finally, the para-substituent $\mathrm{E}$ was varied between $\mathrm{H}, \mathrm{OH}, \mathrm{OSiMe}_{2}$ and ${ }^{t} \mathrm{Bu}$ in order to tune the electron density in the aromatic system. $\mathrm{SO}_{2}$ binding is possible irrespective of which of the four monodentate ligands $(\mathrm{X})$ is chosen. However, $\mathrm{SO}_{2}$ binding is suppressed when all four substituents at the $\mathrm{N}$ atoms are ethyl groups. At least one of them has to be a methyl-substituent otherwise there is apparently too much steric bulk. Solution titrations show that the nature of the para-substituent $\mathrm{E}$ has relatively little influence because the equilibrium constants for $\mathrm{SO}_{2}$-binding of 7 complexes with variable $\mathrm{E}$ are all in the range between $8.48 \pm 0.34 \mathrm{M}^{-1}$ and $14.81 \pm 0.35 \mathrm{M}^{-1}$ in benzene. Stopped-flow experiments in benzene solution showed that the reaction of pincer complexes with different $\mathrm{X}, \mathrm{E}$, and $\mathrm{R}$ is complete within $50 \mu \mathrm{s}$. In air at room temperature, the complexes lose $\mathrm{SO}_{2}$ over several weeks, but when heated to $40^{\circ} \mathrm{C}$ the initial state can be recovered within minutes.

$\operatorname{Pt}(\mathrm{II})$ complexes with the anionic $\mathrm{N}^{\wedge} \mathrm{C}^{\wedge} \mathrm{N}$ pincer ligand in the generic complex $\mathbf{5 2}$ have an enhanced nucleophilicity when compared to other $\mathrm{d}^{8}$ metal complexes. ${ }^{110}$ This explains why they react with the Lewis acid $\mathrm{SO}_{2}$, yet the selective recognition of sulfur dioxide even in presence of 
other acids such as $\mathrm{HCl}, \mathrm{CO}_{2}$ or $\mathrm{H}_{2} \mathrm{O}$ is spectacular. Two additional fundamental observations are noteworthy: (i) platinum-bound $\mathrm{SO}_{2}$ does not undergo subsequent reactions such as insertion into a metal-carbon bond or oxidation to sulfate in air; (ii) in the complexes with $\mathrm{X}=\mathrm{I}$ there is no $\mathrm{SO}_{2}$-binding to the iodide, despite the expected competitive behavior of iodide in terms of nucleophilicity. ${ }^{111}$ In-depth mechanistic studies (theoretical and experimental) lead to the conclusion that iodide-bound $\mathrm{SO}_{2}$ does not even play a role as a reaction intermediate during $\mathrm{SO}_{2}$ uptake or release. ${ }^{112}$ Using ${ }^{1} \mathrm{H}$ NMR spectroscopy the exchange rate of the $\mathrm{SO}_{2}$ ligand on the complex with $\mathrm{X}=\mathrm{I}, \mathrm{R}=\mathrm{CH}_{3}$, and $\mathrm{E}=\mathrm{H}$ was investigated at cryogenic temperatures. When extrapolating to room temperature, one obtains an exchange rate of $1.5 \cdot 10^{8} \mathrm{~s}^{-1}$, which is close to the rate constants for some of the fastest enzymatic reactions. This underscores the point that these $\mathrm{Pt}(\mathrm{II})$ pincer complexes are suitable for on-line monitoring of the $\mathrm{SO}_{2}$ concentration in air.

\subsubsection{NHC complexes}

Scheme 25. Vapochromic Pt(II) complexes with NHC ligands.

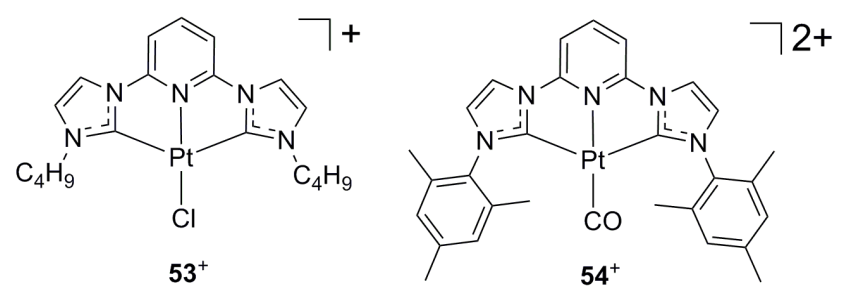

Transition-metal complexes with N-heterocyclic carbenes (NHCs) are playing an increasingly important role in organometallic chemistry, ${ }^{113-115}$ and until now two vapochromic Pt(II) complexes with such ligands have been reported (Scheme 25). ${ }^{116,117}$ Complex $\mathbf{5 3}^{+}$is synthesized via transmetallation from an $\mathrm{Ag}(\mathrm{I})$ precursor complex and crystallizes in two different structures 
depending on what solvent is used. ${ }^{116}$ Recrystallization from methanol/diethyl ether yields a hydrated form with the sum formula $53 \mathrm{Cl} \cdot 2.5 \mathrm{H}_{2} \mathrm{O}$, whereas crystallization from $\mathrm{CH}_{2} \mathrm{Cl}_{2} /$ hexane affords the anhydrate form $\mathbf{5 3 C l}$. Both crystal structures contain dimers of head-to-tail oriented complexes with short $\mathrm{Pt}(\mathrm{II})-\mathrm{Pt}(\mathrm{II})$ contacts (Figure 25). In $\mathbf{5 3} \mathrm{Cl} \cdot 2.5 \mathrm{H}_{2} \mathrm{O}$ the shortest intermetallic distance is $3.5096(7) \AA$, in $\mathbf{5 3 C l}$ it is $3.5185(19) \AA$. The interplanar $(\pi-\pi)$ stacking distances are not much different either and vary between $3.342 \AA\left(\mathbf{5 3 C l} \cdot 2.5 \mathrm{H}_{2} \mathrm{O}\right)$ and $3.472 \AA(\mathbf{5 3 C l})$. However, the hydrate exhibits orange luminescence $\left(\lambda_{\max }=614 \mathrm{~nm}\right)$ whereas the anhydrate form emits green $\left(\lambda_{\max }=555 \mathrm{~nm}\right)$ which is difficult to explain by the observed structural changes. At any rate, when the green-emitting dehydrated form $(\mathbf{5 3 C l})$ is exposed to moisture, the emission changes to orange and powder X-ray analysis is in line with the formation of $53 \mathrm{Cl} \cdot 2.5 \mathrm{H}_{2} \mathrm{O}$.

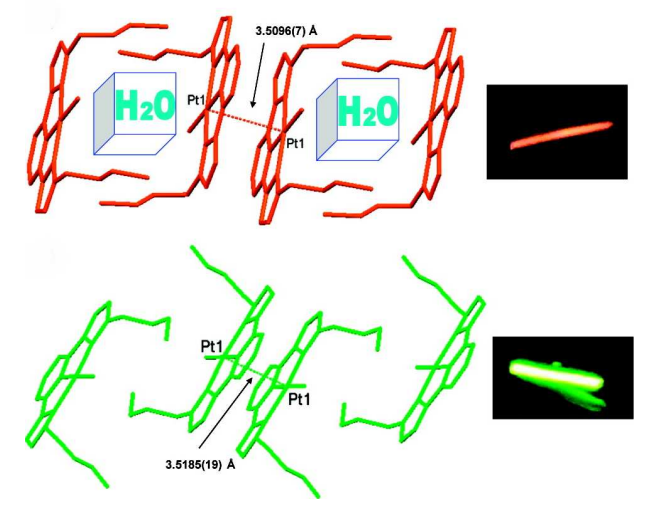

Figure 25. Crystal packing and emission colors of $\mathbf{5 3} \mathrm{Cl} \cdot 2.5 \mathrm{H}_{2} \mathrm{O}$ (top) and $\mathbf{5 3 C l}$ (bottom). Reprinted with permission from ref. ${ }^{116}$. Copyright 2010 American Chemical Society.

Complex $54^{2+}$ contains mesityl-substituents instead of $n$-butyl groups and the fourth coordination site is occupied by a carbonyl instead of a chloro-ligand. The bulky mesityls form a small pocket which allows VOCs to enter the crystal structure of $\mathbf{5 4}\left(\mathrm{PF}_{6}\right)_{2}$ in order to form 
solvent adducts with different luminescence properties than the desolvated form. ${ }^{117}$ The solventfree form of $54\left(\mathrm{PF}_{6}\right)_{2}$ exhibits structured emission with a band maximum at $462 \mathrm{~nm}$ but exposure to vapors of small molecules containing nitrogen or oxygen donor atoms such as methanol, water, THF, diethyl ether, DMF, or pyridine leads to a yellow featureless emission with $\lambda_{\max }=$ $529 \mathrm{~nm}$. Small VOCs without donor atoms such as $\mathrm{CH}_{2} \mathrm{Cl}_{2}, \mathrm{CHCl}_{3}$, or benzene do not trigger any response. The exact mechanism for the luminescence vapochromism is not clear, but the crystal structure of $54\left(\mathrm{PF}_{6}\right)_{2} \cdot 2\left(\mathrm{CH}_{3}\right)_{2} \mathrm{CO}$ shows signs of solvate/Pt-CO interactions. Specifically, the distance of $2.82 \AA$ between the O-atom of acetone and the $\mathrm{C}$-atom of the carbon monoxide ligand is significantly shorter than what is expected based on the van-der-Waals radii of oxygen and carbon $(3.22 \AA)$. Moreover, the CO stretching frequency of the solvated acetone is $10 \mathrm{~cm}^{-1}$ lower than that of free acetone, and the $\mathrm{CO}$ stretching frequency for the carbon monoxide ligand is $15 \mathrm{~cm}^{-1}$ lower in $\mathbf{5 4}\left(\mathrm{PF}_{6}\right)_{2} \cdot 2\left(\mathrm{CH}_{3}\right)_{2} \mathrm{CO}$ than in desolvated $\mathbf{5 4}\left(\mathrm{PF}_{6}\right)_{2}$.

\subsection{Pt(II) complexes with S-, P-, and As-ligand atoms}

Scheme 26. Syn- and anti-isomers of a vapochromic Pt(II) complex with thiolate ligands.
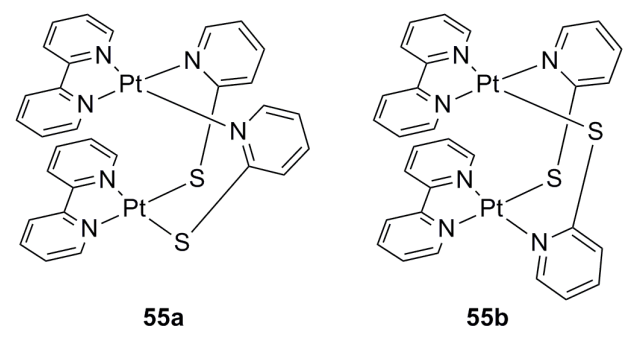

A dinuclear pyridine-2-thiolate bridged Pt(II) bpy complex was obtained both as a syn- (55a) and an anti-isomer (55b) (Scheme 26). ${ }^{118}$ The syn-isomer (55a) has one Pt(II) ion in a 
coordination sphere of four N-atoms (2 from bpy, 2 from pyridine-2-thiolate), and the second metal center is coordinated to the two thiolate functions in addition to bpy. In the anti-isomer (55b) both $\mathrm{Pt}(\mathrm{II})$ centers are coordinated to $3 \mathrm{~N}$-atoms and $1 \mathrm{~S}$-atom. Both isomers exhibit unusually short (intramolecular) Pt(II)-Pt(II) distances of 2.923(1) $\AA$ (syn) and 2.997(1) A (anti). The syn isomer changes color from dark red to lighter red upon standing in air, and this is accompanied by changes in the luminescence properties as illustrated in Figure 26. Exposure to methanol or acetonitrile reverses the color and luminescence changes.

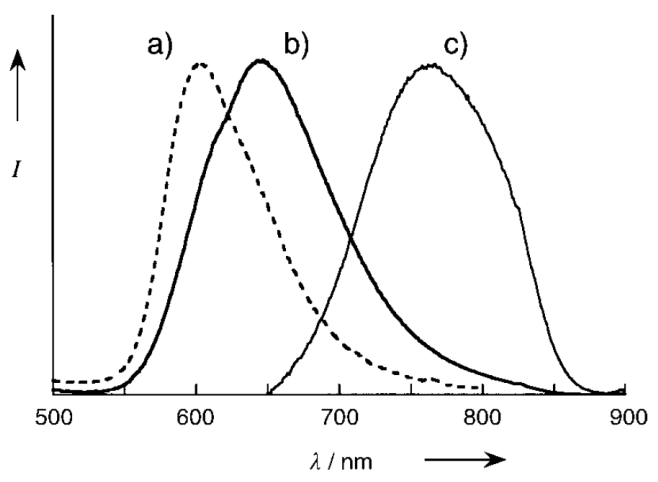

Figure 26. Room-temperature photoluminescence spectra of (a) the anti-isomer 55b, (b) the desolvated form of the $s y n$-isomer 55a, (c) the solvated form of $s y n$-isomer 55a. (M. Kato, A. Omura, A. Toshikawa, S. Kishi, Y. Sugimoto: Vapor-Induced Luminescence Switching in Crystals of the Syn Isomer of a Dinuclear (Bipyridine)platinum(II) Complex Bridged with Pyridine-2-Thiolate Ions. Angew. Chem. Int. Ed., 2000, 41, 3183-3185. Copyright Wiley-VCH Verlag GmbH \& Co. KGaA. Reproduced with permission.)

The crystal structure of the dark red acetonitrile adduct $\left(\mathbf{5 5 a} \cdot \mathrm{CH}_{3} \mathrm{CN}\right)$ exhibits short intermolecular Pt(II)-Pt(II) distances of 3.384(1) $\AA$ in addition to the short intramolecular Pt(II)$\mathrm{Pt}(\mathrm{II})$ contacts mentioned above. Thus, there is extensive interaction between metal centers along 
one dimension, and therefore the strongly red-shifted emission at $\lambda_{\max }=766 \mathrm{~nm}$ is most likely due to a low-energy ${ }^{3} \mathrm{MMLCT}$ state. The structure of $\mathbf{5 5 a} \cdot \mathrm{CH}_{3} \mathrm{CN}$ contains channels in which the solvate molecules are located, providing a pathway for them to diffuse in and out of the lattice. The sensitivity of 55a for VOCs decreases with increasing steric bulk of the solvent vapors, in line with the hypothesis that the adsorbates must be small enough to penetrate these channels. Methanol and acetonitrile produce a rapid response, ethanol and isopropanol lead to slower color and luminescence changes, whereas $t$-butanol triggers no response at all, despite the fact that these five VOCs have similar vapor pressures. The anti-isomer $\mathbf{( 5 5 b )}$ is neither vapochromic nor vapoluminescent but emits orange emission $\left(\lambda_{\max }=603 \mathrm{~nm}, \tau=240 \mathrm{~ns}\right)$, presumably from a ${ }^{3}$ MMLCT state resulting from intramolecular $\mathrm{Pt}(\mathrm{II})-\mathrm{Pt}(\mathrm{II})$ interactions.

Scheme 27. A vapochromic Pt(II) dithiooxamide complex.

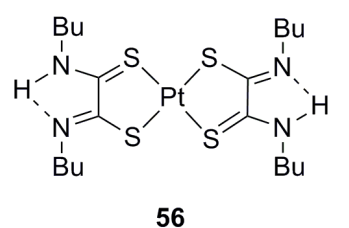

56

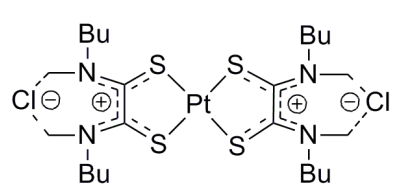

$56^{*} 2 \mathrm{HCl}$

The Pt(II) dithiooxamide complex 56 is sensitive to gaseous $\mathrm{HCl}$ (Scheme 27). ${ }^{119}$ The initial form of this material is orange-red and non-luminescent, but when exposed to $\mathrm{HCl}$ it forms an adduct $(\mathbf{5 6} \cdot 2 \mathrm{HCl})$ which is purple-brown and emits in the red spectral range $\left(\lambda_{\max } \approx 740 \mathrm{~nm}, \tau=\right.$ $28 \mathrm{~ns}$ ). According to prior studies of the same process in solution the red emission is due to a charge transfer state in which electron density has been transferred from the $\mathrm{Pt} / \mathrm{S}$ moiety to the dithiooxamide backbone. ${ }^{120}$ In the course of $\mathrm{HCl}$ uptake this state shifts to lower energy and begins to emit, whereas in the initial form the CT state is energetically close to other non- 
emissive excited states leading to nonradiative energy dissipation. Conversion back from $\mathbf{5 6} \cdot 2 \mathrm{HCl}$ to $\mathbf{5 6}$ is possible either by heating to $80{ }^{\circ} \mathrm{C}$ or by exposure to $\mathrm{NH}_{3}$ vapor. ${ }^{119}$

Scheme 28. Vapochromic Pt(II) complexes with S, P, or As-ligands.
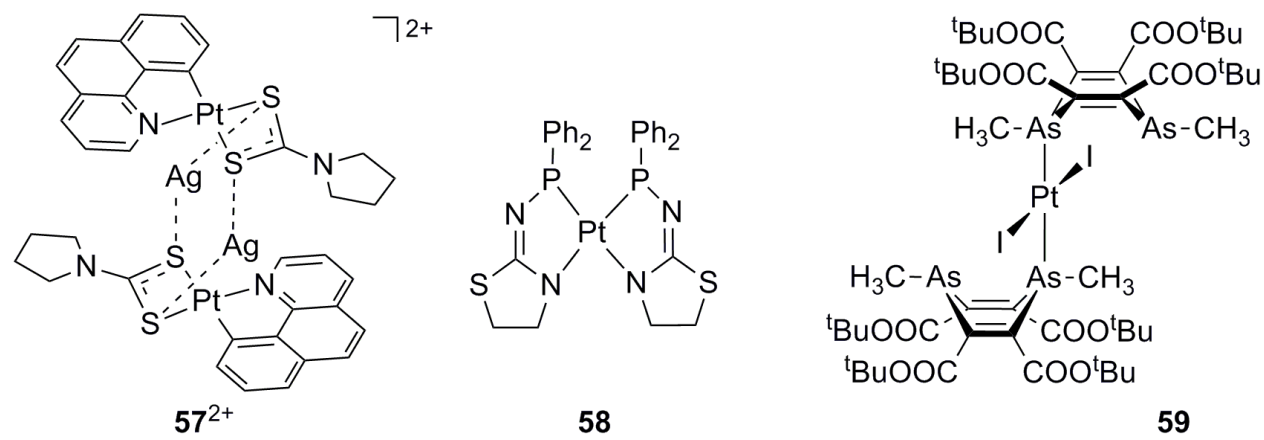

Complex $\mathbf{5 7}^{2+}$ is a tetranuclear $\left[\mathrm{Pt}_{2} \mathrm{Ag}_{2}\right]$ cluster made from two $\mathrm{Pt}(\mathrm{II})$ benzoquinoline pyrrolidinedithiocarbamate units bridged via the sulfur atoms through two $\mathrm{Ag}(\mathrm{I})$ cations (Scheme 28). ${ }^{121}$ The separation distance between the two silver ions (3.0394(18) $\AA$ ) is significantly shorter than the sum of their van der Waals radii $(3.44 \AA)$, i. e., they show argentophilic interactions. In the perchlorate salt of complex $\mathbf{5 7}^{2+}$ the $\left[\mathrm{Pt}_{2} \mathrm{Ag}_{2}\right]$ clusters form a polymer along the crystallographic c-axis with short $(3.1390(7) \AA) \operatorname{Pt}(\mathrm{II})-\mathrm{Pt}(\mathrm{II})$ contacts. Consequently, the red emission of solid $\mathbf{5 7}\left(\mathrm{ClO}_{4}\right)_{2}\left(\lambda_{\max }=610 \mathrm{~nm}\right)$ is most likely due to ${ }^{3} \mathrm{MMLCT}$ or excimeric ${ }^{3} \pi \pi^{*}$ states. Exposure of solid $\mathbf{5 7}\left(\mathrm{ClO}_{4}\right)_{2}$ to acetonitrile induces a rapid change in color from orange to garnet red (Figure 27), but several other vapors (including $\mathrm{CH}_{2} \mathrm{Cl}_{2}$, methanol, $\mathrm{H}_{2} \mathrm{O}$, acetone, diethyl ether, DMF, DMSO, toluene, $n$-hexane) produce no response. The origin of the selective vapochromism with $\mathrm{CH}_{3} \mathrm{CN}$ is not known but it has been noted that acetonitrile may replace the perchlorate anions which are weakly coordinated to the $\mathrm{Ag}(\mathrm{I})$ ions. The smaller size of $\mathrm{CH}_{3} \mathrm{CN}$ relative to $\mathrm{ClO}_{4}$ would then allow the individual $\left[\mathrm{Pt}_{2} \mathrm{Ag}_{2}\right]$ clusters to get closer to each other, and 
this may well lead to the observed vapochromism. The selectivity of $\mathbf{5 7}\left(\mathrm{ClO}_{4}\right)_{2}$ to acetonitrile is quite unusual, but unfortunately the vapochromic response does not appear to be easily reversible.

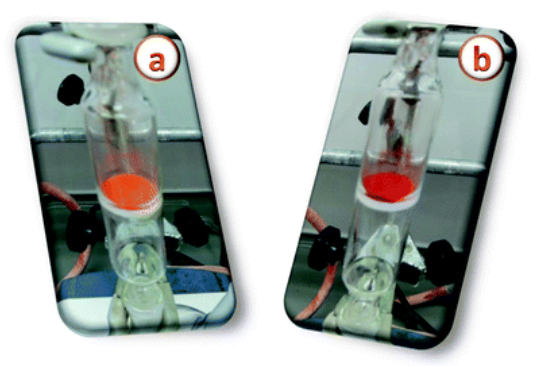

Figure 27. Sample of $\mathbf{5 7}\left(\mathrm{ClO}_{4}\right)_{2}$ before (a) and after (b) exposure to $\mathrm{CH}_{3} \mathrm{CN}$ vapor. Reprinted with permission from ref. ${ }^{121}$. Copyright 2008 The Royal Society of Chemistry.

The bischelated $\mathrm{Pt}(\mathrm{II})$ complex 58 with two identical aminophosphine ligands was obtained in its cis-form and exhibits a vapoluminescence response to small alcohols. ${ }^{122}$ Two crystal structures of this complex were studied by X-ray diffraction but none of them contains short $\mathrm{Pt}(\mathrm{II})-\mathrm{Pt}(\mathrm{II})$ contacts. The shortest intermetallic distances found are 5.9267(2) $\AA$ in $\mathbf{5 8} \cdot \mathrm{C}_{6} \mathrm{H}_{5} \mathrm{CH}_{3}$ and $8.9268(2) \AA$ in $\mathbf{5 8} \cdot 2 \mathrm{CH}_{3} \mathrm{OH} \cdot \mathrm{CH}_{3} \mathrm{CN}$. The origin of the emission which turns on after methanol exposure is unclear, but given the large intermetallic distances participation of ${ }^{3}$ MMLCT states appears highly unlikely. It has been speculated that a rigidochromic effect induced by hydrogen-bonding could be the reason why methanol-exposed $\mathbf{5 8}$ is emissive. (Rigidochromism is a change of color occurring as a consequence of changes in the rigidity of the surrounding medium). Hydrogen-bond donation from methanol to the aminophosphine ligands may render the overall complex less flexible, making multiphonon relaxation less 
efficient. Aside from methanol, ethanol, and (to a lesser extent) isopropanol cause a luminescence turn-on, but $t$-butanol produces no significant response.

The organoarsenic complex 59 can be crystallized either in neat form or as adducts of dichloromethane $\left(\mathbf{5 9} \cdot 2 \mathrm{CH}_{2} \mathrm{Cl}_{2}\right)$, acetone $\left(\mathbf{5 9} \cdot 2\right.$ acetone) or toluene $\left(\mathbf{5 9} \cdot \mathrm{C}_{6} \mathrm{H}_{5} \mathrm{CH}_{3}\right) .{ }^{123}$ In the crystal structure of $\mathbf{5 9} \cdot 2 \mathrm{CH}_{2} \mathrm{Cl}_{2}$ there are no large cavities and the void volume is only $1.1 \%$ of the total crystal volume, but in the structure of neat $\mathbf{5 9}$ the void volume amounts to $6.0 \%$. Consequently, when exposing neat 59 to vapors of $\mathrm{CH}_{2} \mathrm{Cl}_{2}$, acetone, or toluene, these solvent vapors are taken up and the abovementioned adducts are formed rapidly. Vapor sorption is accompanied by the appearance of very intense red luminescene $\left(\lambda_{\max }=658 \mathrm{~nm}\right)$ within seconds. This emission turnon has been tentatively explained by a conformational fixation of the emissive species due to tighter crystal packing in the solvent adducts compared to neat $\mathbf{5 9 .}$

\subsection{MMX chains made from $\left[\mathrm{Pt}_{2}(\text { pop })_{4} \mathrm{I}\right]^{4-}$ units}

The photochemistry of the $\left[\mathrm{Pt}_{2}(\mathrm{pop})_{4}\right]^{4-}$ complex (pop $=\mu$-pyrophoshito) in solution has been explored extensively. ${ }^{124,} 125$ This diphosphito-bridged $d^{8}-d^{8}$ dimer exhibits favorable photophysical and photochemical properties due its short $(2.925(1) \AA)$ intramolecular Pt(II)$\mathrm{Pt}(\mathrm{II})$ distance. ${ }^{31}$ Halogenides can bind to the $\left[\mathrm{Pt}_{2}(\mathrm{pop})_{4}\right]^{4-}$ core, resulting in so-called MMX compounds in which $\mathrm{M}=\mathrm{Pt}$ and $\mathrm{X}=$ halogenide. A few of these MMX materials were found to exhibit vapochromism. ${ }^{126-128}$ The compound $\left[\mathrm{NH}_{3}\left(\mathrm{CH}_{2}\right)_{4} \mathrm{NH}_{3}\right]_{2}\left[\mathrm{Pt}_{2}(\text { pop })_{4} \mathrm{I}\right] \cdot 4 \mathrm{H}_{2} \mathrm{O}$ (60) forms linear PtPtI chains along the crystallographic c-axis with $\mathrm{Pt}(\mathrm{II})-\mathrm{Pt}(\mathrm{II})$ distances of $2.837 \AA$ and Pt(II)-I distances of $2.722 \AA$, the counter-cations are in the spaces between individual chains. ${ }^{126}$ At $296 \mathrm{~K}$ there is a single Pt-Pt vibration band at $98 \mathrm{~cm}^{-1}$ but upon heating to $340 \mathrm{~K}$ the 
respective IR signal splits into two separate bands, indicating that there are two kinds of Pt-Pt units at elevated temperatures. Simultaneously, the color of the compound changes from green to red (Figure 28). These observations were explained in terms of a structural transition from a paramagnetic charge-polarization (CP) state to a diamagnetic charge-density-wave (CDW) state. In the initial CP state the individual molecular components are formally best regarded as $\mathrm{Pt}^{2+}-$ $\mathrm{Pt}^{3+}-\mathrm{I}$ units which are linearly linked through weak interactions from the terminal iodo-ligand of one unit to the $\mathrm{Pt}^{2+}$ center of the nearest neighbor $\left(\mathrm{Pt}^{2+}-\mathrm{Pt}^{3+}-\mathrm{I} \ldots \mathrm{Pt}^{2+}-\mathrm{Pt}^{3+}-\mathrm{I}\right)$. In the CDW state, there are two different kinds of $\mathrm{Pt}_{2}$ units because this structure is formally best described by alternating $\mathrm{Pt}^{2+}-\mathrm{Pt}^{2+}$ and $\mathrm{I}-\mathrm{Pt}^{2+}-\mathrm{Pt}^{3+}-\mathrm{I}$ units $\left(\mathrm{Pt}^{2+}-\mathrm{Pt}^{2+} \ldots \mathrm{I}-\mathrm{Pt}^{2+}-\mathrm{Pt}^{3+}-\mathrm{I}\right)$, resulting in a lower band gap of only $1.12 \mathrm{eV}(1110 \mathrm{~nm})$ compared to $2.52 \mathrm{eV}(520 \mathrm{~nm})$ in the $\mathrm{CP}$ state. In dry atmosphere, the red CDW state remains stable upon cooling from $340 \mathrm{~K}$ to room temperature. However, upon exposure of the metastable CDW form to saturated water vapor the CP state is recovered, manifesting itself in a color change from red to green. ${ }^{126}$ The anhydrous red form of 60 can be crystallized directly from methanol solution and X-ray diffraction on single crystals confirms the CDW structure of this modification. ${ }^{128}$ The difference in lattice volume between anhydrous 60 and $\mathbf{6 0} \cdot 4 \mathrm{H}_{2} \mathrm{O}$ amounts to $150 \AA^{3}$ whereas the volume of a water molecule is generally approximated to $30 \AA^{3}$, suggesting that the total volume of eight $\mathrm{H}_{2} \mathrm{O}$ molecules in the unit cell of $\mathbf{6 0} \cdot 4 \mathrm{H}_{2} \mathrm{O}$ should be around $240 \AA^{3}$. This analysis suggests that crystal packing in anhydrous 60 is not as tight as it could be, and this might account for the facile water uptake in humid atmosphere. The X-ray crystal structure of a methanol adduct $\left(\mathbf{6 0} \cdot 2 \mathrm{CH}_{3} \mathrm{OH}\right)$ has also been reported, ${ }^{128}$ but it is not yet clear whether this material exhibits vapochromism. 


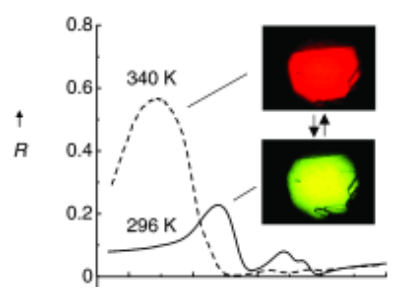

Figure 28. Reflectivity spectra and microscope images of compound $\mathbf{6 0}$ at two different temperatures. (Vapochromic Behavior Accompanied by Phase Transition between ChargePolarization and Charge-Density-Wave States in a Quasi-One-Dimensional Iodine-Bridged Dinuclear Platinum Compound. Angew. Chem. Int. Ed., 2005, 44, 3240-3243. Copyright WileyVCH Verlag GmbH \& Co. KGaA. Reproduced with permission.)

When replacing the $\left[\mathrm{NH}_{3}\left(\mathrm{CH}_{2}\right)_{4} \mathrm{NH}_{3}\right]^{2+}$ cation of compound $\mathbf{6 0}$ by the larger $\left[\mathrm{NH}_{3}\left(\mathrm{CH}_{2}\right)_{5} \mathrm{NH}_{3}\right]^{2+}$ cation one obtains another MMX material (61) which exhibits an analogous transition from a green CP state to a red CDW state upon heating. ${ }^{127}$ However, in this case the transition occurs between $297 \mathrm{~K}$ and $308 \mathrm{~K}$, i. e., at significantly lower temperature than in compound $60(340 \mathrm{~K})$. Thermogravimetric studies show that up to $350 \mathrm{~K}$ compound $\mathbf{6 1}$ releases four water molecules per formula unit hence the initial CP compound is to be formulated as $\left[\mathrm{NH}_{3}\left(\mathrm{CH}_{2}\right)_{5} \mathrm{NH}_{3}\right]_{2}\left[\mathrm{Pt}_{2}(\text { pop })_{4} \mathrm{I}\right] \cdot 4 \mathrm{H}_{2} \mathrm{O}\left(\mathbf{6 1} \cdot 4 \mathrm{H}_{2} \mathrm{O}\right)$. Anhydrous 61 sorbs water readily from air at room temperature whereas anhydrous $\mathbf{6 0}$ requires water-saturated atmosphere. The higher sensitivity of $\mathbf{6 1}$ compared to $\mathbf{6 0}$ has been explained by the larger distances between individual MMX chains (caused by the larger cation), facilitating water diffusion into the crystal structure.

\section{Gold(I) compounds}

3.1 Dicyanoaurates 
When reacting $\mathrm{Cu}\left(\mathrm{ClO}_{4}\right)_{2}$ with $\mathrm{KAu}(\mathrm{CN})_{2}$ in DMSO, two different polymorphs of $\mathrm{Cu}\left[\mathrm{Au}(\mathrm{CN})_{2}\right]_{2}(\mathrm{DMSO})_{2}\left(\mathbf{6 2} \cdot(\mathrm{DMSO})_{2}\right)$ can be obtained. ${ }^{129}$ Reactant concentrations below $0.2 \mathrm{M}$ lead to a green polymorph, whereas blue crystals of a second polymorph are obtained at concentrations above $0.5 \mathrm{M}$. This concentration dependence suggests that the blue material is a kinetic reaction product while the green polymorph is presumably the thermodynamically more stable form. The X-ray crystal structures of the two forms are significantly different, one of the most evident differences is the five-fold (square-pyramidal) coordination of $\mathrm{Cu}$ (II) in the green polymorph compared to the six-coordinate $\mathrm{Cu}(\mathrm{II})$ center in the blue form (Figure 29).
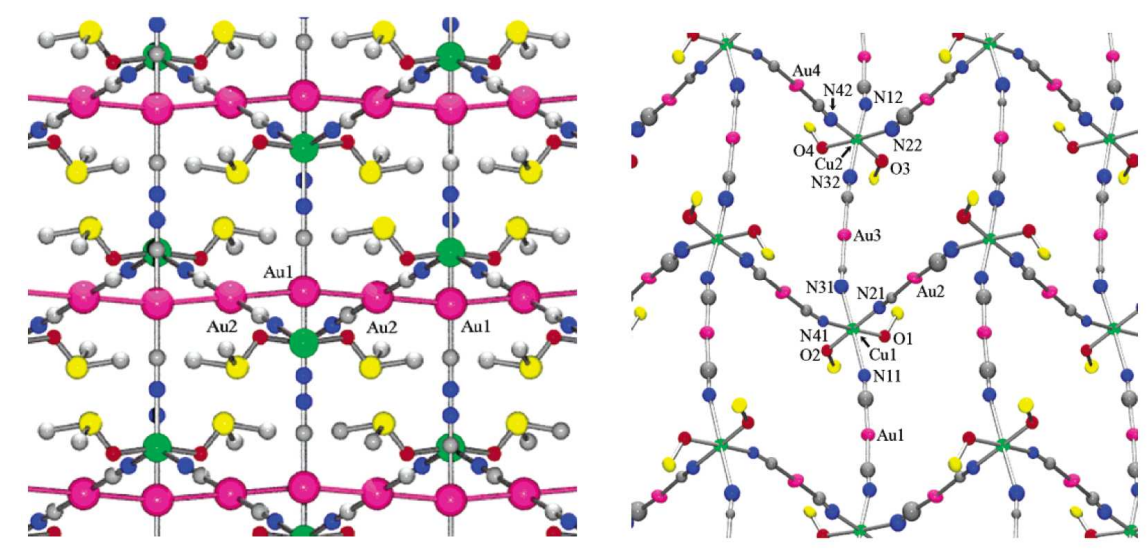

Figure 29. Extracts of the crystal structures of the green (left) and blue (right) polymorph of $\mathrm{Cu}\left[\mathrm{Au}(\mathrm{CN})_{2}\right]_{2}(\mathrm{DMSO})_{2}\left(\mathbf{6 2} \cdot(\mathrm{DMSO})_{2}\right)$. Reprinted with permission from ref. ${ }^{129}$. Copyright 2004 American Chemical Society.

The green structure exhibits an extended 1D zigzag chain structure in which $\mathrm{Cu}(\mathrm{II})$ bridges between individual $\mathrm{Au}(\mathrm{CN})_{2}^{-}$units. Each chain is connected to four neighboring chains through $\mathrm{Au}(\mathrm{I})-\mathrm{Au}(\mathrm{I})$ interactions occurring through an intermetallic contact of 3.22007(5) $\AA$. The DMSO molecules, ligated to $\mathrm{Cu}(\mathrm{II})$, occupy the voids between the chains. The blue polymorph contains 
2-D layers of interconnected $\mathrm{Au}(\mathrm{CN})_{2}{ }^{-}$units and octahedral $\mathrm{Cu}(\mathrm{II})$ complexes, individual layers are stacked through aurophilic interactions of 3.419(3) $\AA$ to yield a 3-D network. The different colors of the two polymorphs are due to the different coordination numbers (5 or 6 ) and geometries (square-pyramidal vs. octahedral) of the $\mathrm{Cu}(\mathrm{II})$ ions, causing substantially different crystal field splittings of the d-d excited states. Both polymorphs are thermally stable up to 100 ${ }^{\circ} \mathrm{C}$, but they easily sorb a variety of different small molecules with $\mathrm{N}$ - or O-atoms and thereby release DMSO. Specifically water, acetonitrile, DMF, dioxane, pyridine, and $\mathrm{NH}_{3}$ were tested. A combination of elemental analysis, thermogravimetry, X-ray diffraction, and IR spectroscopy leads to the conclusion that the compounds generated by vapor uptake are identical to those that can be obtained directly from solutions containing the respective $\mathrm{N}$ - or O-atom-containing small molecules. A key finding is that all adsorbed solvent molecules are ligated to $\mathrm{Cu}$ (II) by replacing some or all of the initially present DMSO molecules. This behavior is in clear contrast to many other vapochromic materials in which adsorbed VOCs are loosely trapped in channels or voids of the crystalline host lattice. The ratio of adsorbed molecule to $\mathrm{Cu}(\mathrm{II})$ varies between 1:1 (DMF), 2:1 $\left(\mathrm{H}_{2} \mathrm{O}, \mathrm{CH}_{3} \mathrm{CN}\right.$, pyridine), and 4:1 $\left(\mathrm{NH}_{3}\right)$, producing color changes which are easily detectable (Figure 30): The maximum visible reflectance varies between $433 \pm 7 \mathrm{~nm}$ for $\mathrm{Cu}\left[\mathrm{Au}(\mathrm{CN})_{2}\right]_{2}\left(\mathrm{NH}_{3}\right)_{4}$ and $560 \pm 20 \mathrm{~nm}$ for solvent-free $\mathrm{Cu}\left[\mathrm{Au}(\mathrm{CN})_{2}\right]_{2}$. As the color variations are entirely due to changes in the $\mathrm{Cu}(\mathrm{II})$ coordination number and geometry it might be argued that $\mathrm{Cu}\left[\mathrm{Au}(\mathrm{CN})_{2}\right]_{2}$ is a copper- rather than gold-based vapochromic material. However, on the one hand the aurophilic interactions between individual cyanoaurate units are crucial for obtaining the vapor-responsive structures of $\mathrm{Cu}\left[\mathrm{Au}(\mathrm{CN})_{2}\right]_{2},{ }^{17}$ and on the other hand the $\mathrm{Au}(\mathrm{CN})_{2}{ }^{-}$units provide a spectroscopic handle which is at least as sensitive to solvent uptake as the changes in the UV-vis (reflectance) spectrum. Specifically, the CN stretching frequency is very susceptible 
to $\pi$-backbonding from the $\mathrm{Cu}(\mathrm{II})$ center to the cyano-groups, producing shifts between $10 \mathrm{~cm}^{-1}$ and $40 \mathrm{~cm}^{-1}$ depending on solvent. ${ }^{129}$

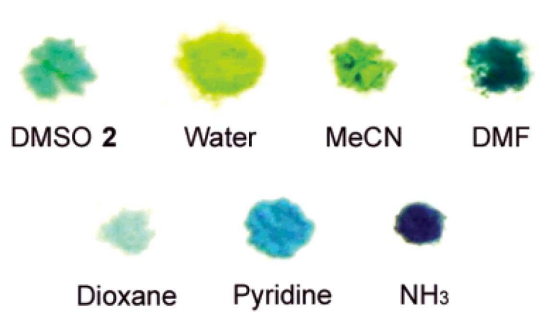

Figure 30. Vapochromic response of $\mathrm{Cu}\left[\mathrm{Au}(\mathrm{CN})_{2}\right]_{2}(\mathrm{DMSO})_{2}\left(\mathbf{6 2} \cdot(\mathrm{DMSO})_{2}\right)$ to different vapors. Reprinted with permission from ref. ${ }^{129}$. Copyright 2004 American Chemical Society.

The solvent exchange on $\mathrm{Cu}(\mathrm{II})$ is completely reversible, permitting dynamic vapor sensing, at least for $\mathrm{H}_{2} \mathrm{O}, \mathrm{CH}_{3} \mathrm{CN}$, DMF, and dioxane. ${ }^{14}$ The stronger pyridine and $\mathrm{NH}_{3}$ ligands are less easily replaced by other solvents hence in the case of $\mathrm{Cu}\left[\mathrm{Au}(\mathrm{CN})_{2}\right]_{2}$ (pyridine $)_{2}$ and $\mathrm{Cu}\left[\mathrm{Au}(\mathrm{CN})_{2}\right]_{2}\left(\mathrm{NH}_{3}\right)_{4}$ thermal treatment is necessary to reactivate the vapochromic behavior.

The strong binding of $\mathrm{NH}_{3}$ to $\mathrm{Cu}$ (II) in $\mathbf{6 2}$ was one of the motivations for investigating analogous zinc(II) compounds in which the reversibility of $\mathrm{NH}_{3}$ uptake was anticipated to be better. The second reason why $\mathrm{Zn}\left[\mathrm{Au}(\mathrm{CN})_{2}\right]_{2}(\mathbf{6 3})$ was studied is that in this material no d-d absorptions of the $3 \mathrm{~d}$ metal can mask any gold-localized emission. ${ }^{130} \mathrm{~A}$ vapoluminescence response in lieu of a vapochromic effect would potentially increase the detection sensitivity. Depending on reaction conditions (starting material, solvent, concentration) four different polymorphs of compound $\mathbf{6 3}$ were obtained. Particularly noteworthy is the fact that even the counterions of the zinc(II) and $\mathrm{Au}(\mathrm{CN})_{2}{ }^{-}$starting materials influence which polymorph is formed even though these counterions are not incorporated into the final product. Despite careful 
systematic investigations the rationale behind the preferential formation of a particular polymer under a given set of conditions has not become clear. All four polymorphs of $\mathrm{Zn}\left[\mathrm{Au}(\mathrm{CN})_{2}\right]_{2}$ have been characterized structurally. They all have $\mathrm{Zn}(\mathrm{II})$ in tetrahedral coordination geometry, and they all exhibit short $\mathrm{Au}(\mathrm{I})-\mathrm{Au}(\mathrm{I})$ contacts in the range of $3.11-3.34 \AA$. Two polymorphs exhibit diamond-like networks, among the other two polymorphs there is a quartz-like and a herringbone-like network with different degrees of interpenetration. Because of the presence of aurophilic interactions, UV excitation leads to photoluminescence in three of the four polymorphs. One polymorph shows even two emissions, namely a short-lived $(\tau=240 \mathrm{~ns})$ band at $390 \mathrm{~nm}$ attributed to fluorescence and a longer lived $(\tau=930 \mathrm{~ns})$ band at $480 \mathrm{~nm}$ assigned to phosphorescence. Along the series of the three emissive polymorphs the phosphorescence energy is inversely proportional to the $\mathrm{Au}(\mathrm{I})-\mathrm{Au}(\mathrm{I})$ distance, as expected. ${ }^{131,132}$

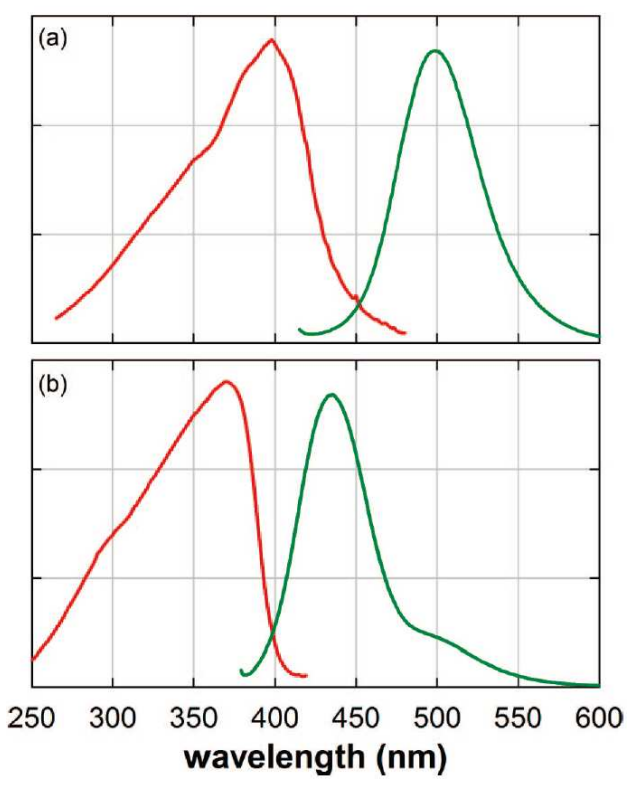

Figure 31. Excitation and emission spectra of (a) $\left[\mathrm{Zn}\left(\mathrm{NH}_{3}\right)_{2}\right]\left[\mathrm{Au}(\mathrm{CN})_{2}\right]_{2}$ and (b) $\left[\mathrm{Zn}\left(\mathrm{NH}_{3}\right)_{4}\right]\left[\mathrm{Au}(\mathrm{CN})_{2}\right]_{2}$ illustrating the vapochromic and vapoluminescent response of compound 
62 to ammonia vapor. Reprinted with permission from ref. ${ }^{130}$. Copyright 2008 American Chemical Society.

Exposure of any of the four polymorphs to ammonia vapors produces a new emission with a band maximum at $430 \mathrm{~nm}$ (Figure 31). ${ }^{130}$ The resulting species, identified as $\left[\mathrm{Zn}\left(\mathrm{NH}_{3}\right)_{4}\right]\left[\mathrm{Au}(\mathrm{CN})_{2}\right]_{2}$, decomposes fairly rapidly once it is removed from ammonia-rich atmosphere, and the $\left[\mathrm{Zn}\left(\mathrm{NH}_{3}\right)_{2}\right]\left[\mathrm{Au}(\mathrm{CN})_{2}\right]_{2}$ compound with a lower ammonia content emitting at $500 \mathrm{~nm}$ is formed. In IR spectroscopy the $\mathrm{CN}$ stretch of $\left[\mathrm{Zn}\left(\mathrm{NH}_{3}\right)_{2}\right]\left[\mathrm{Au}(\mathrm{CN})_{2}\right]_{2}$ shows up as a single band at $2158 \mathrm{~cm}^{-1}$, and there is evidence for metal-bound $\mathrm{NH}_{3}$, suggesting that $\mathrm{Zn}$ (II) is either octahedrally or tetrahedrally coordinated by ammonia. From powder X-ray diffraction data it was inferred that $\left[\mathrm{Zn}\left(\mathrm{NH}_{3}\right)_{2}\right]\left[\mathrm{Au}(\mathrm{CN})_{2}\right]_{2}$ contains $\mathrm{Zn}(\mathrm{II})$ centers in $\mathrm{D}_{4 \mathrm{~h}}$ local symmetry with $\mathrm{NH}_{3}$ ligands in trans-disposition and four equatorial N-bound cyanides. When $\left[\mathrm{Zn}\left(\mathrm{NH}_{3}\right)_{2}\right]\left[\mathrm{Au}(\mathrm{CN})_{2}\right]_{2}$ was left standing in air for 30 minutes, neat $\mathrm{Zn}\left[\mathrm{Au}(\mathrm{CN})_{2}\right]_{2}$ was formed, i. e., the vapoluminescence response has the anticipated higher reversibility compared to $\mathrm{Cu}\left[\mathrm{Au}(\mathrm{CN})_{2}\right]_{2}$. Although all four polymorphs of $\mathrm{Zn}\left[\mathrm{Au}(\mathrm{CN})_{2}\right]_{2}$ show vapoluminescence behavior, the material made from $\mathrm{Zn}\left(\mathrm{NO}_{3}\right)_{2}$ and $\left[(n-\mathrm{Bu})_{4} \mathrm{~N}\right]\left[\mathrm{Au}(\mathrm{CN})_{2}\right]$ exhibits the highest sensitivity for ammonia with a detection limit of $1 \mathrm{ppb} .{ }^{17}$ The permissible long-term exposure limit for $\mathrm{NH}_{3}$ is $20 \mathrm{ppm}$, the human nose starts sensing ammonia at concentrations of 50 ppm. ${ }^{133}$

\subsection{Di- and trinuclear $\mathrm{Au}(\mathrm{I})$ complexes}

Reaction of $\mathrm{KS}_{2} \mathrm{CN}\left(\mathrm{C}_{5} \mathrm{H}_{11}\right)_{2}$ with " $\mathrm{AuCl}_{2}{ }^{-6 "}$ generated in situ from $\mathrm{K}\left[\mathrm{AuCl}_{4}\right]$ and $\mathrm{Na}_{2} \mathrm{~S}_{2} \mathrm{O}_{3}$ affords a dimeric gold(I) dithiocarbamate complex (Scheme 29), $\left[\mathrm{Au}\left(\mathrm{S}_{2} \mathrm{CN}\right)\left(\mathrm{C}_{5} \mathrm{H}_{11}\right)_{2}\right]_{2}$ (64), 
which exhibits reversible vapoluminescence upon exposure to polar aprotic molecules such as acetone, $\mathrm{CH}_{3} \mathrm{CN}, \mathrm{CH}_{2} \mathrm{Cl}_{2}, \mathrm{CHCl}_{3}{ }^{134}$ Vapors of protic solvents such as methanol or ethanol produce no response. X-ray diffraction of single crystals of $64 \cdot \mathrm{DMSO}$ and $64 \cdot \mathrm{CH}_{3} \mathrm{CN}$ shows that there are infinite chains of Au atoms along the crystallographic c-axis with intermolecular Au(I)$\mathrm{Au}(\mathrm{I})$ contacts of $2.9617(7) \AA(64 \cdot \mathrm{DMSO})$ and $3.0241(12) \AA\left(64 \cdot \mathrm{CH}_{3} \mathrm{CN}\right)$. The intramolecular $\mathrm{Au}(\mathrm{I})-\mathrm{Au}(\mathrm{I})$ distances in the two solvates are 2.7690(7) $\AA$ and 2.7916(12) $\AA$. In solvent-free 64 the intramolecular metal-metal contacts are equally short $(2.7653(3) \AA)$, but the closest intermolecular $\mathrm{Au}(\mathrm{I})-\mathrm{Au}(\mathrm{I})$ distance increases to $8.135 \AA$ hence there is no infinite chain of mutually interacting gold atoms. Thus, the orange emission $\left(\lambda_{\max }=604 \mathrm{~nm}\right)$ is only observed when intermolecular $\mathrm{Au}(\mathrm{I})-\mathrm{Au}(\mathrm{I})$ interactions between dimers are present, and the emissive excited states are likely to have either $\left(d \sigma^{*}\right)^{1}(\mathrm{p} \sigma)^{1}$ or $\left(\mathrm{d} \delta^{*}\right)^{1}(\mathrm{p} \sigma)^{1}$ valence electron configurations. $^{135}$

Scheme 29. Dinuclear gold(I) complexes exhibiting vapochromism and tribochromism.

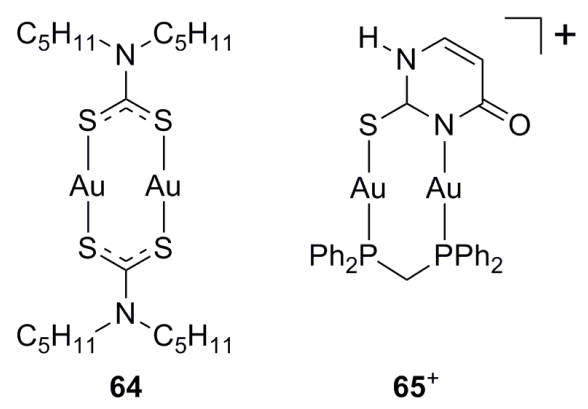

A gold(I) 2-thiouracilato complex with a bridging bis(diphenylphosphino)methane (dppm) ligand (65a $\left.\cdot \mathrm{CF}_{3} \mathrm{COO}\right)$ exhibits a somewhat longer (2.8797(4) $\AA$ ) intramolecular $\mathrm{Au}(\mathrm{I})-\mathrm{Au}(\mathrm{I})$ distance than complex $64 .{ }^{136}$ The helical supramolecular arrangement in the crystal structure of 
$\mathbf{6 5 a} \cdot \mathrm{CF}_{3} \mathrm{COO}$ precludes the formation of extended chains of interacting gold atoms (Figure 32 ), and the substance is not luminescent. When it is gently crushed with a spatula blue photoluminescence $\left(\lambda_{\max }=483 \mathrm{~nm}\right)$ can be detected, i. e., the substance shows luminescence tribochromism. ${ }^{137}$ The emissive form can also be obtained upon gentle heating $\left(37^{\circ} \mathrm{C}\right)$ or by sonication, ${ }^{136}$ and in the course of this treatment acid is released as monitored by using $\mathrm{pH}$ paper. When compound 65a $\cdot \mathrm{CF}_{3} \mathrm{COO}$ is stirred in $\mathrm{CH}_{2} \mathrm{Cl}_{2} / \mathrm{CH}_{3} \mathrm{OH}$ solutions over $\mathrm{Na}_{2} \mathrm{CO}_{3}$ it is possible to obtain the deprotonated product $\mathbf{6 5 b}$ which consists of dimers held together with short (2.9235(4) $\AA$ ) intermolecular $\mathrm{Au}(\mathrm{I})-\mathrm{Au}(\mathrm{I})$ contacts (Figure 32), i. e., the crystal packing is completely different. The available experimental evidence including powder X-ray analysis of crushed $65 \mathbf{a} \cdot \mathrm{CF}_{3} \mathrm{COO}$ supports the hypothesis that $\mathbf{6 5 b}$ is the emissive material resulting from mechanical (or thermal) treatment of $\mathbf{6 5 a} \cdot \mathrm{CF}_{3} \mathrm{COO}$. Thus it appears that the tribochromism is due to rearrangement of the molecules in the crystal lattice coupled to release of volatile acid. Exposure of $\mathbf{6 5} \mathbf{b}$ to $\mathrm{CF}_{3} \mathrm{COOH}$ vapor leads (very slowly) to a loss of the photoluminescence, but the emission can be recovered by subsequent exposure to triethylamine vapor. The C-O bond lengths in the crystal structures of $\mathbf{6 5 a} \cdot \mathrm{CF}_{3} \mathrm{COO}$ and $\mathbf{6 5} \mathbf{b}$ are similar hence the probable site of protonation in $\mathbf{6 5 b}$ is most likely the uncoordinated pyrimidine $\mathrm{N}$-atom. 


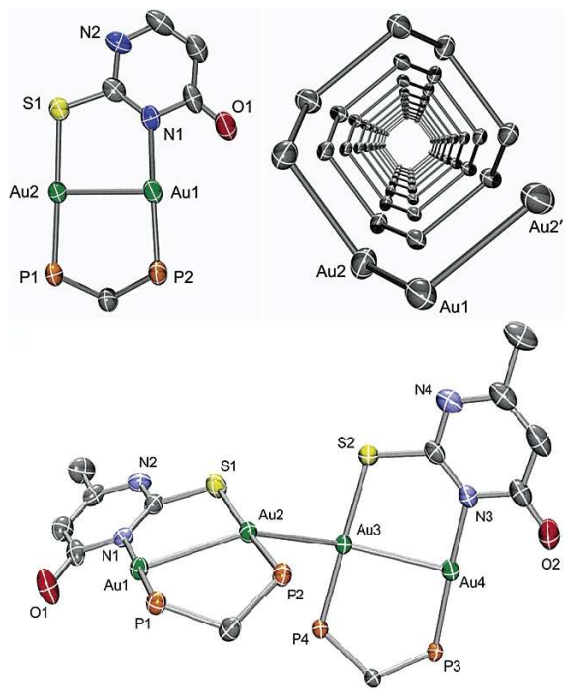

Figure 32. Top left: Crystal structure of compound $\mathbf{6 5 a} \cdot \mathrm{CF}_{3} \mathrm{COO}$. Top right: helical arrangement of gold atoms in $\mathbf{6 5 a} \cdot \mathrm{CF}_{3} \mathrm{COO}$. Bottom: Dimers of complexes in compound $\mathbf{6 5} \mathbf{b}$. Reprinted with permission from ref. ${ }^{136}$. Copyright 2003 American Chemical Society.

Scheme 30. Trinuclear gold(I) complexes.

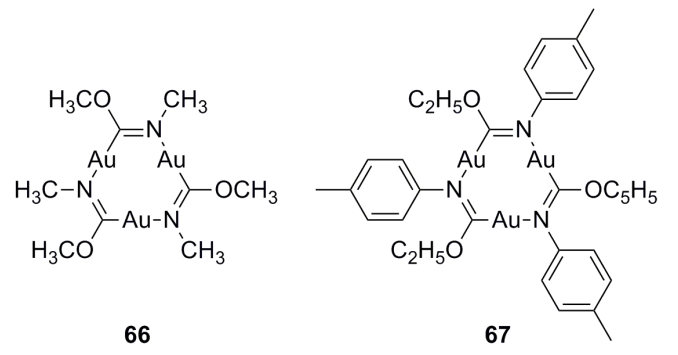

The trinuclear gold(I) complex 66 (Scheme 30) exhibits the unusual phenomenon of solventstimulated luminescence. ${ }^{138,139}$ This means that emission is triggered when liquids are brought into contact with crystals of $\mathbf{6 6}$ that have been previously irradiated at $366 \mathrm{~nm}$. Compound $\mathbf{6 6}$ features short intra- (3.308(2) $\AA$ ) and intermolecular $\mathrm{Au}(\mathrm{I})-\mathrm{Au}(\mathrm{I})$ interactions (3.346(1) $\AA$ ), and thus it seems plausible that aurophilic interactions are important for the luminescence behavior 
of 66, particularly in view of the fact that a reference compound without any short intermetallic contacts is non-emissive. In the crystal structure of $\mathbf{6 6}$ there are extended stacks of individual molecules along the c-axis, and it has been speculated that upon UV irradiation energy might be stored in these stacks in the form of electron-hole pairs which only recombine following addition of solvent. This tentative explanation is plausible because one would expect relatively facile charge migration along these stacks, ${ }^{140}$ and electrons or holes can easily be trapped at defect sites. Solvent addition can then trigger minor structural changes such that the electrons and holes are released from the defect sites. Interestingly, $\mathrm{CHCl}_{3}$ and $\mathrm{CH}_{2} \mathrm{Cl}_{2}$ in which compound $\mathbf{6 6}$ has the highest solubility produce the strongest luminescence. It has been noted that the solventstimulated luminescence of $\mathbf{6 6}$ is related to the phenomenon of lyoluminescence, ${ }^{141}$ in which light emission occurs when dissolving a solid that has been previously exposed to ionizing radiation - with the important difference that radiation of much lower energy is required to induce emission in compound 66. ${ }^{138}$ The solvoluminescence from planar trigold(I) complexes has been reviewed. ${ }^{142}$

The charge mobility in microwires of compound $\mathbf{6 6}$ has been explored with a view to obtaining materials with vapor-sensitive conductive properties. ${ }^{143}$ For this purpose a $\mathrm{CH}_{2} \mathrm{Cl}_{2}$ solution of $\mathbf{6 6}$ was drop-cast between two gold electrodes on a $\mathrm{SiO}_{2}$ surface, and the resulting microwires formed from stacks of $\mathbf{6 6}$ were found to bridge the $150 \mu \mathrm{m}$ gap between the two gold electrodes. Hole mobilities on the order of $0.2 \mathrm{~cm}^{2} \mathrm{~V}^{-1} \mathrm{~s}^{-1}$ were determined for 10 devices of this type. At a voltage of $1.5 \mathrm{~V}$ between the two gold electrodes currents on the order of $0.6 \mathrm{nA}$ flow through the microwires. Exposure to ethanol vapor decreases the flowing current by two orders of magnitude, but this decrease is reversible when purging with pure $\mathrm{N}_{2}$ afterwards. In addition to ethanol, THF, $\mathrm{CH}_{3} \mathrm{CN}$, acetone, methanol, $n$-propanol, $n$-butanol, $n$-pentanol, benzene, and $p$ - 
xylene have been tested, but only ethanol, methanol and $\mathrm{CH}_{3} \mathrm{CN}$ were found to produce a significant response. It has been argued that hydrogen-bonding interactions between compound 66 and adsorbed VOCs might disturb the 1D-stacking of the complexes and thereby disrupt efficient charge transfer pathways. ${ }^{143}$

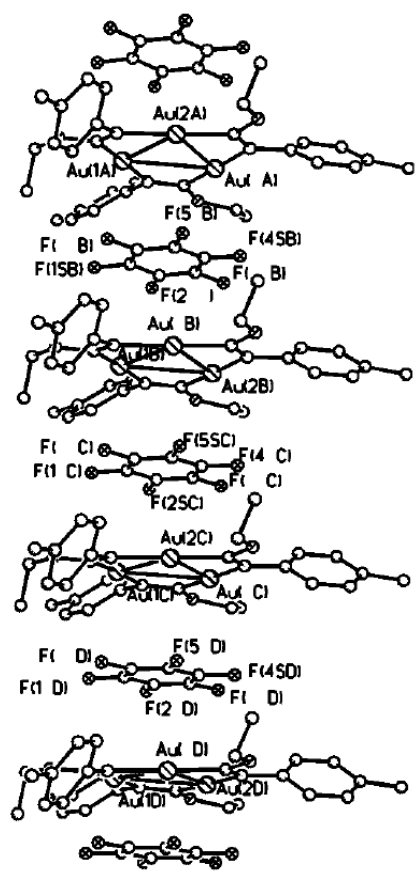

Figure 33. Columnar structure of $\mathbf{6 7} \cdot \mathrm{C}_{6} \mathrm{~F}_{6}$. Reprinted with permission from ref. ${ }^{144}$. Copyright 2001 American Chemical Society.

The trinuclear gold(I) complex 67 differs from compound 66 mainly in that the $\mathrm{N}$-atoms bear p-tolyl groups instead of methyl-substituents. Solid 67 exhibits blue photoluminescence $\left(\lambda_{\max } \approx\right.$ $440 \mathrm{~nm}$ ), but when exposed to vapor of $\mathrm{C}_{6} \mathrm{~F}_{6}$ the emission is quenched. ${ }^{144} \mathrm{X}$-ray structural investigations provide a plausible explanation for this behavior. Neat $\mathbf{6 7}$ crystallizes in such a way that dimers of $\mathbf{6 7}$ with short intermolecular $\mathrm{Au}(\mathrm{I})-\mathrm{Au}(\mathrm{I})$ contacts are formed, ${ }^{145}$ whereas the 
crystal structure of $\mathbf{6 7} \cdot \mathrm{C}_{6} \mathrm{~F}_{6}$ consists of $1 \mathrm{D}$-chains of alternating gold complexes and hexafluorobenzene molecules interacting with each other through (Lewis) acid-base interactions (Figure 33). ${ }^{144}$ Thus, uptake of $\mathrm{C}_{6} \mathrm{~F}_{6}$ disrupts intermolecular $\mathrm{Au}(\mathrm{I})-\mathrm{Au}(\mathrm{I})$ contacts, and this is likely the reason for the emission quenching described above.

A chemically related trinuclear $\mathrm{Au}(\mathrm{I})$ complex with imidazolate instead of carbeniate ligands forms analogous 1D chains with intercalating TCNQ molecules, but for the respective complex no vapoluminescence behavior has been reported. ${ }^{144}$

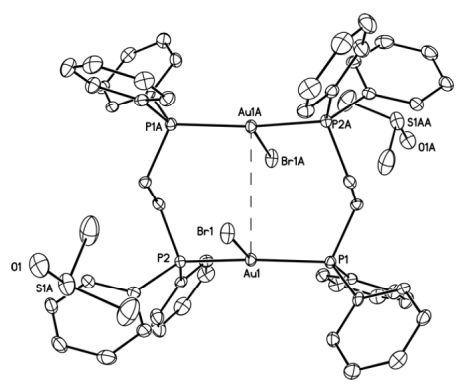

Figure 34. Drawing of the structure of 68-2DMSO (type A representative). Reprinted with permission from ref. ${ }^{146}$. Copyright 2010 American Chemical Society.

The dimer $\mathrm{Au}_{2}\left(\mu\right.$-bis-(diphenylphosphino)ethane) ${ }_{2} \mathrm{Br}_{2}$ (68) was found to exhibit remarkable molecular flexibility and for this reason may be regarded as a molecular accordion with vapoluminescent properties. ${ }^{146}$ Depending on crystallization conditions three different types of structures of the same compound are obtained. Type A crystals are obtained for 68.2DMSO, 68. $2 \mathrm{Me}_{2} \mathrm{CO}, \mathbf{6 8} \cdot 2 \mathrm{CH}_{2} \mathrm{Cl}_{2}, \mathbf{6 8} \cdot 2 \mathrm{DMF}$ and contain discrete $\mathrm{Au}_{2}$ dimers (Figure 34). They are colorless and exhibit orange emission $\left(\lambda_{\max }=620-640 \mathrm{~nm}\right)$ upon UV excitation. The intramolecular $\mathrm{Au}(\mathrm{I})-\mathrm{Au}(\mathrm{I})$ distances in type A crystals are relatively long and range from $3.8479(3) \AA$ for $\mathbf{6 8} \cdot 2 \mathrm{DMSO}$ to $3.5142(3) \AA$ in $\mathbf{6 8} \cdot 2 \mathrm{DMF}$. The expected $\mathrm{Au}(\mathrm{I})-\mathrm{Au}(\mathrm{I})$ separation 
based on the van der Waals radius is about $3.6 \AA \AA^{147}$ i. e., there are little to no aurophilic interactions in these crystals. The solvent molecules merely fill space in the crystal structures but do not interact with the metal centers. Type B crystals are green photoluminescent $\left(\lambda_{\max }=550\right.$ $\mathrm{nm})$ and exhibit aurophilic interactions within discrete dimers since there are short $\mathrm{Au}(\mathrm{I})-\mathrm{Au}(\mathrm{I})$ contacts between $3.3249(2) \AA$ and $3.09841(18) \AA$ in $\mathbf{6 8} \cdot 2 \mathrm{CH}_{3} \mathrm{CN}$ and $\mathbf{6 8} \cdot 0.5 \mathrm{Et}{ }_{2} \mathrm{O}$. Type C crystals are polymers which are not considered further here because they are not vapochromic or vapoluminescent. The finding of intermolecular $\mathrm{Au}(\mathrm{I})-\mathrm{Au}(\mathrm{I})$ distances varying between 3.09841(18) $\AA$ and 3.8479(3) $\AA$ for the same compound is highly unusual and justifies usage of the term "molecular accordion".
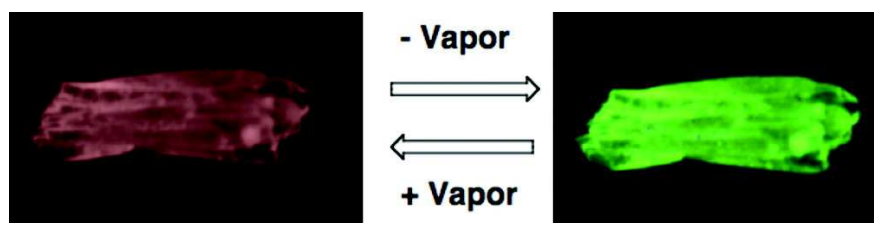

Figure 35. Vapor-induced luminescence changes in compound 68. Reprinted with permission from ref. ${ }^{146}$. Copyright 2010 American Chemical Society.

When drying type A crystals of $68 \cdot 2 \mathrm{CH}_{2} \mathrm{Cl}_{2}$ and $68 \cdot \mathrm{Me}_{2} \mathrm{CO}$ their orange emission disappears, and they begin to exhibit the green luminescence observed for type B crystals (Figure 35). Subsequent exposure to acetone or $\mathrm{CH}_{2} \mathrm{Cl}_{2}$ vapor recovers the orange emission of the initial type A material, but no vapoluminescence response is observed for acetonitrile, diethyl ether, DMF, DMSO, benzene, pyridine, nitrobenzene, and carbon disulfide. It seems quite obvious that the remarkable flexibility of the $\mathrm{Au}_{2}(\mu \text {-dppe })_{2} \mathrm{Br}_{2}$ molecule is responsible for the vapoluminescence 
behavior. The different luminescence colors between type A (orange) and type B (green) seem to be primarily an effect of a smaller Stokes shift in type B crystals.

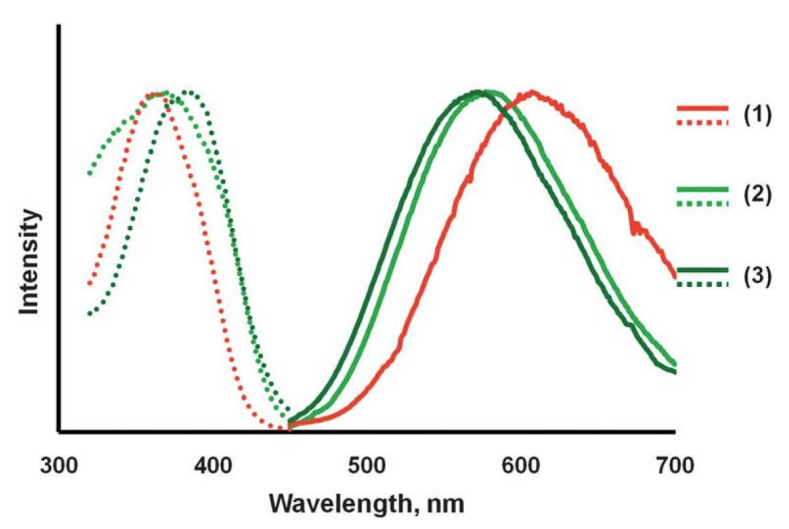

Figure 36. Excitation (dotted lines) and emission (solid lines) spectra of (a) the $\alpha$-polymorph of 69. $2 \mathrm{Me}_{2} \mathrm{CO}$; (b) the $\beta$-form obtained after gentle drying of $\alpha-69 \cdot 2 \mathrm{Me}_{2} \mathrm{CO}$ (light green traces); (c) the material obtained after drying of $\alpha \mathbf{- 6 9} \cdot 2 \mathrm{Me}_{2} \mathrm{CO}$ for three hours (dark green traces). Reprinted with permission from ref. ${ }^{148}$. Copyright 2012 The Royal Society of Chemistry.

An analogous gold(I) dimer with iodo- instead of bromo-ligands, $\mathrm{Au}_{2}(\mu$-bis(diphenylphosphino)ethane) $)_{2} \mathrm{I}_{2} \cdot 2 \mathrm{Me}_{2} \mathrm{CO} \quad\left(\mathbf{6 9} \cdot 2 \mathrm{Me}_{2} \mathrm{CO}\right), \quad$ exhibits similarly spectacular behavior. ${ }^{148}$ Depending on crystallization conditions two different polymorphs of $\mathbf{6 9} \cdot 2 \mathrm{Me}_{2} \mathrm{CO}$ can be obtained: The $\alpha$-polymorph luminesces in the orange spectral range $\left(\lambda_{\max }=607 \mathrm{~nm}\right)$, whereas the $\beta$-polymorph is a green emitter $\left(\lambda_{\max }=577 \mathrm{~nm}\right)$ (Figure 36$)$. The two polymorphs can be reversibly converted into one another. Gentle drying of $\alpha-69 \cdot 2 \mathrm{Me}_{2} \mathrm{CO}$ crystals in air transforms them into the green-emitting $\beta$-form, and subsequent exposure to acetone or $\mathrm{CH}_{2} \mathrm{Cl}_{2}$ vapor converts them back to the orange-glowing $\alpha$-polymorph. This single crystal to single crystal conversion does not involve any loss or uptake of acetone, but it is possible to remove 2 
molecules of acetone from the $\beta$-polymorph by prolonged drying. In the course of the conversion of the $\alpha$ - to the $\beta$-form the intramolecular $\mathrm{Au}(\mathrm{I})-\mathrm{Au}(\mathrm{I})$ distance decreases from $3.6720(2) \AA$ to $3.3955(2) \AA$.

Scheme 31. Di- and trinuclear gold complexes.
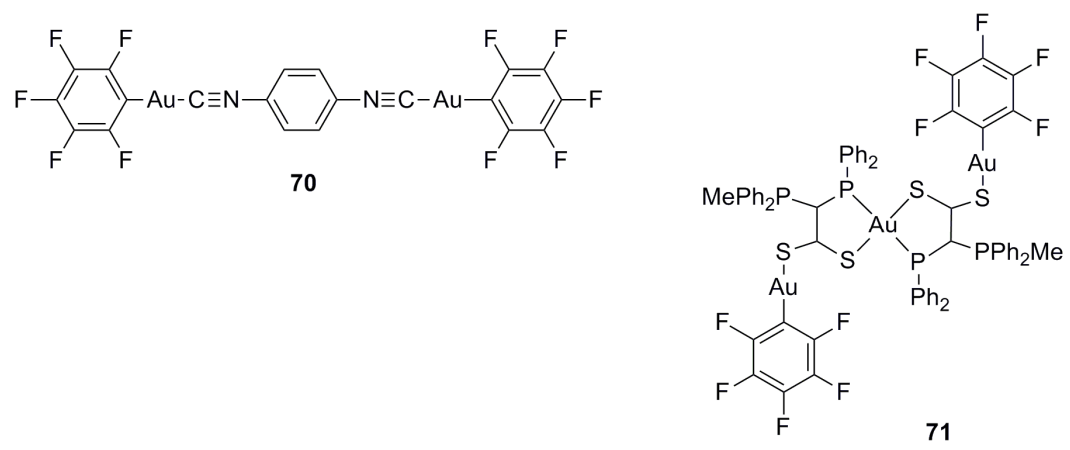

When reacting $\mathrm{C}_{6} \mathrm{~F}_{5} \mathrm{Au}$ (tetrahydrothiophene) with 1,4-diisocyanobenzene in $\mathrm{CH}_{2} \mathrm{Cl}_{2}$ one obtains the dinuclear gold(I) complex 70 (Scheme 31) which is a mechanochromic and vapochromic substance. ${ }^{149}$ The blue photoluminescence of untreated powder or crystals of $\mathbf{7 0}$ was attributed to ligand-localized $\pi-\pi^{*}$ transitions. X-ray diffraction on a single crystal shows that the shortest intermolecular $\mathrm{Au}(\mathrm{I})-\mathrm{Au}(\mathrm{I})$ distance is $5.19 \AA$, i. e., there are no aurophilic interactions between individual molecules. When grinding a sample of $\mathbf{7 0}$ in an agate mortar the luminescence changes to yellow (Figure 37). Powder X-ray diffraction shows that an amorphous material is formed, and it has been speculated that the yellow luminescence of this material might be due to aurophilic interactions that arise from rearrangement of the individual molecules relative to each other. Significant changes in the $\mathrm{N} \equiv \mathrm{C}$ stretching frequencies upon mechanical grinding suggest that the coordination mode of the isocyanide ligands is altered, and this could indeed be due to the formation of aurophilic bonds. ${ }^{150}$ When exposing a ground sample of 70 to 
$\mathrm{CH}_{2} \mathrm{Cl}_{2}$ vapor the blue luminescence is restored, indicating that the structural transformation is reversible. ${ }^{149}$ A simple slipping motion of the planar molecules appears as the most plausible molecular rearrangement accompanying mechano- and vapochromism in compound $\mathbf{7 0 .}$
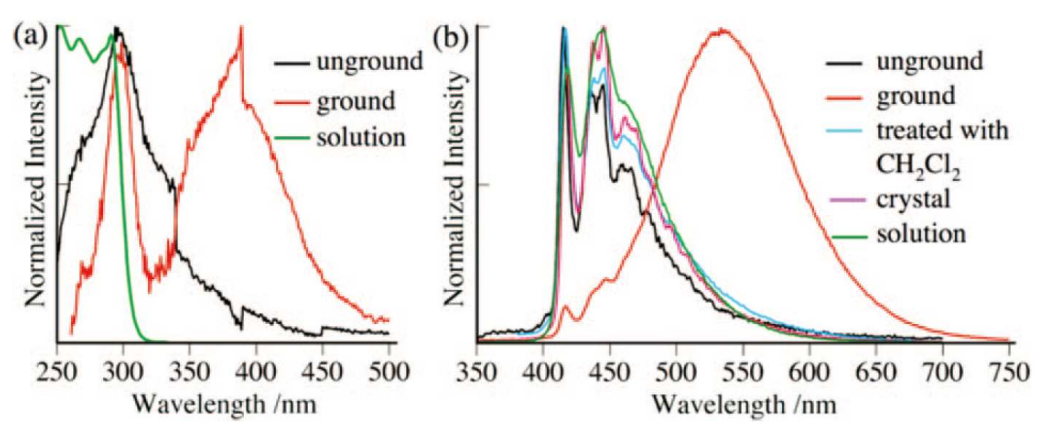

Figure 37. (a) Absorption and (b) photoluminescence spectra of compound $\mathbf{7 0}$ in various states. Reprinted with permission from ref. ${ }^{149}$. Copyright 2008 American Chemical Society.

The dinuclear complex 71 changes color from orange to black when exposed to vapors of acetone, $\mathrm{CH}_{2} \mathrm{Cl}_{2}$, or $\mathrm{CHCl}_{3}$. ${ }^{151,152}$ This behavior was exploited for the construction of VOCsensitive optical fibers. The sensors consisted of a standard $1.3 \mu \mathrm{m}$ optical fiber onto which the vapochromic material was deposited at one end. Since the vapochromic material undergoes a change in refractive index upon solvent exposure, the reflectance of the overall optical fiber changes dramatically in the $500-1800 \mathrm{~nm}$ wavelength range when the material is exposed to VOCs. Changes of up to $13.5 \mathrm{~dB}$ in the transmitted optical power were detected for acetone and $\mathrm{CH}_{2} \mathrm{Cl}_{2}$, but the devices respond to other solvents as well, for example to $\mathrm{CHCl}_{3}$, dichloroethane, ethanol, ethyl acetate, THF, and toluene. ${ }^{151,152}$

\subsection{Gold-thallium complexes}


When equimolar quantities of $\left[\mathrm{NBu}_{4}\right]\left[\mathrm{Au}\left(\mathrm{C}_{6} \mathrm{Cl}_{5}\right)_{2}\right]$ and $\mathrm{TlPF}_{6}$ are brought to reaction in THF one obtains $\left[\mathrm{Tl}\left[\mathrm{Au}\left(\mathrm{C}_{6} \mathrm{Cl}_{5}\right)_{2}\right]\right]_{\mathrm{n}}(\mathbf{7 2})$ as a pale yellow solid. ${ }^{153}$ This vapochromic material contains linear chains of alternating (and nearly planar) $\left[\mathrm{Au}\left(\mathrm{C}_{6} \mathrm{Cl}_{5}\right)_{2}\right]^{-}$anions and $\mathrm{Tl}^{+}$cations along the crystallographic z-axis with unsupported $\mathrm{Au}(\mathrm{I})$-Tl(I) interactions at distances of 3.044(5) and 2.9726(5) A. Theoretical studies lead to the conclusion that this heterobimetallic $\mathrm{d}^{10}-\mathrm{s}^{2}$ interaction (of Lewis acid - Lewis base type) is associated with a stabilization energy of about $275 \mathrm{~kJ} / \mathrm{mol} .{ }^{154}$ Between individual $\mathrm{Au}(\mathrm{I})-\mathrm{Tl}(\mathrm{I})$ chains there are channels with hole diameters as large as $10.471 \AA$ running parallel to the $\mathrm{z}$-axis hence there is considerable room for incorporation of solvent guests. Compound $\mathbf{7 2}$ changes color from yellow to red when exposed to vapors of acetylacetone or pyridine but stays yellow upon exposure to acetone, acetonitrile, THF, triethylamine, 2-fluoropyridine, or tetrahydrothiophene. However, all of these VOCs produce detectable vapoluminescence responses with emission maxima ranging from $507 \mathrm{~nm}$ (THF) to $650 \mathrm{~nm}$ (acetylacetone) compared to $\lambda_{\max }=531 \mathrm{~nm}$ for neat 72 (Figure 38). ${ }^{153}$

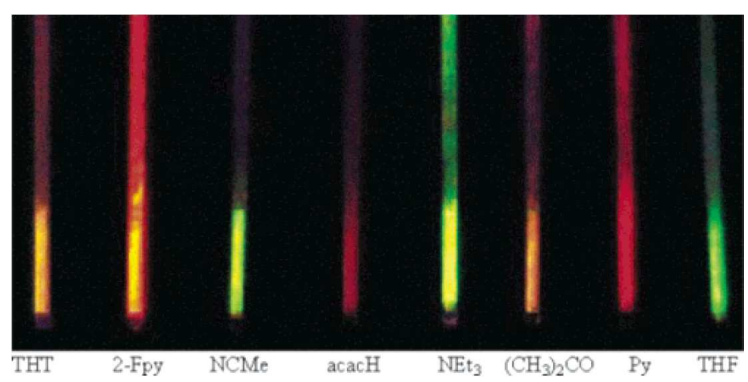

Figure 38. Luminescence vapochromism of compound $\mathbf{7 2}$ observed after exposure to various VOCs. Reprinted with permission from ref. ${ }^{155}$. Copyright 2004 American Chemical Society. 
Using the appropriate VOCs as solvents, it is possible to synthesize a range of solvent adducts with the general stoichiometry $\left[\mathrm{TlL}_{2}\left[\mathrm{Au}\left(\mathrm{C}_{6} \mathrm{Cl}_{5}\right)_{2}\right]\right]_{\mathrm{n}}\left(72 \mathrm{~L}_{2}\right)$, two of which have been structurally characterized (72(tetrahydrothiophene) $\left.\left.)_{2}, \mathbf{7 2 ( 2 - f l u o r o p y r i d i n e )}\right)_{2}\right) .{ }^{155}$ The respective structures contain polymeric chains of cations and anions with unsupported $\mathrm{Au}(\mathrm{I})-\mathrm{Tl}(\mathrm{I})$ contacts at distances between 2.90894(5) and 3.1981(4) $\AA$ which are close to the sum of thallium and gold metallic radii (3.034 $\AA$ ). The tetrahydrothiophene and 2-fluoropyridine molecules ligate to Tl(I) which is now in pseudo trigonal-bipyramidal coordination with a vacant equatorial coordination site occupied by a lone pair. As a consequence, the $\mathrm{Au}(\mathrm{I})-\mathrm{Tl}(\mathrm{I})-\mathrm{Au}(\mathrm{I})$ interaction is no longer as linear as in neat 72 but more zigzag-like (the $\mathrm{Au}(\mathrm{I})-\mathrm{Tl}(\mathrm{I})-\mathrm{Au}(\mathrm{I})$ angle is $164^{\circ}$ ). The emission of the individual solvent adducts undergoes a significant red-shift between room temperature and $77 \mathrm{~K}$, suggesting that the luminescence of $\left[\mathrm{Tl}\left[\mathrm{Au}\left(\mathrm{C}_{6} \mathrm{Cl}_{5}\right)_{2}\right]\right]_{\mathrm{n}}$ has its origin in gold-thallium interactions. Time-dependent DFT supports this hypothesis. The geometrical changes around the $\mathrm{Tl}(\mathrm{I})$ cation in the course of solvent uptake lead to a change in HOMO-LUMO energy gap because the $\mathrm{Au}(\mathrm{I})-\mathrm{Tl}(\mathrm{I})$ interaction is perturbed by solvent ligation to the Lewis acid. Importantly, the vapoluminescence response of compound $\mathbf{7 2}$ is reversible: Heating of the $72 \mathrm{~L}_{2}$ compounds to $100^{\circ} \mathrm{C}$ for a few minutes regenerates the solvent-free starting material.

Scheme 32. Vapochromic substances $(\mathbf{7 3 a} / \mathbf{7 3 b})$ based on ketimine formation $(\mathbf{7 4 a} / \mathbf{7 4 b})$.

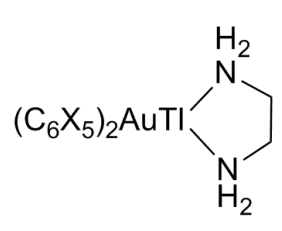

73a $X=F$

$73 \mathrm{~b} X=\mathrm{Cl}$

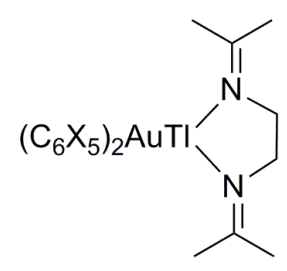

$74 \mathrm{a} X=\mathrm{F}$

74b $\mathrm{X}=\mathrm{Cl}$ 
When reacting equimolar amounts of $\left[\mathrm{Tl}\left[\mathrm{Au}\left(\mathrm{C}_{6} \mathrm{X}_{5}\right)_{2}\right]\right]_{\mathrm{n}}(\mathrm{X}=\mathrm{F}, \mathrm{Cl})$ and 1,2-ethylenediamine (en) one obtains $\left[\mathrm{Tl}(\mathrm{en})\left[\mathrm{Au}\left(\mathrm{C}_{6} \mathrm{~F}_{5}\right)_{2}\right]\right]_{\mathrm{n}}(\mathbf{7 3 a})$ and $\left[\mathrm{Tl}(\mathrm{en})\left[\mathrm{Au}\left(\mathrm{C}_{6} \mathrm{Cl}_{5}\right)_{2}\right]\right]_{\mathrm{n}}(\mathbf{7 3 b})$ as green and white solids, respectively. ${ }^{156}$ The ethylenediamine ligand ligates to $\mathrm{Tl}(\mathrm{I})$, leading to the pseudo trigonal-bipyramidal coordination geometry discussed above for the $72 \mathrm{~L}_{2}$ compounds. When exposing solid 73a to acetone or acetophenone vapor it changes color from green to yellow, whereas 73b changes from white to red with acetone and from white to orange with acetophenone. In order to understand this vapochromic behavior it is important to know that the reaction of $\mathbf{7 3 a}$ or $\mathbf{7 3 b}$ with 2 (or more) equivalents of acetone in THF solution yields compounds 74a and 74b which are ketimines formed through reaction of the ethylenediamine ligand and acetone. The vapochromism of solids of 73a and $\mathbf{7 3 b}$ is most likely due to the same reaction because IR spectroscopy provides clear evidence for the disappearance of the amine N$\mathrm{H}$ stretch in the course of VOC exposure with the simultaneous appearance of imine $\mathrm{C}=\mathrm{N}$ stretches near $1650 \mathrm{~cm}^{-1}$. Solid $\mathbf{7 3 a} / \mathbf{7 4 a}$ and $\mathbf{7 3 b} / \mathbf{7 4 b}$ are brightly luminescent in different colors hence the compounds can also be used as vapoluminescent sensors. The absorption and emission color changes following ketimide formation have been attributed to perturbation of excitonic states along $\mathrm{Tl}(\mathrm{I})-\mathrm{Au}(\mathrm{I})$ chains caused by changes in the $\mathrm{Tl}(\mathrm{I})$ coordination environment.

\subsection{Gold-silver complexes}

Bimetallic gold-silver compounds of the general formula $\left[\mathrm{Au}_{2} \mathrm{Ag}_{2}\left(\mathrm{C}_{6} \mathrm{~F}_{5}\right)_{4} \mathrm{~L}_{2}\right]_{\mathrm{n}}\left(75 \mathrm{~L}_{2}\right)$ with a variety of different donor ligands L exhibit vapochromic behavior. ${ }^{12,157}$ Structural studies of the systems with $\mathrm{L}=\mathrm{Et}_{2} \mathrm{O}\left(\mathbf{7 5}\left(\mathrm{Et}_{2} \mathrm{O}\right)_{2}\right), \mathrm{Me}_{2} \mathrm{CO}\left(\mathbf{7 5}\left(\mathrm{Me}_{2} \mathrm{CO}\right)_{2}\right)$, THF $\left(\mathbf{7 5}(\mathrm{THF})_{2}\right)$, and $\mathrm{CH}_{3} \mathrm{CN}$ $\left.\left(\mathbf{7 5}\left(\mathrm{CH}_{3} \mathrm{CN}\right)_{2}\right)\right)$ reveal that this class of compounds contains tetranuclear $\mathrm{Au}_{2} \mathrm{Ag}_{2}$ units linked to 
each other along the crystallographic $\mathrm{z}$ axis through unsupported $\mathrm{Au}(\mathrm{I})-\mathrm{Au}(\mathrm{I})$ interactions at distances between 3.1674(11) $\AA$ and 3.1959(3) $\AA$, resulting in extended linear-chain compounds (Figure 39). ${ }^{158}$

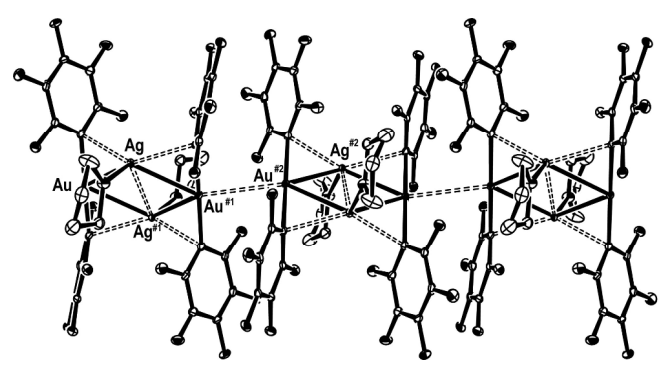

Figure 39. Extract of the crystal structure of compound $\left.75(\mathrm{THF})_{2}\right)$. Reprinted with permission from ref. ${ }^{158}$. Copyright 2008 American Chemical Society.

Compound $75\left(\mathrm{Et}_{2} \mathrm{O}\right)_{2}$ is obtained by reacting equimolar quantities of $\left[\mathrm{Bu}_{4} \mathrm{~N}\right]\left[\mathrm{Au}\left(\mathrm{C}_{6} \mathrm{~F}_{5}\right)_{2}\right]$ and $\mathrm{AgClO}_{4}$ in a $\mathrm{CH}_{2} \mathrm{Cl}_{2} / \mathrm{Et}_{2} \mathrm{O}$ solvent mixture and can be used as a starting material for the syntheses of the other $75 \mathrm{~L}_{2}$ compounds. ${ }^{159,160}$ Moreover, exposure of solid $\mathbf{7 5}\left(\mathrm{Et}_{2} \mathrm{O}\right)_{2}$ to vapors of acetone, THF or acetonitrile produces rapid color changes that are consistent with replacement of $\mathrm{Et}_{2} \mathrm{O}$ by the respective other VOCs (Figure 40).

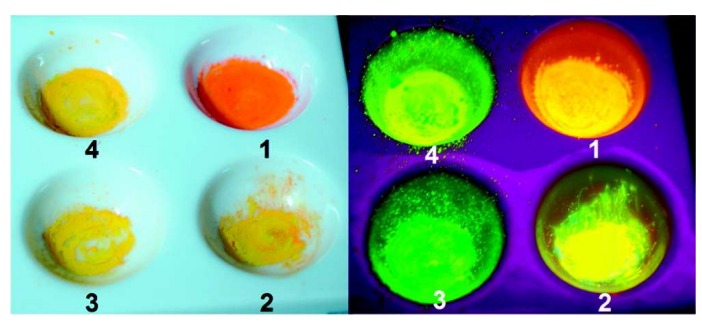


Figure 40. Left: Samples of compound $75\left(\mathrm{Et}_{2} \mathrm{O}\right)_{2}$ before (1) and after exposure to vapors of acetone (2), THF (3), $\mathrm{CH}_{3} \mathrm{CN}$ (4). Right: Reprinted with permission from ref. ${ }^{158}$. Copyright 2008 American Chemical Society.

IR spectroscopy provides clear evidence for the substitution of the initial O-donor by the stronger N-donor ligand. The exchange ability of the individual VOCs follows the order $\mathrm{CH}_{3} \mathrm{CN}$ $>\mathrm{Me}_{2} \mathrm{CO}>\mathrm{THF}>\mathrm{Et}_{2} \mathrm{O}$, i. e., acetonitrile is able to replace all oxygen donor ligands but not vice versa. This observation suggests that true ligand substitution reactions take place at the $\mathrm{Au}_{2} \mathrm{Ag}_{2}$ core and that the vapochromic behavior of this class of compounds is not simply due to adsorption of the VOCs into the crystal lattice. Thermogravimetric analyses of the $75 \mathrm{~L}_{2}$ compounds reveal significant differences between the temperatures at which the donor ligands (L) are lost, and these variations were interpreted in terms of different boiling points of the individual VOCs and the strengths of their interactions with the $\mathrm{Ag}(\mathrm{I})$ centers. ${ }^{158}$ The $75 \mathrm{~L}_{2}$ compounds are emissive at room temperature and $77 \mathrm{~K}$, presumably involving electronic transitions on the $\mathrm{Au}_{2} \mathrm{Ag}_{2}$ core which may be perturbed by changes in the $\mathrm{Au}(\mathrm{I})-\mathrm{Au}(\mathrm{I})$ and $\mathrm{Au}(\mathrm{I})$ $\operatorname{Ag}(\mathrm{I})$ interactions.

Scheme 33. Vapochromic $\mathrm{Au}_{2} \mathrm{Ag}_{2}$ compounds. $\mathrm{R}=\mathrm{C}_{6} \mathrm{~F}_{5}$. 


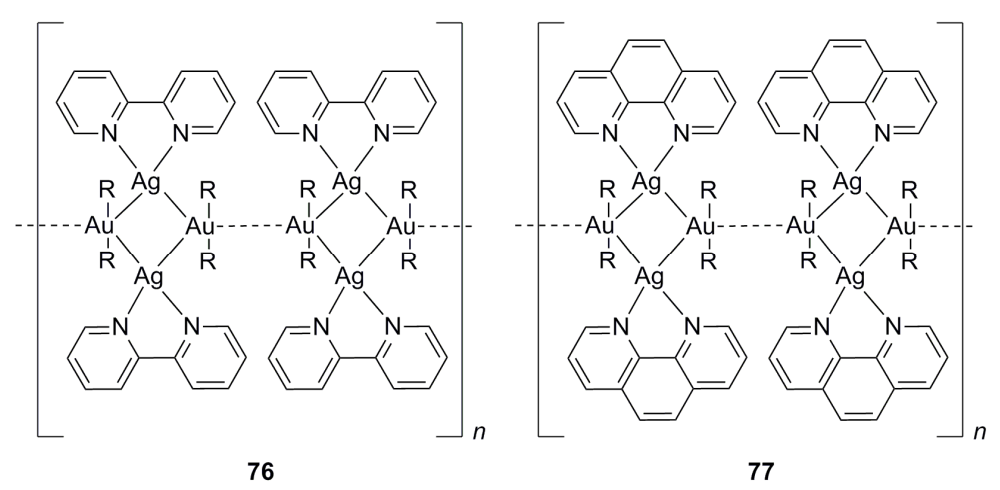

Several compounds of the stoichiometry $\left[\mathrm{Au}_{2} \mathrm{Ag}_{2}\left(\mathrm{C}_{6} \mathrm{~F}_{5}\right)_{4} \mathrm{~L}_{2}\right]_{\mathrm{n}}$ have been the subject of more application-oriented studies in which these vapochromic materials were deposited on optical fibers. ${ }^{161-163}$ VOC-induced changes in reflected optical power on the order of $2.5 \mathrm{~dB}-4 \mathrm{~dB}$ were detected. ${ }^{161-163}$ In one set of experiments it was possible to distinguish isopropanol from ethanol and methanol, but discrimination between the two shorter alcohols proved more difficult. ${ }^{12}$ In several of these vapochromic sensor materials the donor ligand $\mathrm{L}$ was a bidentate 2,2'-bipyridine (bpy) or 1,10-phenanthroline (phen) ligand, i. e., these materials can be formulated as $\left[\mathrm{Au}_{2} \mathrm{Ag}_{2}\left(\mathrm{C}_{6} \mathrm{~F}_{5}\right)_{4}(\mathrm{bpy})_{2}\right]_{\mathrm{n}}(\mathbf{7 6})$ and $\left[\mathrm{Au}_{2} \mathrm{Ag}_{2}\left(\mathrm{C}_{6} \mathrm{~F}_{5}\right)_{4}(\mathrm{phen})_{2}\right]_{\mathrm{n}}$ (77) (Scheme 33). ${ }^{12,} 162$ Prior to VOC exposure many of these materials are bright yellow but then turn colorless upon sorption of different donor solvents. The loss of color has been attributed to the rupture of intermolecular $\mathrm{Au}(\mathrm{I})-\mathrm{Au}(\mathrm{I})$ contacts between individual $\mathrm{Au}_{2} \mathrm{Ag}_{2}$ metallacycles. ${ }^{157,}$, 159, 162

The reaction between $\left[\mathrm{Bu}_{4} \mathrm{~N}\right]\left[\mathrm{Au}\left(4-\mathrm{C}_{6} \mathrm{~F}_{4} \mathrm{I}\right)_{2}\right]$ and $\mathrm{AgClO}_{4}$ affords a creme-colored solid which can be identified as $\left[\mathrm{Au}_{2} \mathrm{Ag}_{2}\left(4-\mathrm{C}_{6} \mathrm{~F}_{4} \mathrm{I}\right)_{4}\right]_{\mathrm{n}}(\mathbf{7 8}) .{ }^{164}$ Utilization of the $4-\mathrm{C}_{6} \mathrm{~F}_{4} \mathrm{I}$ group instead of $\mathrm{C}_{6} \mathrm{~F}_{5}$ was motivated by the possibility that the $p$-iodo-substituent might form noncovalent halogenbonds to Lewis donor atoms. ${ }^{165}$ Compound 78 is vapochromic toward $\mathrm{Me}_{2} \mathrm{CO}$, THF, or $\mathrm{CH}_{3} \mathrm{CN}$, but no response is detected for non-coordinating solvents such as diethyl ether or toluene. Solvates of compound 78 with the general formula $\left[\mathrm{Au}_{2} \mathrm{Ag}_{2}\left(4-\mathrm{C}_{6} \mathrm{~F}_{4} \mathrm{I}_{4} \mathrm{~L}_{2}\right]_{\mathrm{n}} \times \mathrm{xL}\left(\mathbf{7 8} \mathrm{L}_{2} \cdot \mathrm{xL}\right)\right.$ are 
readily obtained when reacting $\left[\mathrm{Au}_{2} \mathrm{Ag}_{2}\left(4-\mathrm{C}_{6} \mathrm{~F}_{4} \mathrm{I}\right)_{4}\right]_{\mathrm{n}}$ in $\mathrm{Me}_{2} \mathrm{CO}$, THF, or $\mathrm{CH}_{3} \mathrm{CN}$. The respective substances are brightly colored and contain the desired halogen bonds with I-O, I-F, and I-N distances in the range from $2.837(23)$ to $3.494(15) \AA .^{164}$ The acetone solvate $\left.\left(78\left(\mathrm{Me}_{2} \mathrm{CO}\right)_{2} \cdot 2 \mathrm{Me}_{2} \mathrm{CO}\right)\right)$ and the THF solvate $\left.\left(\mathbf{7 8}(\mathrm{THF})_{2}\right)\right)$ can both be converted to the acetonitrile solvate $\left.\left(\mathbf{7 8}\left(\mathrm{CH}_{3} \mathrm{CN}\right)_{2}\right)\right)$ by exposure to vapors of $\mathrm{CH}_{3} \mathrm{CN}$, manifesting in an emission color change from red to bright yellow. Combined structural and emission studies (the latter in fluid solution) lead to the conclusion that two factors drive the vapoluminescence response: (i) the degree of aggregation of individual $\mathrm{Au}_{2} \mathrm{Ag}_{2}$ clusters into polymeric chains, and (ii) the geometry of the $\mathrm{Au}_{2} \mathrm{Ag}_{2}$ clusters itself. ${ }^{164}$ The aggregation of individual clusters results from an interplay between aurophilic interactions (with $\mathrm{Au}(\mathrm{I})-\mathrm{Au}(\mathrm{I})$ distances in the range from 2.7853(14) to $2.9481(3) \AA$ ) and noncovalent halogen bonds. TD-DFT calculations indicate that in the acetone solvate the HOMO is mostly spread over the 4- $\mathrm{C}_{6} \mathrm{~F}_{4} \mathrm{I}$ ligands with a some contribution of $5 \mathrm{~d}_{\mathrm{z} 2} \sigma^{*}$ character from interacting $\mathrm{Au}(\mathrm{I})-\mathrm{Au}(\mathrm{I})$ centers. The LUMO is a mixture of $5 p \sigma$ bonding density between the $\mathrm{Au}(\mathrm{I})$ and $\mathrm{Ag}(\mathrm{I})$ centers.

Analogous tetranuclear $\mathrm{Au}_{2} \mathrm{Ag}_{2}$ compounds with vapochromic properties can be obtained when using 3,5- $\mathrm{C}_{6} \mathrm{Cl}_{2} \mathrm{~F}_{3}$ or $\mathrm{C}_{6} \mathrm{Cl}_{5}$ groups as ligands to the gold atoms. ${ }^{166}$ From $\mathrm{Et}_{2} \mathrm{O} / \mathrm{CH}_{2} \mathrm{Cl}_{2}$ solution one obtains compounds with the formulas $\left[\mathrm{Au}_{2} \mathrm{Ag}_{2}\left(3,5-\mathrm{C}_{6} \mathrm{Cl}_{2} \mathrm{~F}_{3}\right)_{4}\left(\mathrm{Et}_{2} \mathrm{O}\right)_{2}\right]_{\mathrm{n}}\left(\mathbf{7 9}\left(\mathrm{Et}_{2} \mathrm{O}\right)_{2}\right)$ and $\left[\mathrm{Au}_{2} \mathrm{Ag}_{2}\left(\mathrm{C}_{6} \mathrm{Cl}_{5}\right)_{4}\left(\mathrm{Et}_{2} \mathrm{O}\right)_{2}\right]_{\mathrm{n}}\left(\mathbf{8 0}\left(\mathrm{Et}_{2} \mathrm{O}\right)_{2}\right) .{ }^{166}$ Upon exposure to the respective VOCs the diethyl ether molecules in $\mathbf{7 9}\left(\mathrm{Et}_{2} \mathrm{O}\right)_{2}$ and $\mathbf{8 0}\left(\mathrm{Et}_{2} \mathrm{O}\right)_{2}$ can be replaced with THF, acetone or acetonitrile, manifesting itself in a vapochromic response. X-ray crystal structure analyses of $\left[\operatorname{Au}_{2} \operatorname{Ag}_{2}(3,5-\right.$ $\left.\left.\mathrm{C}_{6} \mathrm{Cl}_{2} \mathrm{~F}_{3}\right)_{4}(\mathrm{THF})_{2}\right]_{\mathrm{n}}$ and $\left[\mathrm{Au}_{2} \mathrm{Ag}_{2}\left(3,5-\mathrm{C}_{6} \mathrm{Cl}_{2} \mathrm{~F}_{3}\right)_{4}(\text { toluene })_{2}\right]_{\mathrm{n}}$ demonstrate that there are polymeric chains of $\mathrm{Au}_{2} \mathrm{Ag}_{2}$ units held together via aurophilic interactions. The intermolecular $\mathrm{Au}(\mathrm{I})-\mathrm{Au}(\mathrm{I})$ distances are $2.8617(7)$ and $2.8863(7) \AA$ in $79(\mathrm{THF})_{2}$ which is appreciably shorter than in the 
related pentafluorophenyl derivative with THF $\left(\mathbf{7 5}(\mathrm{THF})_{2}\right)(3.1959(3) \AA)$. However, the compounds with the $3,5-\mathrm{C}_{6} \mathrm{Cl}_{2} \mathrm{~F}_{3}$ ligand were found to exhibit a relatively poor thermal stability when compared to the pentachlorophenyl derivatives. Contrary to the behavior of compound $\mathbf{7 5}$ which has a strong preference for acetonitrile over $\mathrm{Et}_{2} \mathrm{O}, \mathrm{THF}$, or acetone (see above), ${ }^{158}$ in the $\left[\mathrm{Au}_{2} \mathrm{Ag}_{2}\left(3,5-\mathrm{C}_{6} \mathrm{Cl}_{2} \mathrm{~F}_{3}\right)_{4}\left(\mathrm{CH}_{3} \mathrm{CN}\right)_{2}\right]_{\mathrm{n}}$ material acetonitrile is displaced by vapors of $\mathrm{THF}$ or acetone. $^{166}$ Similarly, the THF molecules of $79(\mathrm{THF})_{2}$ can be displaced by acetone from the gaseous phase, but exposure to vapors of acetonitrile leads only to solvate mixtures and incomplete THF substitution.

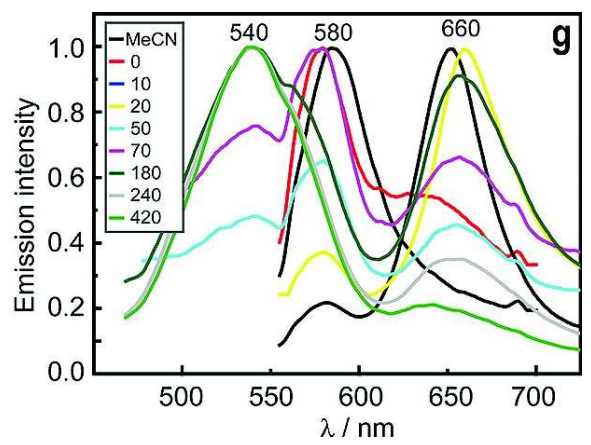

Figure 41. Luminescence changes of compound 81 observed in the course of solvation with fluid $\mathrm{CH}_{3} \mathrm{CN}$. The inset marks the reaction time in minutes. Reprinted with permission from ref. ${ }^{167}$. Copyright 2011 American Chemical Society.

When using $2-\mathrm{C}_{6} \mathrm{~F}_{4} \mathrm{I}$ instead of $4-\mathrm{C}_{6} \mathrm{~F}_{4} \mathrm{I}$ as a ligand to gold(I), the iodine-atom can ligate to $\operatorname{Ag}(\mathrm{I})$, thereby mitigating the propensity for polymerization of this class of materials. ${ }^{167}$ Accordingly, reaction of $\mathrm{Ag}(\mathrm{tfa})$ (tfa $=$ trifluoroacetate) with an equimolar amount of $\mathrm{NBu}_{4}\left[\mathrm{Au}\left(2-\mathrm{C}_{6} \mathrm{~F}_{4} \mathrm{I}\right)_{2}\right]$ in $\mathrm{CH}_{2} \mathrm{Cl}_{2}$ affords $\left(\mathrm{NBu}_{4}\right)_{2}\left[\mathrm{Au}_{2} \mathrm{Ag}_{2}\left(2-\mathrm{C}_{6} \mathrm{~F}_{4} \mathrm{I}\right)_{4}\right](\mathrm{tfa})_{2}(\mathbf{8 1})$ which is comprised of tetranuclear monomers with $\mathrm{Au}(\mathrm{I})-\mathrm{Ag}(\mathrm{I})$ distances in the range from 2.7738(7) to 2.9269(7) $\AA$. 
Both 2- $\mathrm{C}_{6} \mathrm{~F}_{4} \mathrm{I}$ ligands of $\mathrm{Au}(\mathrm{I})$ coordinate to $\mathrm{Ag}(\mathrm{I})$ with Ag-I distances of 2.7987(9) - 2.9011(9) Å. Solvation of green emitting $\mathbf{8 1}$ with fluid $\mathrm{CH}_{3} \mathrm{CN}$ leads to the rapid formation of a yellow glowing intermediate (Figure 41), and finally a red luminescent polymeric compound of stoichiometry $\left[\mathrm{Au}_{2} \mathrm{Ag}_{2}\left(2-\mathrm{C}_{6} \mathrm{~F}_{4} \mathrm{I}\right)_{4}\left(\mathrm{CH}_{3} \mathrm{CN}\right)_{2}\right]_{\mathrm{n}}$ is obtained. The yellow intermediate is believed to be a material of stoichiometry $\left[\mathrm{Au}_{2} \mathrm{Ag}_{2}\left(2-\mathrm{C}_{6} \mathrm{~F}_{4} \mathrm{I}\right)_{4}\right]_{2}(\mathbf{8 2})$ composed of dimers of tetranuclear $\mathrm{Au}_{2} \mathrm{Ag}_{2}$ clusters. The dimer compound $\mathbf{8 2}$ can be obtained from reaction of $\mathrm{NBu}_{4}\left[\mathrm{Au}\left(2-\mathrm{C}_{6} \mathrm{~F}_{4} \mathrm{I}\right)_{2}\right]$ with $\mathrm{AgClO}_{4}$ and is selectively vapochromic toward coordinating solvents such as $\mathrm{CH}_{3} \mathrm{CN}$, THF, and acetone. The fact that the $\mathrm{Ag}(\mathrm{I})$ ions in $\mathbf{8 2}$ are coordinatively unsaturated seems to be key to the vapochromic behavior.

\subsection{Other $\mathrm{Au}(\mathrm{I})$ complexes}

Scheme 34. Solvoluminescent gold(I) complexes.

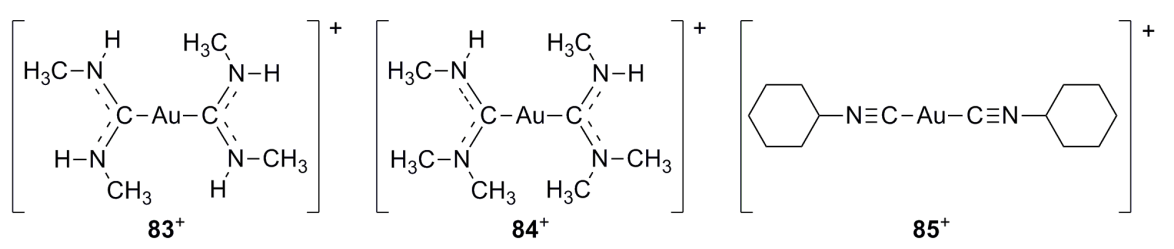

Three carbene complexes of gold(I) $\left(\mathbf{8 3 P F}_{6}, \mathbf{8 3 B F}_{4}, 84 \mathrm{PF}_{6}\right)\left(\mathrm{Scheme}_{34}\right)$ are frequently cited in the context of vapochromism even though they show the phenomenon of solvoluminescence rather than true vapochromism or vapoluminescence. ${ }^{168}$ The $77 \mathrm{~K}$ emission of $\mathbf{8 3 P F}_{6}$ is green in acetonitrile, blue in DMSO and pyridine, and orange in acetone (Figure 42). 
Detailed structural and spectroscopic studies lead to the conclusion that the emission changes induced by concentration and temperature variation are due to the formation of aggregates (dimers, trimers, and higher oligomers) of emissive gold(I) complexes. Thus it appears that aurophilic attractions can overcome the Coulomb repulsion between individual cationic complexes. This can lead to the formation of a band of orbitals made from overlapping (filled) $5 \mathrm{~d}_{\mathrm{z} 2}$ orbitals of interacting $\mathrm{Au}(\mathrm{I})$ centers and a corresponding unoccupied band made from $6 \mathrm{p}_{\mathrm{z}}$ orbitals of gold. The X-ray crystal structure of $\mathbf{8 3 P F}_{6} \cdot 0.5\left(\mathrm{Me}_{2} \mathrm{CO}\right)$ features extended columns of cations with an $\mathrm{Au}(\mathrm{I})-\mathrm{Au}(\mathrm{I})$ separation of only 3.1882(1) $\AA$. Hydrogen-bonding interactions between the emissive cations and the anions could potentially play an important role for the emission properties, at least this would explain the observable differences between $\mathbf{8 3 P F}_{6}$ and $\mathbf{8 3 B F}_{4}$. The observation of a hydrogen-bonding network in the abovementioned crystal structure supports this interpretation.

The $\left[(\text { cyclohexyl-isocyanide })_{2} \mathrm{Au}\right]\left(\mathrm{PF}_{6}\right)$ compound $\left(\mathbf{8 5} \mathrm{PF}_{6}\right)$ exhibits similarly spectacular solvoluminescence behavior as the carbene compounds $83 \mathrm{PF}_{6}, 83 \mathrm{BF}_{4}$, and $\mathbf{8 4 P F}_{6}{ }^{150}$ A colorless 
polymorph of the isocyanide compound $\mathrm{86PF}_{6}$ exhibits linear chains with regular $\mathrm{Au}(\mathrm{I})-\mathrm{Au}(\mathrm{I})$ distances of 3.1822(3) $\AA$, whereas the structure of a yellow polymorph is more complicated with 4 independent $\mathrm{Au}(\mathrm{I})-\mathrm{Au}(\mathrm{I})$ contacts ranging from 2.9643(6) to 2.9803(6) $\AA$. Such distances are clearly on the short end of known aurophilic interactions. ${ }^{28}$

Scheme 35. A vapochromic $\mathrm{Cu}(\mathrm{I})-\mathrm{Au}(\mathrm{I})-\mathrm{Cu}(\mathrm{I})$ complex $\left(\mathbf{8 6}^{3+}\right)$ and its reaction product $\left(\mathbf{8 7}^{3+}\right)$ after exposure to $\mathrm{MeOH}$ vapor.

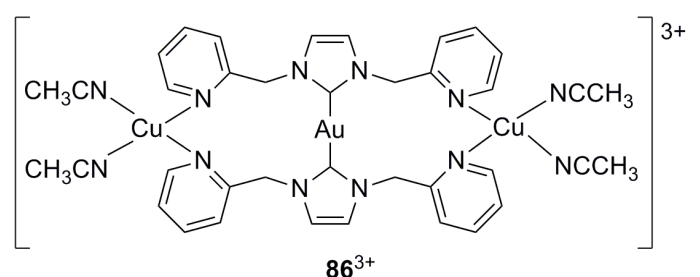

$86^{3+}$

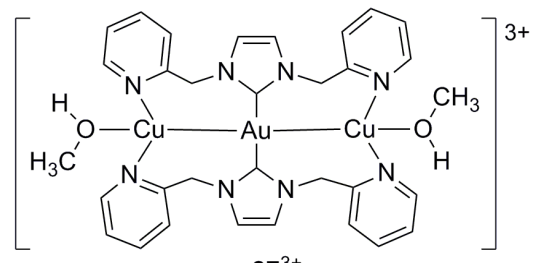

$87^{3+}$

The heterotrinuclear $\mathrm{Cu}(\mathrm{I})-\mathrm{Au}(\mathrm{I})-\mathrm{Cu}(\mathrm{I})$ complex $\mathbf{8 6}^{3+}$ (Scheme 35) is one out of comparatively few vapochromic substances in which the VOC-induced color change is a direct consequence of a ligand exchange reaction. ${ }^{169}$ This complex formed by addition of $\left[\mathrm{Cu}\left(\mathrm{CH}_{3} \mathrm{CN}\right)_{4}\right]\left(\mathrm{PF}_{6}\right)$ to an acetonitrile solution of the gold(I) imidazole (im) complex $\left[\mathrm{Au}\left(\mathrm{im}\left(\mathrm{CH}_{2}-\mathrm{py}\right)_{2}\right)_{2}\right]\left(\mathrm{PF}_{6}\right)$ which has pendant pyridine (py) units that can bind to copper(I). The intermetallic distances are long $(\sim 4.6$ $\AA$ ) and presumably repulsive. Single crystals of $\mathbf{8 6}\left(\mathrm{PF}_{6}\right)_{3}$ grown from acetonitrile solution contain two lattice $\mathrm{CH}_{3} \mathrm{CN}$ molecules which are lost upon evacuation or prolonged exposure to air, resulting in solvent-free and blue photoluminescent $\mathbf{8 6}\left(\mathrm{PF}_{6}\right)_{3}$. Subsequent exposure of dry 86 $\left(\mathrm{PF}_{6}\right)_{3}$ to methanol, $\mathrm{H}_{2} \mathrm{O}$, or acetone causes a change in luminescence color from blue to green (Figure 43). THF and $\mathrm{CH}_{2} \mathrm{Cl}_{2}$ do not induce any change in emission behavior. Crystallization of the trinuclear complex from $\mathrm{MeOH} / \mathrm{Et}_{2} \mathrm{O}$ mixture directly yields the green emitting compound, which has been identified as $\mathbf{8 7}\left(\mathrm{PF}_{6}\right)_{3}$. X-ray diffraction on single crystals of $\mathbf{8 7}\left(\mathrm{PF}_{6}\right)_{3}$ reveals the 
presence of short $(2.7915(7) \AA) \mathrm{Au}(\mathrm{I})-\mathrm{Cu}(\mathrm{I})$ distances. This attractive interaction between individual metals is likely the consequence of the replacement of two $\mathrm{CH}_{3} \mathrm{CN}$ molecules per $\mathrm{Cu}(\mathrm{I})$ center by only one methanol ligand, making one coordination site of the tetrahedral copper(I) centers available for metal-metal bonding. Compound $\mathbf{8 7}\left(\mathrm{PF}_{6}\right)_{3}$ can be converted to 86( $\left(\mathrm{PF}_{6}\right)_{3}$ by exposure to $\mathrm{CH}_{3} \mathrm{CN}$ vapor, i. e., the vapoluminescence is reversible.

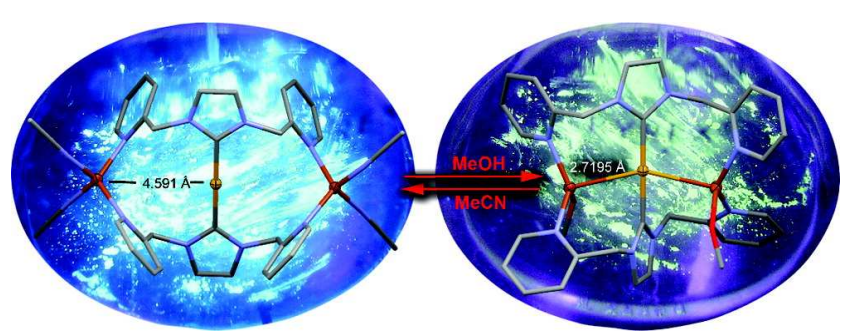

Figure 43. Crystal structures and emission colors of complexes $\mathbf{8 6}^{3+}$ and $\mathbf{8 7 ^ { 3 + }}$. Reprinted with permission from ref. ${ }^{169}$. Copyright 2010 American Chemical Society.

Scheme 36. A cationic gold(I) complex whose vapochromic properties strongly depend on the counter-anion.<smiles>c1ccc(P(c2ccccc2)c2ccccc2P(c2ccccc2)(c2ccccc2)(c2ccccc2)c2ccccc2)cc1</smiles>

$88^{+}$

The tetrahedral gold(I) complex $\left[\mathrm{Au}(\mathrm{dppb})_{2}\right]^{+}\left(\mathbf{8 8}^{+}\right)$(Scheme 36) with two bidentate dppb $(\mathrm{dppb}=1,2$-bis-(diphenylphosphino)benzene $)$ ligands was isolated with seven different anions. ${ }^{170}$ Small anions such as $\mathrm{NO}_{3}^{-}, \mathrm{Cl}^{-}$or $\mathrm{BF}_{4}^{-}$permit symmetrical coordination of the two 
dppb ligands to the $\mathrm{Au}(\mathrm{I})$ center in the crystal lattice, resulting in blue phosphorescence for $\mathbf{8 8} \mathrm{NO}_{3}$ (Figure 44), $\mathbf{8 8 C l}$, and $\mathbf{8 8 B F}_{4}$. Larger cations (e. g., $\mathrm{PF}_{6}$ or $\mathrm{B}\left(4-\mathrm{C}_{6} \mathrm{H}_{4} \mathrm{~F}\right)_{4}{ }^{-}$) enforce small conformational changes of the dppb ligands in the solid state, resulting in yellow-orange phosphorescence for $\mathbf{8 8 P F}_{6}$ and $\mathbf{8 8} \mathrm{B}\left(4-\mathrm{C}_{6} \mathrm{H}_{4} \mathrm{~F}\right)_{4}$. The nitrate salt is a vapoluminescent substance (Figure 44). ${ }^{170}$ Solid $\mathbf{8 8} \mathrm{NO}_{3}$ emits blue light, and the luminescence spectrum is similar to that of free $\mathrm{dppb}$, indicative of ligand-localized phosphorescence $(\tau=3.3 \mu \mathrm{s})$. Exposure of microcrystalline $\mathbf{8 8} \mathrm{NO}_{3}$ to vapors of ethanol and methanol leads to a rapid change in emission color from blue to orange-yellow (Figure 44), but longer alcohols trigger no response. The respective solvent adducts $\left(\mathbf{8 8 N O} \mathrm{NO}_{3} \cdot 2 \mathrm{EtOH}\right.$ and $\left.\mathbf{8 8} \mathrm{NO}_{3} \cdot 3 \mathrm{MeOH}\right)$ were characterized by single crystal X-ray diffraction and were found to contain structurally distorted $\left[\mathrm{Au}(\mathrm{dppb})_{2}\right]^{+}$units similar to what has been noted above for larger anions. When heating the solvent adducts to 100 ${ }^{\circ} \mathrm{C}$ for $\sim 20$ minutes, blue-emitting neat $\mathbf{8 8} \mathrm{NO}_{3}$ is restored.

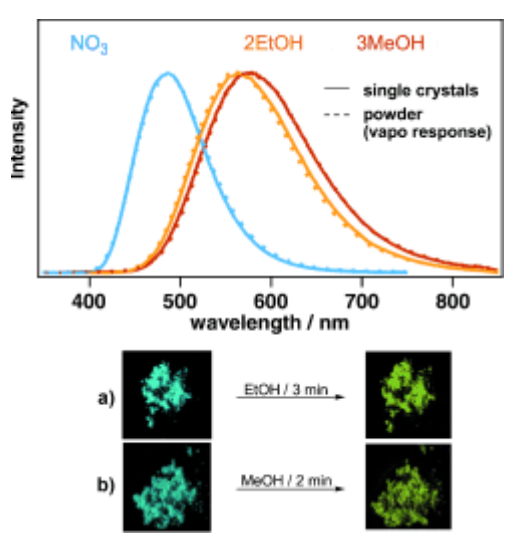

Figure 44. Vapochromic response of $\mathbf{8 8} \mathrm{NO}_{3}$ to ethanol and methanol. (M. Osawa, I. Kawata, S. Igawa, M. Hoshino, T. Fukunaga, D. Hashizume: Vapochromic and Mechanochromic Tetrahedral Gold(I) Complexes Based on the 1,2-Bis(diphenylposphino)benzene Ligand. Chem. 
Eur. J., 2010, 16, 12114-12126. Copyright Wiley-VCH Verlag GmbH \& Co. KGaA. Reproduced with permission.)

The tetrafluoroborate salt of $\mathbf{8 8}^{+}$exhibits mechanochromism. ${ }^{170}$ Upon extensive grinding the emission color eventually changes from blue to yellow-orange, suggesting that a conformational change of the $\left[\mathrm{Au}(\mathrm{dppb})_{2}\right]^{+}$complex can be induced mechanically. Ground $\mathbf{8 8 B F}_{4}$ is vapoluminescent and exhibits the reverse emission color change following exposure to vapors of acetone, acetonitrile, $\mathrm{CH}_{2} \mathrm{Cl}_{2}$, diethyl ether, and THF.

A referee of this review article speculated that the cations in some of the emissive salts formed with $\mathbf{8 8}^{+}$have gold(I) only in a three-coordinate state, because luminescence is a common phenomenon for three-coordinate $\mathrm{Au}(\mathrm{I})$ but almost unknown for four-coordinate $\mathrm{Au}(\mathrm{I})$. Potentially, a hydrogen bond from an alcohol to an anion or to a phosphorus atom can give rise to structural changes, and mechanical stress might cause a flattening of the cations from a quasitetrahedral structure.

\section{Compounds with metals other than platinum or gold}

Most of the platinum compounds and many of the gold materials from the previous two sections are type I vapochromic systems according to the definition used in section 1.3 , i. e., changes in weak intermolecular interactions (e. g., metal-metal interactions, $\pi$-stacking, hydrogen-bonding, or C-H- $\pi$ interactions) as a result of analyte uptake trigger the vapochromic response. This common theme and the large number of platinum and gold based vapochromic 
substances compared to other VOC-sensitive materials provided the rationale for grouping them into two separate sections.

Section 4 contains many $3 \mathrm{~d}$ metal complexes which are inherently more labile than complexes of $4 \mathrm{~d}$ or $5 \mathrm{~d}$ elements. As a consequence type II vapochromic behavior, defined in section 1.3 as the vapochromism or vapoluminescence response triggered by analyte-induced changes in the first coordination sphere of the metal, is a unifying theme for many of the VOC-sensitive materials in this section. Specifically, this encompasses roughly 20 compounds which are treated in subsection 4.1, sorted along the metal component from vanadium to cobalt, nickel, copper, and tin; an additional short chapter on metalloporphyrins with various metal centers concludes this subsection on type II vapochromic materials containing metals other than Pt or Au. In the majority of the compounds presented in section 4.1, vapochromism is a direct consequence of changes in the ligand field around the metal leading to significant changes in the $\mathrm{d}-\mathrm{d}$ and/or MLCT absorptions.

Subsection 4.2 contains about 15 coordination compounds in which the vapochromism is the result of changes in weak intermolecular interactions. As a matter of fact, the origin of the vapochromism in these 15 type I materials is quite diverse, and the identification of common themes for the different classes of materials presented in this subsection is rather difficult; an attempt to do so has resulted in the division of subsection 4.2 into 5 individual chapters.

4.1 Vapochromism as a result of analyte-induced changes in the first coordination sphere of the metal

4.1.1 A vanadium complex 
Scheme 37. A vapochromic oxovanadium(IV) complex.

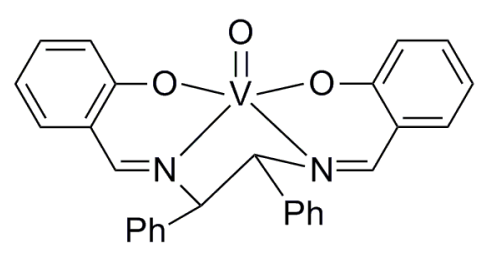

89

The oxovanadium(IV) complex 89 (Scheme 37 ) is the only vapochromic vanadium complex known to date. ${ }^{171}$ Green crystals are obtained from chloroform solution $\left(\mathbf{8 9} \cdot \mathrm{CHCl}_{3}\right)$ whereas recrystallization from acetonitrile affords orange crystals $\left(\mathbf{8 9} \cdot \mathrm{CH}_{3} \mathrm{CN}\right)$. The two forms can be converted into one another and contain either monomeric complexes or polymeric chains thereof. ${ }^{172-174}$ In the monomeric green form, the vanadium(IV) center is in square-pyramidal coordination with the $\mathrm{V}=\mathrm{O}$ group in apical position, in the orange form the vanadyl oxygen atom of one complex ligates to the sixth coordination site of the neighboring vanadium center, resulting in an infinite $-\mathrm{V}=\mathrm{O}-\mathrm{V}=\mathrm{O}$ - chain. The polymeric acetonitrile adduct $\left(\mathbf{8 9} \cdot \mathrm{CH}_{3} \mathrm{CN}\right)$ contains two independent molecules per unit cell with $\mathrm{V}=\mathrm{O}$ bond distances of $1.625(5)$ and 1.636(5) $\AA$, the distances between the vanadium center and the oxygen atom of a neighboring vanadyl group are $2.188(5)$ and $2.196(5) \AA$. When exposing orange crystals of $89 \cdot \mathrm{CH}_{3} \mathrm{CN}$ to chloroform vapor they turn green (Figure 45). Conversely, green crystals of $\mathbf{8 9} \cdot \mathrm{CHCl}_{3}$ change color to orange when exposed to acetonitrile vapor. Due to changes in $\mathrm{V}=\mathrm{O}$ stretching frequencies the interconversion between the two forms can also be detected by IR spectroscopy. Another interesting observation is the occurrence of mechanochromism in the orange form: Grinding of $\mathbf{8 9} \cdot \mathrm{CH}_{3} \mathrm{CN}$ affords a green powder, and subsequent addition of a small volume of 
$\mathrm{CH}_{3} \mathrm{CN}$ regenerates the initial orange material. Thermochromism is observed for the green form as it turns orange when heated to $120^{\circ} \mathrm{C}$ for a few minutes. ${ }^{171}$
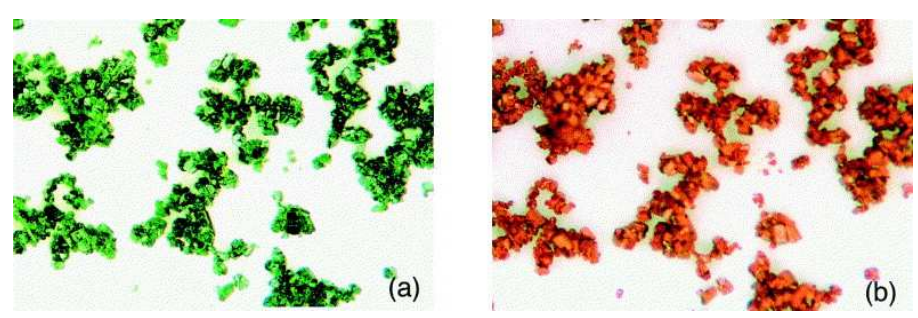

Figure 45. Vapochromism of compound 89 observed following exposure to $\mathrm{CH}_{3} \mathrm{CN}$ (green to orange) or $\mathrm{CHCl}_{3}$ (orange to green). Reprinted with permission from ref. ${ }^{171}$. Copyright 2003 Elsevier.

\subsubsection{Cobalt complexes}

Cobalt(II) complexes are known to undergo relatively facile inter-conversion between octahedral and tetrahedral coordination geometries accompanied by drastic color changes. ${ }^{175}$ This property forms the basis of the vapochromic behavior of a few compounds in which octahedral clusters of $\left[\operatorname{Re}_{6} \mathrm{~S}_{8}(\mathrm{CN})_{6}\right]^{4-}$ or $\left[\mathrm{Re}_{6} \mathrm{Se}_{8}(\mathrm{CN})_{6}\right]^{4-}$ connect partially hydrated $\mathrm{Co}(\mathrm{II})$ complexes in extended solid frameworks with porous structures. ${ }^{176}$ The crystal structure of $\left[\mathrm{Co}_{2}\left(\mathrm{H}_{2} \mathrm{O}\right)_{4}\right]\left[\mathrm{Re}_{6} \mathrm{~S}_{8}(\mathrm{CN})_{6}\right] \cdot 12 \mathrm{H}_{2} \mathrm{O}\left(\mathbf{9 0} \cdot 12 \mathrm{H}_{2} \mathrm{O}\right)$ exhibits a three-dimensional network comprised of $\left[\mathrm{Re}_{6} \mathrm{~S}_{8}\right]^{2+}$ and $\left[\mathrm{Co}_{2}\left(\mu-\mathrm{OH}_{2}\right)_{2}\right]^{4+}$ cations linked by cyanides (Figure 46). 


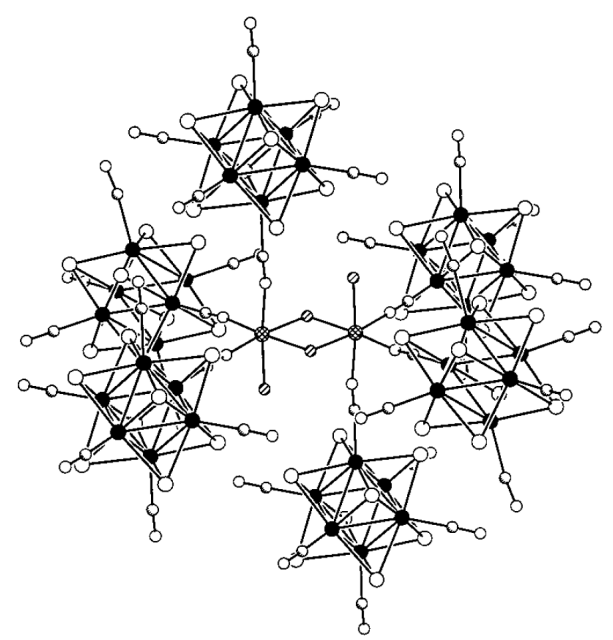

Figure 46. Extract from the crystal structure of $\left(\mathbf{9 0} \cdot 12 \mathrm{H}_{2} \mathrm{O}\right)$ showing the $\left[\mathrm{Co}_{2}\left(\mu-\mathrm{OH}_{2}\right)_{2}\right]$ in the middle and the $\left[\operatorname{Re}_{6} \mathrm{~S}_{8}\right]^{2+}$ clusters around it. Reprinted with permission from ref. ${ }^{176}$. Copyright 2000 American Chemical Society.

The $\mathrm{Co}(\mathrm{II})$ ions are in $f a c$-configuration with three $\mathrm{N}$-atoms from cyanide and three water ligands, each $\mathrm{Re}_{6}$ moiety is in turn connected to six $\mathrm{Co}_{2}$ clusters yielding a Prussian blue type structure. The relatively large size of the $\left[\mathrm{Re}_{6} \mathrm{~S}_{8}\right]^{2+}$ and $\left[\mathrm{Co}_{2}\left(\mu-\mathrm{OH}_{2}\right)_{2}\right]$ cations entails the formation of large cube-like cages within the Prussian blue type structure comprising a volume of $258 \AA^{3}$. Each of these cages contains 6 water molecules. The structure of $\left[\mathrm{Co}\left(\mathrm{H}_{2} \mathrm{O}\right)_{3}\right]_{4}\left[\mathrm{Co}_{2}\left(\mathrm{H}_{2} \mathrm{O}\right)_{4}\right]\left[\mathrm{Re}_{6} \mathrm{Se}_{8}(\mathrm{CN})_{6}\right]_{3} \cdot 44 \mathrm{H}_{2} \mathrm{O}\left(\mathbf{9 1} \cdot 44 \mathrm{H}_{2} \mathrm{O}\right)$ contains a mixture of isolated $\mathrm{Co}(\mathrm{II})$ complexes with octahedral coordination and $\left[\mathrm{Co}_{2}\left(\mu-\mathrm{OH}_{2}\right)_{2}\right]^{4+}$ clusters which are linked via cyanide to the $\left[\mathrm{Re}_{6} \mathrm{Se}_{8}\right]^{2+}$ units. All framework atoms together occupy only $56 \%$ of the total volume of this structure hence the large content of crystal water. Exposure of $\mathbf{9 0} \cdot 12 \mathrm{H}_{2} \mathrm{O}$ or 91. $44 \mathrm{H}_{2} \mathrm{O}$ to vapors of diethyl ether leads to a rapid change in color from orange to blue-violet and blue, exposure to THF induces a change to violet or green (Figure 47). 


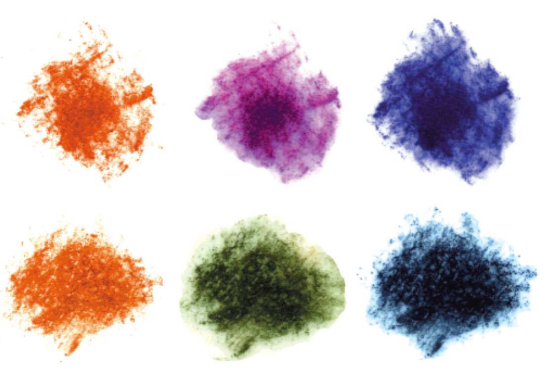

Figure 47. Powder samples of $\mathbf{9 0} \cdot 12 \mathrm{H}_{2} \mathrm{O}$ (upper line) and $\mathbf{9 1} \cdot 44 \mathrm{H}_{2} \mathrm{O}$ (lower line) treated with water (as prepared), THF, and diethyl ether (from left to right). Reprinted with permission from ref. ${ }^{176}$. Copyright 2000 American Chemical Society.

A range of VOCs influence the absorption properties of these two compounds, but diethyl ether leads to the most rapid response. For $\mathbf{9 0} \cdot 12 \mathrm{H}_{2} \mathrm{O}$ substantial color changes are detected by the naked eye for nitromethane, THF, acetone, propionitrile, $n$-octanol, $n$-propanol, ethyl acetate, isopropanol, and diethyl ether. For $\mathbf{9 1} \cdot 44 \mathrm{H}_{2} \mathrm{O}$ the most important color changes occur upon exposure to vapors of triethylamine, acetonitrile, THF, EtOH, DMF, acetone, propionitrile, $n$ octanol, methyl tert-butyl ether, ethyl acetate, $n$-propanol, isopropanol, and diethyl ether. The changes in the optical absorption spectrum following VOC exposure are fully consistent with inter-conversion of some or all of the $\mathrm{Co}(\mathrm{II})$ ions from octahedral to tetrahedral coordination geometry. Specifically, one observes the characteristic ${ }^{4} \mathrm{~T}_{1}(\mathrm{~F}) \leftarrow{ }^{4} \mathrm{~A}_{2}$ and ${ }^{4} \mathrm{~T}_{1}(\mathrm{P}) \leftarrow{ }^{4} \mathrm{~A}_{2}$ transitions of tetrahedral $\mathrm{e}^{4} \mathrm{t}_{2}{ }^{3}$ species. As far as the mechanism of this conversion is concerned, it has been proposed that VOCs enter the cavitites and channels of compounds $\mathbf{9 0} \cdot 12 \mathrm{H}_{2} \mathrm{O}$ and 91. $44 \mathrm{H}_{2} \mathrm{O}$, thereby disrupting the hydrogen-bonding network which stabilizes the octahedral coordination of $\mathrm{Co}(\mathrm{II})$. With bulkier VOC molecules present, labile water ligands are released and the tetrahedral coordination geometry is adopted. 
Reaction of $\mathrm{CoSO}_{4} \cdot 7 \mathrm{H}_{2} \mathrm{O}$ with the N,N'-ditopic 2-aminopyrazine (ampyz) ligand in aqueous solution gives a coordination framework with the composition $\left[\mathrm{Co}\left(\mathrm{H}_{2} \mathrm{O}\right)_{4}(\operatorname{ampyz})_{2}\right]\left[\mathrm{Co}\left(\mathrm{H}_{2} \mathrm{O}\right)_{6}\right]\left(\mathrm{SO}_{4}\right)_{2}\left(\mathrm{H}_{2} \mathrm{O}\right)_{2}(\mathbf{9 2}) .{ }^{177}$ Intermolecular hydrogen-bonding and $\pi-\pi$ interactions lead to the formation of $2 \mathrm{D}$ sheets with the sulfate anion playing a key role as a structural element. In diffuse reflectance one detects d-d absorptions of high-spin Co(II) at 9000 $\mathrm{cm}^{-1}$ and $19500-22000 \mathrm{~cm}^{-1}$ due to ${ }^{4} \mathrm{~T}_{2 \mathrm{~g}} \leftarrow{ }^{4} \mathrm{~T}_{1 \mathrm{~g}}$ and ${ }^{4} \mathrm{~T}_{1 \mathrm{~g}}(\mathrm{P}) \leftarrow{ }^{4} \mathrm{~T}_{1 \mathrm{~g}}$ transitions. When heating compound 92 to $220{ }^{\circ} \mathrm{C}$, a color change from orange to purple occurs, accompanied by a loss in crystallinity due to collapse of the supramolecular framework. The color change is most likely the result of a change in the coordination environment of the $\mathrm{Co}$ (II) centers, leading to shifts of the d-d absorption bands. Thermogravimetric analysis reveals that the resulting material has the composition $\left.\left[\mathrm{Co}_{2}(\mathrm{ampyz})_{2}\right]\left(\mathrm{SO}_{4}\right)\right]$. Exposure of the dehydrated compound to laboratory air during 8 hours restores the initial orange crystalline material. An isostructural Fe(II) compound and a mixed $\mathrm{Co}(\mathrm{II}) / \mathrm{Fe}(\mathrm{II})$ compound exhibit similar behavior, but their water-vapor sensing properties are less favorable because the color changes occurring upon water uptake are minor. ${ }^{177}$

\subsubsection{Nickel complexes}

Scheme 38. A vapochromic Ni(II) complex (93) and its reaction product with acetonitrile (94).

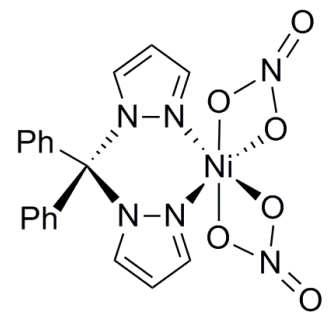

93

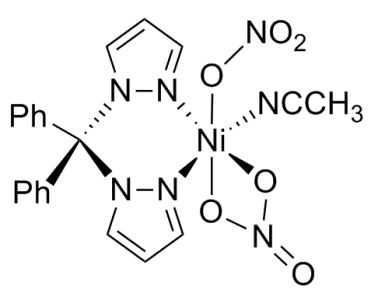

94 
A nickel(II) complex with a chelating diphenyl(dipyrazolyl)methane and two nitrate ligands (93) (Scheme 38) shows enough flexibility in its coordination sphere that one of the nitrates can undergo a change in hapticity from $\eta^{2}$ to $\eta^{1}$ as a function of temperature or acetonitrile vapor pressure. ${ }^{178}$ This ability makes complex 93 a thermochromic and vapochromic substance because the conversion of $\mathbf{9 3}$ into 94 is associated with a color change from green to blue. Shifts in d-d absorption bands due to electronic transitions from the ${ }^{3} \mathrm{~A}_{2 \mathrm{~g}}$ ground state to ${ }^{3} \mathrm{~T}_{2 \mathrm{~g}},{ }^{3} \mathrm{~T}_{1 \mathrm{~g}}\left({ }^{3} \mathrm{~F}\right)$, and ${ }^{3} \mathrm{~T}_{1 \mathrm{~g}}\left({ }^{3} \mathrm{P}\right)$ excited states are responsible for this change in color. The nitrate hapticity switch is further associated with a change in the IR spectrum. Complexes 93 and 94 were both characterized structurally, and their most notable feature is the small bite angle of the bidentate nitrate ligands leading to $c i s-\mathrm{O}-\mathrm{Ni}-\mathrm{O}$ angles of about $62^{\circ}$, causing significant distortions from the ideal octahedral geometry. The vapor-induced conversion from 93 to 94 can be reversed by heating to $100{ }^{\circ} \mathrm{C}$ for a few minutes. The formation of the $\eta^{2}$ complex is favored at higher temperatures due to entropic effects associated with the release of $\mathrm{CH}_{3} \mathrm{CN}$ and chelation of the nitrate ligand.

Scheme 39. Vapochromic Ni(II) complexes.
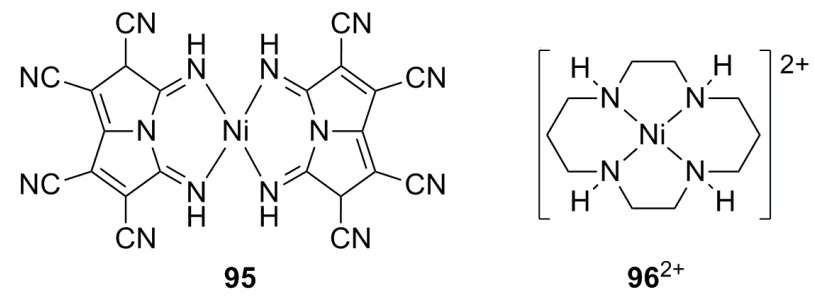

The bis(pyrrolizinato)nickel(II) complex 95 (Scheme 39) acts as a vapochromic substance in polyvinylbutyral (PVB) matrices. ${ }^{179}$ The initially prepared spin-coated film containing about 
0.02 moles of 95 per liter of PVB is light blue but changes to colorless on heating to $90{ }^{\circ} \mathrm{C}$ for a few minutes. The colorless state persists at room temperature unless the films are exposed to vapors of various VOCs with alcohols triggering the most rapid response and manifesting in the appearance of an absorption maximum at $661 \mathrm{~nm}$. It is believed that the blue form of 95 is in fact an octahedral complex with two solvent molecules completing the coordination sphere of Ni(II) whereas the colorless form corresponds to the four-coordinate $\mathrm{NiN}_{4}$ complex represented by structure 95. The selectivity for alcohols has been attributed to their coordinating ability, the poor response to acetonitrile vapor has been explained by the observation that this solvent shows little tendency to coordinate to $\mathbf{9 5}$ even in solution. Curiously, toluene triggers a vapochromic response as well, but this has been ascribed to the affinity of the PVB matrix for this particular solvent.
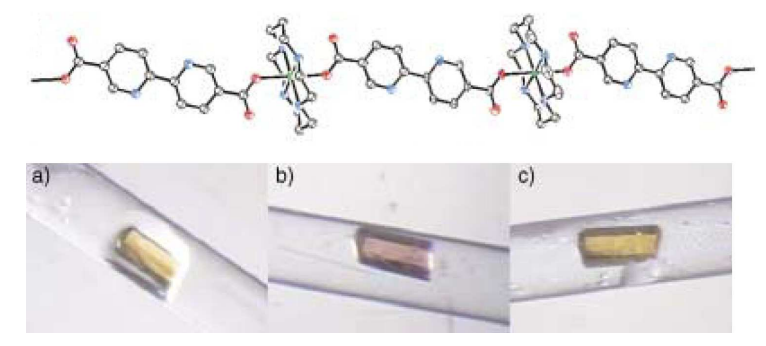

Figure 48. Top: $1 \mathrm{D}$ chain structure of $[\mathrm{Ni}(\mathrm{cyclam})]^{2+}$ and $5,5^{\prime}$-dcbpy ${ }^{2-}$. Bottom: (a) Crystal of $\left[\mathrm{Ni}(\right.$ cyclam $)($ dcbpy) $] \cdot 5 \mathrm{H}_{2} \mathrm{O}$ in the mother liquor; (b) same crystal after evacuation at $150^{\circ} \mathrm{C}$; (c) same crystal after subsequent exposure to water vapor. (E. Y. Lee, M. P. Suh: A Robust Porous Material Constructed of Linear Coordination Polymer Chains: Reversible Single-Crystal to Single-Crystal Transformation upon Dehydration and Rehydration. Angew. Chem. Int. Ed., 2004, 43, 2798-2801. Copyright Wiley-VCH Verlag GmbH \& Co. KGaA. Reproduced with permission.) 
The $[\mathrm{Ni}(\text { cyclam })]^{2+}$ complex $\left(\mathbf{9 6}^{2+}\right)$ and 2,2'-bipyridine-5,5'-dicarboxylate $\left(5,5^{\prime}\right.$-dcbpy $\left.{ }^{2-}\right)$ form together a robust metal-organic open framework of composition $[\mathrm{Ni}($ cyclam $)(\mathrm{dcbpy})] \cdot 5 \mathrm{H}_{2} \mathrm{O}$ which is able to undergo reversible single crystal to single crystal transformations. ${ }^{180}$ The Ni(II) center is octahedrally coordinated with axial $5,5^{\prime}-\mathrm{dcbpy}^{2-}$ ligands binding in monodentate fashion and resulting in a linear coordination polymer chain (Figure 48). Individual chains are linked to each other through C-H- $\pi$ interactions involving a carbon atom of the macrocycle and the pyridyl rings of $5,5^{\prime}-\mathrm{dcbpy}^{2-}$. When heating single crystals of $[\mathrm{Ni}($ cyclam $)(\mathrm{dcbpy})] \cdot 5 \mathrm{H}_{2} \mathrm{O}$ to $150{ }^{\circ} \mathrm{C}$ under $10^{-5}$ Torr for several hours there is a color change from yellow to pink. The packing of the porous framework stays intact, and it appears that the $\mathrm{C}-\mathrm{H}-\pi$ interactions are largely responsible for this. The Ni-O(carboxylate) bonds shorten by $0.025 \AA$ upon dehydration which may be responsible for the observed color change. In this sense, complex $96^{2+}$ is not a clear type II vapochromic substance (according to the definition used in section 1.3), yet the metal-ligand bond length change is clearly a significant modification of the first coordination sphere of the metal center. When exposing the pink dehydrated crystals to air the yellow color is restored within minutes with retention of single crystallinity.

\subsubsection{Copper complexes}

When adding excess 4-picoline (4-pic) to a solution of $\mathrm{CuI}$ in concentrated aqueous $\mathrm{KI}$ one obtains the material $[\mathrm{CuI}(4-p i c)]_{\infty}(97)$ which crystallizes in a double-zigzag configuration with $\mathrm{Cu}(\mathrm{I})-\mathrm{I}-\mathrm{Cu}(\mathrm{I})$ - connections propagating along the crystallographic b axis (Figure 49). The shortest $\mathrm{Cu}(\mathrm{I})-\mathrm{Cu}(\mathrm{I})$ distances in this compound are $2.8087(8) \AA \AA^{181,}{ }^{182}$ and this polymeric 
material is blue photoluminescent $\left(\lambda_{\max }=437 \mathrm{~nm}\right)$ due to the presence of an emissive XLCT (halogen-to-ligand charge transfer) state. ${ }^{20}$ When exposing it to toluene vapors in a sealed vial for 2 days, it converts into $[\mathrm{CuI}(4-\text { pic })]_{4} \cdot 2 \mathrm{C}_{6} \mathrm{H}_{5} \mathrm{CH}_{3}\left(\mathbf{9 8} \cdot 2 \mathrm{C}_{6} \mathrm{H}_{5} \mathrm{CH}_{3}\right)$. The tetrameteric copper(I) species of the toluene adduct exhibits comparatively short $\mathrm{Cu}(\mathrm{I})-\mathrm{Cu}(\mathrm{I})$ distances ranging from 2.651 to $2.735 \AA$, and the yellow emission of this compound $\left(\lambda_{\max }=580 \mathrm{~nm}\right)$ has been attributed to a cluster-centered $\left({ }^{3} \mathrm{CC}\right)$ electronic transition. ${ }^{20}$ The incorporation of toluene molecules permits arrangement of the tetrameric units into chains without leaving too many voids between them, and this fact presumably facilitates the conversion of $[\mathrm{CuI}(4-\mathrm{pic})]_{4} \cdot 2 \mathrm{C}_{6} \mathrm{H}_{5} \mathrm{CH}_{3}$ back to $[\mathrm{CuI}(4-\text { pic })]_{\infty}$ occurring upon exposure to pentane vapor, simply because the copper units are already pre-arranged into chains. It has been noted that for practical sensing applications the slowness of the VOC-induced chemical conversions between 97 and $\mathbf{9 8} \cdot 2 \mathrm{C}_{6} \mathrm{H}_{5} \mathrm{CH}_{3}$ is a problem.
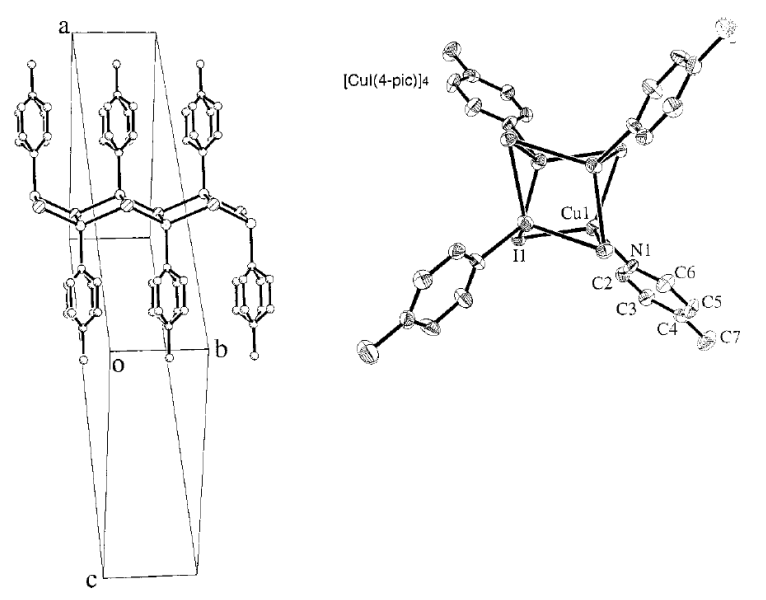

Figure 49. Left: Polymer chain of $[\mathrm{CuI}(4-\mathrm{pic})]_{\infty}$ (97) propagating along the b-axis. Right: Structure of the $[\mathrm{CuI}(4-\mathrm{pic})]_{4}$ (98) cluster. Reprinted with permission from ref. ${ }^{180}$. Copyright 2000 American Chemical Society. 

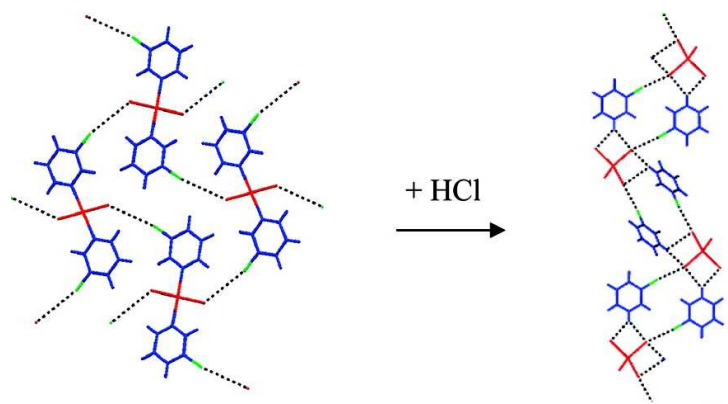

Figure 50. 2D network of compound 99 (with square-planar $\mathrm{Cu}(\mathrm{II})$ ) and $1 \mathrm{D}$ network of compound $\mathbf{1 0 0}$ (with tetrahedral Cu(II). Reprinted with permission from ref. ${ }^{182}$. Copyright 2007 American Chemical Society.

Reaction of $\mathrm{CuCl}_{2}$ and 3-chloropyridine (3-Clpy) in methanol solution affords the chargeneutral coordination compound trans $-\left[\mathrm{CuCl}_{2}(3-\mathrm{Clpy})_{2}\right](\mathbf{9 9})$ in which the copper(II) center is in square planar coordination. ${ }^{183,184}$ This material is blue and reacts with gaseous $\mathrm{HCl}$ to form the yellow salt $(3-\mathrm{ClpyH})_{2}\left[\mathrm{CuCl}_{4}\right](\mathbf{1 0 0})$ in which $\mathrm{Cu}(\mathrm{II})$ is tetrahedrally coordinated. This vaporinduced conversion is remarkable because it not only involves cleavage of two $\mathrm{Cu}-\mathrm{N}$ coordination bonds but also the rupture of the covalent $\mathrm{H}-\mathrm{Cl}$ bonds to form two new $\mathrm{Cu}-\mathrm{Cl}$ and $\mathrm{N}-\mathrm{H}$ bonds. The crystal structure changes from a 2D-network propagated via $\mathrm{Cu}-\mathrm{Cl}-\mathrm{Cl}-\mathrm{C}$ halogen bonds (99) (Figure 50) to a $1 \mathrm{D}$-network propagated via $\mathrm{N}-\mathrm{H}-\mathrm{Cl}_{2} \mathrm{Cu}$ hydrogen bonds and $\mathrm{Cu}-\mathrm{Cl}-\mathrm{Cl}-\mathrm{C}$ halogen bonds (100). $\mathrm{HCl}$ uptake has been monitored by FTIR spectroscopy from which an equilibrium constant of $1.03(5) \cdot 10^{-5}$ was determined, indicating good sensitivity for $\mathrm{HCl}$ detection in the $200-20000 \mathrm{ppm}$ concentration range. Temperature dependent FTIR studies show that $\mathrm{HCl}$ extrusion is endothermic. X-ray diffraction at a synchrotron facility was used to search for intermediate crystalline phases present at small concentrations but occurring in the process of interconversion between 99 and 100. However, no such phase could be found and 
Rietveld analysis of X-ray powder patterns gave an excellent fit to a two-phase model without the need for involvement of an intermediate (amorphous) phase. This study shows that the molecular solid state can be far more flexible and dynamic that it is generally perceived to be. ${ }^{183}$, 184

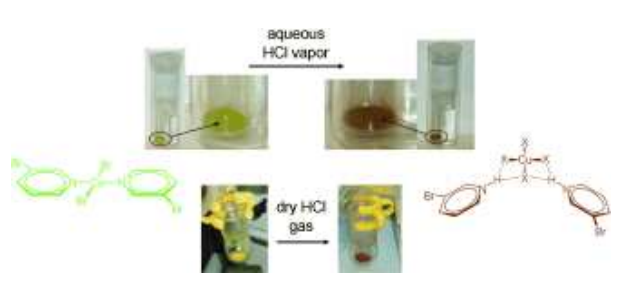

Figure 51. Reaction of trans- $\left[\mathrm{CuBr}_{2}(3-\mathrm{Brpy})_{2}\right]$ (101) to (3-BrpyH $)_{2}\left[\mathrm{CuBr}_{2} \mathrm{Cl}_{2}\right]$ (102). (G. Mínguez Espallargas, J. van de Streek, P. Fernandes, A. J. Florence, M. Brunelli, K. Shankland, L. Brammer: Mechanistic Insights into a Gas-Solid Reaction in Molecular Crystals: The Role of Hydrogen Bonding. Angew. Chem. Int. Ed., 2010, 49, 8892-8896. Copyright Wiley-VCH Verlag GmbH \& Co. KGaA. Reproduced with permission.)

Subsequent related work focused on the isostructural trans-[CuBr $\left.2(3-\mathrm{Brpy})_{2}\right]$ (101) complex and its reaction with gaseous $\mathrm{HCl} .{ }^{185}$ This study provided significant new insight into the mechanism of $\mathrm{HCl}$ uptake. One important observation is that upon conversion of green $\mathbf{1 0 1}$ to brown (3-BrpyH $)_{2}\left[\mathrm{CuBr}_{2} \mathrm{Cl}_{2}\right]$ (102) (Figure 51) the initially present bromo-ligands are not lost. It has been hypothesized that insertion of $\mathrm{HCl}$ into $\mathrm{Cu}-\mathrm{N}$ bonds of $\mathbf{1 0 1}$ is followed by a structural reorientation of the $\left[\mathrm{CuBr}_{2} \mathrm{Cl}_{2}\right]^{2-}$ anions which is driven by the formation of hydrogen bonds and halogen bonds. Indeed it was found that the chloride population of a given crystallographic site correlates with the total number of strong intermolecular interactions formed, either hydrogen or halogen bonds. Thus, the hypothesis from above makes sense because the respective noncovalent 
(and mainly electrostatically driven) interactions are expected to be stronger with chloride than with bromide due to the more negative electrostatic potential of $\mathrm{Cl}^{-}$. Methodologically, the reaction of trans-[CuBr $\left.2(3-\mathrm{Brpy})_{2}\right]$ with $\mathrm{HCl}$ resembles isotope labeling experiments only that $\mathrm{Cl}$ and $\mathrm{Br}$ exhibit sufficiently different X-ray scattering power that differentiation of the two halides becomes easily possible with X-ray diffraction.

Green trans-[CuBr $\left.2(3-\mathrm{Brpy})_{2}\right]$ (101) reacts with $\mathrm{HBr}$ to brown (3-BrpyH $)_{2}\left[\mathrm{CuBr}_{4}\right]$, but this material has a different crystallographic structure with different supramolecular connections than 100 and 102. ${ }^{186}$ However, release of $\mathrm{HBr}$ from $(3-\mathrm{BrpyH})_{2}\left[\mathrm{CuBr}_{4}\right]$ or $\mathrm{HCl}$ from $\mathbf{1 0 0} / \mathbf{1 0 2}$ leads to an isostructural series of compounds.

Scheme 40. Vapochromism based on ligand flip isomerization.
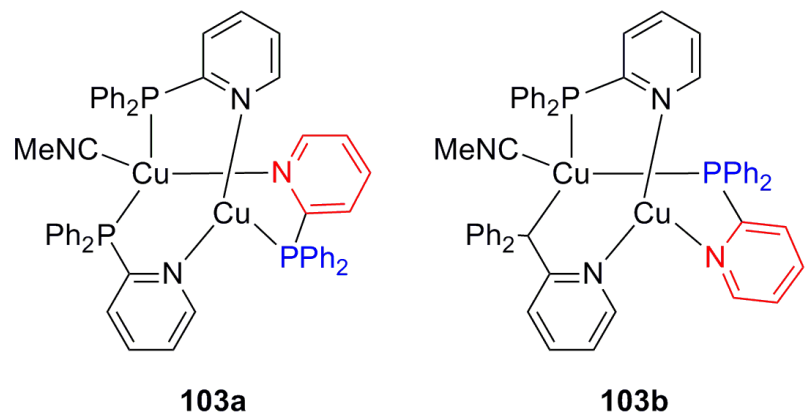

An interesting case of linkage isomerism has been reported for $\left[\mathrm{Cu}_{2}(\mathrm{dppy})_{3}\left(\mathrm{CH}_{3} \mathrm{CN}\right)\right]\left(\mathrm{BF}_{4}\right)_{2}$ (dppy $=$ diphenylphosphino-pyridine) (Scheme 40). ${ }^{187}$ This binuclear complex has its dppy ligands arranged in head-to-tail fashion with two phosphorus atoms binding to one copper(I) center and the third to the other one (103a). Recrystallization of 103a from a mixture of $\mathrm{CH}_{2} \mathrm{Cl}_{2}$ and $\mathrm{CH}_{3} \mathrm{OH}$ affords the methanol adduct $\left(\mathbf{1 0 3 b} \cdot \mathrm{CH}_{3} \mathrm{OH}\right)$ which has one of its dppy ligands flipped, resulting in head-to-head orientation of all three ligands. Because of the hemilability of 
the dppy ligand it is further possible to convert blue photoluminescent 103a $\left(\lambda_{\max }=489 \mathrm{~nm}\right)$ into green emissive $\mathbf{1 0 3 b} \cdot \mathrm{CH}_{3} \mathrm{OH}\left(\lambda_{\max }=520 \mathrm{~nm}\right)$ by exposure of solid 103a to methanol vapor, and this process can be fully reversed when heating the methanol adduct to $203{ }^{\circ} \mathrm{C}$. The linkage isomerization reaction is accompanied by a significant increase of the $\mathrm{Cu}(\mathrm{I})-\mathrm{Cu}(\mathrm{I})$ separation from $2.721(3) \AA$ in 103a to $2.7961(4) \AA$ in $\mathbf{1 0 3} \mathbf{b} \cdot \mathrm{CH}_{3} \mathrm{OH}$ and by an increase of $\pi-\pi$ interactions manifesting by short distances between the phenyl and pyridyl planes in the methanol adduct. These two structural changes are most likely jointly responsible for the shift in emission wavelength upon $\mathrm{CH}_{3} \mathrm{OH}$ uptake.

Scheme 41. A copper complex exhibiting concentration lumichromism.

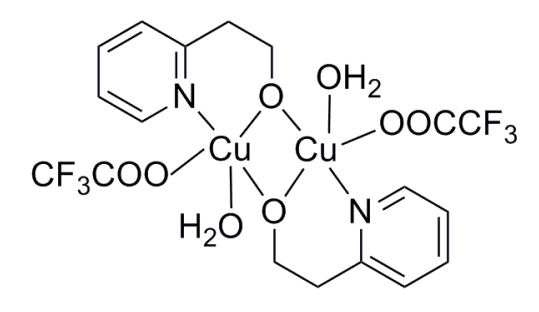

104

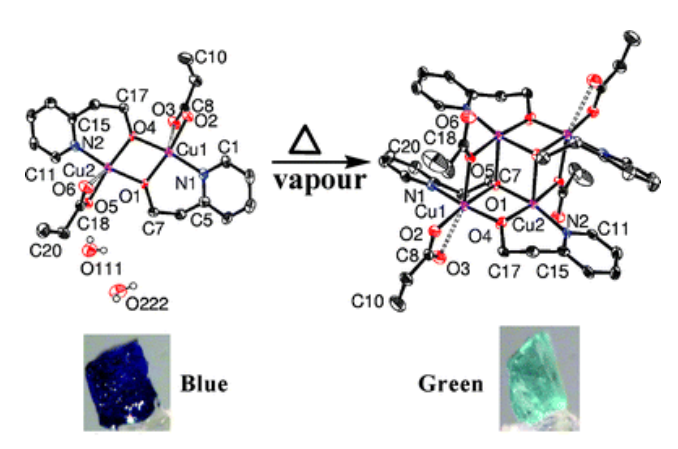

Figure 52. Conversion of dimeric blue $\mathbf{1 0 4} \cdot 2 \mathrm{H}_{2} \mathrm{O}$ to a tetrameric green product. Copyright 2010 The Royal Society of Chemistry. 
A dinuclear copper(I) complex with 2-(2-hydroxyethyl)pyridine ( $\mu$-hep) and n-propionate $\left(\mathrm{O}^{\mathrm{n}} \mathrm{Pr}\right)$ ligands $(\mathbf{1 0 4})$ shows the unusual phenomenon of a vapor-induced single crystal to single crystal transformation. ${ }^{188}$ Initially the $\left[\left(\mathrm{O}^{\mathrm{n}} \mathrm{Pr}\right) \mathrm{Cu}(\mu-\mathrm{hep})_{2} \mathrm{Cu}\left(\mathrm{O}^{\mathrm{n}} \mathrm{Pr}\right)\right]$ complex is obtained as a dihydrate $\left(\mathbf{1 0 4} \cdot 2 \mathrm{H}_{2} \mathrm{O}\right)$. When heated to $110{ }^{\circ} \mathrm{C}$ this blue compound releases water and undergoes a structural change to a green tetrametric complex under retention of its crystallinity (Figure 52). The tetramer has the structure of a double open cubane. The same structural conversion can be induced at room temperature when exposing $\mathbf{1 0 4} \cdot 2 \mathrm{H}_{2} \mathrm{O}$ to various VOCs, albeit with different response times. Whereas $\mathrm{CH}_{3} \mathrm{OH}$ produces a response within 5 minutes, ethanol, isopropanol, and acetonitrile require exposure times of 2 hours, 24 hours, and 8 days, respectively. In view of the fact that multiple bond breaking and bond making processes must occur, this structural conversion in the single crystalline state is remarkable. However, the overall process is irreversible. Analogous compounds with acetate instead of $n$-propionate were also investigated but did not show vapochromic behavior. ${ }^{188}$

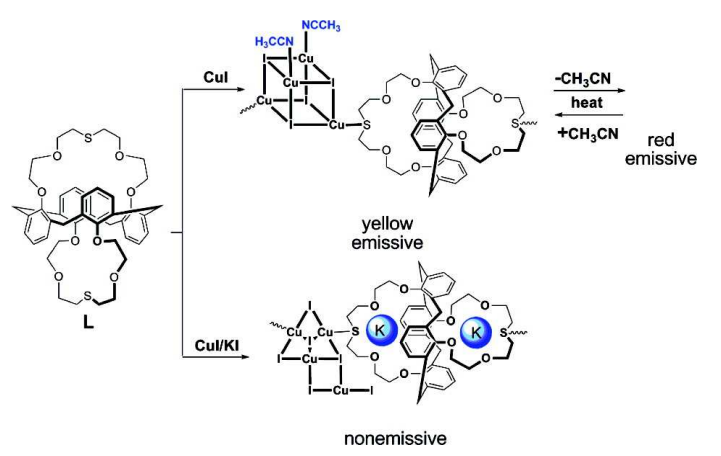

Figure 53. Reactivity and luminescence behavior of $\left[\left(\mathrm{Cu}_{4} \mathrm{I}_{4}\right) \mathrm{L}\left(\mathrm{CH}_{3} \mathrm{CN}\right)_{2}\right]_{\mathrm{n}}\left(\mathbf{1 0 5} \cdot\left(\mathrm{CH}_{3} \mathrm{CN}\right)_{2}\right)$. Reprinted with permission from ref. ${ }^{189}$. Copyright 2008 American Chemical Society. 
Reaction of a calix[4]-bis-monothiacrown (L) with $\mathrm{CuI}$ in acetonitrile leads to the formation of a 1D polymeric material with the formulation $\left[\left(\mathrm{Cu}_{4} \mathrm{I}_{4}\right) \mathrm{L}\left(\mathrm{CH}_{3} \mathrm{CN}\right)_{2}\right]_{\mathrm{n}}\left(\mathbf{1 0 5} \cdot\left(\mathrm{CH}_{3} \mathrm{CN}\right)_{2}\right)$ (Figure 53). ${ }^{189}$ It contains cubane-like $\mathrm{Cu}_{4} \mathrm{I}_{4}$ clusters which are linked to one another by the calix[4]-bismonothiacrown ligands through two of the four $\mathrm{Cu}(\mathrm{I})$ ions, while the two other metal centers bear acetonitrile ligands. The yellow photoluminescence of compound $105\left(\lambda_{\max }=567 \mathrm{~nm}\right)$ was assigned to a cluster-centered excited state with admixed halide-to-metal charge transfer (XLCT) character. Addition of KI leads to the incorporation of $\mathrm{K}^{+}$ions into the thiacrowns, a process which is accompanied by emission quenching, perhaps because of $\eta^{5}$-type cation $-\pi$ interactions. When heating potassium-free samples to $150{ }^{\circ} \mathrm{C}$ for 1 hour the acetonitrile ligands are released, producing a red photoluminescent $\left(\lambda_{\max }=600 \mathrm{~nm}\right)$ compound. Bulk crystallinity is maintained and thus the process is reversible, manifesting in a vapoluminescence response upon exposure of the de-solvated material to $\mathrm{CH}_{3} \mathrm{CN}$.

Six different coordination compounds have been isolated as products from the reaction between $\mathrm{CuI}$ and triphenylphosphine $\left(\mathrm{PPh}_{3}\right) .{ }^{190}$ One out of two cubane-type polymorphs with the stoichiometry $\left[\mathrm{CuI}\left(\mathrm{PPh}_{3}\right)_{4}\right](\mathbf{1 0 6 a})$ converts to an isomer when exposed to vapors of acetonitrile, dichloromethane or ethanol. In the product $(\mathbf{1 0 6 b})$, two opposite edges of the cubane-like structure are broken up, and a molecular structure resembling that of cyclooctane is formed. Compound 106a emits green light $\left(\lambda_{\max }=518 \mathrm{~nm}, \tau=3.2 \mu \mathrm{s}\right)$ upon UV excitation at room temperature whereas its isomer $\mathbf{1 0 6 b}$ is essentially nonluminescent under these conditions, paving the way to vapor-induced luminescence on/off switching.

Copper(I) cyanide (107) reacts with a variety of different amines (both in the liquid and vapor phase) to produce adducts of the stoichiometry $\mathrm{CuCN} \cdot \mathrm{L}_{\mathrm{n}}$ with $\mathrm{n}=0.75-2.0 .{ }^{191-193} \mathrm{Neat} \mathrm{CuCN}$ emits at the edge of the visible spectral range with $\lambda_{\max }=392 \mathrm{~nm}$, but the solvent adducts 
luminesce with different colors throughout the visible spectral range with $\lambda_{\max }$ depending on the exact nature of the amine (L) (Figure 54). ${ }^{191}$ The $\mathrm{CuCN} \cdot \mathrm{L}_{\mathrm{n}}$ adducts can be obtained on the preparative scale by heating $\mathrm{CuCN}$ suspensions in neat amines and hence can be characterized structurally. Single crystals suitable for X-ray diffraction were obtained with L = pyridine, 2methylpyridine, 4-methylpyridine, 3-ethylpyridine, 4-(t-butyl)pyridine, piperidine, $N$ methylmorpholine, and $N, N$-dimethylcyclohexane. Each of these structures contains chains of $\mathrm{CuCN}$ with the cyano $\mathrm{C} / \mathrm{N}$ positions disordered in most cases, and in each structure (except for $\mathrm{CuCN} \cdot 4-(t$-butyl)pyridine) the amine is directly bonded to copper(I). Depending on the amine content (n), the $\mathrm{Cu}(\mathrm{I})$ centers are either 3- or 4-coordinate. The photoluminescence behavior of these authentic solvent adducts is identical to that observed for samples of $\mathrm{CuCN}$ that have been exposed to vapors of the respective amines. However, powder X-ray diffraction reveals that only a fraction of vapor-exposed $\mathrm{CuCN}$ reacts to the adduct $\mathrm{CuCN} \cdot \mathrm{L}_{\mathrm{n}}$, and thus it seems that only the surface of $\mathrm{CuCN}$ is able to react with the amine vapors. This interpretation is compatible with the high reversibility of the vapoluminescent response. Based on DFT calculations the HOMO of the $\mathrm{CuCN} \cdot \mathrm{L}_{\mathrm{n}}$ compounds is mostly comprised of the $3 \mathrm{~d}_{\mathrm{z} 2}$ orbital of the metal while the LUMO is a mixture of $4 \mathrm{p}$ orbitals of $\mathrm{Cu}(\mathrm{I})$ and $\pi^{*}$ orbitals of the cyano ligand, ${ }^{194}$ and consequently it might be argued that the emission has mixed d-d and MLCT character.

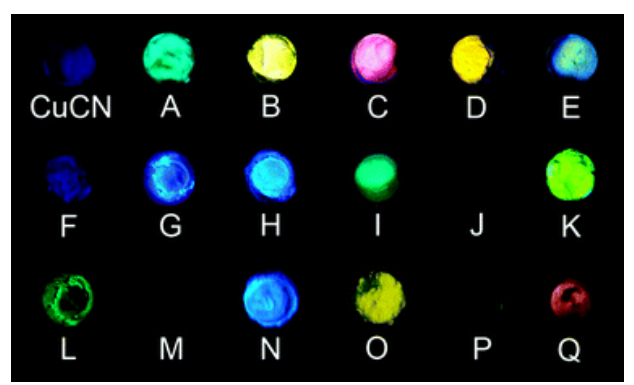


Figure 54. Luminescence of neat $\mathrm{CuCN}$ (upper left) and various solvent adducts of $\mathrm{CuCN}$ (AQ). Copyright 2010 The Royal Society of Chemistry.

The reaction of $\mathrm{CuI}$ with selected $N, N$ '-disubstituted piperazines (pip) in acetonitrile yields $(\mathrm{CuI})_{2}$ (pip) compounds consisting of chains with piperazine-linked $\mathrm{Cu}_{2} \mathrm{I}_{2}$ rombs. ${ }^{195}$ These structures with 3-coordinate $\mathrm{Cu}(\mathrm{I})$ are obtained only for sterically crowded $N, N^{\prime}-$ diethylpiperazine (Et 2 pip), N,N'-dibenzylpiperazine (Bnpip), N,N'-bis-phenylethylpiperazine (PhEtpip), producing compounds $(\mathrm{CuI})_{2}\left(\mathrm{Et}_{2} \mathrm{pip}\right) \quad(\mathbf{1 0 8 a}), \quad(\mathrm{CuI})_{2}\left(\mathrm{Bn}_{2} \mathrm{pip}\right) \quad(\mathbf{1 0 8 b}), \quad$ and $(\mathrm{CuI})_{2}\left((\mathrm{PhEt})_{2}\right.$ pip) (108c), whereas sterically less demanding piperazines lead to structures with 4-coordinate $\mathrm{Cu}(\mathrm{I})$. The $\mathrm{Cu}(\mathrm{I})-\mathrm{Cu}(\mathrm{I})$ distances in 108a-c range from 2.4716(11) to 2.4837(14) $\AA$ and are significantly below the van der Waals distance $(\sim 2.80 \AA)$, indicative of substantial metallophilic interactions. Exposure of 108a and 108b to vapors of amine and sulfide nucleophiles $\mathrm{(Nu})$ leads to brightly photoluminescent materials which show identical luminescence properties as the respective $(\mathrm{CuI})_{4}(\mathrm{Nu})_{4}$ compounds, suggesting that $\mathrm{Nu}$ vapor exposure induces the reaction $2(\mathrm{CuI})_{2}($ pip $)+4 \mathrm{Nu} \rightarrow(\mathrm{CuI})_{4}(\mathrm{Nu})_{4}+2$ pip. Depending on the nucleophile, luminescent materials with emission colors ranging from blue $(\mathrm{Nu}=2$ methylpyridine $)$ to red $(\mathrm{Nu}=$ morpholine $)$ are obtained. Other nucleophiles which give a vapoluminescence response are pyridine, 3-methylpyridine, , piperidine, pyrrolidine, pyrrolidine, diethylamine, dimethyl sulfide. ${ }^{195}$ Vapors of 2-chloropyridine, 3-chloropyridine, and $N$ methylpiperidine yield non-emissive compounds.

\subsubsection{Tin}


Four commercial tin(II) salts were found to be useful for optical sensing of amine vapors at concentrations as low as $100 \mathrm{ppb} .{ }^{196}$ Specifically, tin(II) sulfate ( $\mathrm{SnSO}_{4}$, 109a), tin(II) methanesulfonate $\left(\mathrm{Sn}\left(\mathrm{CH}_{3} \mathrm{SO}_{3}\right)_{2}, \quad \mathbf{1 0 9 b}\right), \quad \operatorname{tin}(\mathrm{II})$ triflate $\left(\mathrm{Sn}(\mathrm{OTf})_{2}, \quad \mathbf{1 0 9 c}\right)$, and $\operatorname{tin}(\mathrm{II})$ fluorophosphate $\left(\mathrm{SnPO}_{3} \mathrm{~F}, \mathbf{1 0 9 d}\right)$ were found to display visible room temperature emission after exposure to vapors of $\mathrm{NH}_{3}, \mathrm{EtNH}_{2}, \mathrm{Et}_{2} \mathrm{NH}, \mathrm{Et}_{3} \mathrm{~N}$, or $\mathrm{N}\left(\mathrm{C}_{5} \mathrm{H}_{5}\right)_{3}$. Importantly, each of the four tin(II) salts responds differently to the five amines, and consequently similar analytes can be distinguished from each other rather easily. Many other nucleophilic analytes have little impact on the emission properties, but it has been noted that for real-world applications the watersensitivity of several of the tin(II) salts is problematic. For instance the emission intensity of amine-vapor exposed $\mathrm{Sn}\left(\mathrm{CH}_{3} \mathrm{SO}_{3}\right)_{2}$ and $\mathrm{Sn}(\mathrm{OTf})_{2}$ drops considerably in presence of atmospheric humidity. The fundamental reasons for the luminescence turn-on response in presence of amines is unclear, ${ }^{196}$ it was merely noted that tin(II) is known to form complexes with amine-containing molecules. ${ }^{197,198}$

\subsubsection{Metalloporphyrins}

Due to their intense colors and the presence of axial binding sites metalloporphyrins are of interest for sensing of coordinating VOCs. An application-oriented study falling into the category of "electronic nose" research made use of arrays containing 11 different tetraphenylporphyrin-based compounds for achieving chemoselective vapor visualization. The tetraphenylporphyrin was either used as a free base, or with $\mathrm{Sn}(\mathrm{IV}), \mathrm{Co}(\mathrm{III}), \mathrm{Cr}(\mathrm{III}), \mathrm{Mn}(\mathrm{III})$, $\mathrm{Fe}(\mathrm{III}), \mathrm{Co}(\mathrm{II}), \mathrm{Cu}(\mathrm{II}), \mathrm{Ru}(\mathrm{II}), \mathrm{Zn}(\mathrm{II})$ and $\mathrm{Ag}(\mathrm{II}) .{ }^{199}$ These metals span a wide range of ligand affinity which opens the possibility for obtaining unique color fingerprints upon VOC exposure 
at analyte concentrations below $2 \mathrm{ppm}$. A wide range of ligating solvents including alcohols, amines, thiols, thioethers, and phosphines can be detected and distinguished from each other by taking the difference before and after vapor-exposure of the scanned images of the arrays. The porphyrins were dissolved in dibutylphtalate in polystyrene matrix, and deposition of small spots with $0.5 \mathrm{~mm}$ diameter was found to optimize the response time. The porphyrin spots can be deposited using an ink-jet technique in order to obtain cheap disposable sensor arrays.

Zinc(II) tetraphenylporphyrin (110) dissolved in silicone rubber can be used for detection of ammonia vapor at concentrations as low as $0.7 \mathrm{ppm} .{ }^{200}$ In the course of $\mathrm{NH}_{3}$ ligation to $\mathrm{ZnTPP}$ the Soret band shifts from 414 to $424 \mathrm{~nm}$, and similar spectral changes were observed on exposure to triethylamine. Silicone films of ZnTPP produce significantly better results than Nafion or ethyl cellulose support matrices. The latter is apparently impermeable for ammonia gas while the Nafion films were very thin $(10 \mu \mathrm{m})$ and resulted in weak absorption.

\subsection{Vapochromism as a result of indirect analyte-metal interactions}

This subsection treats the remainder of metal-containing vapochromic substances that cannot easily be grouped according to a single unifying theme. These materials contain different metals and their vapochromism has diverse origins. The division into 5 chapters is an attempt to group these substances according to common themes and/or origin of their vapochromic properties.

\subsubsection{Vapochromism as a consequence of a change in spin state}


A single crystal to single crystal transformation has been reported for the spin-crossover compound $\mathrm{Fe}(\mathrm{tpa})(\mathrm{NCS})_{2} \quad(\mathbf{1 1 1}) \quad\left(\right.$ tpa $=$ tris-(2-pyridylmethyl)amine). ${ }^{201}$ This molecule crystallizes in a relatively open structure with individual molecules arranged via $\pi-\pi$ interactions in one direction and hydrogen bonds in a second direction. The Fe-N distances are between 1.977(8) to 2.091(6) $\AA$, which is typical for low-spin Fe(II)-N bonds. Exposure to methanol vapor leads to a new compound which is best formulated as $\left[\mathrm{Fe}(\right.$ tpa $\left.)(\mathrm{NCS})_{2}\right] \cdot\left[\mathrm{Fe}(\mathrm{tpa})(\mathrm{NCS})_{2} \cdot \mathrm{CH}_{3} \mathrm{OH}\right] \quad\left(\mathbf{1 1 1} \cdot\left[\mathbf{1 1 1} \cdot \mathrm{CH}_{3} \mathrm{OH}\right]\right) . \quad$ In the crystal structure determined at $120 \mathrm{~K}$ this methanol adduct exhibits Fe-N distances contracted by about $0.2 \AA$, indicating that a low-spin to high-spin transition has taken place. The change in spin state has been confirmed by Mössbauer spectroscopy and is accompanied by a change in color from yellow (111) to red (111 $\left.\left[\mathbf{1 1 1} \cdot \mathrm{CH}_{3} \mathrm{OH}\right]\right)$ (Figure 55). Remarkably, the methanol molecule is not directly interacting with any of the two metal centers, but it merely changes the way individual molecules interact with each other yet this suffices to induce the spin transition. As an additional subtlety the two crystallographically distinct iron centers give rise to three different spin crossover phases: At $120 \mathrm{~K}$ both metal centers are low-spin, at $298 \mathrm{~K}$ one Fe(II) is high-spin while the other is low-spin, and at $350 \mathrm{~K}$ both metals are high-spin.

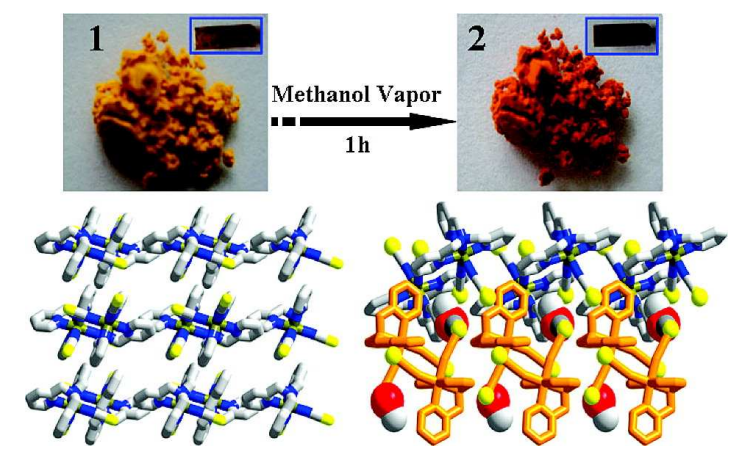


Figure 55. Change in appearance and crystal structure of compound 111 upon exposure to $\mathrm{MeOH}$ vapor. The red form contains two crystallographically distinct types of Fe complexes and is best formulated as 111 $\cdot\left[\mathbf{1 1 1} \cdot \mathrm{CH}_{3} \mathrm{OH}\right]$. Reprinted with permission from ref. ${ }^{201}$. Copyright 2010 American Chemical Society.

Ethanol gives an adduct of similar stoichiometry as methanol $\left(\mathbf{1 1 1} \cdot\left[\mathbf{1 1 1} \cdot \mathrm{C}_{2} \mathrm{H}_{5} \mathrm{OH}\right]\right)$, i. e., a compound with two crystallographically distinct Fe(II) centers. By contrast, all other tested solvents ( $n$ - $\mathrm{PrOH}, i$-PrOH, $\mathrm{CH}_{3} \mathrm{CN}, \mathrm{CH}_{2} \mathrm{Cl}_{2}$, and $\mathrm{CHCl}_{3}$ ) yield adducts of the same stoichiometry as the solvent-free parent compound (111) in which all Fe(II) centers are identical. ${ }^{202}$ Adducts of 111 with any of the latter five solvents undergo a color change from yellow/brown to red following exposure to ethanol vapor, indicating that a similar low-spin to high-spin transition as discussed above for methanol is occurring. When 111 $\left[111 \cdot \mathrm{C}_{2} \mathrm{H}_{5} \mathrm{OH}\right]$ is exposed to vapors of $\mathrm{CH}_{2} \mathrm{Cl}_{2}$ or $\mathrm{CHCl}_{3}$ the color reverts to yellow. Comparison of magnetic and structural properties within this family of materials has led to the conclusion that hydrogen-bonding interactions between solvent molecules and the metal complexes tend to enhance the ligand field exerted on the $\mathrm{Fe}(\mathrm{II})$ center, and this obviously plays a key role for the spin-crossover behavior. ${ }^{203}$

\subsubsection{Hydrogen-bonded proton transfer assemblies}




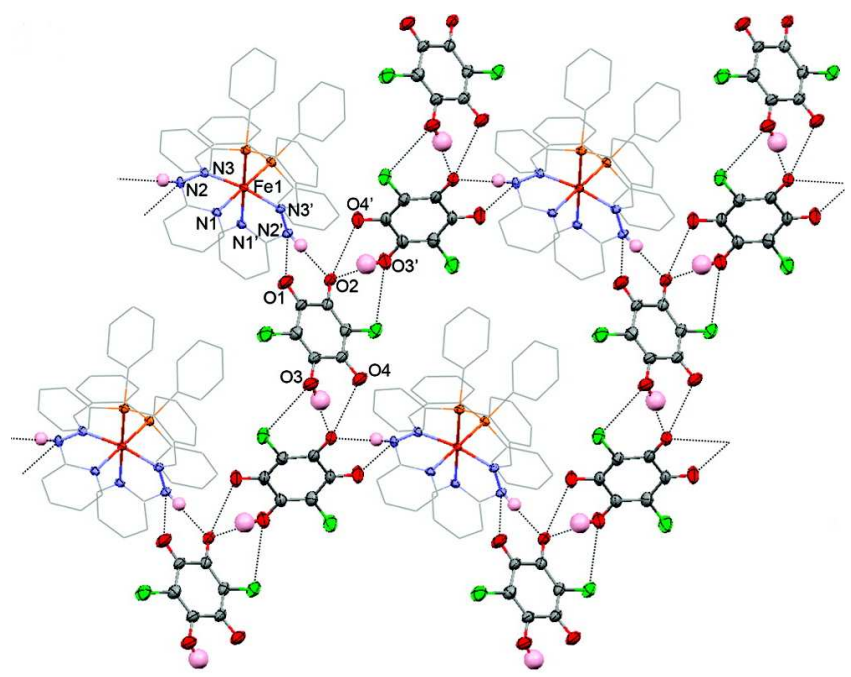

Figure 56. Extract from the crystal structure of 112.2THF. Reprinted with permission from ref. ${ }^{204}$. Copyright 2011 American Chemical Society.

A vapochromic hydrogen-bonded proton transfer (HBPT) assembly is obtained from reaction between $\mathrm{Fe}(\mathrm{pbph})_{2} \cdot 3 \mathrm{H}_{2} \mathrm{O}(\mathrm{pbph}=2$-(diphenylphosphino)benzaldehyde-2-pyridylhydrazone $)$ and chloranilic acid $\left(\mathrm{H}_{2} \mathrm{CA}\right)$ in $\mathrm{THF}^{204}$ The stoichiometry of the final compound is $\mathrm{Fe}(\mathrm{Hpbph})_{2}(\mathrm{HCA})_{2} \cdot 2 \mathrm{THF}(\mathbf{1 1 2} \cdot 2 \mathrm{THF})$, i. e., two protons are transferred from two chloranilic acid molecules to the pbph ligands. In the crystal structure of this compound (Figure 56) there are two 2D hydrogen-bonded sheets containing interactions between cationic metal complexes and $\mathrm{HCA}^{-}$, as well as interactions between individual $\mathrm{HCA}^{-}$anions. The $\mathrm{THF}$ guest molecules are located between these sheets. When $\mathbf{1 1 2} \cdot 2 \mathrm{THF}$ is heated to $158{ }^{\circ} \mathrm{C}$ all $\mathrm{THF}$ molecules are eliminated from the lattice. Subsequent exposure to vapors of THF restores the initial assembly. Adduct 112.2THF itself is susceptible to various organic vapors including aprotic and protic solvents. Diffuse reflectance reveals spectral changes around $610 \mathrm{~nm}$ with $\mathrm{CH}_{2} \mathrm{Cl}_{2}$ and $\mathrm{Et}_{2} \mathrm{O}$ producing distinctly different changes than $\mathrm{MeOH}$, EtOH or acetic acid. The spectral changes 
occurring with the protic solvents are perceived as a color change from brick-red to orange, resulting presumably from perturbation of hydrogen-bonding interactions in the HBPT assembly. The iron(II) center does not appear to be directly involved in the vapochromic behavior.

Palladium has also been incorporated into a vapochromic hydrogen-bonded proton transfer (HBPT) assembly. ${ }^{205}$ Specifically, a Pd(II)-hydrazone complex (PdBr(Hmtbhp); Hmtbhp = 2-(2(2-methylthio)benzylidene)hydrazinyl)pyridine) was combined with bromanilic acid $\left(\mathrm{H}_{2} \mathrm{BA}\right)$, a widely used building block for supramolecular architectures known for its ability to accept one electron and donate two protons. ${ }^{206}$, 207 The HBPT assembly 113 $\left([\mathrm{PdBr}(\mathrm{Hmtbhp})]_{2}(\mathrm{HBA})_{2}\left(\mathrm{H}_{2} \mathrm{BA}\right)\right)$ can uptake $\mathrm{CH}_{3} \mathrm{CN}$ reversibly, resulting in a color change from reddish purple to dark red. In the resulting solvent adduct the acetonitrile molecules form $1 \mathrm{D}$ channels along the crystallographic b-axis (Figure 57), and upon heating to $100{ }^{\circ} \mathrm{C}$ in argon atmosphere the guest-free assembly can be recovered.

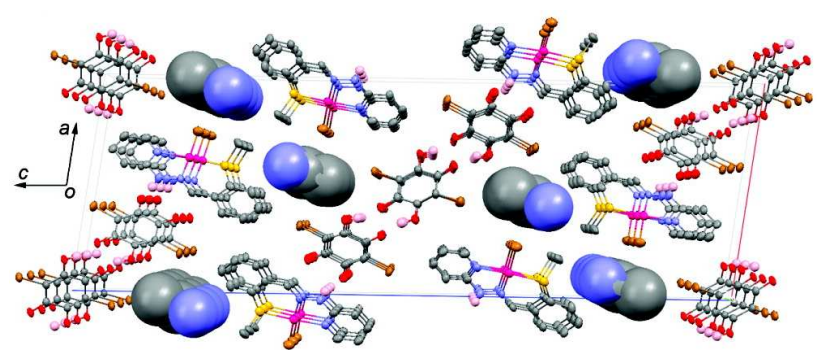

Figure 57. Packing diagram of HBPT assembly 113 with $\mathrm{CH}_{3} \mathrm{CN}$ guest molecules shown as space filling models. Reprinted with permission from ref. ${ }^{205}$. Copyright 2010 American Chemical Society.

However, acetonitrile removal alters the powder X-ray diffraction pattern significantly, indicating that the supramolecular assembly is not robust enough to retain its structure without 
the $\mathrm{CH}_{3} \mathrm{CN}$ guests. Depending on what solvent vapors HBPT assembly $\mathbf{1 1 3}$ is exposed to, the lowest energetic absorption band either blue-shifts (DMF, pyridine, dimethylacetoamide, DMSO) or red-shifts (1,4-dioxane, $\left.\mathrm{CH}_{3} \mathrm{CN}, \mathrm{MeOH}, \mathrm{EtOH}\right)$. The absorption band shifts seem to correlate with Gutmann donor and acceptor numbers of the solvents. ${ }^{208}$ Presumably, the hydrogen-bonding mode of the supramolecular assembly is fundamentally changed upon sorption of solvents with a high donor number, and such proton-accepting solvents seem to be adsorbed more easily than proton-donating solvents with a large acceptor number. Palladium does not appear to be directly involved in the vapochromic behavior of assembly 113; in this regard the classification of this material as a Pd-based vapochromic substance is not optimal.

\subsubsection{Metallophilic, $\pi-\pi$, and donor-acceptor interactions}

A zinc(II) complex of 1,3,5-tris( $p$-(2,2'-dipyridylamino)phenyl)benzene (TPDPB) (Scheme 42) can selectively detect benzene vapors at concentrations of $\sim 500 \mathrm{ppm} .{ }^{209}$ Depending on crystallization conditions, two different forms are obtained. When using a small amount of benzene in $\mathrm{CH}_{2} \mathrm{Cl}_{2}$, form $\mathrm{A}$ with the composition $\left[\left(\mathrm{ZnCl}_{2}\right)_{3}(\mathrm{TPDPB})\right] \cdot 3 \mathrm{CH}_{2} \mathrm{Cl}_{2} \cdot 0.25 \mathrm{C}_{6} \mathrm{H}_{6}$ $\left(\mathbf{1 1 4} \cdot 3 \mathrm{CH}_{2} \mathrm{Cl}_{2} \cdot 0.25 \mathrm{C}_{6} \mathrm{H}_{6}\right)$ crystallizes, whereas a 1:1 mixture of benzene and $\mathrm{CH}_{2} \mathrm{Cl}_{2}$ affords form B with the composition $\left[\left(\mathrm{ZnCl}_{2}\right)_{3}(\mathrm{TPDPB})\right] \cdot 3 \mathrm{C}_{6} \mathrm{H}_{6}\left(\mathbf{1 1 4} \cdot 3 \mathrm{C}_{6} \mathrm{H}_{6}\right)$. In the crystal structure of form A individual molecules of 114 build pairs with a separation of 3.85(1) $\AA$ between their central phenyl rings, and the TPDPB ligands are rotated by $120^{\circ}$ relative to each other to give a staggered face-to-face orientation. Benzene guest molecules are sandwiched between two pairs of host molecules, undergoing $\pi-\pi$ stacking with the central phenyl rings of 114 at an interplanar distance of 3.60(1) $\AA$. In form B the molecular packing is fundamentally different with both 
edge-to-edge and face-to-face interactions between benzene and the host present. The occurrence of two forms of benzene inclusion structures was taken as evidence for the affinity of $\mathbf{1 1 4}$ for benzene, and hence the benzene-sensing properties of this compound were tested by depositing it onto a polydimethylsiloxane (PDMS) bead which was attached onto an optical fiber tip. In the solid state, 114 is blue photoluminescent $\left(\lambda_{\max }=430 \mathrm{~nm}\right)$ with an emission band resembling that of the free TPDPB ligand, only red-shifted by $\sim 30 \mathrm{~nm}$. Upon exposure to vapors of benzene the emission is quenched, presumably because the benzene guests undergo $\pi-\pi$ stacking with the host, similar to what is observed in the two crystal structures discussed above. Interestingly, toluene, xylene, and ethyl benzene induce a much weaker response, similar to what is observed for hexane, cyclohexane, methanol, ethanol, $\mathrm{CH}_{2} \mathrm{Cl}_{2}$, trichloroethylene, or perchloroethylene. Thus, compound $\mathbf{1 1 4}$ exhibits a remarkable selectivity for benzene vapors.

Scheme 42. Zinc(II) complexes investigated in the context of vapochromism.
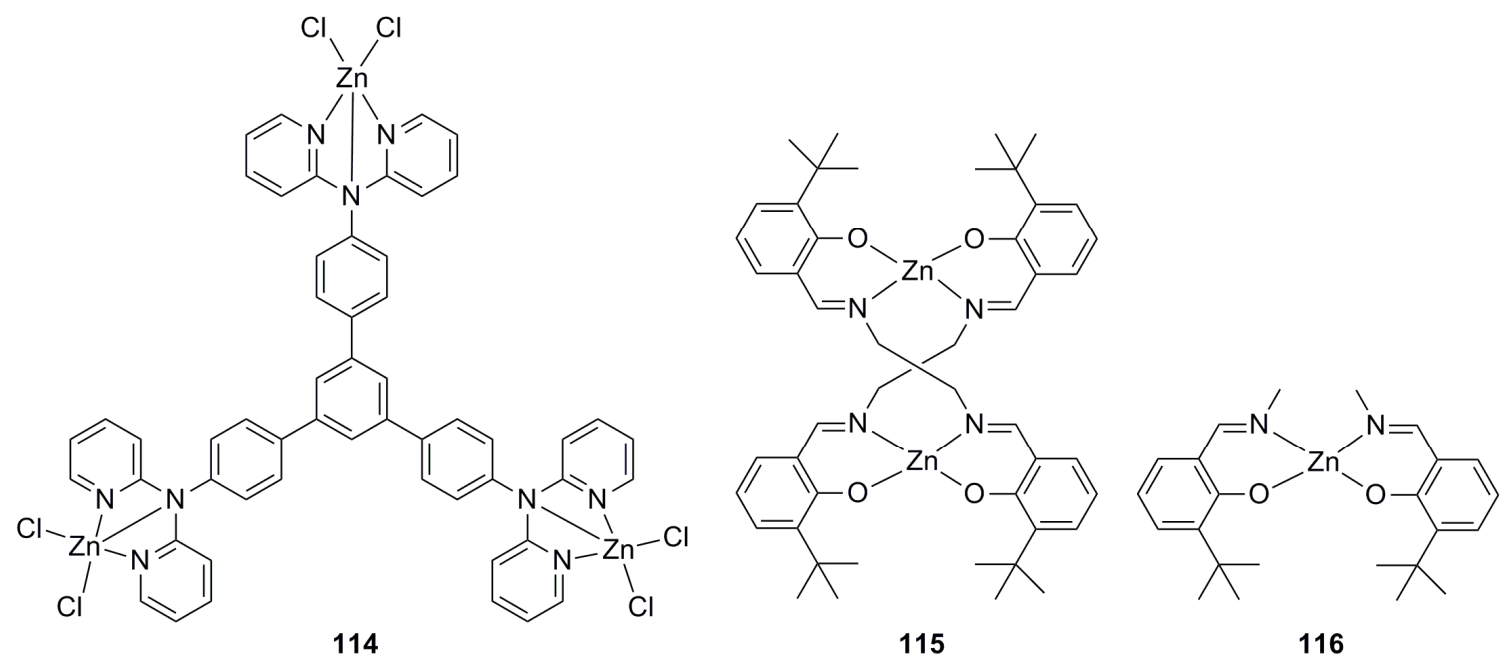

A helical zinc(II) dimer complex with two 3,3'-di-tert-butylsalen ( ${ }^{t}$ Busalen) ligands (115) shows mechanochromic and vapochromic behavior. ${ }^{210}$ The $\left[\mathrm{Zn}_{2}\left({ }^{t} \text { Busalen }\right)_{2}\right]$ complex is green 
photoluminescent $\left(\lambda_{\max }=473 \mathrm{~nm}\right)$, quite different from its monomer analogue (116) which emits blue light upon UV irradiation $\left(\lambda_{\max }=456 \mathrm{~nm}\right)$. The X-ray crystal structure of the dimer complex 115 reveals significant intramolecular $\pi-\pi$ stacking interactions between individual phenyl rings of the ${ }^{t}$ Busalen ligands. Mechanical grinding of 115 or exposure to THF vapor produces a blue luminescent substance, suggesting at first glance that these external stimuli disrupt the intramolecular $\pi-\pi$ interactions, leading to non-interacting luminophors which exhibit similar emission properties as the monomer reference substance (116). However, careful analysis of X-ray diffraction and emission data of $115 \cdot \mathrm{THF}$ and $115 \cdot \mathrm{MeOH}$ reveals that the emission color is in fact correlated with the crystal packing structure and that intermolecular $\pi$ - $\pi$ stacking is the key to the change in photoluminescence color. ${ }^{210}$

Scheme 43. A vapochromic silver(I) complex.

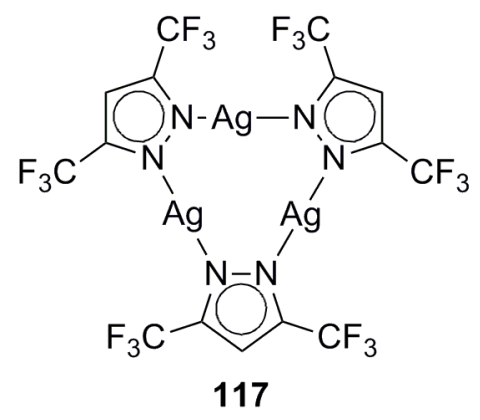

The trinuclear pyrazolyl-bridged silver(I) complex $\left[\left[3,5-\left(\mathrm{CF}_{3}\right)_{2} \mathrm{pz}\right] \mathrm{Ag}\right]_{3}$ (117) (Scheme 43) forms $\pi$-acid/ $\pi$-base binary adducts with benzene and some of its methylated derivatives. ${ }^{211} \mathrm{X}$ ray crystal structure analysis of a benzene adduct reveals the presence of discrete tetramolecular units comprised of a benzene $/ \mathbf{1 1 7} / \mathbf{1 1 7} /$ benzene sequence. Being a stronger $\pi$-base than benzene, mesitylene is able to overcome the argentophilic interactions between neighboring complexes, 
and consequently an infinite chain of $\mathbf{1 1 7 / m e s i t y l e n e / 1 1 7 / m e s i t y l e n e ~ u n i t s ~ i s ~ f o r m e d ~ w i t h ~ t h i s ~}$ compound. This difference in packing structure between benzene and mesitylene adducts has important implications for the photoluminescence behavior. While neat $\mathbf{1 1 7}$ is non-emissive, the benzene adduct shows green luminescence $\left(\lambda_{\max } \approx 520 \mathrm{~nm}\right)$ and the mesitylene adduct emits in the blue spectral range $\left(\lambda_{\max } \approx 410 \mathrm{~nm}\right)$. The green luminescence has been attributed to excimeric states involving argentophilic interactions, ${ }^{212}$ the disruption of these intermetallic contacts in the mesitylene adduct leads to blue emission. Thin films of $\mathbf{1 1 7}$ respond to vapors of benzene, toluene, and mesitylene with a luminescence turn-on response, in line with the formation of the solvent adducts described above. Aromatic solvents with electron-withdrawing substituents such as chlorobenzene and hexafluorobenzene do not switch on the luminescence. Similarly, nonaromatic solvents such as acetone, methanol, and THF do not trigger a response. These observations support the notion of $\pi$-acid/ $\pi$-base interactions in the benzene, toluene, and mesitylene adducts.

Hupp and coworkers explored a variety of molecular rectangles based on rhenium(I) tricarbonyl diimines, ${ }^{213}$ and one of them exhibits vapoluminescence. ${ }^{214}$ Notably, it is a chargeneutral compound (118) (Scheme 44) in which no counterions are blocking the channels formed within and between individual rectangles. The crystal structure of $\left[\operatorname{Re}(\mathrm{CO})_{3}(\right.$ bibzim $)\left(4,4^{\prime}-\right.$ bpy) $\left.\operatorname{Re}(\mathrm{CO})_{3}\right]_{2}(\mathbf{1 1 8})$ (bibzim $=2,2$ '-bibenzimidazole) contains both intra- and intermolecular vacancies of rectangular shape and similar size $(\sim 10 \AA \times 6 \AA)$. The emission intensity of 118 changes upon exposure to various VOCs, the affinity of thin films of $\mathbf{1 1 8}$ for aromatic compounds decreases along the series toluene $>4$-fluorotoluene $>$ benzene $>$ fluorobenzene $>$ hexafluorobenzene. This order suggests that electron donor/acceptor (host/guest) interactions might play an important role for guest uptake. The host/guest stoichiometry can exceed unity, 
indicating that the guest molecules fill both intra- and intermolecular cavities. The estimated internal surface area is $\sim 120 \mathrm{~m}^{2} / \mathrm{g}$.

Scheme 44. Vapochromic rhenium(I) and iridium(III) complexes.

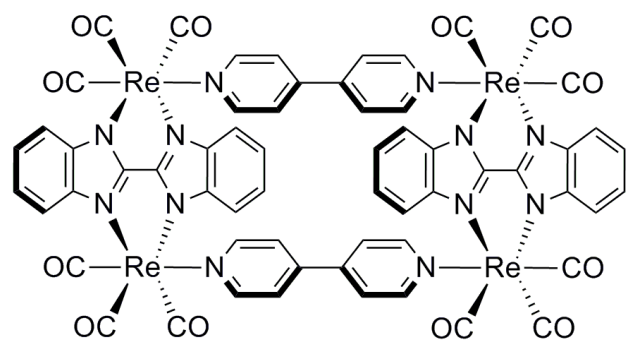

118

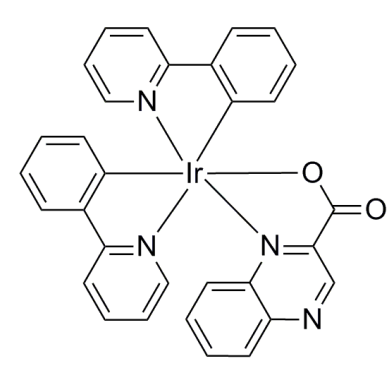

119

Many cyclometalated iridium(III) complexes exhibit favorable emission properties which makes them interesting for triplet harvesting in OLEDs. ${ }^{215,} 216$ The $\left[\operatorname{Ir}(p p y)_{2}(q x n)\right]$ (ppy $=2$ phenylpyridine, qxn = quinoxaline-2-carboxylate) complex (119) can be crystallized in two differently colored forms one of which can be converted into the other by exposure to $\mathrm{CH}_{3} \mathrm{CN}$ vapor. $^{217}$ From mixed ethanol/chloroform solution one obtains black crystals of 119.0.25EtOH$\cdot 0.5 \mathrm{CHCl}_{3}$ while from acetonitrile/chloroform red crystals of $119 \cdot \mathrm{CH}_{3} \mathrm{CN}$ are formed. In the black form there are $\pi-\pi$ interactions between qxn ligands from different complexes which may lead to an energetic stabilization of the ligand-based LUMO with respect to the red structure in which such $\pi-\pi$ interactions are absent hence the different colors of the two forms. The black form is weakly emissive with $\lambda_{\max }=692 \mathrm{~nm}$ and a decay time of only $43 \mathrm{~ns}$, but the red form exhibits intense photoluminescence at $654 \mathrm{~nm}$ with a lifetime of $130 \mathrm{~ns}$. Exposure of black 119.0.25EtOH$\cdot 0.5 \mathrm{CHCl}_{3}$ to acetonitrile vapor converts it to the red form within $\sim 1$ minute while several other VOC vapors (propionitrile, acetone, acetic acid, ethyl 
acetate, methanol, ethanol, 2-propanol, pyridine, THF, diethyl ether, $\mathrm{CH}_{2} \mathrm{Cl}_{2}, \mathrm{CHCl}_{3}, \mathrm{CH}_{3} \mathrm{I}$, hexane, benzene) gave no response. Reconversion of the red form to the black form does not occur as easily, and the most efficient procedure is to dissolve the complex in $\mathrm{CHCl}_{3}$ followed by subsequent evaporation of the solvent.

\subsubsection{Vapochromism in coordination polymers and metal-organic frameworks}

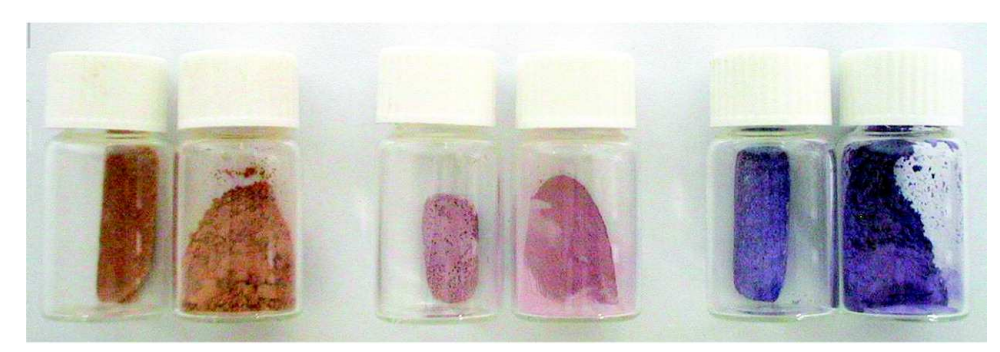

Figure 58. Left: Anhydrous $\mathrm{Cu}(\mathrm{pz})_{2}(\mathbf{1 2 0})$; middle: $\mathrm{Cu}(\mathrm{pz})_{2} \cdot \mathrm{H}_{2} \mathrm{O}\left(\mathbf{1 2 0} \cdot \mathrm{H}_{2} \mathrm{O}\right)$; right: $\mathrm{Cu}(\mathrm{pz})_{2} \cdot \mathrm{NH}_{3}$ $\left(\mathbf{1 2 0} \cdot \mathrm{NH}_{3}\right)$. Reprinted with permission from ref. ${ }^{218}$. Copyright 2009 American Chemical Society.

The $\mathrm{Cu}(\mathrm{pz})_{2}$ compound ( $\mathrm{pz}=$ pyrazolato) $(\mathbf{1 2 0})$ is most easily obtained in the form of a pink hydrate $\left(\mathbf{1 2 0} \cdot \mathrm{H}_{2} \mathrm{O}\right)$. This material forms a 1D coordination polymer with weakly bound water molecules and $\mathrm{Cu}-\mathrm{O}$ distances of 2.913(4) $\AA^{219}$ Gentle heating leads to the anhydrous beige form. In humid air the beige substance readily reconverts to the pink hydrate but under dry conditions anhydrous $\mathbf{1 2 0}$ can be used for detection of $\mathrm{NH}_{3}$, methylamine, methanol, ethanol, acetonitrile, and pyridine vapors. The resulting materials are solvent adducts of the general formula 120 solvent and exhibit colors ranging from pink (methanol and acetonitrile adduct) to blue (other adducts). However, vapor uptake is slow and requires between 20 minutes $\left(\mathrm{NH}_{3}\right)$ and 2 days (ethanol) in order to be complete. 
The structural changes accompanying water sorption of $\mathbf{1 2 0}$ have been studied in detail. ${ }^{218}$ Interestingly the anhydrous form has no pores yet $\mathrm{H}_{2} \mathrm{O}$ uptake occurs with remarkable ease (within 2 minutes), and hence it has been noted that this material exhibits "porosity without pores".

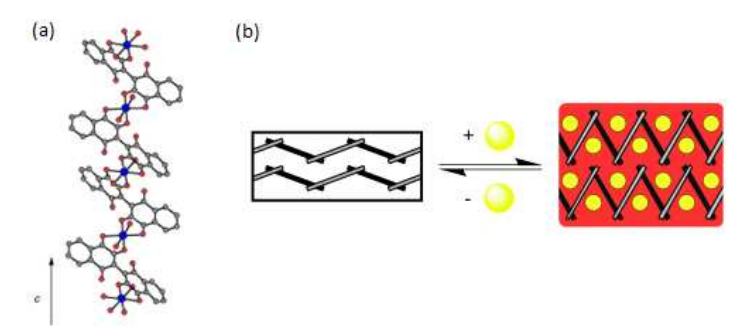

Figure 59. (a) Chain of $\left[\mathrm{Cu}(\right.$ bhnq $\left.)\left(\mathrm{H}_{2} \mathrm{O}\right)_{2}\right]$ complexes in $\left(\mathbf{1 2 1} \cdot \mathrm{H}_{2} \mathrm{O} \cdot 3 \mathrm{EtOH}\right)$; (b) schematic representation of the hinge-like behavior of the 2,2'-bi(3-hydroxy-1,4-naphthoquinone) ligand upon VOC uptake. (K. Yamada, S. Yagishita, H. Tanaka, K. Tohyama, K. Adachi, S. Kaizaki, H. Kumagai, K. Inoue, R. Kitaura, H.-C. Chang, S. Kitagawa, S. Kawata: Metal-Complex Assemblies Constructed From the Flexible Hinge-Like Ligand $\mathrm{H}_{2}$ bhnq: Structural Versatility and Dynamic Behavior in the Solid State. Chem. Eur. J., 2004, 10, 2647-2660. Copyright WileyVCH Verlag GmbH \& Co. KGaA. Reproduced with permission.)

When reacting $\mathrm{CuSO}_{4}$ and the 2,2'-bi(3-hydroxy-1,4-naphthoquinone) ligand $\left(\mathrm{H}_{2}\right.$ bhnq) in water-ethanol mixtures one obtains a coordination polymer of formulation $\left[\left[\mathrm{Cu}(\text { bhnq })\left(\mathrm{H}_{2} \mathrm{O}\right)_{2}\left(\mathrm{H}_{2} \mathrm{O}\right)(\mathrm{EtOH})_{3}\right]_{\mathrm{n}} \quad\left(\mathbf{1 2 1} \cdot \mathrm{H}_{2} \mathrm{O} \cdot 3 \mathrm{EtOH}\right)\right.$ which has infinite $1 \mathrm{D}$ chains of $\left[\mathrm{Cu}\left(\right.\right.$ bhnq) $\left.\left(\mathrm{H}_{2} \mathrm{O}\right)_{2}\right]$ units (Figure 59) with interstitial ethanol and water molecules. ${ }^{220}$ The chelating bhnq ${ }^{2-}$ ligands bridge neighboring $\mathrm{Cu}(\mathrm{II})$ centers in an anti fashion to form zigzag 
chains, the coordination sphere around each metal is a distorted octahedron with four O-atoms from two bhnq ${ }^{2-}$ ligands and two water molecules. Once removed from the mother liquor red crystals of $121 \cdot \mathrm{H}_{2} \mathrm{O} \cdot 3 \mathrm{EtOH}$ turn black due to loss of ethanol, but this process is reversible for example when using $\mathrm{MeOH}$ or $\mathrm{EtOH}$ vapor. Crystallographic investigations show that the $\mathrm{Cu}(\mathrm{II})-\mathrm{Cu}(\mathrm{II})$ distance shortens when going from the black to the red form, the reason being that sorbed EtOH molecules establish a hydrogen-bonding network with the bhnq ${ }^{2-}$ ligands and the coordinated waters. These noncovalent interactions lead to a contraction of the 1D chains which is possible thanks to the flexible hinge-like structure of the bhnq ${ }^{2-}$ ligand (Figure 59).

In THF the reaction between $\mathrm{CuSO}_{4}$ and the $\mathrm{H}_{2}$ bhnq ligand leads to the compound $\left[\left[\mathrm{Cu}(\mathrm{bhnq})(\mathrm{THF})_{2}\right](\mathrm{THF})\right]_{\mathrm{n}}(\mathbf{1 2 2} \cdot \mathrm{THF}) .{ }^{221}$ This material forms similar $1 \mathrm{D}$ chains as compound 121 $\cdot \mathrm{H}_{2} \mathrm{O} \cdot 3 \mathrm{EtOH}$ only with THF ligands and additional interstitial THF molecules which can be removed in vacuum. The de-solvated form has a longer $\mathrm{Cu}(\mathrm{II})-\mathrm{Cu}(\mathrm{II})$ distance than the THF solvate ( 6.45 vs. $7.8 \AA$ ), and a shift of the absorption band maximum in the visible spectral range from 500 to $540 \mathrm{~nm}$ accompanies de-solvation. THF uptake restores the initial material, and the reversibility of this transformation has been attributed to the hinge-like bhnq ${ }^{2-}$ ligand.

Depending on reaction conditions two different forms of a vapochromic metal-organic framework (MOF) can be obtained from the reaction of $\mathrm{CuI}$ with 1,4-diazabicyclo[2.2.2] octane (DABCO ${ }^{222}$ In both forms DABCO completes the coordination sphere of $\mathrm{Cu}(\mathrm{I})$ by ligating to four corners of the $\mathrm{Cu}_{4} \mathrm{I}_{4}$ cubane-like clusters. In form A (obtained from aqueous solution) the supertetrahedral $\left[\mathrm{Cu}_{4} \mathrm{I}_{4}(\mathrm{DABCO})_{4}\right]$ units are arranged in a self-interpenetrating network (123a). In form $\mathrm{B}$ (obtained from $\mathrm{CH}_{3} \mathrm{CN}$ solution, 123b) two independent networks interpenetrate each other. In both forms there is $\sim 20 \%$ of volume accessible for solvent molecules because there are channels of $\sim 7 \AA$ diameter propagating through the crystalline lattices. Both forms exhibit long- 
lived $(\tau=8.0,13.4 \mu \mathrm{s})$ emission from cluster-centered excited states $\left({ }^{3} \mathrm{CC}\right)$ which might have some admixture from XMCT states resulting from iodide-to-copper charge transfer. Emission occurs with large Stokes shifts (11400 and $\left.10700 \mathrm{~cm}^{-1}\right)$ indicative of strong excited-state distortions and significant structural reorganization of the photoexcited cubane-like clusters. The clusters are not exactly identical in both forms, consequently, the emission occurs at slightly different wavelengths (form A: $\lambda_{\max }=580 \mathrm{~nm}$; form B: $\lambda_{\max }=556 \mathrm{~nm}$ ). This fact can be exploited for vapoluminescence sensing because exposure of form A to vapors of acetonitrile induces a structural conversion to form B.
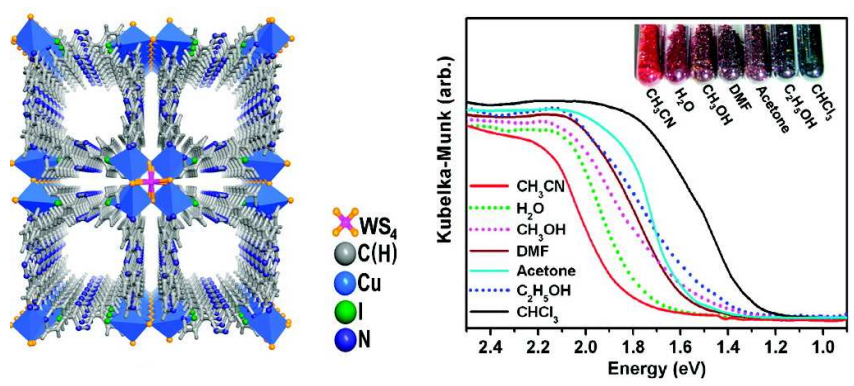

Figure 60. Left: Nanotubular structure of $\left[\left(\mathrm{WS}_{4} \mathrm{Cu}_{4}\right) \mathrm{I}_{2}(\mathrm{dptz})_{3}\right]_{\mathrm{n}}(\mathbf{1 2 4})$; right: UV-Vis spectra and photographs of different solvent adduct of 124. Reprinted with permission from ref. ${ }^{223}$. Copyright 2011 American Chemical Society.

Reaction of $\left(\mathrm{NH}_{4}\right)_{2} \mathrm{WS}_{4}, \mathrm{CuI}$, and dptz (dptz = 3,6-(dipyridin-4-yl)-1,2,4,5-tetrazine) in DMF yields a nanotubular metal-organic framework with the stoichiometry $\left[\left[\left(\mathrm{WS}_{4} \mathrm{Cu}_{4}\right) \mathrm{I}_{2}(\mathrm{dptz})_{3}\right] \cdot \mathrm{DMF}\right]_{\mathrm{n}}(\mathbf{1 2 4} \cdot \mathrm{DMF})$ in which each $\mathrm{WS}_{4}{ }^{2-}$ anion chelates four $\mathrm{Cu}(\mathrm{I})$ cations (Figure 60). ${ }^{223}$ Each $\mathrm{Cu}(\mathrm{I})$ center is tetrahedrally coordinated, individual $\mathrm{WS}_{4} \mathrm{Cu}_{4}{ }^{2+}$ units are paired up by pyrazines which exhibit $\pi-\pi$ interactions at interplanar distances of 3.578(2) A. 
There are square-shaped $(5.4 \times 5.3 \AA)$ nanotubes along the c-axis containing DMF guests which can be removed at $100{ }^{\circ} \mathrm{C}$. Immersion of the de-solvated MOF into various organic solvents causes significant color changes that can also be induced by exposure to the respective vapors, albeit leading to a much slower response. Systematic studies revealed a negative solvatochromic effect with a solvent-induced absorption band shift of $245 \mathrm{~nm}$ between $\mathrm{CH}_{3} \mathrm{CN}$ and $\mathrm{CHCl}_{3}$ (Figure 60). Moreover, there is a good correlation between the magnitude of the absorption band shift and the Reichardt solvent polarity parameter. ${ }^{224}$ The strong $\pi$-acceptor property of the dptz ligand is believed to play a key role for this solvatochromic and vapochromic behavior, a structurally analogous MOF with 2,2'-bipyridine instead of dptz does not show such behavior. ${ }^{223}$

\subsubsection{Vapochromism in cyanometallates}

2,2'-Bipyridinetetracyanoruthenate(II) complexes exhibit strongly solvent-dependent absorption and luminescence properties, ${ }^{225-229}$ and a few of them (or closely related complexes) are sensitive to vapors of certain chemical substances. For instance, the $\mathrm{Ru}\left(4,4^{\prime}-{ }^{t} \mathrm{Bubpy}\right)_{2}(\mathrm{CN})_{2}$ complex (125) is responsive to water vapor. $^{230} \mathbf{1 2 5}, \mathbf{1 2 5} \cdot \mathrm{H}_{2} \mathrm{O}$, and $\mathbf{1 2 5} \cdot 2 \mathrm{H}_{2} \mathrm{O}$ exhibit luminescence band maxima at 740, 685, and $640 \mathrm{~nm}$, i. e., there is a correlation between emission peak and number of crystal waters. Simultaneously, the increase in the number of crystal waters is accompanied by a decrease of the CN stretching frequency in the IR spectrum. Thin films of $\mathbf{1 2 5}$ are most sensitive to moisture, operating at water vapor pressures as low as $10^{-}$ ${ }^{2} \mathrm{~Pa}$. Complex 125 is also responsive to vapors of various VOCs. ${ }^{231}$ Neat $\mathbf{1 2 5}$ has an emission band maximum at $740 \mathrm{~nm}$, but $\lambda_{\max }$ shifts to $700 \mathrm{~nm}$ when exposed to benzene, to $660 \mathrm{~nm}$ for quinoline, $650 \mathrm{~nm}$ for $\mathrm{CH}_{2} \mathrm{Cl}_{2}$, and $640 \mathrm{~nm}$ for $\mathrm{MeOH}$ and pyridine. Thus, complex 125 has a 
certain discrimination capability for several VOCs, which parallels its solvatochromic behavior. In fluid solution there is a good correlation between the MLCT energy and the acceptor number $(\mathrm{AN})^{232}$ of the solvent, furthermore the $\mathrm{CN}$ stretching frequencies correlate with $\mathrm{AN}$.

The tetrakis(bis-3,5-trifluoromethylphenylborate) ( $\left.\mathrm{tfpb}^{-}\right)$salt of tris(5,6-dimethyl-1,10phenanthroline)ruthenium(II) (126) is an excellent sensor for benzene vapors at concentrations down to $7600 \mathrm{ppm}^{233}$ The vapoluminescence effect manifests in a rapid spectral change dominated by a shift in emission band maximum from 572 to $558 \mathrm{~nm}$. The most interesting aspect of $\left[\mathrm{Ru}\left(5,6-\mathrm{Me}_{2} \text { phen }\right)_{3}\right](\mathrm{tfpb})_{2}$ is its cross-sensitivity for the simultaneous sensing of benzene and oxygen. $\mathrm{O}_{2}$ quenches the luminescence of neat $\mathbf{1 2 6}$, but simultaneous exposure to vapors of benzene and $\mathrm{O}_{2}$ leads to benzene uptake and very little emission quenching is observed. A crystal structure of $\mathbf{1 2 6} \cdot 1.5 \mathrm{C}_{6} \mathrm{H}_{6}$ reveals that benzene guest molecules block channels in the crystal structure in such a way that oxygen diffusion can be suppressed.

\section{Summary of detectable VOCs}

Even though many of the vapochromic and vapoluminescent coordination complexes from the previous sections cannot realistically be used in real-world applications for reasons explained for each individual case above, a summary of analytes which can be detected and, where available, quantitative information regarding sensitivity is given in Table 1. The table lists the vapochromic substances in the same order as they appear in the text, for the abbreviations used the reader is referred to the text.

Table 1. Summary of vapochromic sensing materials and analytes considered in this review. 


\begin{tabular}{|c|c|}
\hline sensing material & analyte \\
\hline$\left[\mathrm{Pt}(\mathrm{bpy})(\mathrm{CN})_{2}\right](\mathbf{1})$ & $\mathrm{HF}, \mathrm{H}_{2} \mathrm{O}, \mathrm{H}_{2} \mathrm{~S}^{35,38}$ \\
\hline$\left[\mathrm{Pt}\left(5,5^{\prime}-\mathrm{Me}_{2} \mathrm{bpy}\right)(\mathrm{CN})_{2}\right](\mathbf{5})$ & $\mathrm{H}_{2} \mathrm{O}^{37}$ \\
\hline$\left[\mathrm{Pt}\left(4,4^{\prime}-\mathrm{H}_{2} \mathrm{dcbpy}\right)(\mathrm{CN})_{2}\right](\mathbf{6})$ & $\begin{array}{l}\mathrm{DMSO}, \mathrm{DMF}, \mathrm{CH}_{3} \mathrm{CN}, \mathrm{EtOH}, \mathrm{MeOH} \text {, } \\
\mathrm{Me}_{2} \mathrm{CO}, \mathrm{CH}_{2} \mathrm{Cl}_{2}, \mathrm{CHCl}_{3}, \mathrm{CH}_{3} \mathrm{COOH}, \mathrm{CCl}_{4} \text {, } \\
\mathrm{C}_{6} \mathrm{H}_{6}{ }_{13,39}\end{array}$ \\
\hline $\mathrm{Na}_{2}\left[\mathrm{Pt}(\mathrm{dcbpy})(\mathrm{CN})_{2}\right] \cdot 2 \mathrm{H}_{2} \mathrm{O}\left(\mathbf{7} \cdot 2 \mathrm{H}_{2} \mathrm{O}\right)$ & $\mathrm{MeOH}, \mathrm{Me}_{2} \mathrm{CO}, \mathrm{DMF}^{40}$ \\
\hline$\left[\mathrm{Pt}\left(4,4^{\prime}-\mathrm{H}_{2} \mathrm{dcbpy}\right)(\mathrm{SCN})_{2}\right](\mathbf{8})$ & $\begin{array}{l}\text { DMSO, DMF, dimethylacetamide, } \mathrm{MeOH} \text {, } \\
\text { EtOH, } \mathrm{Me}_{2} \mathrm{CO}, \mathrm{CH}_{3} \mathrm{CN}^{50}\end{array}$ \\
\hline $\mathrm{Zn}\left[\mathrm{Pt}\left(5,5^{\prime}-\mathrm{dcbpy}\right)(\mathrm{CN})_{2}\right](\mathrm{Zn9})$ & $\mathrm{H}_{2} \mathrm{O}^{4 \mathrm{I}}$ \\
\hline $\begin{array}{l}\mathrm{Mg} / \mathrm{Ca} / \mathrm{Sr} / \mathrm{Ba}\left[\mathrm{Pt}\left(5,5^{\prime} \text {-dcbpy }\right)(\mathrm{CN})_{2}\right] \\
(\mathrm{Mg} / \mathrm{Ca} / \mathrm{Sr} / \mathrm{Ba} 9)\end{array}$ & $\mathrm{H}_{2} \mathrm{O}, \mathrm{MeOH}^{42}$ \\
\hline$\left[\mathrm{Pt}\left({ }^{t} \mathrm{Bu}_{2} \mathrm{bpy}\right)(4 \text {-ethynylpyridine })_{2}\right](\mathbf{1 0})$ & $\mathrm{CH}_{2} \mathrm{Cl}_{2}(25 \mathrm{ppm}), \mathrm{CHCl}_{3}(450 \mathrm{ppm})^{59}$ \\
\hline$\left[\mathrm{Pt}\left({ }^{t} \mathrm{Bu}_{2} \mathrm{bpy}\right)\left(\mathrm{C} \equiv \mathrm{C}-\mathrm{C}_{6} \mathrm{~F}_{5}\right)_{2}\right](\mathbf{1 1})$ & $\mathrm{CH}_{2} \mathrm{Cl}_{2}{ }^{59}$ \\
\hline $\left.\mathrm{Pt}\left({ }^{t} \mathrm{Bu}_{2} \mathrm{bpy}\right)(\text { ethynyltriarylboron })_{2}\right](\mathbf{1 2})$ & $\begin{array}{l}\mathrm{CH}_{2} \mathrm{Cl}_{2}, \mathrm{CHCl}_{3}, \mathrm{Me}_{2} \mathrm{CO}, \mathrm{EtOH}, \mathrm{CH}_{3} \mathrm{CN} \text {, } \\
\mathrm{THF} \text { : green luminescence; toluene, hexane, } \\
\text { MeOH: luminescence quenching; benzene, } \\
\text { cyclohexane: red emission } 60\end{array}$ \\
\hline $\begin{array}{l}{\left[\mathrm{Pt}\left(5,5^{\prime} \text { '-bis }(\mathrm{TMS}-\mathrm{C} \equiv \mathrm{C}) \text {-bpy }\right)_{2}(5 \text {-ethynyl-bpy })_{2}\right]} \\
(\mathbf{1 3})\end{array}$ & $\begin{array}{l}\mathrm{Me}_{2} \mathrm{CO}, \quad \mathrm{CH}_{2} \mathrm{Cl}_{2}, \quad n \text {-hexane, and many } \\
\text { others }\end{array}$ \\
\hline$\left.\left[\mathrm{Pt}\left(5,5^{\prime} \text {-bis(TMS-C } \equiv \mathrm{C}\right)-\mathrm{bpy}\right)_{2}\left(\mathrm{C} \equiv \mathrm{CC}_{6} \mathrm{H}_{5}\right)_{2}\right](\mathbf{1 4})$ & $\mathrm{CH}_{2} \mathrm{Cl}_{2}, \mathrm{CHCl}_{3}, \mathrm{CH}_{3} \mathrm{I}^{67}$ \\
\hline $\begin{array}{l}{\left[\mathrm{Pt}\left(5,5^{\prime} \text {-bis }(\mathrm{TMS}-\mathrm{C} \equiv \mathrm{C})-\mathrm{bpy}\right)_{2}\left(\mathrm{C} \equiv \mathrm{CC}_{6} \mathrm{H}_{4} \mathrm{~F}-3\right)_{2}\right]} \\
(\mathbf{1 5})\end{array}$ & $\mathrm{CHCl}_{3}{ }^{68}$ \\
\hline $\begin{array}{l}{\left[\mathrm{Pt}\left(5,5^{\prime} \text {-bis }(\mathrm{TMS}-\mathrm{C} \equiv \mathrm{C})-\mathrm{bpy}\right)_{2}\left(\mathrm{C} \equiv \mathrm{CC}_{6} \mathrm{H}_{4} \mathrm{~F}-4\right)_{2}\right]} \\
(\mathbf{1 6})\end{array}$ & $\mathrm{CH}_{2} \mathrm{Cl}_{2}, \mathrm{CHCl}_{3}{ }^{68}$ \\
\hline $\begin{array}{l}{\left[\mathrm{Pt}\left(5,5^{\prime} \text {-bis }(\mathrm{TMS}-\mathrm{C} \equiv \mathrm{C})-\mathrm{bpy}\right)_{2}\left(\mathrm{C} \equiv \mathrm{CC}_{6} \mathrm{H}_{4}-\mathrm{CF}_{3}-4\right)_{2}\right]} \\
(\mathbf{1 7})\end{array}$ & dioxane, THF, THP ${ }^{69}$ \\
\hline$c i s-\left[\mathrm{Pt}\left(\mathrm{CN}-\mathrm{C}_{6} \mathrm{H}_{4}-\mathrm{C}_{2} \mathrm{H}_{5}\right)_{2}(\mathrm{CN})_{2}\right],(c i s-\mathbf{1 8})$ & $\begin{array}{l}\text { toluene, benzene, chlorobenzene, } p \text {-xylene, } \\
\text { mesitylene, EtOH }{ }^{70}\end{array}$ \\
\hline$c i s-\left[\mathrm{Pt}\left(\mathrm{CN}-{ }^{i} \mathrm{C}_{3} \mathrm{H}_{7}\right)_{2}(\mathrm{CN})_{2}\right]($ cis-19) & benzene (selective) $^{72}$ \\
\hline$\left[\mathrm{Pt}\left(\mathrm{CN}-{ }^{t} \mathrm{Bu}\right)_{2}(\mathrm{CN})_{2}\right](\mathbf{2 0})$ & $\begin{array}{l}\mathrm{MeOH}, \mathrm{CH}_{3} \mathrm{CN} \text {, toluene; no response to: } \\
\mathrm{THF}, \mathrm{Me}_{2} \mathrm{CO}, \text { EtOAc, } \mathrm{Et}_{2} \mathrm{O} \text {, petroleum }\end{array}$ \\
\hline
\end{tabular}




\begin{tabular}{|c|c|}
\hline & 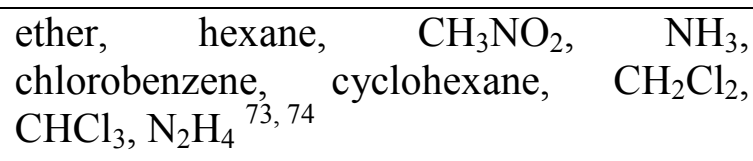 \\
\hline$\left[\mathrm{Pt}\left(\mathrm{CN}_{-}{ }^{i} \mathrm{C}_{3} \mathrm{H}_{7}\right)_{4}\right]\left[\mathrm{Pt}(\mathrm{CN})_{4}\right](\mathbf{2 1})$ & $\mathrm{H}_{2} \mathrm{O}, \mathrm{MeOH}, \mathrm{CF}_{3} \mathrm{CH}_{2} \mathrm{OH}, \mathrm{CHCl}_{3}{ }^{75}$ \\
\hline$\left[\mathrm{Pt}\left(\mathrm{CN}-\mathrm{C}_{6} \mathrm{H}_{4}-\mathrm{C}_{10} \mathrm{H}_{21}\right)_{4}\right]\left[\mathrm{Pd}(\mathrm{CN})_{4}\right](\mathbf{2 3})$ & $\begin{array}{l}\mathrm{CHCl}_{3} \text { (response time } 350 \mathrm{~ms} \text { ), } \mathrm{MeOH} \text {, } \\
\mathrm{CH}_{2} \mathrm{Cl}_{2} \text {, acetone } ;^{76,77} \text { detection limit for } \\
\mathrm{CHCl}_{3} \text { : a few } \mathrm{mg} / \mathrm{m}^{3}\end{array}$ \\
\hline$\left[\mathrm{Pt}\left(\mathrm{CN}-\mathrm{C}_{6} \mathrm{H}_{4}-\mathrm{C}_{10} \mathrm{H}_{21}\right)_{4}\right]\left[\mathrm{Pt}(\mathrm{CN})_{4}\right](\mathbf{2 4 c})$ & $\begin{array}{l}\mathrm{CHCl}_{3} \text { (response time } 500 \mathrm{~ms} \text { ), } \mathrm{CH}_{2} \mathrm{Cl}_{2} \text {, } \\
\mathrm{MeOH}, \text { EtOH, 2-propanol, } \mathrm{Et}_{2} \mathrm{O}, \mathrm{CH}_{3} \mathrm{CN} \text {, } \\
\text { hexanes, acetone, } \mathrm{C}_{6} \mathrm{H}_{6}{ }^{78}\end{array}$ \\
\hline$\left[\mathrm{Pt}\left(\mathrm{CN}-\mathrm{C}_{6} \mathrm{H}_{4}-\mathrm{C}_{10} \mathrm{H}_{21}\right)_{4}\right]\left[\mathrm{Pt}\left(\mathrm{NO}_{2}\right)_{4}\right](\mathbf{2 5})$ & $\mathrm{Me}_{2} \mathrm{CO}^{81}$ \\
\hline electronic nose made from $\mathbf{2 6}, \mathbf{2 7}, \mathbf{2 8}$ & $\begin{array}{l}\mathrm{CHCl}_{3}, \mathrm{H}_{2} \mathrm{O}, \mathrm{MeOH}, \mathrm{CH}_{2} \mathrm{Cl}_{2}, 1-\mathrm{PrOH}, n- \\
\text { hexane, cyclohexane }\end{array}$ \\
\hline electronic nose made from $26, \mathbf{2 7}, 29$ & $\begin{array}{l}\mathrm{Me}_{2} \mathrm{CO}\left(12 \% \text { saturation, } 75 \mathrm{~g} / \mathrm{m}^{3}\right), \mathrm{MeOH} \\
\left(3 \% \text { saturation, } 6 \mathrm{~g} / \mathrm{m}^{3}\right){ }^{84}\end{array}$ \\
\hline$\left[\mathrm{Pt}(\mathrm{CN} \text {-cyclododecyl })_{4}\right]\left[\mathrm{Pt}(\mathrm{CN})_{4}\right] \mathbf{( 3 0 )}$ & $\begin{array}{l}\mathrm{H}_{2} \mathrm{O} \text { (unique two-step response); } \\
\mathrm{CH}_{2} \mathrm{Cl}_{2} / \mathrm{CHCl}_{3} \text { (weaker two-step response); } \\
\text { benzene, toluene, } p \text {-xylene (one-step } \\
\text { response) }\end{array}$ \\
\hline $\begin{array}{l}{\left[\mathrm{Pt}(R / S \text { - } \beta \text {-methylphenethylisocyanide })_{4}\right]\left[\mathrm{Pt}(\mathrm{CN})_{4}\right]} \\
\text { (31) }\end{array}$ & $\begin{array}{l}\text { differentiates between } R-2-\mathrm{BuOH} \text { and } S-2- \\
\mathrm{BuOH} \text { at } 90 \% \text { confidence level }\end{array}$ \\
\hline $\begin{array}{l}{[\mathrm{Pt}(\mathrm{R}-\mathrm{tpy}) \mathrm{Cl}] \mathrm{X}\left(\mathrm{R}=\mathrm{H}, \mathrm{OC}_{4} \mathrm{H}_{9}, \mathrm{OC}_{6} \mathrm{H}_{13}, \mathrm{OC}_{8} \mathrm{H}_{17},\right.} \\
\mathrm{OC}_{12} \mathrm{H}_{25} ; \mathrm{X}=\mathrm{Cl}^{-}, \mathrm{ClO}_{4}^{-}, \mathrm{PF}_{6}^{-}\left(\mathbf{3 2}^{+} \mathrm{X}^{-}\right) ;\left[\mathrm{Pt}^{t}{ }^{+} \mathrm{Bu}_{3}-\right. \\
\text { tpy)Cl]X }\left(\mathrm{X}=\mathrm{Cl}^{-}, \mathrm{ClO}_{4}^{-}, \mathrm{PF}_{6}^{-}\right)\left(\mathbf{3 3}^{+} \mathrm{X}^{-}\right)\end{array}$ & $\begin{array}{l}\mathrm{CH}_{3} \mathrm{CN} \text {, piperidine, DMF, and other VOCs } \\
\text { with lone pairs }{ }^{88}\end{array}$ \\
\hline$[\mathrm{Pt}(\mathrm{Cl}-\mathrm{tpy}) \mathrm{Cl}] \mathrm{Cl}(\mathbf{3 4 C l})$ & $\mathrm{MeOH}$ (selective) ${ }^{90}$ \\
\hline$[\mathrm{Pt}(\mathrm{tpy})(\mathrm{NCS})] \mathrm{SCN}(35 \mathrm{SCN})$ & $\mathrm{MeOH}$, two-step response ${ }^{91}$ \\
\hline$[\mathrm{Pt}(\mathrm{tpy})(\mathrm{NCS})] \mathrm{SCN}\left(\mathbf{3 5 S b F}_{6}\right)$ & selective for $\mathrm{CH}_{3} \mathrm{CN}, \mathrm{DMF}$, pyridine ${ }^{92}$ \\
\hline$[\mathrm{Pt}(\mathrm{tpy}$-nicotinamide $) \mathrm{Cl}]\left(\mathrm{PF}_{6}\right)_{2}\left(37\left(\mathrm{PF}_{6}\right)_{2}\right)$ & $\mathrm{MeOH}, \mathrm{CH}_{3} \mathrm{CN}$, pyridine ${ }^{93}$ \\
\hline$[\mathrm{Pt}($ pentaphenyl-benzene-tpy)Cl] $\mathrm{Cl}(\mathbf{3 8})$ & $\begin{array}{l}\text { selective for } \mathrm{CH}_{2} \mathrm{Cl}_{2}, \quad \mathrm{EtOH}, \mathrm{CH}_{3} \mathrm{CN} \text {, } \\
\text { EtOAc } 94\end{array}$ \\
\hline$\left[\mathrm{Pt}\left(\mathrm{Me}_{2}\right.\right.$ bzimpy $\left.) \mathrm{Cl}\right] \mathrm{Cl}(\mathbf{3 9 C l})$ & $\mathrm{MeOH}, \mathrm{EtOH}, \mathrm{CHCl}_{3}, \mathrm{CH}_{3} \mathrm{CN}^{95}$ \\
\hline$\left[\mathrm{Pt}\left(\mathrm{Me}_{2} \mathrm{bzimpy}\right) \mathrm{Cl}\right] \mathrm{PF}_{6}\left(\mathbf{3 9 P F}_{6}\right)$ & $\begin{array}{l}\mathrm{CH}_{3} \mathrm{CN}, \text { DMF (unresponsive to } \mathrm{H}_{2} \mathrm{O} \text {, } \\
\mathrm{MeOH}, \mathrm{EtOH}, 2-\mathrm{PrOH}, \mathrm{Et}_{2} \mathrm{O}, \mathrm{CH}_{2} \mathrm{Cl}_{2} \text {, } \\
\mathrm{CHCl}_{3}, \mathrm{CCl}_{4}, \mathrm{Me}_{2} \mathrm{CO} \text {, hexanes, benzene) }\end{array}$ \\
\hline
\end{tabular}




\begin{tabular}{|c|c|}
\hline & 97 \\
\hline$\left[\mathrm{Pt}\left(\mathrm{Me}_{2}\right.\right.$ bzimpy $\left.) \mathrm{Cl}\right] \mathrm{Cl}$ in $\mathrm{ZrP}\left(\mathbf{3 9}^{+}\right.$in $\left.\mathrm{ZrP}\right)$ & $\begin{array}{l}\mathrm{H}_{2} \mathrm{O}, \mathrm{MeOH}, \mathrm{CH}_{3} \mathrm{CN}, \mathrm{Me}_{2} \mathrm{CO},{ }_{98} \mathrm{CH}_{2} \mathrm{Cl}_{2} \text {, } \\
\text { THF, benzene, toluene, } n \text {-hexane }\end{array}$ \\
\hline $\begin{array}{l}{\left[\mathrm{Pt}\left(\mathrm{R}_{2} \text { bzimpy }\right) \mathrm{Cl}\right] \mathrm{X}\left(\mathbf{4 0 a}: \mathrm{R}=\mathrm{C}_{8} \mathrm{H}_{17}, \mathbf{4 0 b}: \mathrm{C}_{12} \mathrm{H}_{25},\right.} \\
\left.\text { 40c: } \mathrm{C}_{16} \mathrm{H}_{33} ; \mathrm{X}=\mathrm{Cl}, \mathrm{PF}_{6}, \mathrm{BF}_{4}, \mathrm{ClO}_{4}, \mathrm{OTf}, \mathrm{OAc}\right)\end{array}$ & $\begin{array}{l}\mathrm{Me}_{2} \mathrm{CO}, \mathrm{CH}_{3} \mathrm{CN}, \mathrm{MeOH}, \mathrm{EtOH}, \mathrm{CH}_{2} \mathrm{Cl}_{2} \text {, } \\
\mathrm{CHCl}_{3}, \text { EtOAc, benzene }\end{array}$ \\
\hline$[\mathrm{Pt}(2,6$-bis $(1 H$-imidazol-2-yl)pyridine $) \mathrm{Cl}] \mathrm{Cl}(\mathbf{4 1})$ & $\mathrm{CH}_{2} \mathrm{Cl}_{2}, \mathrm{CH}_{3} \mathrm{CN}, \mathrm{CH}_{3} \mathrm{OH}, \mathrm{Me}_{2} \mathrm{CO}{ }^{100}$ \\
\hline$\left[(\operatorname{Pt}(2,6 \text {-diphenylpyridine }))_{2}(\mathrm{dppm})\right](\mathbf{4 2})$ & $\underset{101}{\mathrm{CH}_{2} \mathrm{Cl}_{2}, \mathrm{CH}_{3} \mathrm{OH}, \mathrm{Me}_{2} \mathrm{CO} \text {, benzene, pentane }}$ \\
\hline$[\operatorname{Pt}(2,6-d i($ hexanoylamide-phenyl)pyridine $)](\mathbf{4 3})$ & $\mathrm{DMF}, \mathrm{CH}_{3} \mathrm{OH}^{102}$ \\
\hline $\begin{array}{l}{[\mathrm{Pt}(4,6 \text {-di(phenyl)-2,2'-bipyridine })](44) \text { on silica }} \\
\text { gel }\end{array}$ & pentane, benzene, $\mathrm{CH}_{2} \mathrm{Cl}_{2}, \mathrm{CHCl}_{3}{ }^{103}$ \\
\hline $\begin{array}{l}{\left[\left(\mathrm{Pt}\left(\mathrm{C}^{\wedge} \mathrm{N}^{\wedge} \mathrm{N}\right)\right) 2(\text { cis }-1,2-\right.} \\
\text { bis }(\text { diphenylphosphino }) \text { ethylene })]\left(\mathrm{ClO}_{4}\right)_{2} \\
\left(\mathbf{4 5}\left(\mathrm{ClO}_{4}\right)_{2}\right)\end{array}$ & 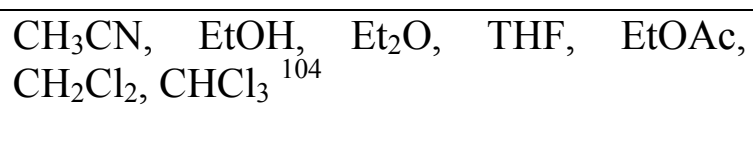 \\
\hline$\left[(\operatorname{Pt}(2,6-d i(2 ' \text {-naphthyl }) \text { pyridine }))_{2}(\mathrm{dppm})\right](\mathbf{4 6})$ & $\begin{array}{l}\text { strong response: } \mathrm{CH}_{2} \mathrm{Cl}_{2}, \mathrm{CH}_{2} \mathrm{Br}_{2}, \mathrm{CHCl}_{3} \text {, } \\
\mathrm{ClCH}_{2} \mathrm{CH}_{2} \mathrm{Cl}, \mathrm{BrCH}_{2} \mathrm{CH}_{2} \mathrm{Br}, \mathrm{CH}_{3} \mathrm{I} \text {; weak } \\
\text { response: } \mathrm{Me}_{2} \mathrm{CO}, \mathrm{Et}_{2} \mathrm{O}, \mathrm{THF}, \mathrm{EtOAc} \text {; no } \\
\text { response: } \mathrm{CH}_{3} \mathrm{CN}, \mathrm{MeOH}, \mathrm{EtOH} \text {, benzene, } \\
\text { toluene, } n \text {-hexane }\end{array}$ \\
\hline $\mathrm{K}\left[\mathrm{Pt}(\mathrm{bzq})(\mathrm{CN})_{2}\right] \cdot \mathrm{H}_{2} \mathrm{O}\left(\mathrm{K} 47 \cdot \mathrm{H}_{2} \mathrm{O}\right)$ & $\begin{array}{l}\text { MeOH (response time: } \sim 5 \mathrm{~s}), \mathrm{EtOH}(\sim 10 \\
\mathrm{s}), \mathrm{CH}_{3} \mathrm{CN}(\sim 30 \mathrm{~s}), \mathrm{Me}_{2} \mathrm{CO}(\sim 2 \mathrm{~min}), \mathrm{THF} \\
(\sim 45 \mathrm{~min})\end{array}$ \\
\hline $\mathrm{K}\left[\mathrm{Pt}(\mathrm{bzq})(\mathrm{CN})_{2}\right](\mathrm{K} 47)$ & $\mathrm{H}_{2} \mathrm{O}^{106}$ \\
\hline $\mathrm{K}\left[\mathrm{Pt}(\mathrm{ppy})(\mathrm{CN})_{2}\right](\mathrm{K} 48)$ & $\mathrm{H}_{2} \mathrm{O}{ }^{106}$ \\
\hline$[\mathrm{Pt}(\mathrm{NCN}-$ pincer$) \mathrm{Cl}](\mathbf{4 9})$ & $\mathrm{SO}_{2}{ }^{107}$ \\
\hline$[\mathrm{Pt}(\mathrm{NCN} \text {-pincer }) \mathrm{Cl}]_{3}$-dendrimers (50 and $\left.\mathbf{5 1}\right)$ & $\begin{array}{l}\mathrm{SO}_{2} \text { at conc. of } 100 \mu \mathrm{M}\left(6 \mu \mathrm{g} \mathrm{S_{2 }} \mathrm{cm}^{-3}\right) \text {, } \\
\text { response time: } 2 \mathrm{~ms} 108\end{array}$ \\
\hline$\left[\mathrm{Pt}\left(\mathrm{NHC}-\right.\right.$ butyl $\left.\left._{2}\right) \mathrm{Cl}\right] \mathrm{Cl}(\mathbf{5 3})$ & $\mathrm{H}_{2} \mathrm{O}^{116}$ \\
\hline$\left[\mathrm{Pt}\left(\mathrm{NHC}-\mathrm{mesityl}_{2}\right)(\mathrm{CO})\right]\left(\mathrm{PF}_{6}\right)_{2}(\mathbf{5 4})$ & $\begin{array}{l}\mathrm{MeOH}, \mathrm{H}_{2} \mathrm{O}, \mathrm{THF}, \mathrm{Et}_{2} \mathrm{O}, \mathrm{DMF}, \text { pyridine; } \\
\text { no response to } \mathrm{CH}_{2} \mathrm{Cl}_{2}, \mathrm{CHCl}_{3} \text {, benzene }\end{array}$ \\
\hline$[\mathrm{Pt}($ bpy $)($ pyridine-2-thiolate $)]\left(\mathrm{PF}_{6}\right)_{2}(\mathbf{5 5})$ & $\begin{array}{l}\text { Rapid response: } \mathrm{MeOH}, \mathrm{CH}_{3} \mathrm{CN} ; \text { slow } \\
\text { response: } \mathrm{EtOH},{ }^{i} \mathrm{PrOH} ; \text { no response: } \\
{ }^{t} \mathrm{BuOH}^{118}\end{array}$ \\
\hline
\end{tabular}




\begin{tabular}{|c|c|}
\hline$\left[\mathrm{Pt}(\text { dithiooxamide })_{2}\right](\mathbf{5 6})$ & $\mathrm{HCl}^{119}$ \\
\hline $\begin{array}{l}{\left[\mathrm{Pt}_{2} \mathrm{Ag}_{2}\right] \text { cluster made from two } \mathrm{Pt}(\mathrm{II})} \\
\text { benzoquinoline pyrrolidinedithiocarbamate units } \\
\left(\mathbf{5 7}\left(\mathrm{ClO}_{4}\right)_{2}\right)\end{array}$ & $\begin{array}{l}\mathrm{CH}_{3} \mathrm{CN} \text {; does not respond to } \mathrm{MeOH}, \mathrm{H}_{2} \mathrm{O} \text {, } \\
\mathrm{CH}_{2} \mathrm{Cl}_{2}, \mathrm{Et}_{2} \mathrm{O}, \mathrm{DMF} \text {, DMSO, n-hexane, } \\
\text { toluene }\end{array}$ \\
\hline cis-[Pt(aminophosphine $\left.)_{2}\right](\mathbf{5 8})$ & ${ }_{122}^{\mathrm{MeOH}}$, EtOH, ${ }^{i} \mathrm{PrOH} ;$ no response: ${ }^{t} \mathrm{BuOH}$ \\
\hline$\left[\mathrm{PtI}_{2}(\text { diarsinine })_{2}\right](\mathbf{5 9})$ & $\mathrm{CH}_{2} \mathrm{Cl}_{2}, \mathrm{Me}_{2} \mathrm{CO}$, toluene ${ }^{123}$ \\
\hline$\left[\mathrm{NH}_{3}\left(\mathrm{CH}_{2}\right)_{4} \mathrm{NH}_{3}\right]_{2}\left[\mathrm{Pt}_{2}(\text { pop })_{4} \mathrm{I}\right](\mathbf{6 0})$ & $\mathrm{H}_{2} \mathrm{O}^{126,128}$ \\
\hline$\left[\mathrm{NH}_{3}\left(\mathrm{CH}_{2}\right)_{5} \mathrm{NH}_{3}\right]_{2}\left[\mathrm{Pt}_{2}(\text { pop })_{4} \mathrm{I}\right](\mathbf{6 1})$ & $\mathrm{H}_{2} \mathrm{O}^{127}$ \\
\hline $\mathrm{Cu}\left[\mathrm{Au}(\mathrm{CN})_{2}\right]_{2}(\mathrm{DMSO})_{2}\left(\mathbf{6 2} \cdot(\mathrm{DMSO})_{2}\right)$ & $\begin{array}{l}\mathrm{H}_{2} \mathrm{O}, \mathrm{CH}_{3} \mathrm{CN}, \mathrm{DMF} \text {, dioxane, morpholine } \\
\text { pyridine, } \mathrm{NH}_{3} 14,129\end{array}$ \\
\hline $\mathrm{Zn}\left[\mathrm{Au}(\mathrm{CN})_{2}\right]_{2}(\mathbf{6 3})$ & $\mathrm{NH}_{3}(1 \mathrm{ppb} \text { detection limit })^{17,130}$ \\
\hline$\left[\mathrm{Au}\left(\mathrm{S}_{2} \mathrm{CN}\left(\mathrm{C}_{5} \mathrm{H}_{11}\right)_{2}\right)\right]_{2}(\mathbf{6 4})$ & $\begin{array}{l}\mathrm{Me}_{2} \mathrm{CO}, \quad \mathrm{CH}_{3} \mathrm{CN}, \quad \mathrm{CH}_{2} \mathrm{Cl}_{2}, \\
\text { insensitive to: } \mathrm{MeOH}, \mathrm{CHCl}_{3},\end{array}$ \\
\hline $\begin{array}{l}{\left[\mathrm{Au}_{2}(\mu \text {-thiouracilato })(\mu \text {-dppm }) \mathrm{CF}_{3} \mathrm{COO}\right.} \\
\left(65 \mathrm{CF}_{3} \mathrm{COO}\right)\end{array}$ & $\mathrm{Et}_{3} \mathrm{~N}$ vs. $\mathrm{CF}_{3} \mathrm{COOH}^{136}$ \\
\hline$\left[\mathrm{Au}_{3}\left(\mathrm{CH}_{3} \mathrm{~N}=\mathrm{COCH}_{3}\right)_{3}\right](\mathbf{6 6})$ & $\begin{array}{l}\text { solvent-stimulated luminescence strongest } \\
\text { with } \mathrm{CHCl}_{3} \text { and } \mathrm{CH}_{2} \mathrm{Cl}_{2}{ }^{138}\end{array}$ \\
\hline$\left[\mathrm{Au}_{3}\left(\mathrm{CH}_{3} \mathrm{~N}=\mathrm{COCH}_{3}\right)_{3}\right](\mathbf{6 6})$ & $\begin{array}{l}\text { conductivity in microwires (not } \\
\text { vapochromism): significant response for: } \\
\text { MeOH, EtOH, } \mathrm{CH}_{3} \mathrm{CN} \text {; no response: THF, } \\
\text { acetone, } n \text {-PrOH, } n \text { - } \mathrm{BuOH}, n \text {-pentanol, } \\
\text { benzene, and } p \text {-xylene }\end{array}$ \\
\hline$\left[\mathrm{Au}_{3}\left(\mathrm{H}_{3} \mathrm{C}-p-\mathrm{C}_{6} \mathrm{H}_{4}-\mathrm{N}=\mathrm{COC}_{2} \mathrm{H}_{5}\right)_{3}\right](\mathbf{6 7})$ & $\mathrm{C}_{6} \mathrm{~F}_{6}{ }^{144}$ \\
\hline $\mathrm{Au}_{2}\left(\mu\right.$-bis-(diphenylphosphino)ethane) ${ }_{2} \mathrm{Br}_{2}(\mathbf{6 8})$ & $\begin{array}{l}\mathrm{CH}_{2} \mathrm{Cl}_{2}, \mathrm{Me}_{2} \mathrm{CO} \text {; no response to: } \mathrm{CH}_{3} \mathrm{CN} \text {, } \\
\mathrm{Et}_{2} \mathrm{O} \text {, DMF, DMSO, benzene, pyridine, } \\
\text { nitrobenzene, } \mathrm{CS}_{2}{ }_{146}\end{array}$ \\
\hline $\begin{array}{l}\mathrm{Au}_{2}(\mu \text {-bis-(diphenylphosphino)ethane })_{2} \mathrm{I}_{2} \cdot 2 \mathrm{Me}_{2} \mathrm{CO} \\
\left(\mathbf{6 9} \cdot 2 \mathrm{Me}_{2} \mathrm{CO}\right)\end{array}$ & $\mathrm{CH}_{2} \mathrm{Cl}_{2}, \mathrm{Me}_{2} \mathrm{CO}^{148}$ \\
\hline$\left[\left(\mathrm{C}_{6} \mathrm{~F}_{5} \mathrm{Au}\right)_{2}(\mu-1,4\right.$-diisocyanobenzene $\left.)\right](\mathbf{7 0})$ & $\mathrm{CH}_{2} \mathrm{Cl}_{2}{ }^{149}$ \\
\hline$\left[\mathrm{Au}\left(\mathrm{PPh}_{2} \mathrm{C}\left(\mathrm{CSSAuC} \mathrm{C}_{6}\right) \mathrm{PPh}_{2} \mathrm{Me}\right)_{2}\right]\left(\mathrm{ClO}_{4}\right)(\mathbf{7 1})$ & $\begin{array}{l}\mathrm{Me}_{2} \mathrm{CO}, \quad \mathrm{CH}_{2} \mathrm{Cl}_{2}, \mathrm{CHCl}_{3}, \underset{\mathrm{ClCH}}{\mathrm{Cl}_{2} \mathrm{CH}_{2} \mathrm{Cl}} \text {, } \\
\text { EtOH, EtOAc, THF, toluene }\end{array}$ \\
\hline$\left[\mathrm{Tl}\left[\mathrm{Au}\left(\mathrm{C}_{6} \mathrm{Cl}_{5}\right)_{2}\right]\right]_{\mathrm{n}}(\mathbf{7 2})$ & $\mathrm{Me}_{2} \mathrm{CO}, \mathrm{Hacac}, \mathrm{CH}_{3} \mathrm{CN}, \mathrm{THF}, \mathrm{Et}_{3} \mathrm{~N}$, \\
\hline
\end{tabular}




\begin{tabular}{|c|c|}
\hline & $\begin{array}{l}\text { pyridine, 2-fluoropyridine, } \\
\text { tetrahydrothiophene }\end{array}$ \\
\hline$\left[\mathrm{Tl}(\mathrm{en})\left[\mathrm{Au}\left(\mathrm{C}_{6} \mathrm{X}_{5}\right)_{2}\right]\right]_{\mathrm{n}}(\mathbf{7 3 a} \mathrm{X}=\mathrm{F} ; \mathbf{7 3 b} \mathrm{X}=\mathrm{Cl})$ & $\mathrm{Me}_{2} \mathrm{CO}$, acetophenone ${ }^{156}$ \\
\hline$\left[\mathrm{Au}_{2} \mathrm{Ag}_{2}\left(\mathrm{C}_{6} \mathrm{~F}_{5}\right)_{4} \mathrm{~L}_{2}\right]_{\mathrm{n}}\left(\mathrm{L}=\mathrm{Et}_{2} \mathrm{O}\right)\left(\mathbf{7 5}\left(\mathrm{Et}_{2} \mathrm{O}\right)_{2}\right)$ & $\mathrm{Me}_{2} \mathrm{CO}, \mathrm{THF}, \mathrm{CH}_{3} \mathrm{CN}^{158}$ \\
\hline$\left[\mathrm{Au}_{2} \mathrm{Ag}_{2}\left(\mathrm{C}_{6} \mathrm{~F}_{5}\right)_{4}(\mathrm{bpy})_{2}\right]_{\mathrm{n}}(\mathbf{7 6})$ & $\mathrm{MeOH}, \mathrm{EtOH},{ }^{i} \mathrm{PrOH}{ }^{12}$ \\
\hline$\left[\mathrm{Au}_{2} \mathrm{Ag}_{2}\left(\mathrm{C}_{6} \mathrm{~F}_{5}\right)_{4}(\text { phen })_{2}\right]_{\mathrm{n}}(\mathbf{7 7})$ & $\mathrm{MeOH}, \mathrm{EtOH}, \mathrm{Me}_{2} \mathrm{CO}{ }^{162}$ \\
\hline$\left[\mathrm{Au}_{2} \mathrm{Ag}_{2}\left(4-\mathrm{C}_{6} \mathrm{~F}_{4} \mathrm{I}\right)_{4}\right]_{\mathrm{n}}(\mathbf{7 8})$ & $\begin{array}{l}\mathrm{Me}_{2} \mathrm{CO}, \mathrm{THF}, \mathrm{CH}_{3} \mathrm{CN} \text {; insensitive to: } \mathrm{Et}_{2} \mathrm{O} \text {, } \\
\text { toluene }\end{array}$ \\
\hline $\begin{array}{l}{\left[\mathrm{Au}_{2} \mathrm{Ag}_{2}\left(4-\mathrm{C}_{6} \mathrm{~F}_{4} \mathrm{I}\right)_{4}\left(\mathrm{Me}_{2} \mathrm{CO}\right)_{2}\right]_{\mathrm{n}} \cdot 2 \mathrm{Me}_{2} \mathrm{CO}} \\
\left.\left(\mathrm{Me}_{2} \mathrm{CO}\right) \cdot 2 \mathrm{Me}_{2} \mathrm{CO}\right)\end{array}$ & $\mathrm{CH}_{3} \mathrm{CN}^{164}$ \\
\hline$\left[\mathrm{Au}_{2} \mathrm{Ag}_{2}\left(4-\mathrm{C}_{6} \mathrm{~F}_{4} \mathrm{I}\right)_{4}(\mathrm{THF})_{2}\right]_{\mathrm{n}}\left(\mathbf{7 8}(\mathrm{THF})_{2}\right)$ & $\mathrm{CH}_{3} \mathrm{CN}^{164}$ \\
\hline$\left[\mathrm{Au}_{2} \mathrm{Ag}_{2}\left(3,5-\mathrm{C}_{6} \mathrm{Cl}_{2} \mathrm{~F}_{3}\right)_{4}\left(\mathrm{Et}_{2} \mathrm{O}\right)_{2}\right]_{\mathrm{n}}\left(\mathbf{7 9}\left(\mathrm{Et}_{2} \mathrm{O}\right)_{2}\right)$ & $\mathrm{Me}_{2} \mathrm{CO}, \mathrm{THF}, \mathrm{CH}_{3} \mathrm{CN}^{166}$ \\
\hline$\left[\mathrm{Au}_{2} \mathrm{Ag}_{2}\left(3,5-\mathrm{C}_{6} \mathrm{Cl}_{2} \mathrm{~F}_{3}\right)_{4}(\mathrm{THF})_{2}\right]_{\mathrm{n}}\left(\mathbf{7 9}(\mathrm{THF})_{2}\right)$ & $\mathrm{Me}_{2} \mathrm{CO}$, partial reaction with $\mathrm{CH}_{3} \mathrm{CN}^{166}$ \\
\hline$\left[\mathrm{Au}_{2} \mathrm{Ag}_{2}\left(3,5-\mathrm{C}_{6} \mathrm{Cl}_{2} \mathrm{~F}_{3}\right)_{4}\left(\mathrm{CH}_{3} \mathrm{CN}\right)_{2}\right]_{\mathrm{n}}\left(79\left(\mathrm{CH}_{3} \mathrm{CN}\right)_{2}\right)$ & $\mathrm{Me}_{2} \mathrm{CO}, \mathrm{THF}^{166}$ \\
\hline$\left[\mathrm{Au}_{2} \mathrm{Ag}_{2}\left(\mathrm{C}_{6} \mathrm{Cl}_{5}\right)_{4}\left(\mathrm{Et}_{2} \mathrm{O}\right)_{2}\right]_{\mathrm{n}}\left(\mathbf{8 0}\left(\mathrm{Et}_{2} \mathrm{O}\right)_{2}\right)$ & $\mathrm{Me}_{2} \mathrm{CO}, \mathrm{THF}, \mathrm{CH}_{3} \mathrm{CN}^{166}$ \\
\hline $\begin{array}{l}{\left[\mathrm{Au}_{2} \mathrm{Ag}_{2}\left(2-\mathrm{C}_{6} \mathrm{~F}_{4} \mathrm{I}\right)_{4}\right]_{2} \cdot 4 \mathrm{NBu}_{4} \mathrm{ClO}_{4} \cdot \mathrm{THF}} \\
\left(\mathbf{8 1} \cdot 4 \mathrm{NBu}_{4} \mathrm{ClO}_{4} \cdot \mathrm{THF}\right)\end{array}$ & $\mathrm{Me}_{2} \mathrm{CO}, \mathrm{THF}, \mathrm{CH}_{3} \mathrm{CN}^{167}$ \\
\hline$\left[\mathrm{Au}\left(\mathrm{im}\left(\mathrm{CH}_{2}-\mathrm{py}\right)_{2}\right)_{2}\left(\mathrm{Cu}\left(\mathrm{CH}_{3} \mathrm{CN}\right)_{2}\right)_{2}\right]\left(\mathrm{PF}_{6}\right)_{3}(\mathbf{8 6})$ & 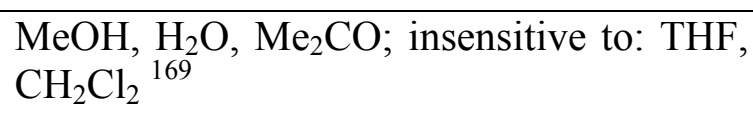 \\
\hline$\left[\mathrm{Au}\left(\mathrm{im}\left(\mathrm{CH}_{2}-\mathrm{py}\right)_{2}\right)_{2}\left(\mathrm{Cu}\left(\mathrm{CH}_{3} \mathrm{OH}\right)\right)_{2}\right]\left(\mathrm{PF}_{6}\right)(\mathbf{8 7 b})$ & $\mathrm{CH}_{3} \mathrm{CN}^{169}$ \\
\hline$\left[\mathrm{Au}(\mathrm{dppb})_{2}\right]\left(\mathrm{NO}_{3}\right)\left(\mathbf{8 8} \mathrm{NO}_{3}\right)$ & $\begin{array}{l}\mathrm{MeOH}, \underset{170}{\mathrm{EtOH} ;} \text { insensitive to longer } \\
\text { alcohols }\end{array}$ \\
\hline$\left[\mathrm{Au}(\mathrm{dppb})_{2}\right]\left(\mathrm{BF}_{4}\right)\left(\mathbf{8 8 B \mathrm { BF } _ { 4 } )}\right.$ & $\mathrm{Me}_{2} \mathrm{CO}, \mathrm{CH}_{3} \mathrm{CN}, \mathrm{CH}_{2} \mathrm{Cl}_{2}, \mathrm{Et}_{2} \mathrm{O}, \mathrm{THF}{ }^{170}$ \\
\hline$[\mathrm{VO}($ sal-(R,R)-stien $\left.)] \cdot \mathrm{CHCl}_{3}\right]\left(\mathbf{8 9} \cdot \mathrm{CHCl}_{3}\right)$ & $\mathrm{CH}_{3} \mathrm{CN}^{171}$ \\
\hline$\left[\mathrm{VO}(\right.$ sal-(R,R)-stien) $\left.] \cdot \mathrm{CH}_{3} \mathrm{CN}\right]\left(\mathbf{8 9} \cdot \mathrm{CH}_{3} \mathrm{CN}\right)$ & $\mathrm{CHCl}_{3}{ }^{171}$ \\
\hline$\left[\mathrm{Co}_{2}\left(\mathrm{H}_{2} \mathrm{O}\right)_{4}\right]\left[\mathrm{Re}_{6} \mathrm{~S}_{8}(\mathrm{CN})_{6}\right] \cdot 12 \mathrm{H}_{2} \mathrm{O}\left(\mathbf{9 0} \cdot 12 \mathrm{H}_{2} \mathrm{O}\right)$ & $\begin{array}{l}\mathrm{CH}_{3} \mathrm{NO}_{2}, \mathrm{Me}_{2} \mathrm{CO}, \mathrm{CH}_{3} \mathrm{CH}_{2} \mathrm{CN},{ }^{n-o c t a n o l} \text {, } \\
\text { 1-PrOH, 2-PrOH, EtOAc, Et }{ }_{2} \mathrm{O}, \mathrm{THF}^{176}\end{array}$ \\
\hline $\begin{array}{l}{\left[\mathrm{Co}\left(\mathrm{H}_{2} \mathrm{O}\right)_{3}\right]_{4}\left[\mathrm{Co}_{2}\left(\mathrm{H}_{2} \mathrm{O}\right)_{4}\right]\left[\mathrm{Re}_{6} \mathrm{Se}_{8}(\mathrm{CN})_{6}\right]_{3} \cdot 44 \mathrm{H}_{2} \mathrm{O}} \\
\left(\mathbf{9 1} \cdot 44 \mathrm{H}_{2} \mathrm{O}\right)\end{array}$ & $\begin{array}{l}\mathrm{Et}_{3} \mathrm{~N}, \mathrm{CH}_{3} \mathrm{CN}, \mathrm{CH}_{3} \mathrm{CH}_{2} \mathrm{CN}, \mathrm{THF}, \mathrm{EtOH} \text {, } \\
\mathrm{DMF}, \mathrm{Me}_{2} \mathrm{CO}, n \text {-octanol, MTBE, EtOAc, } \\
\text { 1-PrOH, 2-PrOH, Et }{ }_{2} \mathrm{O}{ }^{176}\end{array}$ \\
\hline
\end{tabular}




\begin{tabular}{|c|c|}
\hline$\left.\left[\mathrm{Co}_{2}(\mathrm{ampyz})_{2}\right]\left(\mathrm{SO}_{4}\right)\right](=$ dry form of $\mathbf{9 2})$ & $\mathrm{H}_{2} \mathrm{O}^{177}$ \\
\hline$\left[(\mathrm{dpdpm}) \mathrm{Ni}\left(\eta^{2}-\mathrm{NO}_{3}\right)_{2}\right](\mathbf{9 3})$ & $\mathrm{CH}_{3} \mathrm{CN}^{178}$ \\
\hline $\begin{array}{l}\text { Bis(1,2,6,7-tetracyano-3,5-dihydro-3,5- } \\
\text { diiminopyrrolizinido)nickel(II) (95) }\end{array}$ & $\mathrm{CH}_{179} \mathrm{OH}$, toluene; poor response to $\mathrm{CH}_{3} \mathrm{CN}$ \\
\hline$[\mathrm{Ni}(\mathrm{cyclam})(\mathrm{dcbpy})](\mathbf{9 6}(\mathrm{dcbpy}))$ & $\mathrm{H}_{2} \mathrm{O}^{180}$ \\
\hline$[\mathrm{CuI}(4-\mathrm{pic})]_{\infty}(\mathbf{9 7})$ & toluene $^{181,182}$ \\
\hline$[\mathrm{CuI}(4-\mathrm{pic})]_{4} \cdot 2 \mathrm{C}_{6} \mathrm{H}_{5} \mathrm{CH}_{3}\left(\mathbf{9 8} \cdot 2 \mathrm{C}_{6} \mathrm{H}_{5} \mathrm{CH}_{3}\right)$ & pentane $^{181,182}$ \\
\hline trans $-\left[\mathrm{CuCl}_{2}(3-\mathrm{Clpy})_{2}\right](\mathbf{9 9})$ & $\mathrm{HCl}^{184}$ \\
\hline trans $-\left[\mathrm{CuBr}_{2}(3-\mathrm{Brpy})_{2}\right](\mathbf{1 0 1})$ & $\mathrm{HCl}, \mathrm{HBr}{ }^{185,186}$ \\
\hline$\left[\mathrm{Cu}_{2}(\mathrm{dppy})_{3}\left(\mathrm{CH}_{3} \mathrm{CN}\right)\right]\left(\mathrm{BF}_{4}\right)_{2}(\mathbf{1 0 3})$ & $\mathrm{CH}_{3} \mathrm{OH}{ }^{187}$ \\
\hline$\left[\left(\mathrm{O}^{\mathrm{n}} \mathrm{Pr}\right) \mathrm{Cu}(\mu-\mathrm{hep}){ }_{2} \mathrm{Cu}\left(\mathrm{O}^{\mathrm{n}} \mathrm{Pr}\right)\right] \cdot 2 \mathrm{H}_{2} \mathrm{O}\left(\mathbf{1 0 4} \cdot 2 \mathrm{H}_{2} \mathrm{O}\right)$ & $\begin{array}{l}\mathrm{MeOH}, \quad \mathrm{EtOH},{ }^{i} \mathrm{PrOH}, \mathrm{CH}_{3} \mathrm{CN} \text { with } \\
\text { response times of } 5 \mathrm{~min}, 2 \mathrm{~h}, 24 \mathrm{~h}, 8 \mathrm{~d}\end{array}$ \\
\hline$\left[\left(\mathrm{Cu}_{4} \mathrm{I}_{4}\right)(\text { calix }[4] \text {-bis-monothiacrown })\right]_{\mathrm{n}}(\mathbf{1 0 5})$ & $\mathrm{CH}_{3} \mathrm{CN}^{189}$ \\
\hline$\left[\mathrm{CuI}\left(\mathrm{PPh}_{3}\right)_{4}\right](\mathbf{1 0 6 a})$ & $\mathrm{CH}_{3} \mathrm{CN}, \mathrm{CH}_{2} \mathrm{Cl}_{2}, \mathrm{EtOH}^{190}$ \\
\hline $\mathrm{CuCN}(\mathbf{1 0 7})$ & $\begin{array}{l}\text { amines (Py, 2-MePy, 3-MePy, 4-MePy, 3- } \\
\text { EtPy, 4-EtPy, 4- }{ }^{t} \mathrm{BuPy}, \text { piperidine, } N- \\
\text { methylpiperidine, } \quad N \text {-ethylpiperidine, } \\
\mathrm{Me}_{2} \mathrm{NCy} \text { ) and other nucleophilic VOCs (N- } \\
\text { methylmorpholine) }\end{array}$ \\
\hline$(\mathrm{CuI})_{2}\left(\mathrm{Et}_{2} \mathrm{pip}\right)(\mathbf{1 0 8 a}),(\mathrm{CuI})_{2}\left(\mathrm{Bn}_{2} \mathrm{pip}\right)(\mathbf{1 0 8 b})$ & $\begin{array}{l}\text { Py, 2-MePy, 3-MePy, pyrrolidine, } \\
\text { pyrrolidine, morpholine, } \mathrm{Et}_{3} \mathrm{~N} \text {, dimethyl } \\
\text { sulfide }\end{array}$ \\
\hline $\begin{array}{l}\mathrm{SnSO}_{4} \quad(\mathbf{1 0 9 a}), \quad \mathrm{Sn}\left(\mathrm{CH}_{3} \mathrm{SO}_{3}\right)_{2} \quad(\mathbf{1 0 9 b}), \quad \mathrm{Sn}(\mathrm{OTf})_{2}, \\
(\mathbf{1 0 9 c}), \mathrm{SnPO}_{3} \mathrm{~F}(\mathbf{1 0 9 d})\end{array}$ & $\mathrm{NH}_{3}, \mathrm{EtNH}_{2}, \mathrm{Et}_{2} \mathrm{NH}, \mathrm{Et}_{3} \mathrm{~N}, \mathrm{~N}\left(\mathrm{C}_{5} \mathrm{H}_{5}\right)_{3}{ }^{196}$ \\
\hline Zn(II)tetraphenylporphyrin (110) & $\mathrm{NH}_{3}, \mathrm{Et}_{3} \mathrm{~N}^{200}$ \\
\hline Fe(tris-(2-pyridylmethyl)amine)(NCS) $)_{2}(\mathbf{1 1 1})$ & $\mathrm{MeOH}^{201}$ \\
\hline $\begin{array}{l}{\left[\mathrm{Fe}(\mathrm{tpa})(\mathrm{NCS})_{2}\right] \cdot\left[\left[\mathrm{Fe}(\mathrm{tpa})(\mathrm{NCS})_{2}\right] \cdot \mathrm{EtOH}\right]} \\
(\mathbf{1 1 1} \cdot[\mathbf{1 1 1} \cdot \mathrm{EtOH}])\end{array}$ & $\mathrm{CH}_{2} \mathrm{Cl}_{2}, \mathrm{CHCl}_{3}{ }^{202}$ \\
\hline $\mathrm{Fe}(\mathrm{Hpbph})_{2}(\mathrm{HCA})_{2} \cdot 2 \mathrm{THF}(\mathbf{1 1 2} \cdot 2 \mathrm{THF})$ & $\mathrm{CH}_{204} \mathrm{Cl}_{2}, \mathrm{Et}_{2} \mathrm{O}, \mathrm{MeOH}, \mathrm{EtOH}, \mathrm{CH}_{3} \mathrm{COOH}$ \\
\hline $\mathrm{Fe}(\mathrm{Hpbph})_{2}(\mathrm{HCA})_{2}(\mathbf{1 1 2})$ & $\mathrm{THF}^{204}$ \\
\hline
\end{tabular}




\begin{tabular}{|c|c|}
\hline \begin{tabular}{|l}
$\mathrm{PdBr}(\mathrm{Hmtbhp})]_{2}(\mathrm{HBA})_{2}\left(\mathrm{H}_{2} \mathrm{BA}\right)(\mathbf{1 1 3})$ \\
\end{tabular} & $\begin{array}{l}\text { DMF, pyridine, dimethylacetoamide, } \\
\text { DMSO, 1,4-dioxane, } \mathrm{CH}_{3} \mathrm{CN}, \mathrm{MeOH} \text {, } \\
\text { EtOH; with discrimination ability }{ }_{205}\end{array}$ \\
\hline \begin{tabular}{|l|}
{$\left[\left(\mathrm{ZnCl}_{2}\right)_{3}\left(1,3,5-\operatorname{tris}\left(p-\left(2,2{ }^{\prime}-\right.\right.\right.\right.$} \\
dipyridylamino)phenyl)benzene $)](\mathbf{1 1 4})$
\end{tabular} & benzene $(500 \mathrm{ppm})^{209}$ \\
\hline$\left[\mathrm{Zn}_{2}(3,3 \text { '-di-tert-butylsalen })_{2}\right](\mathbf{1 1 5})$ & THF $^{210}$ \\
\hline$\left[\left[3,5-\left(\mathrm{CF}_{3}\right)_{2} \mathrm{pz}\right] \mathrm{Ag}\right]_{3}(\mathbf{1 1 7})$ & $\begin{array}{l}\text { selective to: benzene, toluene, mesitylene } \\
211\end{array}$ \\
\hline$\left[\operatorname{Re}(\mathrm{CO})_{3}(\text { bibzim })\left(4,4^{\prime} \text {-bpy }\right) \operatorname{Re}(\mathrm{CO})_{3}\right]_{2}(\mathbf{1 1 8})$ & $\begin{array}{l}\text { toluene, 4-fluorotoluene, benzene, } \\
\text { fluorobenzene, hexafluorobenzene, } \mathrm{THF}^{214}\end{array}$ \\
\hline $\begin{array}{l}{\left[\operatorname{Ir}(\mathrm{ppy})_{2}(\mathrm{qxn})\right] \cdot 0.25 \mathrm{EtOH} \cdot 0.5 \mathrm{CHCl}_{3}} \\
\left(\mathbf{1 1 9} \cdot 0.25 \mathrm{EtOH} \cdot 0.5 \mathrm{CHCl}_{3}\right)\end{array}$ & $\mathrm{CH}_{3} \mathrm{CN}^{217}$ \\
\hline$\left[\mathrm{Cu}(\mathrm{pz})_{2}\right](\mathbf{1 2 0})$ & $\begin{array}{l}\mathrm{NH}_{3}, \mathrm{CH}_{3} \mathrm{OH}, \\
\mathrm{MeNH}_{2} 218,219\end{array}$ EtOH, $\mathrm{CH}_{3} \mathrm{CN}$, pyridine, \\
\hline$\left[\left[\mathrm{Cu}(\text { bhnq })\left(\mathrm{H}_{2} \mathrm{O}\right)_{2}\left(\mathrm{H}_{2} \mathrm{O}\right)_{\mathrm{n}}\right]_{\mathrm{n}}\left(\mathbf{1 2 1} \cdot\left(\mathrm{H}_{2} \mathrm{O}\right)_{\mathrm{n}}\right)\right.$ & $\mathrm{MeOH}, \mathrm{EtOH}^{220}$ \\
\hline$\left[\mathrm{Cu}(\mathrm{bhnq})(\mathrm{THF})_{2}\right]_{\mathrm{n}}(\mathbf{1 2 2})$ & $\mathrm{THF}^{221}$ \\
\hline$\left[\mathrm{Cu}_{4} \mathrm{I}_{4}(\mathrm{DABCO})_{2}\right](\mathbf{1 2 3})$ & $\mathrm{CH}_{3} \mathrm{CN}^{222}$ \\
\hline$\left[\left(\mathrm{WS}_{4} \mathrm{Cu}_{4}\right) \mathrm{I}_{2}(\mathrm{dptz})_{3}\right]_{\mathrm{n}}(\mathbf{1 2 4})$ & $\begin{array}{l}\mathrm{CH}_{3} \mathrm{CN}, \mathrm{H}_{2} \mathrm{O}, \underset{\mathrm{CH}_{2} \mathrm{OH}}{\mathrm{C}_{2} \mathrm{H}_{5} \mathrm{OH}, \mathrm{CHCl}_{3} 223} \text { DMF, } \mathrm{Me}_{2} \mathrm{CO},\end{array}$ \\
\hline $\mathrm{Ru}\left(4,4^{\prime}-{ }^{t} \mathrm{Bubpy}\right)_{2}(\mathrm{CN})_{2}(\mathbf{1 2 5})$ & $\begin{array}{l}\mathrm{H}_{2} \mathrm{O}{ }^{230}, \\
\text { quinoline, pyridine with discrimination } \\
\text { ability }\end{array}$ \\
\hline$\left[\mathrm{Ru}\left(5,6-\mathrm{Me}_{2} \text { phen }\right)_{3}\right](\mathrm{tfpb})(\mathbf{1 2 6})$ & benzene, detection limit: $7600 \mathrm{ppm}^{233}$ \\
\hline
\end{tabular}

Challenges associated with the use of vapochromic substances in practical sensor device applications differ from material to material; details are found in sections $2-4$. Some frequently occuring issues are the following: Long-term stability of the chemical sensors, interference by atmospheric oxygen or humidity, reversibility of the vapochromic response, selectivity to certain 
VOCs, and sufficiently rapid response times. The targeted synthesis of vapochromic materials is very difficult because even the most basic structure / function relationships have remained elusive for many vapochromic substances. Even the optimization of known vapochromic materials is difficult since very minor structural changes may lead to complete disappearance of the vapochromic property. In many cases the application potential of newly discovered vapochromic materials was apparently considered low and therefore quantititative analytical measurements were only performed in rather few selected cases. ${ }^{17,84,108,130,209,233}$ It seems fair to state that with respect to quantified sensitivity data, the field is still much in its infancy. Changing this situation is certainly a challenge for the future in this field.

\section{Concluding remarks}

Vapochromism and vapoluminescence in coordination complexes is possible through a variety of different mechanisms. Changes in metal-metal interactions play an important role in many platinum(II) and gold(I) based substances, ${ }^{13}, 14,17,35,37,36,50,41,66,67,68,69,70,72,73,88,91,92,93,95,97$, 98, 99, 100, 102, 105, 106, 116, 117, 118, 121, 129, 128,135,144,146, 148, 149, 156, 155, 158, 157, 160, 164, 212 and

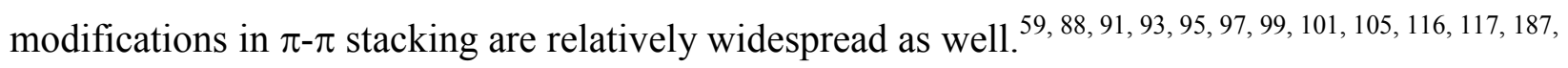
209, 210, 217 . For transition metal ions other than platinum or gold (particularly the $3 \mathrm{~d}$ elements vanadium, iron, cobalt nickel, and copper) changes in the coordination environment of the central metal ion are a frequent source of the vapochromism phenomenon. ${ }^{14,17,107-109,112,121,129,}$ $128,156,167,169,171,174,175,176,177,178,181,182,188,189,190,191,187,188,189,190,191,195,196,199,200$ Occasionally, vapochromsim is triggered through reaction of the analyte at a remote ligand site 
in a complex. ${ }^{156,181,182,234}$ Host-guest interactions in materials with vapor-accessible channels are quite prominenently represented and in the future are likely to become increasingly important since much current effort appears to be devoted to the synthesis of new functional metal-organic frameworks. $^{69,70,220,222,190,223,234,205,214}$

Until now the field of vapochromism and vapoluminescence was mostly driven by coordination chemists with a strong interest in understanding the vapor-induced phenomena at a fundamental (mechanistic) level. The application potential of many of the investigated substances was considered rather limited, and hence quantitative analytical data is available only for relatively few cases. However, it is clear that sensors based on vapochromic and vapoluminescent materials are potentially very sensitive towards VOCs, especially when a luminescence turn-on response can be induced. Provided a sufficiently rapid response time can be obtained, such sensing materials therefore hold great promise for real-time monitoring of VOCs in air. This might be a less cumbersome procedure than adsorbing VOCs on adsorbates for later extraction and chromatographic analysis. When compared to electrochemical gas sensors vapochromic or vapoluminescent sensors have the advantage that detection is not limited to redox-active analytes. However, selectivity for a certain specific analyte is very difficult to achieve with vapochromic or vapoluminescent materials. An important basic problem in this context is that the discovery of such substances frequently relies on serendipity because there is no other choice: In many cases even very minor modifications of the chemical structure of a known vapor-responsive substance leads to disappearance of the vapochromism / vapoluminescence phenomena.

For real-world analytical applications, the future of vapochromic and vapoluminescent substances probably lies in cross-reactive sensor arrays in which many different sensing 
materials are combined, and in which characteristic fingerprint responses for individual analytes can potentially be obtained. On the other hand, the phenomena of vapor-induced color and luminescence changes are interesting in their own right and are likely to continue to fascinate chemists in academic research.

References

(1) Nagel, C. C. U. S. Patent 4,834,909. 1989.

(2) Albert, K. J.; Lewis, N. S.; Schauer, C. L.; Sotzing, G. A.; Stitzel, S. E.; Vaid, T. P.; Walt, D. R., Chem. Rev. 2000, 100, 2595.

(3) Lewis, N. S., Acc. Chem. Res. 2004, 37, 663.

(4) Jurs, P. C.; Bakken, G. A.; McClelland, H. E., Chem. Rev. 2000, 100, 2649.

(5) Rock, F.; Barsan, N.; Weimar, U., Chem. Rev. 2008, 108, 705.

(6) Grate, J. W.; Abraham, M. H., Sens. Actuators B 1991, 3, 85.

(7) Balch, A. L., Struct. Bonding 2007, 123, 1.

(8) He, X. M.; Yam, V. W. W., Coord. Chem. Rev. 2011, 255, 2111.

(9) Keefe, M. H.; Benkstein, K. D.; Hupp, J. T., Coord. Chem. Rev. 2000, 205, 201.

(10) Zhao, Q. A.; Li, F. Y.; Huang, C. H., Chem. Soc. Rev. 2010, 39, 3007.

(11) Fiddler, M. N.; Begashaw, I.; Mickens, M. A.; Collingwood, M. S.; Assefa, Z.; Bililign, S., Sensors 2009, 9, 10447. 
(12) Luquin, A.; Elosúa, C.; Vergara, E.; Estella, J.; Cerrada, E.; Bariáin, C.; Matías, I. R.; Garrido, J.; Laguna, M., Gold Bull. 2007, 40, 225.

(13) Kato, M., Bull. Chem. Soc. Jpn. 2007, 80, 287.

(14) Leznoff, D. B.; Lefebvre, J., Gold Bull. 2005, 38, 47.

(15) Fernández, E.; Laguna, A.; López-De-Luzuriaga, J. M., Coord. Chem. Rev. 2005, 249, 1423.

(16) Wong, K. M. C.; Yam, V. W. W., Coord. Chem. Rev. 2007, 251, 2477.

(17) Katz, M. J.; Sakai, K.; Leznoff, D. B., Chem. Soc. Rev. 2008, 37, 1884.

(18) Zhang, X.; Li, B.; Chen, Z. H.; Chen, Z. N., J. Mater. Chem. 2012, 22, 11427.

(19) Abdou, H. E.; Mohamed, A. A.; Fackler, J. P.; Burini, A.; Galassi, R.; López-deLuzuriaga, J. M.; Olmos, M. E., Coord. Chem. Rev. 2009, 253, 1661.

(20) Ford, P. C.; Cariati, E.; Bourassa, J., Chem. Rev. 1999, 99, 3625.

(21) Houlding, V. H.; Miskowski, V. M., Coord. Chem. Rev. 1991, 111, 145.

(22) Gliemann, G.; Yersin, H., Struct. Bonding 1985, 62, 87.

(23) Balch, A. L., Angew. Chem. Int. Ed. 2009, 48, 2641.

(24) Omary, M. A.; Mohamed, A. A.; Rawashdeh-Omary, M. A.; Fackler, J. P., Coord. Chem. Rev. 2005, 249, 1372.

(25) Linert, W.; Fukuda, Y.; Camard, A., Coord. Chem. Rev. 2001, 218, 113. 
(26) Day, J. H., Chem. Rev. 1968, 68, 649.

(27) Kaupp, G., Crystengcomm 2009, 11, 388.

(28) Schmidbaur, H.; Schier, A., Chem. Soc. Rev. 2008, 37, 1931.

(29) Schmidbaur, H.; Schier, A., Chem. Soc. Rev. 2012, 41, 370.

(30) Pyykkö, P., Chem. Rev. 1997, 97, 597.

(31) Roundhill, D. M., Photochemistry and Photophysics of Metal Complexes. Plenum Press: New York, 1994.

(32) Gray, H. B.; Maverick, A. W., Science 1981, 214, 1201.

(33) Miskowski, V. M.; Houlding, V. H., Inorg. Chem. 1989, 28, 1529.

(34) Miskowski, V. M.; Houlding, V. H., Inorg. Chem. 1991, 30, 4446.

(35) Bielli, E.; Gidney, P. M.; Gillard, R. D.; Heaton, B. T., J. Chem. Soc., Dalton Trans. 1974, 2133.

(36) Morgan, G. T.; Burstall, F. H., J. Chem. Soc. 1934, 965.

(37) Shih, K. C.; Herber, R. H., Inorg. Chem. 1992, 31, 5444.

(38) Kishi, S.; Kato, M., Mol. Cryst. Liquid Cryst. 2002, 379, 303.

(39) Kato, M.; Kishi, S.; Wakamatsu, Y.; Sugi, Y.; Osamura, Y.; Koshiyama, T.; Hasegawa, M., Chem. Lett. 2005, 34, 1368.

(40) Kobayashi, A.; Yonemura, T.; Kato, M., Eur. J. Inorg. Chem. 2010, 2465. 
(41) Kobayashi, A.; Hara, H.; Noro, S.; Kato, M., Dalton Trans. 2010, 39, 3400.

(42) Hara, H.; Kobayashi, A.; Noro, S.; Chang, H. C.; Kato, M., Dalton Trans. 2011, 40, 8012.

(43) Che, C. M.; Butler, L. G.; Gray, H. B.; Crooks, R. M.; Woodruff, W. H., J. Am. Chem. Soc. 1983, 105, 5492.

(44) Che, C. M.; Mak, T. C. W.; Miskowski, V. M.; Gray, H. B., J. Am. Chem. Soc. 1986, 108,7840 .

(45) Connick, W. B.; Miskowski, V. M.; Houlding, V. H.; Gray, H. B., Inorg. Chem. 2000, $39,2585$.

(46) Connick, W. B.; Henling, L. M.; Marsh, R. E.; Gray, H. B., Inorg. Chem. 1996, 35, 6261.

(47) Connick, W. B.; Marsh, R. E.; Schaefer, W. P.; Gray, H. B., Inorg. Chem. 1997, 36, 913.

(48) Bailey, J. A.; Hill, M. G.; Marsh, R. E.; Miskowski, V. M.; Schaefer, W. P.; Gray, H. B., Inorg. Chem. 1995, 34, 4591.

(49) Wenger, O. S.; Garcìa-Revilla, S.; Güdel, H. U.; Gray, H. B.; Valiente, R., Chem. Phys. Lett. 2004, 384, 190.

(50) Kobayashi, A.; Fukuzawa, Y.; Chang, H.-C.; Kato, M., Inorg. Chem. 2012, 51, 7508.

(51) Yam, V. W. W., Acc. Chem. Res. 2002, 35, 555.

(52) Williams, J. A. G., Top. Curr. Chem. 2007, 281, 205. 
(53) Williams, J. A. G.; Develay, S.; Rochester, D. L.; Murphy, L., Coord. Chem. Rev. 2008, $252,2596$.

(54) Lu, W.; Mi, B. X.; Chan, M. C. W.; Hui, Z.; Che, C. M.; Zhu, N. Y.; Lee, S. T., J. Am. Chem. Soc. 2004, 126, 4958.

(55) Hijazi, A.; Walther, M. E.; Besnard, C.; Wenger, O. S., Polyhedron 2010, 29, 857.

(56) Hissler, M.; Connick, W. B.; Geiger, D. K.; McGarrah, J. E.; Lipa, D.; Lachicotte, R. J.; Eisenberg, R., Inorg. Chem. 2000, 39, 447.

(57) Hissler, M.; McGarrah, J. E.; Connick, W. B.; Geiger, D. K.; Cummings, S. D.; Eisenberg, R., Coord. Chem. Rev. 2000, 208, 115.

(58) Bronner, C.; Wenger, O. S., Dalton Trans. 2011, 40, 12409.

(59) Lu, W.; Chan, M. C. W.; Zhu, N. Y.; Che, C. M.; He, Z.; Wong, K. Y., Chem. Eur. J. 2003, $9,6155$.

(60) Hudson, Z. M.; Sun, C.; Harris, K. J.; Lucier, B. E. G.; Schurko, R. W.; Wang, S. N., Inorg. Chem. 2011, 50, 3447.

(61) Wade, C. R.; Broomsgrove, A. E. J.; Aldridge, S.; Gabbaï, F. P., Chem. Rev. 2010, 110, 3958.

(62) Yamaguchi, S.; Wakamiya, A., Pure Appl. Chem. 2006, 78, 1413.

(63) Entwistle, C. D.; Marder, T. B., Angew. Chem. Int. Ed. 2002, 41, 2927.

(64) Yam, V. W. W.; Wong, K. M. C.; Zhu, N. Y., J. Am. Chem. Soc. 2002, 124, 6506. 
(65) Zuleta, J. A.; Bevilacqua, J. M.; Eisenberg, R., Coord. Chem. Rev. 1991, 111, 237.

(66) Ni, J.; Zhang, L. Y.; Wen, H. M.; Chen, Z. N., Chem. Commun. 2009, 3801.

(67) Ni, J.; Wu, Y. H.; Zhang, X.; Li, B.; Zhang, L. Y.; Chen, Z. N., Inorg. Chem. 2009, 48, 10202.

(68) Ni, J.; Zhang, X.; Wu, Y. H.; Zhang, L. Y.; Chen, Z. N., Chem. Eur. J. 2011, 17, 1171.

(69) Zhang, X.; Wang, J. Y.; Ni, J.; Zhang, L. Y.; Chen, Z. N., Inorg. Chem. 2012, 51, 5569.

(70) Buss, C. E.; Mann, K. R., J. Am. Chem. Soc. 2002, 124, 1031.

(71) Dylla, A. G.; Janzen, D. E.; Pomije, M. K.; Mann, K. R., Organometallics 2007, 26, 6243.

(72) Drew, S. M.; Smith, L. I.; McGee, K. A.; Mann, K. R., Chem. Mater. 2009, 21, 3117.

(73) Zhang, Y.; Zhang, H. Y.; Mu, X. Y.; Lai, S. W.; Xu, B.; Tian, W. J.; Wang, Y.; Che, C. M., Chem. Commun. 2010, 46, 7727.

(74) Sun, Y.; Ye, K.; Zhang, H.; Zhang, J.; Zhao, L.; Li, B.; Yang, G.; Yang, B.; Wang, Y.; Lai, S. W.; Che, C. M., Angew. Chem. Int. Ed. 2006, 45, 5610.

(75) Buss, C. E.; Anderson, C. E.; Pomije, M. K.; Lutz, C. M.; Britton, D.; Mann, K. R., J. Am. Chem. Soc. 1998, 120, 7783.

(76) Exstrom, C. L.; Sowa, J. R.; Daws, C. A.; Janzen, D.; Mann, K. R.; Moore, G. A.; Stewart, F. F., Chem. Mater. 1995, 7, 15.

(77) Bailey, R. C.; Hupp, J. T., J. Am. Chem. Soc. 2002, 124, 6767. 
(78) Daws, C. A.; Exstrom, C. L.; Sowa, J. R.; Mann, K. R., Chem. Mater. 1997, 9, 363.

(79) Exstrom, C. L.; Pomije, M. K.; Mann, K. R., Chem. Mater. 1998, 10, 942.

(80) Abraham, M. H., Chem. Soc. Rev. 1993, 22, 73.

(81) Kunugi, Y.; Mann, K. R.; Miller, L. L.; Exstrom, C. L., J. Am. Chem. Soc. 1998, 120, 589.

(82) Kunugi, Y.; Miller, L. L.; Mann, K. R.; Pomije, M. K., Chem. Mater. 1998, 10, 1487.

(83) Drew, S. M.; Janzen, D. E.; Buss, C. E.; MacEwan, D. I.; Dublin, K. M.; Mann, K. R., J. Am. Chem. Soc. 2001, 123, 8414.

(84) Drew, S. M.; Janzen, D. E.; Mann, K. R., Anal. Chem. 2002, 74, 2547.

(85) Gardner, J. W.; Bartlett, P. N., Sens. Actuators B 1994, 18, 211.

(86) Grate, J. W.; Moore, L. K.; Janzen, D. E.; Veltkamp, D. J.; Kaganove, S.; Drew, S. M.; Mann, K. R., Chem. Mat. 2002, 14, 1058.

(87) Cich, M. J.; Hill, I. M.; Lackner, A. D.; Martinez, R. J.; Ruthenburg, T. C.; Takeshita, Y.; Young, A. J.; Drew, S. M.; Buss, C. E.; Mann, K. R., Sens. Actuators B 2010, 149, 199.

(88) Muro, M. L.; Daws, C. A.; Castellano, F. N., Chem. Commun. 2008, 6134.

(89) Field, J. S.; Haines, R. J.; McMillin, D. R.; Summerton, G. C., J. Chem. Soc., Dalton Trans. 2002, 1369.

(90) Du, P. W., Inorg. Chim. Acta 2010, 363, 1355. 
(91) Kobayashi, A.; Fukuzawa, Y.; Noro, S.; Nakamura, T.; Kato, M., Chem. Lett. 2009, 38, 998.

(92) Field, J. S.; Grimmer, C. D.; Munro, O. Q.; Waldron, B. P., Dalton Trans. 2010, 39, 1558.

(93) Wadas, T. J.; Wang, Q. M.; Kim, Y. J.; Flaschenreim, C.; Blanton, T. N.; Eisenberg, R., J. Am. Chem. Soc. 2004, 126, 16841.

(94) Du, P.; Schneider, J.; Brennessel, W. W.; Eisenberg, R., Inorg. Chem. 2008, 47, 69.

(95) Grove, L. J.; Rennekamp, J. M.; Jude, H.; Connick, W. B., J. Am. Chem. Soc. 2004, 126, 1594.

(96) Wang, K. H.; Haga, M. A.; Monjushiro, H.; Akiba, M.; Sasaki, Y., Inorg. Chem. 2000, $39,4022$.

(97) Grove, L. J.; Oliver, A. G.; Krause, J. A.; Connick, W. B., Inorg. Chem. 2008, 47, 1408.

(98) Rivera, E. J.; Barbosa, C.; Torres, R.; Grove, L.; Taylor, S.; Connick, W. B.; Clearfield, A.; Colon, J. L., J. Mater. Chem. 2011, 21, 15899.

(99) Mathew, I.; Sun, W. F., Dalton Trans. 2010, 39, 5885.

(100)Che, C. M.; Chow, C. F.; Yuen, M. Y.; Roy, V. A. L.; Lu, W.; Chen, Y.; Chui, S. S. Y.; Zhu, N. Y., Chem. Sci. 2011, 2, 216.

(101)Lu, W.; Chan, M. C. W.; Cheung, K. K.; Che, C. M., Organometallics 2001, $20,2477$.

(102)Choi, S. J.; Kuwabara, J.; Nishimura, Y.; Arai, T.; Kanbara, T., Chem. Lett. 2012, 41, 65. 
(103)Che, C. M.; Fu, W. F.; Lai, S. W.; Hou, Y. J.; Liu, Y. L., Chem. Commun. 2003, 118.

(104)Mathew, I.; Li, Y. J.; Li, Z. J.; Sun, W. F., Dalton Trans. 2010, 39, 11201.

(105)Kui, S. C. F.; Chui, S. S. Y.; Che, C. M.; Zhu, N. Y., J. Am. Chem. Soc. 2006, 128, 8297.

(106)Forniés, J.; Fuertes, S.; López, J. A.; Martin, A.; Sicilia, V., Inorg. Chem. 2008, 47, 7166.

(107)Albrecht, M.; Lutz, M.; Spek, A. L.; van Koten, G., Nature 2000, 406, 970.

(108)Albrecht, M.; van Koten, G., Adv. Mater. 1999, 11, 171.

(109)Albrecht, M.; Gossage, R. A.; Lutz, M.; Spek, A. L.; van Koten, G., Chem. Eur. J. 2000, $6,1431$.

(110)Muijsers, J. C.; Niemantsverdriet, J. W.; Wehmanooyevaar, I. C. M.; Grove, D. M.; van Koten, G., Inorg. Chem. 1992, 31, 2655.

(111)Shannon, R. D.; Prewitt, C. T., Acta Crystallogr. B 1969, B 25, 925.

(112)Albrecht, M.; Gossage, R. A.; Frey, U.; Ehlers, A. W.; Baerends, E. J.; Merbach, A. E.; van Koten, G., Inorg. Chem. 2001, 40, 850.

(113)Lin, J. C. Y.; Huang, R. T. W.; Lee, C. S.; Bhattacharyya, A.; Hwang, W. S.; Lin, I. J. B., Chem. Rev. 2009, 109, 3561.

(114)Pugh, D.; Danopoulos, A. A., Coord. Chem. Rev. 2007, 251, 610.

(115)Diéz-González, S.; Marion, N.; Nolan, S. P., Chem. Rev. 2009, 109, 3612.

(116)Lee, C. S.; Sabiah, S.; Wang, J. C.; Hwang, W. S.; Lin, I. J. B., Organometallics 2010, $29,286$. 
(117)Lee, C. S.; Zhuang, R. R.; Sabiah, S.; Wang, J. C.; Hwang, W. S.; Lin, I. J. B., Organometallics 2011, 30, 3897.

(118)Kato, M.; Omura, A.; Toshikawa, A.; Kishi, S.; Sugimoto, Y., Angew. Chem. Int. Ed. 2002, 41, 3183 .

(119)Nastasi, F.; Puntoriero, F.; Palmeri, N.; Cavallaro, S.; Campagna, S.; Lanza, S., Chem. Commun. 2007, 4740.

(120)Rosace, G.; Giuffrida, G.; Saitta, M.; Guglielmo, G.; Campagna, S.; Lanza, S., Inorg. Chem. 1996, 35, 6816.

(121)Forniés, J.; Sicilia, V.; Casas, J. M.; Martín, A.; López, J. A.; Larraz, C.; Borja, P.; Ovejero, C., Dalton Trans. 2011, 40, 2898.

(122)Pattacini, R.; Giansante, C.; Ceroni, P.; Maestri, M.; Braunstein, P., Chem. Eur. J. 2007, $13,10117$.

(123)Naka, K.; Kato, T.; Watase, S.; Matsukawa, K., Inorg. Chem. 2012, 51, 4420.

(124)Zipp, A. P., Coord. Chem. Rev. 1988, 84, 47.

(125)Roundhill, D. M.; Gray, H. B.; Che, C. M., Acc. Chem. Res. 1989, 22, 55.

(126)Mastuzaki, H.; Kishida, H.; Okamoto, H.; Takizawa, K.; Matsunaga, S.; Takaishi, S.; Hitoshi, M. A.; Sugiura, K.; Yamashita, M., Angew. Chem. Int. Ed. 2005, 44, 3240.

(127)Yamashita, M.; Takizawa, K.; Matsunaga, S.; Kawakami, D.; Iguchi, H.; Takaishi, S.; Kajiwara, T.; Iwahori, F.; Ishii, T.; Miyasaka, H.; Sugiura, K.; Matsuzaki, H.; Kishida, H.; Okamoto, H., Bull. Chem. Soc. Jpn. 2006, 79, 1404. 
(128)Iguchi, H.; Takaishi, S.; Kajiwara, T.; Miyasaka, H.; Yamashita, M.; Matsuzaki, H.; Okamoto, H., J. Inorg. Organomet. Polym. 2009, 19, 85.

(129)Lefebvre, J.; Batchelor, R. J.; Leznoff, D. B., J. Am. Chem. Soc. 2004, 126, 16117.

(130)Katz, M. J.; Ramnial, T.; Yu, H. Z.; Leznoff, D. B., J. Am. Chem. Soc. 2008, 130, 10662.

(131)Coker, N. L.; Bauer, J. A. K.; Elder, R. C., J. Am. Chem. Soc. 2004, 126, 12.

(132)Nagasundaram, N.; Roper, G.; Biscoe, J.; Chai, J. W.; Patterson, H. H.; Blom, N.; Ludi, A., Inorg. Chem. 1986, 25, 2947.

(133)Timmer, B.; Olthuis, W.; van den Berg, A., Sens. Actuators B 2005, 107, 666.

(134)Mansour, M. A.; Connick, W. B.; Lachicotte, R. J.; Gysling, H. J.; Eisenberg, R., J. Am. Chem. Soc. 1998, 120, 1329.

(135)King, C.; Wang, J. C.; Khan, M. N. I.; Fackler, J. P., Inorg. Chem. 1989, $28,2145$.

(136)Lee, Y. A.; Eisenberg, R., J. Am. Chem. Soc. 2003, 125, 7778.

(137)Bouas-Laurent, H.; Durr, H., Pure Appl. Chem. 2001, 73, 639.

(138)Vickery, J. C.; Olmstead, M. M.; Fung, E. Y.; Balch, A. L., Angew. Chem. Int. Ed. 1997, $36,1179$.

(139)White-Morris, R. L.; Olmstead, M. M.; Attar, S.; Balch, A. L., Inorg. Chem. 2005, 44, 5021.

(140)Wenger, O. S., Chem. Soc. Rev. 2011, 40, 3538.

(141)Reynolds, G. T., J. Lumin. 1992, 54, 43. 
(142)Fung, E. Y.; Olmstead, M. M.; Vickery, J. C.; Balch, A. L., Coord. Chem. Rev. 1998, 171, 151.

(143)Mu, X. Y.; Liu, D.; Cheng, X.; Li, L.; Zhang, H. Y.; Wang, Y., Org. Electron. 2012, 13, 457.

(144)Rawashdeh-Omary, M. A.; Omary, M. A.; Fackler, J. P.; Galassi, R.; Pietroni, B. R.; Burini, A., J. Am. Chem. Soc. 2001, 123, 9689.

(145)Tiripicchio, A.; Tiripicchiocamellini, M.; Minghetti, G., J. Organomet. Chem. 1979, 171, 399.

(146)Lim, S. H.; Olmstead, M. M.; Balch, A. L., J. Am. Chem. Soc. 2011, 133, 10229.

(147)Pathaneni, S. S.; Desiraju, G. R., J. Chem. Soc., Dalton Trans. 1993, 319.

(148)Lim, S. H.; Olmstead, M. M.; Balch, A. L., Chem. Sci. 2012, DOI: 10.1039/C2SC20820B.

(149)Ito, H.; Saito, T.; Oshima, N.; Kitamura, N.; Ishizaka, S.; Hinatsu, Y.; Wakeshima, M.; Kato, M.; Tsuge, K.; Sawamura, M., J. Am. Chem. Soc. 2008, 130, 10044.

(150)White-Morris, R. L.; Olmstead, M. M.; Balch, A. L., J. Am. Chem. Soc. 2003, 125, 1033.

(151)Bariáin, C.; Matías, I. R.; Romeo, I.; Garrido, J.; Laguna, M., Appl. Phys. Lett. 2000, 77, 2274.

(152)Bariáin, C.; Matías, I. R.; Romeo, I.; Garrido, J.; Laguna, M., Sens. Actuators 2001, B76, 25. 
(153)Fernández, E. J.; López-de-Luzuriaga, J. M.; Monge, M.; Olmos, M. E.; Pérez, J.; Laguna, A.; Mohamed, A. A.; Fackler, J. P., J. Am. Chem. Soc. 2003, 125, 2022.

(154)Fernández, E. J.; Laguna, A.; López-De-Luzuriaga, J. M.; Mendizabal, F.; Monge, M.; Olmos, M. E.; Pérez, J., Chem. Eur. J. 2003, 9, 456.

(155)Fernández, E. J.; López-De-Luzuriaga, J. M.; Monge, M.; Montiel, M.; Olmos, M. E.; Pérez, J.; Laguna, A.; Mendizabal, F.; Mohamed, A. A.; Fackler, J. P., Inorg. Chem. 2004, 43, 3573.

(156)Fernández, E. J.; Laguna, A.; López-de-Luzuriaga, J. M.; Montiel, M.; Olmos, M. E.; Pérez, J., Organometallics 2006, 25, 1689.

(157)Usón, R.; Laguna, A.; Laguna, M.; Manzano, B. R.; Jones, P. G.; Sheldrick, G. M., J. Chem. Soc., Dalton Trans. 1984, 285.

(158)Fernández, E. J.; López-De-Luzuriaga, J. M.; Monge, M.; Olmos, M. E.; Puelles, R. C.; Laguna, A.; Mohamed, A. A.; Fackler, J. P., Inorg. Chem. 2008, 47, 8069.

(159)Fernández, E. J.; Gimeno, M. C.; Laguna, A.; López-de-Luzuriaga, J. M.; Monge, M.; Pyykkö, P.; Sundholm, D., J. Am. Chem. Soc. 2000, 122, 7287.

(160)Fernández, E. J.; Laguna, A.; López-de-Luzuriaga, J. M.; Monge, M.; Montiel, M.; Olmos, M. E.; Rodríguez-Castillo, M., Organometallics 2006, 25, 3639.

(161)Bariain, C.; Matias, I. R.; Fdez-Valdivielso, C.; Elosúa, C.; Luquín, A.; Garrido, J.; Laguna, M., Sens. Actuators B 2005, 108, 535. 
(162)Luquin, A.; Bariain, C.; Vergara, E.; Cerrada, E.; Garrido, J.; Matias, I. R.; Laguna, M., Appl. Organomet. Chem. 2005, 19, 1232.

(163)Elosua, C.; Bariain, C.; Matias, I. R.; Arregui, F. J.; Vergara, E.; Laguna, M., Sens. Actuators B 2009, 137, 139.

(164)Laguna, A.; Lasanta, T.; López-de-Luzuriaga, J. M.; Monge, M.; Naumov, P.; Olmos, M. E., J. Am. Chem. Soc. 2010, 132, 456.

(165)Metrangolo, P.; Neukirch, H.; Pilati, T.; Resnati, G., Acc. Chem. Res. 2005, 38, 386.

(166)Fernández, E. J.; Laguna, A.; López-de-Luzuriaga, J. M.; Olmos, M. E.; Puelles, R. C., Z. Naturforsch. B 2009, 64, 1500.

(167)Lasanta, T.; Olmos, M. E.; Laguna, A.; López-de-Luzuriaga, J. M.; Naumov, P., J. Am. Chem. Soc. 2011, 133, 16358.

(168)White-Morris, R. L.; Olmstead, M. M.; Jiang, F. L.; Tinti, D. S.; Balch, A. L., J. Am. Chem. Soc. 2002, 124, 2327.

(169)Strasser, C. E.; Catalano, V. J., J. Am. Chem. Soc. 2010, 132, 10009.

(170)Osawa, M.; Kawata, I.; Igawa, S.; Hoshino, M.; Fukunaga, T.; Hashizume, D., Chem. Eur. J. 2010, 16, 12114.

(171)Kojima, M.; Taguchi, H.; Tsuchimoto, M.; Nakajima, K., Coord. Chem. Rev. 2003, 237, 183. 
(172)Nakajima, K.; Kojima, M.; Azuma, S.; Kasahara, R.; Tsuchimoto, M.; Kubozono, Y.; Maeda, H.; Kashino, S.; Ohba, S.; Yoshikawa, Y.; Fujita, J., Bull. Chem. Soc. Jpn. 1996, 69, 3207.

(173)Kojima, M.; Nakajima, K.; Tsuchimoto, M.; Treichel, P. M.; Kashino, S.; Yoshikawa, Y., Proc. Jpn. Acad. Ser. B 1995, 71, 175.

(174)Kasahara, R.; Tsuchimoto, M.; Ohba, S.; Nakajima, K.; Ishida, H.; Kojima, M., Inorg. Chem. 1996, 35, 7661.

(175)Helm, L.; Merbach, A. E., Chem. Rev. 2005, 105, 1923.

(176)Beauvais, L. G.; Shores, M. P.; Long, J. R., J. Am. Chem. Soc. 2000, 122, 2763.

(177)Boonmak, J.; Nakano, M.; Chaichit, N.; Pakawatchai, C.; Youngme, S., Dalton Trans. 2010, 39, 8161.

(178)Baho, N.; Zargarian, D., Inorg. Chem. 2007, 46, 299.

(179)Flamini, A.; Mattei, G.; Panusa, A., J. Incl. Phenom. Macrocycl. Chem. 1999, 33, 377.

(180)Lee, E. Y.; Suh, M. P., Angew. Chem. Int. Ed. 2004, 43, 2798.

(181)Cariati, E.; Bourassa, J.; Ford, P. C., J. Chem. Soc., Chem. Commun. 1998, 1623.

(182)Cariati, E.; Bu, X. H.; Ford, P. C., Chem. Mater. 2000, 12, 3385.

(183)Mínguez Espallargas, G.; Brammer, L.; van de Streek, J.; Shankland, K.; Florence, A. J.; Adams, H., J. Am. Chem. Soc. 2006, 128, 9584. 
(184)Mínguez Espallargas, G.; Hippler, M.; Florence, A. J.; Fernandes, P.; van de Streek, J.; Brunelli, M.; David, W. I. F.; Shankland, K.; Brammer, L., J. Am. Chem. Soc. 2007, 129, 15606.

(185)Mínguez Espallargas, G.; van de Streek, J.; Fernandes, P.; Florence, A. J.; Brunelli, M.; Shankland, K.; Brammer, L., Angew. Chem. Int. Ed. 2010, 49, 8892.

(186)Mínguez Espallargas, G.; Florence, A. J.; van de Streek, J.; Brammer, L., Crystengcomm 2011, 13, 4400 .

(187)Li, Y. J.; Deng, Z. Y.; Xu, X. F.; Wu, H. B.; Cao, Z. X.; Wang, Q. M., Chem. Commun. 2011, 47, 9179.

(188)Mobin, S. M.; Srivastava, A. K.; Mathur, P.; Lahiri, G. K., Dalton Trans. 2010, 39, 1447.

(189)Lee, J. Y.; Kim, H. J.; Jung, J. H.; Sim, W.; Lee, S. S., J. Am. Chem. Soc. 2008, 130, 13838.

(190)Maini, L.; Braga, D.; Mazzeo, P. P.; Ventura, B., Dalton Trans. 2012, 41, 531.

(191)Ley, A. N.; Dunaway, L. E.; Brewster, T. P.; Dembo, M. D.; Harris, T. D.; Baril-Robert, F.; Li, X. B.; Patterson, H. H.; Pike, R. D., Chem. Commun. 2010, 46, 4565.

(192)Lim, M. J.; Murray, C. A.; Tronic, T. A.; DeKrafft, K. E.; Ley, A. N.; Debutts, J. C.; Pike, R. D.; Lu, H. Y.; Patterson, H. H., Inorg. Chem. 2008, 47, 6931.

(193)Tronic, T. A.; DeKrafft, K. E.; Lim, M. J.; Ley, A. N.; Pike, R. D., Inorg. Chem. 2007, $46,8897$.

(194)Bayse, C. A.; Brewster, T. P.; Pike, R. D., Inorg. Chem. 2009, 48, 174. 
(195)Safko, J. P.; Kuperstock, J. E.; McCullough, S. M.; Noviello, A. M.; Li, X.; Killarney, J.

P.; Murphy, C.; Patterson, H. H.; Bayse, C.; Pike, R. D., Dalton Trans. 2012, 41, 11663.

(196)Baldauff, E. A.; Buriak, J. M., Chem. Commun. 2004, 2028.

(197)Molloy, K. C.; Bigwood, M. P.; Herber, R. H.; Zuckerman, J. J., Inorg. Chem. 1982, 21, 3709.

(198)Donaldson, J. D.; Nicholson, D. G.; Senior, B. J., J. Chem. Soc. A 1968, 2928.

(199)Rakow, N. A.; Suslick, K. S., Nature 2000, 406, 710.

(200) Vaughan, A. A.; Baron, M. G.; Narayanaswamy, R., Anal. Commun. 1996, 33, 393.

(201)Li, B.; Wei, R. J.; Tao, J.; Huang, R. B.; Zheng, L. S.; Zheng, Z. P., J. Am. Chem. Soc. 2010, $132,1558$.

(202)Wei, R. J.; Tao, J.; Huang, R. B.; Zheng, L. S., Inorg. Chem. 2011, 50, 8553.

(203)Gütlich, P.; Hauser, A.; Spiering, H., Angew. Chem. Int. Ed. 1994, 33, 2024.

(204)Chang, M.; Kobayashi, A.; Nakajima, K.; Chang, H. C.; Kato, M., Inorg. Chem. 2011, 50,8308 .

(205)Kobayashi, A.; Dosen, M.; Chang, M.; Nakajima, K.; Noro, S.; Kato, M., J. Am. Chem. Soc. 2010, 132, 15286.

(206)Ishida, H.; Kashino, S., Acta Crystallogr. C 1999, 55, 1714.

(207)Suzuki, H.; Mori, H.; Yamaura, J. I.; Matsuda, M.; Tajima, H.; Mochida, T., Chem. Lett. 2007, 36, 402. 
(208)Gutmann, V., The Donor-Acceptor Approach to Molecular Interaction. Plenum Press: 1978.

(209)Pang, J.; Marcotte, E. J. P.; Seward, C.; Brown, R. S.; Wang, S. N., Angew. Chem. Int. Ed. 2001, 40, 4042 .

(210)Mizukami, S.; Houjou, H.; Sugaya, K.; Koyama, E.; Tokuhisa, H.; Sasaki, T.; Kanesato, M., Chem. Mater. 2005, 17, 50.

(211)Rawashdeh-Omary, M. A.; Rashdan, M. D.; Dharanipathi, S.; Elbjeirami, O.; Ramesh, P.; Dias, H. V. R., Chem. Commun. 2011, 47, 1160.

(212)Omary, M. A.; Patterson, H. H., J. Am. Chem. Soc. 1998, 120, 7696.

(213)Benkstein, K. D.; Hupp, J. T.; Stern, C. L., J. Am. Chem. Soc. 1998, 120, 12982.

(214)Benkstein, K. D.; Hupp, J. T.; Stern, C. L., Angew. Chem. Int. Ed. 2000, 39, 2891.

(215)Baldo, M. A.; O'Brien, D. F.; You, Y.; Shoustikov, A.; Sibley, S.; Thompson, M. E.; Forrest, S. R., Nature 1998, 395, 151.

(216)Yersin, H., Transition Metal and Rare Earth Compounds III 2004, 241, 1.

(217)Liu, Z. W.; Bian, Z. Q.; Bian, J.; Li, Z. D.; Nie, D. B.; Huang, C. H., Inorg. Chem. 2008, 47,8025 .

(218)Bencini, A.; Casarin, M.; Forrer, D.; Franco, L.; Garau, F.; Masciocchi, N.; Pandolfo, L.; Pettinari, C.; Ruzzi, M.; Vittadini, A., Inorg. Chem. 2009, 48, 4044. 
(219)Cingolani, A.; Galli, S.; Masciocchi, N.; Pandolfo, L.; Pettinari, C.; Sironi, A., J. Am. Chem. Soc. 2005, 127, 6144.

(220)Yamada, K.; Yagishita, S.; Tanaka, H.; Tohyama, K.; Adachi, K.; Kaizaki, S.; Kumagai, H.; Inoue, K.; Kitaura, R.; Chang, H. C.; Kitagawa, S.; Kawata, S., Chem.-Eur. J. 2004, 10, 2648.

(221)Yamada, K.; Tanaka, H.; Yagishita, S.; Adachi, K.; Uemura, T.; Kitagawa, S.; Kawata, S., Inorg. Chem. 2006, 45, 4322.

(222)Braga, D.; Maini, L.; Mazzeo, P. P.; Ventura, B., Chem.-Eur. J. 2010, 16, 1553.

(223)Lu, Z. Z.; Zhang, R.; Li, Y. Z.; Guo, Z. J.; Zheng, H. G., J. Am. Chem. Soc. 2011, 133, 4172.

(224)Reichardt, C., Chem. Rev. 1994, 94, 2319.

(225)Chang, Q.; Murtaza, Z.; Lakowicz, J. R.; Rao, G., Anal. Chim. Acta 1997, 350, 97.

(226)Bignozzi, C. A.; Chiorboli, C.; Indelli, M. T.; Scandola, M. A. R.; Varani, G.; Scandola, F., J. Am. Chem. Soc. 1986, 108, 7872.

(227)Winkler, J. R.; Creutz, C.; Sutin, N., J. Am. Chem. Soc. 1987, 109, 3470.

(228)Kato, M.; Yamauchi, S.; Hirota, N., J. Phys. Chem. 1989, 93, 3422.

(229)Timpson, C. J.; Bignozzi, C. A.; Sullivan, B. P.; Kober, E. M.; Meyer, T. J., J. Phys. Chem. 1996, 100, 2915.

(230)Abe, T.; Shinozaki, K., Inorg. Chem. 2005, 44, 849. 
(231)Abe, T.; Suzuki, T.; Shinozaki, K., Inorg. Chem. 2010, 49, 1794.

(232)Gutmann, V., Coord. Chem. Rev. 1976, 18, 225.

(233)McGee, K. A.; Marquardt, B. J.; Mann, K. R., Inorg. Chem. 2008, 47, 9143.

(234)Evju, J. K.; Mann, K. R., Chem. Mat. 1999, 11, 1425.
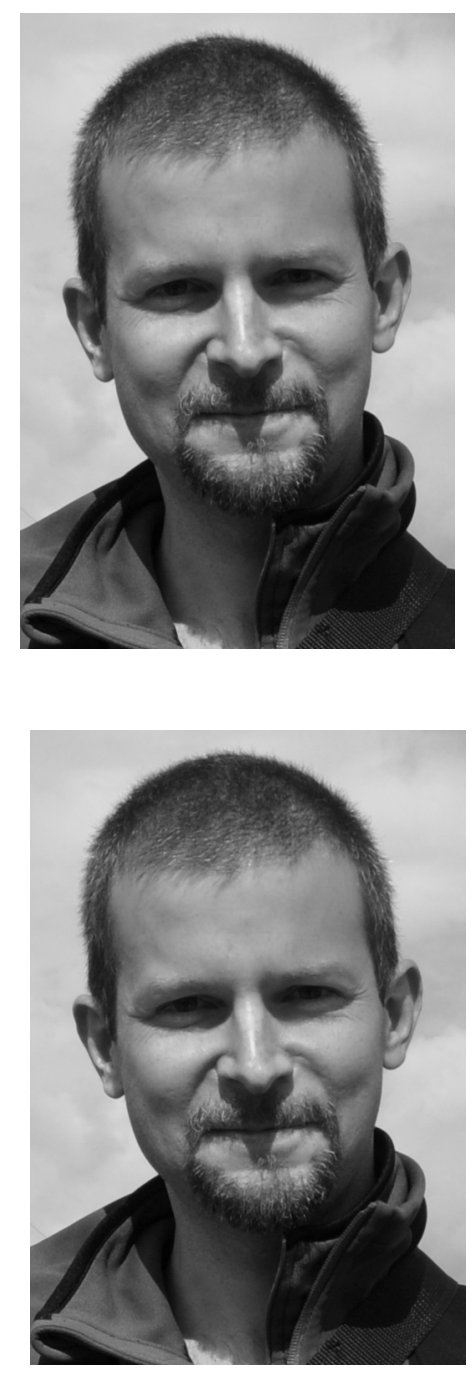

\section{AUTHOR BIOGRAPHY}


Oliver S. Wenger received a Ph. D. degree from the University of Berne (Switzerland) in 2002 after work with Hans U. Güdel. From 2002 to 2004 he was a postdoctoral researcher in the group of Harry B. Gray at Caltech and from 2004 to 2006 in the group of Jean-Pierre Sauvage at Université Louis Pasteur in Strasbourg (France). From 2006 to 2009 he performed independent research as an assistant professor at the University of Geneva, endowed with a "Förderungsprofessur" from the Swiss National Science Foundation. From 2009 to 2012 he held an associate professor position (W2) at Georg-August-Universität Göttingen (Germany). In 2012 he moved back to Switzerland to the University of Basel where he currently has a tenured professorship.

\section{ACKNOWLEDGMENT}

Financial support from the Deutsche Forschungsgemeinschaft (DFG) through grant number WE4815/2-1 and from the Swiss National Science Foundation (SNSF) through grant number 200021-117578 is gratefully acknowledged. The author is grateful for useful comments made by 7 reviewers.

SYNOPSIS TOC / COVER ART 


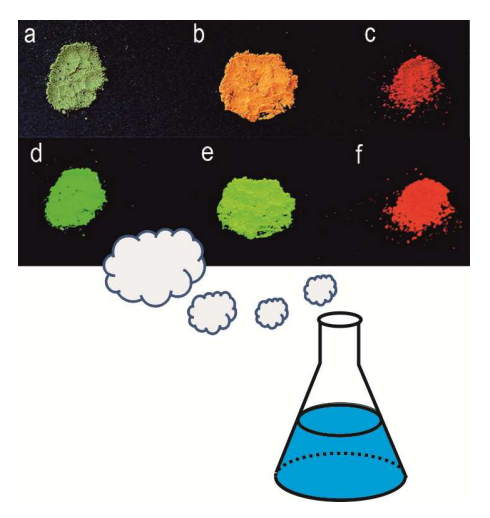

1

2

3

4

5

6

7

8

9

10

11

12

13

14

16

17

18

19

20

21

22

23

24

25

26

27

28

29

30

31

32

33

34

35

36

37

38

39

40

41

42

43

44

45

46

47

48

49

50

51

52

53

54

55

56

57

58

59

60 